UNIVERSIDADE DE SÃO PAULO

ESCOLA POLITÉCNICA

PAULO JOSÉ SCHIAVON ARA

DESEMPENHO DE SISTEMAS DE CONDICIONAMENTO DE AR COM UTILIZAÇÃO DE ENERGIA SOLAR EM EDIFÍCIOS DE ESCRITÓRIOS 
PAULO JOSÉ SCHIAVON ARA

\title{
DESEMPENHO DE SISTEMAS DE CONDICIONAMENTO DE AR COM UTILIZAÇÃO DE ENERGIA SOLAR EM EDIFÍCIOS DE ESCRITÓRIOS
}

\author{
Dissertação apresentada à Escola \\ Politécnica da Universidade de São \\ Paulo para obtenção do titulo de \\ Mestre em Engenharia \\ Área de concentração: \\ Engenharia de Construção Civil e \\ Urbana \\ Orientador: \\ Prof. Associado \\ Racine Tadeu Araujo Prado
}

São Paulo

2010 
O presente trabalho foi realizado com o apoio: da Coordenação de Aperfeiçoamento de Pessoal de Nível Superior - CAPES da FAPESP - Fundação de Amparo à pesquisa do Estado de São Paulo. 
Este exemplar foi revisado e alterado em relação à versão original, sob responsabilidade única do autor e com a anuência de seu orientador.

São Paulo, 21 de dezembro de 2010.

Assinatura do autor

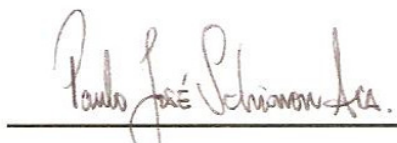

Assinatura do orientador

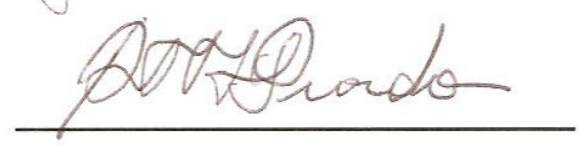

FICHA CATALOGRÁFICA

Ara, Paulo José Schiavon

Desempenho de sistemas de condicionamento de ar com utilização de energia solar em edifícios de escritórios / P.J.S. Ara. -- ed.rev. -- São Paulo, 2010.

$191 \mathrm{p}$.

Dissertação (Mestrado) - Escola Politécnica da Universidade de São Paulo. Departamento de Engenharia de Construção Civil.

1. Ar condicionado (Sistemas) 2. Energia solar 3. Edifício de Escritórios 4. Energia I. Universidade de São Paulo. Escola Politécnica. Departamento de Engenharia de Construção Civil II. t. 


\section{DEDICATÓRIA}

Dedico esse trabalho a Deus e a Maria, minha mãe.

Também o dedico ao meu pai Amilton, a minha mãe Nice e ao meu irmão Thiago. 


\section{AGRADECIMENTOS}

A Deus e a Maria, minha mãe, por me darem as graças e forças necessárias para completar mais essa etapa de minha vida.

Ao meu pai Amilton, minha mãe Nice e meu irmão Thiago, por me ajudarem a cada momento, sendo família, unidade e amor na alegria, na tristeza, nos desafios e nas vitórias.

Ao Frei Sebastião Sebastião Benito Quaglio O.F.M.Conv., por ter me mostrado o caminho da fé, da vida e da felicidade.

Aos missionários e missionárias da Imaculada Padre Kolbe, meus irmãos e irmãs.

A Milícia da Imaculada, minha família, vocação e ideal de vida.

A Raquel, presente de Deus na minha vida.

A minha comunidade, meus amigos e irmãos de caminhada, por serem o tesouro precioso que encontrei.

A todos que me acompanharam pelas orações, pelo apoio e pela companhia.

A todos que fazem e fizeram parte de minha vida, de minha formação profissional, intelectual, humana e espiritual.

Aos meus colegas da pós-graduação, especialmente aos amigos do Laboratório de Sistemas Prediais e da Sala Buraco Negro.

Aos meus professores e colegas de profissão.

Ao meu orientador Prof. Dr. Racine Tadeu Araújo Prado, em primeiro lugar pela amizade e pela confiança depositada em mim, assim como pelos ensinamentos e oportunidades por ele doadas a mim, através de sua presença, dos seus conselhos e de sua experiência de vida.

A Fundação de Amparo à Pesquisa do Estado de São Paulo (FAPESP) e a Coordenação de Aperfeiçoamento de Pessoal de Nível Superior (CAPES), pelo apoio sem o qual não seria possível a realização desta pesquisa.

Aos Professores José Roberto Simões Moreira (PME-EPUSP), Murilo Tadeu Werneck Fagá (IEE-USP) e Eliane Aparecida Faria Amaral Fadigas (PEA-EPUSP) por comporem as bancas de qualificação e de dissertação e pelos preciosos comentários e orientações sobre o trabalho. 
"A fim de guiar a humanidade para uma gestão globalmente sustentável do ambiente e dos recursos da terra, o homem é chamado a concentrar sua inteligência no campo da pesquisa científica e tecnológica e na aplicação das descobertas que daí derivam".

Papa Bento XVI 


\section{RESUMO}

A preocupação energética tem impulsionado a humanidade a buscar alternativas sustentáveis de energia. Neste contexto, os edifícios de escritórios têm um papel importante, em especial, devido ao elevado consumo de energia dos sistemas de condicionamento de ar. Para esses sistemas, a possibilidade de utilização de energia solar é uma alternativa tecnicamente possível e interessante de ser considerada, principalmente porque, quando a carga térmica do edifício é mais elevada, a radiação solar também é mais elevada. Dentre os sistemas de condicionamento de ar solar, o sistema térmico - que associa coletores solares térmicos com chiller de absorção - é o mais disseminado, na atualidade. Entretanto, dependendo do caso, outras tecnologias podem ser vantajosas. Uma opção, por exemplo, no caso de edifícios de escritórios, é o sistema elétrico - que associa painéis fotovoltaicos ao chiller convencional de compressão de vapor. Neste trabalho, para um edifício de escritórios de 20 pavimentos e $1000 \mathrm{~m}^{2}$ por pavimento, na cidade de São Paulo, no Brasil, duas alternativas de ar condicionado solar tiveram seus desempenhos energéticos analisados: 0 sistema térmico - com coletores solares térmicos somente na cobertura - e o sistema elétrico - com painéis FV somente nas superfícies opacas das fachadas. Para isso, com o software EnergyPlus do Departamento de Energia dos Estados Unidos obteve-se as carga térmica atuantes no edifício e com a aplicação do método de cálculo de consumo de energia dos sistemas de ar condicionado solar, proposto pelo Projeto SOLAIR da União Européia, adaptado para a realidade da pesquisa, obteve-se o desempenho energético dos sistemas. Os resultados mostraram que, para o edifício de 20 pavimentos, o sistema elétrico tem o melhor desempenho energético, economizando $28 \%$ e $71 \%$ da energia elétrica que consumiria um sistema de ar condicionado convencional, em um dia de verão e de inverno, respectivamente. O sistema térmico, ao contrário, apresentou um desempenho energético ruim para o edifício estudado, consumindo, por exemplo, em um dia de verão, cerca de 4 vezes mais energia elétrica do que um sistema de ar condicionado convencional. Constatouse que isso ocorreu pois a área coletora limitada à cobertura foi insuficiente para atender a demanda do chiller de absorção, que passou a operar com frações solares baixas, da ordem de $50 \%$ e $20 \%$, de pico, no dia de inverno e de verão, respectivamente. Assim, constatou-se que para que o sistema térmico apresente um desempenho energético satisfatório é preciso que o edifício não seja tão alto. De fato, os resultados mostraram que somente se o edifício tivesse no máximo 2 pavimentos, o sistema térmico teria um desempenho energético melhor do que um sistema convencional. No caso de ser aplicado ao edifício térreo de $1000 \mathrm{~m}^{2} \mathrm{de}$ área, por exemplo, esse sistema economizaria aproximadamente $65 \%$ da energia elétrica do sistema convencional. Por fim, constatou-se também que o desempenho energético do sistema térmico seria elevado com a otimização da área e da tecnologia de coletores solares, com o aprimoramento do sistema de aquecimento auxiliar e com a redução da carga térmica do edifício por meio de técnicas passivas de climatização.

Palavras-chave: sistema de ar condicionado solar, aproveitamento solar térmico, aproveitamento solar fotovoltaico, chiller solar de absorção, chiller de compressão de vapor, edifícios de escritórios, desempenho energético. 


\section{ABSTRACT}

Energy concern has driven human kind to seek sustainable energy alternatives. In this context, office buildings have an important role, especially due to the high energy consumption of air conditioning systems. For these systems, the possibility of using solar energy is technically feasible and interesting to be considered, mainly because generally when the building thermal load is higher, the solar radiation is also higher. Among solar airconditioning systems, the thermal system - which combines solar collectors with absorption chiller - is the most widespread, nowadays. However, depending on the case, other technologies may take advantage. One option, for example, in the case of office buildings, is the electrical system - which combines photovoltaic panels with conventional vapor compression chiller. In this work, an office building of 20 floors with 1,000 $\mathrm{m}^{2}$ floor area, in Sao Paulo, Brazil, two technologies of solar air conditioning had their performance analyzed: the thermal system - presenting solar thermal collectors only on the roof - and the electrical system - with PV panels only on the opaque surfaces of the facades. For this, the software EnergyPlus of the United States Department of Energy obtained the building thermal load and the with the solar air conditioning energy consumption calculating method proposed by SOLAIR project of the European Union and adapted to this work, energy performance of systems was obtained. The results showed that for this building, the electrical system had the best energy performance, saving $28 \%$ and $71 \%$ of electricity that would consume a conventional air conditioning system in a summer day and a winter day, respectively. The thermal system, in contrast, showed a poor energy performance, consuming, for example, on a summer day, about four times more electricity than a conventional air conditioning system. It was found that this occurred because the collectors area limited to the roof of the building was insufficient to meet the absorption chiller demand, causing low solar fractions in the operation, of around $50 \%$ and $20 \%$ peak, in a winter day and in a summer day, respectively. Thus, in order of provide a satisfactory energy performance, the thermal system requires that the building not to be so tall. In fact, the results showed that only if the building had up to two floors, the system would perform better than a conventional system. In case of be installed in a building with the ground floor only, and floor area of $1000 \mathrm{~m}^{2}$, for example, this system would save about $65 \%$ of the electricity comparing to a conventional system. Finally, it was found that this energy performance would be elevated as well with the optimization of solar collectors area and technology, with auxiliary heating system improvement and with the reduction of thermal load of the building by means of passive air conditioning techniques.

Keys words: solar air conditioning system, solar thermal system, solar photovoltaic system, absorption chiller, vapor compression chiller, office buildings, energy performance. 


\section{LISTA DE FIGURAS E GRÁFICOS}

Figura 1.1 - Crescimento dos sistemas solares térmicos na Europa. (fonte: ESTIF, Solar Thermal Action Plan, p.8, 2007).

Figura 1.2 - Crescimento da área de coletores solares no Brasil. (fonte: Cidades Solares, Material do curso de "Projetista Solar", 2009).

Figura 1.3 - Capacidade fotovoltaica acumulada na Europa. (fonte: EPIA, Solar Generation V, p.22, 2008).

Figura 1.4 - Sistemas fotovoltaicos autônomos instalados no município de Pentecostes, no Estado do Ceará, Brasil. (fonte: CEPEL, 2003).

Figura 2.1 - Diagrama esquemático de um sistema de condicionamento de ar com utilização de células fotovoltaicas e chiller de compressão de vapor. (fonte: Kim e Ferreira, p.3, 2007).

Figura 2.2 - Esquema simplificado do ciclo de absorção. (fonte: Grossmann e Johannsen, p.195, modificado, 1981).

Figura 2.3 - Esquema de um sistema de condicionamento de ar com ciclo de absorção e utilização de energia solar. (fonte: Barghouthi et al., 2007).

Figura 2.4 - COP ideais dos sistemas por absorção e adsorção. (fonte: Henning, p.1736, 2007).

Figura 2.5 - Distribuição por países dos sistemas no mundo. (fonte: Núñez, 2010).

Figura 2.6 - Coletores solares do edifício da Ott Ingenieure, Langenau, Alemanha. (fonte: SOLAIR, Best Practices Catalog, 2008).

Figura 2.7 - Sistema em edifício em Saint Denis de la Réunion, França. (fonte: SOLAIR, Best Practices Catalog, 2008).

Figura 2.8 - Escola de Engenharia de Sevilha, Espanha. (fonte: Bermejo, P.; Pino, F.J.; Rosa, F., 2010).

Figura 2.9 - Chiller de adsorção instalado em hospital na Alemanha. (fonte: Henning, p.1742, 2007).

Figura 3.1 - Modelo do pavimento com suas zonas térmicas. 
Figura 3.2 - Esquema de decisão para a escolha das duas alternativas a serem analisadas.

Figura 3.3 - Esquema do edifício de escritórios com o sistema de ar condicionado solar térmico.

Figura 3.4 - Esquema do edifício de escritórios com o sistema de ar condicionado solar elétrico.

Figura 3.5 - Esquema do sistema de ar condicionado solar térmico simulado.

Figura 3.6 - Esquema do sistema de ar condicionado solar elétrico simulado.

Figura 3.7 - Esquema do sistema de ar condicionado convencional simulado.

Figura 3.8 - Interface com o usuário do EP-Launch. (EnergyPlus, versão 5.0).

Figura 3.9 - Interface com o usuário do IDF-Editor (EnergyPlus, versão 5.0).

Figura 3.10 - Esquema do modelo geométrico utilizado para a simulação de carga térmica.

Figura 3.11 - Modelo geométrico das zonas correspondentes ao piso elevado para o piso $\mathrm{k}$.

Figura 3.12 - Modelo geométrico das zonas correspondentes a área de escritórios para o piso $\mathrm{k}$.

Figura 3.13 - Perfil adotado para ocupação, equipamentos e iluminação ao longo do dia.

Figura 3.14 - Interface do usuário do EnergyPlus mostrando a escolha do período de simulação, no qual será utilizado o dia 21 de junho e o dia 21 de dezembro.

Figura 3.15 - Representação gráfica do comportamento da função carga térmica $\mathrm{Q}(\mathrm{t})$ ao longo do tempo.

Figura 3.16 - Resumo do Método utilizado na pesquisa.

Figura 4.1 - Carga térmica horária do edifício simulado.

Figura 4.2 - valores máximos e mínimos de carga térmica para os dias 21/06 e $21 / 12$. 
Figura 4.3 - Área de escritório por TR de carga térmica, no dia 21/06 e no dia 21/12, comparadas com o valor usual (padrão) de 20m2/TR usualmente adotado em São Paulo.

Figura 4.4 - Carga térmica diária em função do número de pavimentos do edifício.

Figura 4.4 - Consumo de energia elétrica, em MWh/dia, dos sistemas de ar condicionado estudados, nos dias 21/06 e 21/12, para o edifício de 20 pavimentos.

Figura 4.5 - Consumo de energia adicional, em MWh/dia, do sistema convencional em relação ao solar elétrico e do sistema solar térmico em relação ao convencional, nos dias 21/06 e 21/12.

Figura 4.6 - Frações solares para o ar condicionado solar térmico para inverno e verão.

Figura 4.7 - Irradiância solar simulada no plano dos coletores inclinados a $23^{\circ}$ e orientados ao norte.

Figura 4.8 - Valores de K para o sistema de ar condicionado solar térmico.

Figura 4.9 - Consumo de energia dos sistemas de ar condicionado solar ao longo dos dias $21 / 06$.

Figura 4.10 - Consumo de energia dos sistemas de ar condicionado solar ao longo dos dias $21 / 12$.

Figura 4.11 - Produção de energia fotovoltaica em kWh/dia nos dias 21/06 e 21/12.

Figura 4.12 - Área de escritórios condicionada, na hora de pico, para cada kWh de energia convencional consumida.

Figura 4.13 - Energia térmica fornecida à água, em KWh, pelo aquecimento auxiliar (AUXILIAR) e pelo sistema de aquecimento solar (SOLAR) ao longo dos dias 21 de junho e 21 de dezembro.

Figura 4.14 - Energia térmica fornecida à água, em $\mathrm{MWh}$, pelo aquecimento auxiliar (AUXILIAR) e pelo sistema de aquecimento solar (SOLAR) total dos dias 21 de junho e 21 de dezembro.

Figura 4.15 - Distribuição da energia elétrica consumida pelos subsistemas (auxiliar: aquecedor auxiliar; chiller solar: chiller de absorção solar; SAS: sistema de 
aquecimento solar; torre de resf.: sistema de rejeição de calor) do sistema de ar condicionado solar térmico nos dias 21 de junho e 21 de dezembro.

Figura 4.16 - Consumo de energia elétrica dos sistemas de ar condicionado estudados em função do número de pavimentos para os dias 21/06 e 21/12.

Figura 4.17 - Redução do consumo de energia elétrica dos sistemas de ar condicionado por ocasião da alteração do número de pavimentos do edifício de 20 para 1, 2, 3, 4, 5 e 8 .

Figura 4.18 - Consumos de energia dos sistemas de ar condicionado solar elétrico e térmico para os dias 21/06 e 21/12, aplicados ao edifício de 1, 2 e 3 pavimentos.

Figura 4.19 - redução porcentual no consumo de energia elétrica do sistema de ar condicionado solar térmico, causado pela redução do número de pavimentos do edifício de $(n+1)$ pavimentos para $n$ pavimentos (em \%), em função do número $n$ de pavimentos.

Figura 4.20 - Proporções entre os consumos de energia dos sistemas de ar condicionado solar e o do sistema de ar condicionado convencional para o dia 21 de junho, em função do número de pavimentos do edifício.

Figura 4.21 - Proporções entre os consumos de energia dos sistemas de ar condicionado solar e o do sistema de ar condicionado convencional para o dia 21 de dezembro, em função do número de pavimentos do edifício.

Figura 4.22 - Potência instantânea produzida pelo sistema fotovoltaico alocado nas fachadas do edifício, nos dias 21 de junho e 21 de dezembro.

Figura 4.23 - Economia de energia elétrica dos sistemas de ar condicionado solar para o mesmo edifício em função do número de pavimentos para o dia 21 de Junho.

Figura 4.24 - Economia de energia elétrica dos sistemas de ar condicionado solar para o mesmo edifício em função do número de pavimentos para o dia 21 de Dezembro.

Figura 4.25 - valor máximo de n para que o desempenho energético do sistema térmico e do sistema térmico com apoio fotovoltaico seja melhor do que o do sistema convencional. 
Figura 4.26 - valor máximo de $\mathrm{n}$ para que o desempenho energético do sistema térmico e do sistema térmico com apoio fotovoltaico seja melhor do que o do sistema elétrico.

Figura 4.27 - Comportamento dos valores de fração solar diária (média e mínima) em função do número de pavimentos para o sistema de ar condicionado solar térmico e para os dias 21/06 e 21/12.

Figura 4.28 - Comportamento dos valores de fração não solar diária média em função do número de pavimentos para o sistema de ar condicionado solar térmico e para os dias 21/06 e 21/12.

Figura 4.29 - Energia térmica fornecida à água pelo aquecedor auxiliar em função do número de pavimentos para o sistema de ar condicionado solar térmico e para os dias $21 / 06$ e $21 / 12$.

Figura 4.30 - Consumos de energia dos subsistemas do ar condicionado solar térmico $(21 / 06)$.

Figura 4.31 - Consumos de energia dos subsistemas do ar condicionado solar térmico (21/12).

Figura 4.32 - Distribuição da energia elétrica consumida pelos subsistemas (auxiliar: aquecedor auxiliar; chiller solar: chiller de absorção solar; SAS: sistema de aquecimento solar; torre de resf.: sistema de rejeição de calor) do sistema de ar condicionado solar térmico nos dias 21 de junho e 21 de dezembro, para o edifício com 2 pavimentos.

Figura 4.33 - Frações solares obtidas na operação do sistema de ar condicionado solar térmico nos dias 21/06 e 21/12, para a adoção de coletores FPC ou coletores ETC, e para o edifício de 20 pavimentos.

Figura 4.34 - Frações solares médias diárias obtidas na operação do sistema de ar condicionado solar térmico, com coletores planos (FPC), no dia 21/06 e no dia 21/12, para o edifício de 20 pavimentos.

Figura 4.35 - Frações solares médias diárias obtidas na operação do sistema de ar condicionado solar térmico, com coletores de tubo à vácuo (ETC), no dia 21/06 e no dia 21/12, para o edifício de 2- pavimentos. 
Figura 4.36 - Frações solares médias diárias obtidas na operação do sistema de ar condicionado solar térmico, com coletores planos (FPC), no dia 21/06 e no dia 21/12, para o edifício de 4 pavimentos.

Figura 4.37 - Frações solares médias diárias obtidas na operação do sistema de ar condicionado solar térmico, com coletores de tubo à vácuo (ETC), no dia 21/06 e no dia 21/12, para o edifício de 4 pavimentos.

Figura 4.38 - Fator i (em \%) para os sistemas de ar condicionado solar, no dia 21/06, para o edifício de 20 pavimentos.

Figura 4.39 - Fator i (em \%) para os sistemas de ar condicionado solar, no dia 21/12, para o edifício de 20 pavimentos.

Figura 4.40 - Fator i (em \%) para os sistemas de ar condicionado solar, no dia 21/06, para o edifício térreo.

Figura 4.41 - Fator i (em \%) para os sistemas de ar condicionado solar, no dia 21/12, para o edifício térreo.

Figura 4.42 - Economia de energia elétrica, em $\mathrm{KWh} / \mathrm{dia}$, dos sistemas de ar condicionado solar estudados: térmico com apoio fotovoltaico e coletores ETC, "térm+fv (ETC)", térmico e coletores ETC, "térmico (ETC)", térmico com apoio fotovoltaico e coletores FPC, "térm+fv (FPC)", térmico e coletores FPC, "térmico (FPC)" e elétrico, para os edifícios de 1 a 4 pavimentos, no dia 21 de dezembro.

Figura 4.43 - Consumo de energia elétrica, em KWh/dia, do sistema de ar condicionado solar térmico, para o dia 21 de junho, e para o edifício de 1 ou 2 pavimentos, e os coletores FPC ou ETC.

Figura 4.44 - Consumo de energia elétrica, em KWh/dia, do sistema de ar condicionado solar térmico, para o dia 21 de dezembro, e para o edifício de 1 ou 2 pavimentos, e os coletores FPC ou ETC.

Figura 4.45 - Frações solares diárias médias do sistema de ar condicionado solar térmico para $95 \%$ da cobertura com coletores solares, para o edifício simulado com 4 pavimentos e para $21 / 06$ e 21/12.

Figura 4.46 - Frações solares diárias médias do sistema de ar condicionado solar térmico para $70 \%$ da cobertura com coletores solares, para o edifício simulado com 4 pavimentos e para 21/06 e 21/12. 
Figura 4.47 - Frações solares diárias médias do sistema de ar condicionado solar térmico para $50 \%$ da cobertura com coletores solares, para o edifício simulado com 4 pavimentos e para 21/06 e 21/12. 


\section{LISTA DE TABELAS}

Tabela 2.1 - Sistemas com absorção solar. (fonte: Grossmann, p.58, 2001).

Tabela 2.2 - Comparação entre os principais sistemas de ar condicionado solar.

Tabela 3.1 - Vantagens e desvantagens das alternativas em estudo.

Tabela 3.2 - Nomenclatura das zonas térmicas no modelo geométrico. Os campos em azul representam as zonas condicionadas.

Tabela 3.3 - Elementos construtivos simulados para o edifício.

Tabela 3.4 - Dados de entrada das cargas internas para simulação no EnergyPlus.

Tabela 3.5 - Informações geográficas utilizadas para simulação no EnergyPlus.

Tabela 3.6 - Parâmetros da instalação solar.

Tabela 3.7 - Parâmetro do sistema de aquecimento auxiliar elétrico.

Tabela 3.8 - Parâmetros do chiller solar de absorção.

Tabela 3.9 - Parâmetros do sistema de rejeição de calor do ar condicionado solar térmico.

Tabela 3.10 - Parâmetros do chiller do ar condicionado solar elétrico.

Tabela 3.11 - Parâmetros do chiller do ar condicionado convencional. 


\section{LISTA DE ABREVIATURAS E SIGLAS}

$\begin{array}{ll}\text { ABS } & \text { Absorção } \\ \text { adm } & \text { Adimensional } \\ \text { AG } & \text { Água Gelada } \\ \text { ANEEL } & \text { Agencia Nacional de Energia Elétrica } \\ \text { a-Si } & \text { Silício Amorfo } \\ \text { COP } & \text { Coeficient of Performance } \\ \text { CPC } & \text { Compound Parabolic Collector } \\ \text { CV } & \text { Compressão de Vapor } \\ \text { DC/AC } & \text { Direct current }- \text { Alternate Current } \\ \text { DEC } & \text { Sistemas dessecantes de ar condicionado solar } \\ \text { DOE } & \text { United States Department of Energy } \\ \text { EPIA } & \text { European Photovoltaic Industry } \\ \text { ESTIF } & \text { European Solar Thermal Industry Federation } \\ \text { ETC } & \text { Evacuated Tube Collector (Tubo a vácuo) } \\ \text { FPC } & \text { Flat Plate Collector } \\ \text { FV } & \text { Fotovoltaicos } \\ \text { GHG } & \text { greenhouse gases (gases efeito estufa) } \\ \text { HVAC } & \text { Heating, Ventilation and Air Conditioning } \\ \text { IDF } & \text { Input Data File } \\ \text { IEA } & \text { International Energy Agency } \\ \text { IPCC } & \text { Intergovernmental Panel on Climate Change } \\ \text { mono-Si } & \text { Silício monocristalino } \\ \text { MME } & \text { Ministério de Minas e Energia } \\ \end{array}$


Mtep Mega-toneladas equivalentes de petróleo

Poli-Si Silício Policristalino

PRODEEM Programa para desenvolvimento da energia nos estados e municípios

SOLAIR Solar Air Conditioning for Europe

TR Torre de resfriamento 


\section{LISTA DE SÍMBOLOS}

$A_{\text {solar }}$
$\alpha_{\text {térmico,N }}$
$C O P_{S}$
$C O P_{C V}$
$\Delta T$
$\Delta E_{N, e l e ́ t r i c o}$

$\Delta E_{N, \text { térmico }}$

$\Delta E_{N, t e ́ r m+f v}$

$E_{0}$

$E_{0, \text { térmico }}$

$E_{0, e l e ́ t r i c o}$

$E_{0, \text { conv }}$

E

$E_{\text {térmico }}$

Elétrico

$E_{\text {conv }}$

$i_{\text {elétrico,N }}$

$i_{\text {térmico,N }}$

$i_{\text {térm+fv,N }}$
Área dos coletores solares térmicos na cobertura do edifício $\left(\mathrm{m}^{2}\right)$

Redução percentual no consumo de energia elétrica do sistema de ar condicionado solar térmico, causada pela redução do número de pavimentos do edifício de $(N+1)$ para $N$ pavimentos (\%).

Coeficiente de Performance do chiller solar (adm.)

Coeficiente de Performance do chiller de compressão de vapor (adm.)

Período de tempo utilizado para o cálculo de energia do ar condicionado (h).

Economia de energia elétrica do sistema de ar condicionado solar elétrico em relação ao ar condicionado convencional, para o edifício com $N$ pavimentos, para o dia estudado (\%).

Economia de energia elétrica do sistema de ar condicionado solar térmico em relação ao ar condicionado convencional, para o edifício com $N$ pavimentos, para o dia estudado (\%).

Economia de energia elétrica do sistema de ar condicionado solar térmico com apoio fotovoltacio em relação ao ar condicionado convencional, para o edifício com $N$ pavimentos, para o dia estudado (\%).

Consumo de energia primária do sistema de ar condicionado (kWh).

Consumo de energia primária do sistema de ar condicionado solar térmico (kWh).

Consumo de energia primária do sistema de ar condicionado solar elétrico (kWh).

Consumo de energia primária do sistema de ar condicionado convencional (kWh).

Consumo de energia elétrica do sistema de ar condicionado (kWh).

Consumo de energia elétrica do sistema de ar condicionado solar térmico (kWh).

Consumo de energia elétrica do sistema de ar condicionado solar elétrico (kWh).

Consumo de energia elétrica do sistema de ar condicionado convencional (kWh).

Proporção entre o consumo de energia elétrica do sistema de ar condicionado solar elétrico e do sistema de ar condicionado convencional, para o edifício com $N$ pavimentos (\%).

Proporção entre o consumo de energia elétrica do sistema de ar condicionado solar térmico e do sistema de ar condicionado convencional, para o edifício com $N$ pavimentos (\%).

Proporção entre o consumo de energia elétrica do sistema de ar condicionado 
solar térmico com apoio fotovoltaico e do sistema de ar condicionado convencional, para o edifício com $N$ pavimentos (\%).

$f_{e}$

$f_{t}$

K

$N$

$\eta_{1}$

$\eta_{2}$

$\eta_{3}$

$\eta_{e}$

$\eta_{\text {solar }}$

$P_{f v}$

$Q(t)$

$Q_{\text {aux }, i}$

$Q_{\text {cold }}$

$Q_{\text {edifícion, } i}$

$Q_{\text {edificio20,i }}$

$Q_{k, i}$

$Q_{N, i}$

$Q_{\text {solar }, i}$

$q_{\text {térreo,i }}$

$q_{10^{\circ} \mathrm{PAV}, \mathrm{i}}$

Irradiância solar $\left(\mathrm{W} / \mathrm{m}^{2}\right)$.

Demanda específica de eletricidade da instalação solar (\%).

Demanda específica de eletricidade do chiller solar (\%).

Demanda específica de eletricidade do chiller solar (\%).

Função de economia de energia do sistema de ar condicionado solar elétrico de acordo com a variação do número de pavimentos do edifício.

Função de economia de energia do sistema de ar condicionado solar térmico de acordo com a variação do número de pavimentos do edifício.

Fator $\mathrm{K}$ da equação de consumo de energia (adm.).

Número de pavimentos do edifício.

Eficiência do aquecedor auxiliar (\%).

Eficiência energética primária do combustível fóssil utilizado no aquecedor auxiliar (\%).

Eficiência energética primária da eletricidade da rede (\%).

Eficiência do aquecedor auxiliar elétrico (\%).

Eficiência dos coletores solares térmicos (\%).

Produção de energia fotovoltaica pelos painéis nas fachadas, no período estudado (kWh).

Função da carga térmica instantânea no edifício (W).

Energia térmica fornecida ao chiller de absorção solar e proveniente do sistema de aquecimento auxiliar elétrico, na hora $i$ do dia estudado (kWh).

Energia térmica retirada do ambiente condicionado pelo sistema de condicionamento de ar, no período estudado (kWh).

Carga térmica calculada para o edifício de $N$ pavimentos, para a hora $i$ do dia estudado (W).

Carga térmica calculada para o edifício real de 20 pavimentos, para a hora $i$ do dia estudado $(\mathrm{W})$.

Carga térmica do pavimento $\mathrm{k}$ do edifício, para a hora i do dia estudado (W).

Carga térmica do pavimento $N$ do edifício de $N$ pavimentos.

Energia térmica fornecida ao chiller de absorção solar e proveniente dos coletores térmicos na hora $i$ do dia estudado (kWh).

Carga térmica resultante da simulação do pavimento térreo, para a hora $i$ do dia estudado $(\mathrm{W})$.

Carga térmica resultante da simulação do pavimento intermediário, para a hora $i$ do dia estudado (W).

Fração do sistema de ar condicionado solar térmico, média para cada hora $i$ do dia estudado (\%). 


\section{SUMÁRIO}

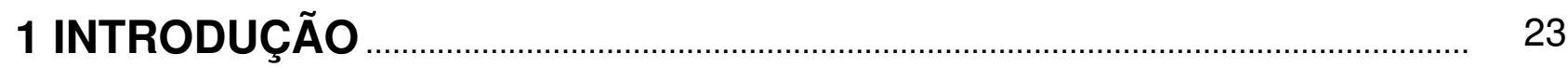

1.1 Problema energético global ................................................................... 24

1.2 Papel dos sistemas de ar condicionado em edifícios de escritórios no problema energético global .................................................................. 26

1.3 Papel da energia solar na busca de soluções para o problema energético global

1.4 Energia solar como possibilidade para sistemas de condicionamento de ar em edifícios de escritórios ................................................................. 35

1.5 Objetivos e estrutura do trabalho............................................................... 37

2 REVISÃO BIBLIOGRÁFICA …………………………………………………... 40

2.1 Sistemas de ar condicionado solar: aspectos gerais ............................... 41

2.2 Descrição dos sistemas ...................................................................... 42

2.3 Aspectos de mercado ...................................................................... 50

2.4 Comentários gerais sobre a tecnologia ............................................... 57

3 MATERIAIS E MÉTODOS ……....................................................................... 60

3.1 Definição do edifício e do sistema de ar condicionado solar em estudo

3.1.1 Definição do edifício de escritório .................................................................. 62

3.1.2 Definição dos sistemas de ar condicionado solar ................................ 64

3.2 Análise do desempenho térmico do edifício ............................................... 73

3.2.1 Ferramenta para simulação do edifício ............................................... 73

3.2.2 Método para a análise térmica do edifício............................................. 77

3.2.2.1 Modelo geométrico do edifício ............................................... 77

3.2.2.2 Modelo construtivo do edifício ................................................. 84

3.2.2.3 Modelo de cargas internas do edifício .................................... 85

3.2.2.4 Modelo climático e geográfico …………………................... 86

3.3 Análise energética dos sistemas de condicionamento de ar .................... 88

3.3.1 Método de análise energética dos sistemas de ar condicionado solar

3.3.1.1 Método de cálculo do consumo de energia primária proposto pelo projeto "SOLAIR" da União Européia

3.3.1.2 Comentários sobre o método proposto pelo projeto "SOLAIR". 
3.3.2 Determinação dos parâmetros a serem utilizados no método de análise energética dos sistemas de ar condicionado solar......................................... 103

3.4 Considerações finais sobre o método de pesquisa …........................................ 108

3.4.1 Síntese do método de pesquisa

3.4.2 Resumo das premissas e hipóteses adotadas na pesquisa.

3.4.2.1 Edifício de Escritórios.

3.4.2.2 Dados geográficos e climáticos..

3.4.2.3 Sistema de ar condicionado solar térmico

3.4.2.4 Sistema de ar condicionado solar elétrico

3.4.2.5 Sistema de ar condicionado convencional.

4 RESULTADOS

4.1 Análise térmica do edifício

4.2 Análise energética do sistema de ar condicionado solar

4.2.1 Consumo de energia dos sistemas de ar condicionado solar 124

4.2.2 Desempenho dos sistemas em função do número de pavimentos

4.2.3 Desempenho do sistema térmico em função da área e do tipo de coletor 
"Desempenho de Sistemas de Condicionamento de Ar com Utilização de Energia Solar em Edifícios de Escritórios"

\section{Capítulo 1 \\ Introdução}




\section{INTRODUÇÃO}

\subsection{Problema Energético Global}

O mundo atual se depara com a necessidade de dar respostas e encontrar soluções para problemas que, embora já vislumbrados no passado, tem se tornado, nos últimos anos, objeto de preocupação crescente da humanidade.

Uma das questões que se apresenta com grande importância atualmente é a do problema energético, que consiste na crescente utilização dos recursos energéticos disponíveis no planeta terra, em especial dos recursos não-renováveis, sujeitos a escassez. Sem um devido enfrentamento dessa questão, graves conseqüências sociais, econômicas, políticas e ambientais ameaçam a humanidade e o planeta nas próximas décadas.

Principalmente a partir da década de 70, com a crise do Petróleo, a questão energética passou ter cada vez mais importância no contexto dos países e organizações. Em um fenômeno crescente, observa-se que as sociedades tem se dado conta da problemática do uso de recursos energéticos, em especial com relação ao seu suprimento e sua exaustão (PERÉZ-LOMBARD; ORTIZ; POUT, 2008).

Em resposta a isso, diversas iniciativas sustentáveis estão em curso atualmente, seja ao nível de governo, da sociedade, das empresas e organizações. Entretanto, ainda muito deve ser feito frente à prática disseminada do uso nãosustentável dos recursos energéticos, sem a preocupação com seus impactos no ambiente, na sociedade e na economia.

Esse problema é mais crítico ainda nos países em desenvolvimento, como é o caso do Brasil. Segundo Peréz-Lombard; Ortiz e Pout (2008, p.394), nos países em desenvolvimento, "o uso de energia crescerá com uma taxa média anual de 3,2\% e superará em 2020 o uso nos países desenvolvidos, que, por sua vez, apresentam uma taxa média anual de crescimento do uso de energia de apenas 1,1\%". Somado a isso, nos países em desenvolvimento, a menor disponibilidade de recursos econômicos e os problemas políticos e sociais afetam ainda mais a questão 
energética, que se traduz no agravamento dos problemas que já existem nessas regiões.

Sendo assim, pode-se dizer que a ausência de providências eficazes na mitigação do problema energético global pode causar sérios impactos na humanidade nos próximos anos. De fato, a escassez dos recursos energéticos coloca em risco o acesso à energia das populações, colocando aspectos sociais e políticos em jogo, ameaçando a segurança das nações e a estabilidade da economia.

Além disso, os impactos ambientais resultantes da utilização de combustíveis fósseis na matriz energética mundial podem conduzir a efeitos desastrosos no ambiente, especialmente relacionados às emissões de gases efeito estufa (GHG) e às mudanças climáticas. Tais impactos, em muitos casos, já podem ser observados atualmente no planeta (PAINEL INTERGOVERNAMENTAL DE MUDANÇAS CLIMÁTICAS, 2007).

Essa preocupação energética se mantém, mesmo com a consciência da existência de teorias que afirmam que o aquecimento global não seja causado por emissões antropogênicas de GHG e sim por causas naturais (NIPCC, 2008 apud BESSA, 2010), já que, de qualquer forma, considerar a necessidade de redução do consumo energético da sociedade é sempre importante.

Essa questão ainda permanece importante, também em países nos quais a matriz energética é em grande parte renovável, como o Brasil, já que neste caso, também o elevado consumo energético conduz a uma sociedade não-sustentável.

De fato, mesmo que a preocupação não fosse com as emissões, o elevado consumo de energia deveria ser levado em conta, pois sempre impõe algum tipo de impacto na sociedade, na política, na economia e no ambiente, impedindo o desenvolvimento sustentável da sociedade.

Neste contexto, portanto, o foco deste trabalho consistirá no estudo da possibilidade de se utilizar energia solar para sistemas de condicionamento de ar, a fim de se buscar alternativas para a questão energética.

Com efeito, como será visto, os sistemas estudados procuram reduzir o impacto causado pelo elevado consumo de energia dos sistemas de condicionamento de ar em edifícios de escritórios, propondo a utilização de uma fonte renovável de energia (energia solar) para esses sistemas. 
Assim, a partir dos próximos itens serão apresentados tanto o papel dos sistemas de ar condicionado nessa questão energética como o potencial da tecnologia solar, a fim de, no contexto do problema energético global, justificar a importância de se estudar o desempenho de sistemas de ar condicionado solar em edifícios de escritórios.

\subsection{Papel dos Sistemas de Ar Condicionado em Edifícios de Escritórios no Problema Energético Global}

Conhecendo-se, então, a problemática energética que o planeta enfrenta e na busca por soluções eficazes para essa questão, não se pode, de forma alguma, desconsiderar o papel importante das edificações. De fato, analisando o consumo de energia dos edifícios, fica evidente a importância de sua contribuição para a questão energética e a relevância da aplicação de práticas sustentáveis nesse setor.

De acordo com Lombard et al. (2008, p.395): "o crescimento populacional, a ampliação dos serviços nos edifícios e dos níveis de conforto, ao lado do crescimento do tempo gasto dentro dos edifícios, elevou o consumo de energia das edificações aos níveis do transporte e da indústria”. Somente na União Européia, o consumo final de energia nos edifícios, segundo Papadopoulos et al. (2003, p.420) "alcança aproximadamente 385,6 Mtep" ${ }^{1}$, que representa quase 40\% da energia total consumida". Sendo assim, as edificações produzem a um impacto significativo no consumo e demanda energética do planeta.

A grande importância dos edifícios nesta questão é, principalmente, devida ao consumo energético dos sistemas de condicionamento de ar. De acordo com Grossman (2002, p.53), “a crescente demanda por condicionamento de ar nos últimos anos, particularmente em climas quentes e úmidos, [...] implicou em um significativo crescimento na demanda por recursos energéticos primários". Sendo assim, o papel dos sistemas de ar condicionado não pode ser negligenciado, quando se pensa no problema energético e alternativas sustentáveis para o planeta.

${ }^{1}$ Mtep $-1 \times 10^{6}$ toneladas equivalentes de petróleo 
O impacto energético dos sistemas de ar condicionado se agrava ainda mais quando se considera, também, a questão da demanda de energia. Na maioria dos países desenvolvidos, por exemplo, devido ao uso cada vez maior desses sistemas, se observa a ocorrência de picos de demanda no verão (PAPADOPOULOS et al., 2003). Essa demanda crescente do sistema, em especial no verão, é devida principalmente, às crescentes cargas térmicas, aos padrões de vida e de conforto elevados e às tendências arquitetônicas que impõem grande área de superfícies transparentes nas fachadas dos edifícios (HENNING, 2007).

Sobre esse assunto, a Agência Internacional de Energia (IEA, 2007, p.25, "Renewable for Heating and Cooling") evidencia uma tendência atual ao afirmar que "os projetos modernos dos edifícios fizeram crescer a demanda por resfriamento, porém reduziram a demanda por energia para aquecimento".

Se quando se fala de edifícios, o papel energético dos sistemas de ar condicionado já é importante, essa relevância aumenta ainda mais quando se trata de edifícios de escritórios. Lombard et al. (2008, p.398) apresentaram justificativas para a preocupação energética com essa tipologia, como por exemplo, "o crescimento substancial da área total construída de escritórios no mundo". Somente no Reino Unido, a área total de escritórios cresceu quase 4\% entre 2000 e 2005, nos Estados Unidos a área de escritórios per capita atinge o valor de $2 \mathrm{~m}^{2}$ e na Espanha todos os novos edifícios de escritórios possuem sistemas de condicionamento de ar (LOMBARD et al., 2008).

Sendo assim, pode-se afirmar que, a consideração dos sistemas de condicionamento de ar dos edifícios de escritório, é de extrema importância quando se buscam soluções para o problema energético que a humanidade vive, que, em outras palavras, consiste no consumo elevado e crescente dos recursos energéticos do planeta.

\subsection{Papel da Energia Solar na Busca de Soluções para o Problema Energético Global}

Se, por um lado, quando se pensa no problema energético global, o papel dos sistemas de ar condicionado em edifícios não pode ser esquecido, por outro, o papel 
das fontes renováveis de energia não pode ser tampouco negligenciado. De fato, a utilização de fontes renováveis de energia representa segundo Pearce (2008, p.1101) "um dos métodos mais promissores para o controle das continuadas emissões de GHG" e corresponde, além disso, a uma alternativa interessante para reduzir a demanda por recursos energéticos convencionais.

Em expansão a nível global, a utilização de energias renováveis tem se apresentado como uma tendência para as próximas décadas. Já em 2004, na União Européia, as fontes renováveis de energia, elétrica ou térmica, embora ainda não fossem as fontes principais de energia, apresentavam uma taxa de crescimento superior ao crescimento do uso de outras fontes, tais como, energia nuclear, gás natural e combustíveis sólidos. Esse crescimento no uso de energias renováveis ficou mais evidente, principalmente, a partir desta presente década (CELIK; MUNEER; CLARKE, 2009).

Atualmente, dentre as alternativas energéticas renováveis, a alternativa de utilização de energia solar tem se mostrado cada vez mais significativa. $O$ aproveitamento da energia proveniente do sol não é um fenômeno recente na história da humanidade. O ser humano e a natureza, mesmo que inconscientemente, sempre fizeram uso, direta ou indiretamente, da energia solar (KALOGIROU, 2004). De fato, a disponibilidade do recurso solar é expressiva no planeta terra, que recebe uma quantidade de energia capaz de alimentar grande parte dos processos energéticos da humanidade (DUFFIE; BECKMAN, 1976).

Reconhece-se, também, que os fenômenos naturais, as demais fontes de energia, tais como, petróleo, carvão, gás natural, entre outras, e até mesmo o vento, tem origem a partir da energia solar. Além disso, é possível observar a diversidade de aplicações da energia solar, tais como, em processos industriais, climatização de edificações, produção de sal ou de água potável, aquecimento de água, geração de eletricidade, processos químicos, entre outros (KALOGIROU, 2004).

Considerando-se, ainda, a imensa quantidade de energia proveniente do Sol, que proporciona uma oferta de energia maior do que a demanda de energia no planeta (DUFFIE; BECKMAN, 1976), e sabendo-se dos inúmeros benefícios apresentados pelo recurso solar como fonte energética, pode-se considerar a energia solar como uma alternativa a ser fortemente considerada quando se buscam alternativas renováveis de energia. Nesse sentido, Kalogirou (2004, p.235) afirma que: 


\begin{abstract}
Existem muitas fontes alternativas de energia que podem ser utilizadas em substituição aos combustíveis fósseis. A decisão sobre qual tipo de energia utilizar deve, em cada caso, ser feita baseada em considerações econômicas, ambientais e de segurança. Devido aos desejáveis aspectos ambientais e de segurança acredita-se amplamente que a energia solar deve ser utilizada ao invés de outras formas de energias alternativas, mesmo quanto os custos envolvidos são um pouco superiores.
\end{abstract}

Para a realidade brasileira, da mesma forma, a utilização de energia solar também pode ser considerada interessante. De fato, em consonância com o avanço em escala mundial, a energia solar no Brasil tem sido também considerada com bastante relevância e possui perspectivas otimistas com relação a sua expansão. Primeiramente, deve-se ter em conta a abundância do recurso solar em terras brasileiras, isto é, que os níveis de radiação solar e de insolação são elevados. Sabe-se que, os países europeus, por exemplo, nos quais existem inúmeros projetos e incentivos à utilização de energia solar, possuem níveis de radiação solares bem menores do que qualquer região do Brasil (MARTINS et al., 2008).

Apesar disso, nota-se que o processo de inserção da tecnologia solar no Brasil, apresenta um histórico de descontinuidades e dificuldades em seu desenvolvimento no país (DHERE et al., 2002), sendo que, somente nos últimos anos, os sistemas de aproveitamento da energia solar no Brasil têm apresentado alguma expansão mais relevante, principalmente através dos sistemas de aquecimento solar de água. Ao mesmo tempo, nota-se, no Brasil, um significativo potencial para os sistemas fotovoltaicos especialmente para aplicações de eletrificação rural (CEPEL, 2003), embora ainda pouco utilizados. Enfim, pode-se dizer que, de forma geral, o Brasil apresenta um grande potencial para o uso de energia solar como alternativa de fonte renovável de energia.

Ainda com relação à energia solar, pode-se dizer que existem, dentre as diversas aplicações, duas principais e mais disseminadas possibilidades tecnológicas. Uma das possibilidades é o aproveitamento da energia solar na forma de calor, isto é, através da conversão da radiação solar em energia térmica por meio de coletores solares térmicos. Outra possibilidade corresponde à conversão da radiação solar em energia elétrica através de células fotovoltaicas (sistemas fotovoltaicos) ou através da conversão da radiação solar em energia térmica 
utilizada posteriormente para produzir eletricidade (sistema heliotermoelétrico) (FRAIDENRAICH, 2002).

Considerando-se que os sistemas heliotermoelétricos são uma tecnologia bem mais incipiente e pouco explorada, pode-se dizer que duas são as alternativas principais de sistemas que aproveitam energia solar: a alternativa solar térmica e a alternativa solar fotovoltaica.

A alternativa solar térmica representa uma das formas mais promissoras de aproveitamento da energia solar. Baseia-se no conceito simples de aquecer um fluido, no interior de uma tubulação, em um sistema que absorva radiação térmica. A tecnologia solar térmica atende uma grande variedade de áreas de aplicação, tais como, o aquecimento de água em edificações, a climatização (aquecimento, resfriamento e condicionamento do ar) de ambientes, processos industriais, aquecimento de piscinas, entre outras.

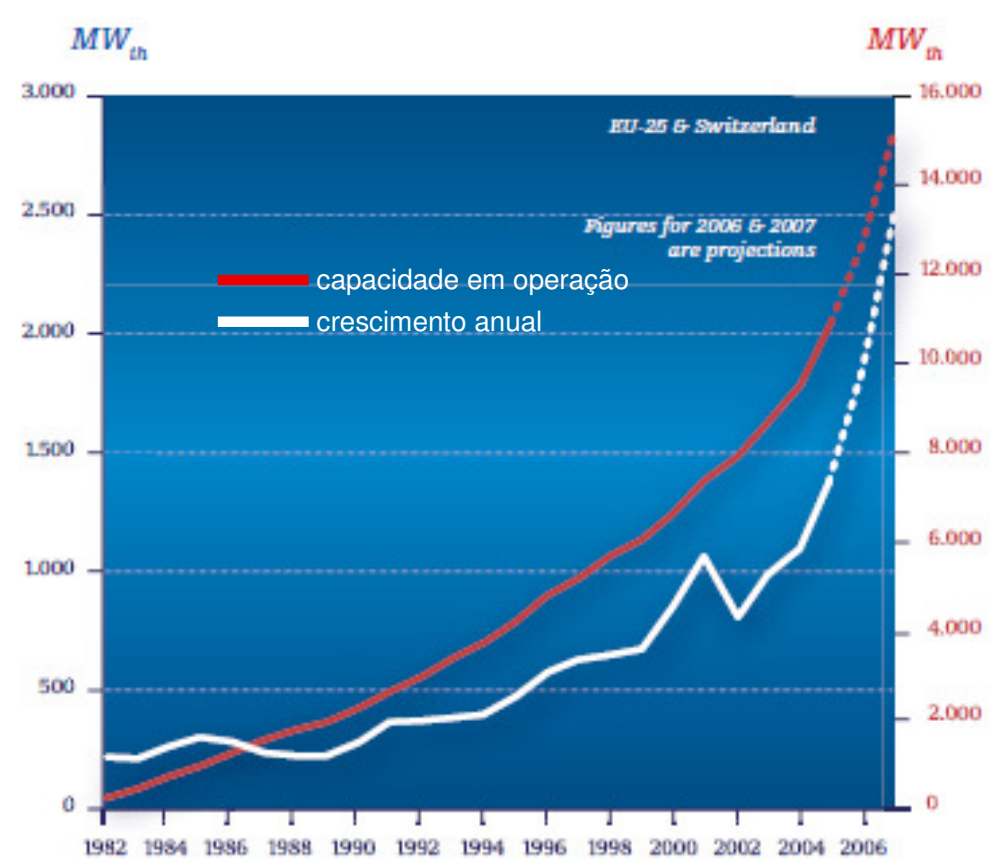

Figura 1.1 - Crescimento dos sistemas solares térmicos na Europa. Fonte: ESTIF ${ }^{2}$ (2007, Solar Thermal Action Plan for Europe, p.8)

${ }^{2}$ ESTIF - European Solar Thermal Industry Federation (Federação das Industrias Solares Térmicas da Europa) 
Os sistemas solares térmicos, segundo a ESTIF (2007, "Solar Thermal Action Plan for Europe", p.6), "representam mais de $90 \%$ da capacidade instalada de sistemas que aproveitam energia solar no mundo". De modo geral, pode-se dizer que é uma das formas mais rentáveis de energia renovável e que possui um grande potencial de expansão (ESTIF, 2007).

Neste sentido, a Figura 1.1 mostra a expansão dos sistemas solares térmicos na União Européia, com relação ao crescimento anual do mercado (linha branca e escala da esquerda) e a capacidade em operação (linha vermelha e escala da direita) dos sistemas solares térmicos na Europa.

No Brasil, por sua vez, o cenário de utilização de energia solar térmica, embora ainda pouco explorado em relação ao seu potencial, é bastante favorável ao crescimento. A predominância, no país, é dos sistemas térmicos destinados ao aquecimento de água, cujo mercado está em expansão em nível nacional. Para residências, por exemplo, segundo Fraidenraich (2002, p.10) os sistemas de aquecimento solar de água podem "contribuir, nas próximas décadas, com uma fração igual ou maior que $22 \%$ do consumo total" de energia térmica em residências.

No país a área de coletores solares térmicos, por exemplo, tem aumentado significativamente ao longo dos últimos anos, conforme mostra a Figura 1.2, abaixo:

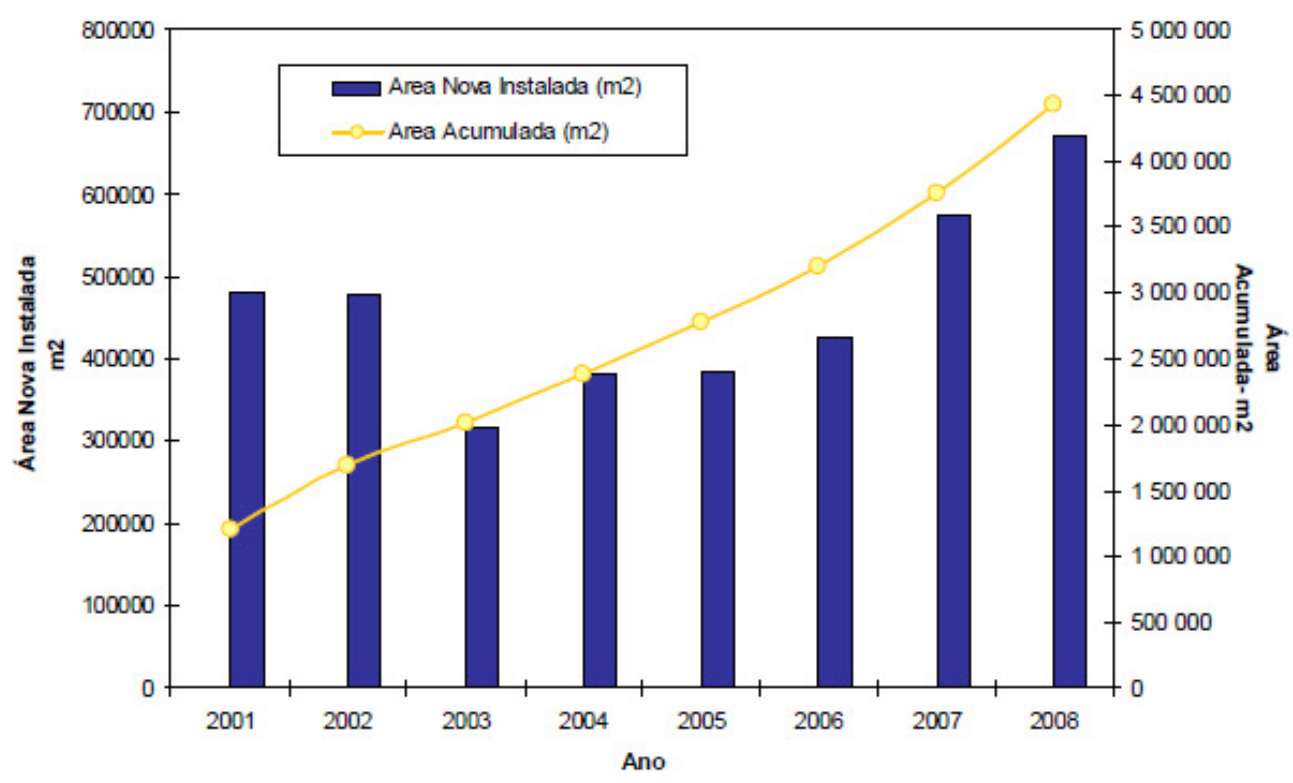

Figura 1.2 - Crescimento da área de coletores solares no Brasil. Fonte: CIDADES SOLARES (2009, Apresentação do Curso de "Projetista Solar") 
Observa-se, também, o surgimento de mecanismos de incentivo a energia solar térmica no país, tais como as "Leis Solares", como são conhecidas (SOL BRASIL, 2008, Revista), além de avanços na normalização e no desenvolvimento das empresas do ramo.

A alternativa solar fotovoltaica, por sua vez, apesar de ainda pouco explorada, representa uma oportunidade tecnológica bastante interessante. Baseada no efeito fotovoltaico, conhecido pela humanidade há pouco menos de dois séculos (STRONG; SCHELLER, 1993), a tecnologia fotovoltaica começou a ser explorada, em termos práticos, somente a partir das décadas de 1950 e 1960, com o desenvolvimento dos semicondutores na indústria eletrônica (EUROPEAN POTHOVOLTAIC TECHNOLOGY PLATFORM, 2007).

Os sistemas fotovoltaicos são compostos de módulos contendo células solares de material semicondutor, em geral, cristalinos ou amorfos e elementos acessórios, tais como, componentes eletrônicos, cabeamento e estrutura suporte. Esses sistemas podem ser conectados ou não à rede elétrica e integrados ou não à edificação (ZILLES, 2007).

A expansão da utilização de sistemas fotovoltaicos está em curso em escala global. Segundo a $\operatorname{EPIA}^{3}$ (2008, "Solar Generation V", p.22) as "instalações de células e módulos fotovoltaicos no mundo têm crescido a uma taxa anual superior a $35 \%$ desde 1998", sendo que, o crescimento atual tem se dado principalmente devido à expansão dos sistemas conectados à rede (EPIA, 2008), em muitos casos, impulsionados por mecanismos de incentivo ou obrigatoriedade por parte dos governos.

Essa expansão é, em grande parte, devida ao crescimento da indústria do Silício. De acordo com o CEPEL; CRESESB (2004), "em 1998, a produção de células fotovoltaicas atingiu a marca de $150 \mathrm{MWp}$, sendo o Silício quase absoluto no ranking dos materiais utilizados". De fato, a maioria das células fotovoltaicas é constituída desse material, podendo ser utilizado, principalmente, nas formas de Silício monocristalino (m-Si), policristalino (poli-Si) ou amorfo (a-Si).

Ainda quanto ao material das células, uma opção interessante para a tecnologia fotovoltaica é a utilização de filmes finos, dentre os quais as células de silício amorfo se enquadram.

\footnotetext{
${ }^{3}$ EPIA - European Photovoltaic Industry Association (Associação Européia das Industrias Fotovoltaicas)
} 
Neste trabalho, esses painéis de Silício amorfo (filmes finos) serão utilizados para a análise de desempenho energético dos sistemas de ar condicionado solar em estudo, já que, como será visto, no caso da pesquisa, se adéquam satisfatoriamente à possibilidade de integração às fachadas dos edifícios (HAGEMANN, 2004).

Uma visão da situação do mercado fotovoltaico pode ser observada na Figura 1.3, que mostra o aumento da capacidade fotovoltaica instalada na Europa.

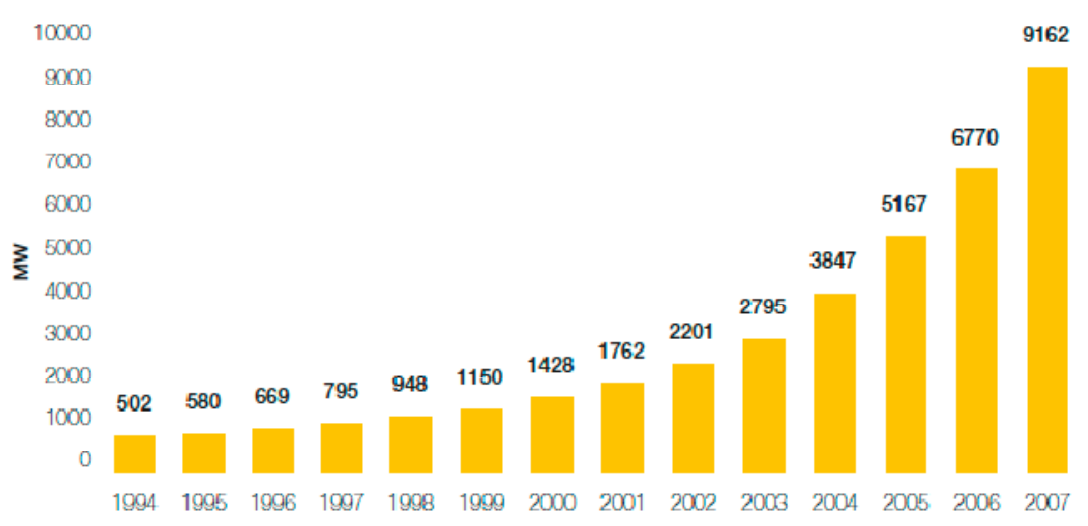

Figura 1.3 - Capacidade fotovoltaica acumulada na Europa Fonte: EPIA (2008, Solar Generation V, p.22)

Da mesma forma, a tecnologia fotovoltaica no Brasil, mesmo sendo bem menos disseminada do que a nível mundial, apresenta um excelente potencial para o futuro. O Brasil, historicamente, mesmo com algumas dificuldades na inserção da tecnologia, contou com a formulação e a implementação de programas de difusão dos sistemas fotovoltaicos e consolidou, ao longo dos anos, grupos de pesquisa e desenvolvimento tecnológico nesta área (ZILLES, 2002).

Um desses programas de incentivo foi, por exemplo, o PRODEEM (Programa para o Desenvolvimento da Energia nos Estados e Municípios), que se desenvolveu no Brasil na década de 90. Como o apoio do Governo, foram implantados centenas de sistemas fotovoltaicos autônomos, em especial, em comunidades isoladas, sem acesso à eletrificação rural (CENTRO DE PESQUISA DE ENERGIA ELÉTRICA, 1996). A Figura 1.4, mostra um sistema implantado pelo PRODEEM, no município de Pentecostes, no Ceará. 


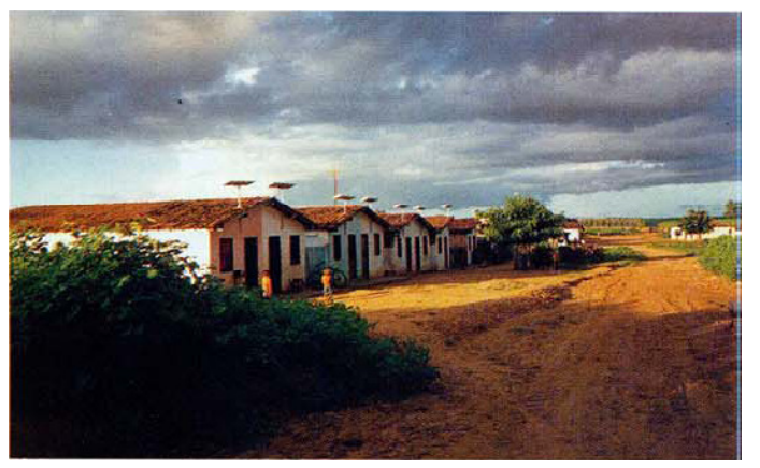

Figura 1.4 - Sistemas Fotovoltaicos Autônomos instalados no município de Pentecostes, no estado do Ceará, Brasil. Fonte: CEPEL, 2003

Apesar dessas iniciativas, atualmente, a utilização de sistemas fotovoltaicos ainda é muito fraca no país, especialmente com relação ao grande potencial energético apresentado pelo Brasil, às grandes possibilidades de aproveitamento solar, e em relação, também, à existência de uma quantidade significativa de informações satisfatórias sobre o recurso solar no país (TIBA C. et al, 2002).

$\mathrm{Na}$ realidade, a tecnologia fotovoltaica no país apresenta atualmente algumas poucas possibilidades de expansão. Dentre elas, as aplicações em eletrificação rural, telecomunicações e bombeamento de água deverão continuar sendo as principais alternativas do mercado nacional (FRAIDENRAICH, 2002).

Essas dificuldades, de forma alguma diminuem a importância dessa alternativa no país, que, em consonância com a expansão a nível global, tende a se desenvolver também no Brasil. Um expressivo avanço desses sistemas é esperado como reflexo da expansão dos sistemas conectados a rede a nível mundial, que representam uma tendência global para os próximos anos. Além disso, a preocupação com as soluções sustentáveis e a queda dos custos iniciais da tecnologia, tendem a impulsionar o mercado, também a nível nacional.

Em resumo, pode-se concluir que, seja a nível mundial, seja a nível nacional, o aproveitamento da energia solar, principalmente nas formas térmica e fotovoltaica, deve ser fortemente considerado na busca por soluções do problema energético global. 


\subsection{Energia Solar como Possibilidade para Sistemas de Condicionamento de Ar em Edifícios de Escritórios}

Pelo que foi apresentado até aqui, pode-se dizer que, sabendo da questão energética global, é muito importante considerar alternativas sustentáveis para os sistemas de ar condicionado em edifícios de escritórios. Assim, coloca-se o desafio de atuar nesses sistemas de forma sustentável, de maneira que o consumo energético, em especial dos recursos convencionais de energia, seja reduzido.

Para isso, por um lado, é possível a aplicação de práticas de eficiência energética e uso racional de energia nos sistemas de ar condicionado. Nesse sentido, é recomendado, além da adoção de sistemas com equipamentos mais eficientes, isto é, com $\mathrm{COP}^{4}$ maior, a prática de estratégias bioclimáticas na edificação, principalmente já na fase de projeto.

Essas práticas incluem a redução de carga térmica por meio do uso de vegetação para sombreamento, o uso de cores claras de revestimento das edificações, o emprego de ventilação cruzada, a redução de transmitância térmica de paredes, janelas e coberturas, o uso de proteções solares nas aberturas e a gestão do uso da edificação e dos sistemas durante a operação (COLLE et al., 2005).

Por outro lado, a fim de atuar em sistemas de condicionamento de ar de forma sustentável, é possível apostar na utilização de novas tecnologias, que resultem em impactos energéticos menores do que as tecnologias convencionais. Nesse sentido, por exemplo, é possível considerar o uso de sistemas que operem termicamente ao invés da utilização da convencional operação elétrica (AFONSO, 2006), tais como, chillers de absorção. Da mesma forma, nesse sentido, é possível também a utilização de sistemas híbridos alimentados por fontes de energia renováveis, como por exemplo, solar ou biomassa (AFONSO, 2006).

\footnotetext{
${ }^{4}$ COP - Coeficient of Performance - representa o desempenho energético de um sistema frigorífico.
} 
Entretanto, estando consciente do potencial da energia solar enquanto fonte renovável de energia, conforme discutido no item anterior (item 1.3), deduz-se que seria bastante interessante aproveitar energia solar para os sistemas de ar condicionado. Esse opção será, portanto, o foco desta pesquisa.

Essa alternativa torna-se mais interessante ainda pelo fato de que a maior disponibilidade de recurso solar acontece nas horas do dia, nas quais o uso do ar condicionado no edifício é maior. Ou seja, nos momentos em que o sistema de ar condicionado apresenta uma demanda de energia mais elevada, a disponibilidade do recurso solar também é mais elevada (KIM; FERREIRA, 2007).

Neste ponto do trabalho, porém, embora consciente do potencial de utilização de energia solar para sistemas de condicionamento de ar, pode-se perguntar como seria possível realmente utilizar energia solar para alimentar sistemas de ar condicionado. De fato, a utilização de energia solar para alimentar sistemas de ar condicionado é possível e viável tecnicamente. Essa utilização pode ser feita por meio de duas formas principais.

Com efeito, tanto a conversão de energia solar em energia térmica, quanto a conversão da energia solar em energia elétrica, podem ser utilizadas em sistemas de condicionamento de ar. A primeira pode ser utilizada como fonte de calor para um sistema de ar condicionado com operação térmica (chiller de absorção, por exemplo) e a segunda, pode ser utilizada como alimentação de um sistema com operação convencional elétrica (chiller de compressão de vapor, por exemplo).

Sendo assim, pode-se dizer que a utilização de energia solar para sistemas de condicionamento de ar de edifícios de escritórios é uma alternativa possível e interessante de ser estudada e aprofundada. Dessa forma, em resposta à preocupação sustentável e às justificativas apresentadas até aqui, os sistemas de ar condicionado solar em edifícios de escritórios serão estudados nesse trabalho.

Para isso, alguns objetivos e uma estrutura de pesquisa foram traçados e serão apresentados no item 1.5 a seguir. 


\subsection{Objetivos e Estrutura do Trabalho}

Dentro do contexto da questão energética global, da importância energética dos sistemas de condicionamento de ar em edifícios de escritórios e do potencial das energias renováveis, pode-se definir os objetivos desse trabalho.

Essa pesquisa tem como objetivo principal estudar a utilização de energia solar nos sistemas de condicionamento de ar em edifícios de escritórios, na cidade de São Paulo, simulando a operação, em um edifício escolhido na cidade, de cada uma das seguintes alternativas de sistemas de ar condicionado solar:

1) Sistema de ar condicionado térmico (absorção) alimentado por energia solar térmica;

2) Sistema de ar condicionado elétrico (compressão de vapor) alimentado por energia solar fotovoltaica.

Isso será realizado, através do cálculo, para cada um dos sistemas acima, do consumo de energia elétrica resultante de sua operação em um dia de verão e em um dia de inverno. Esse cálculo será realizado através do método proposto neste trabalho, que é composto de duas etapas.

Na primeira será obtido o desempenho térmico do edifício, através do calculo da carga térmica pelo software EnergyPlus. Na segunda, é utilizada uma formulação sugerida pelo Projeto SOLAIR da União Européia, adaptada para o caso desse trabalho, que a partir das cargas térmicas e dos parâmetros dos sistemas, calcula o consumo de energia.

Dessa forma, pretende-se discutir o comportamento desses sistemas com relação a sua operação e ao seu desempenho energético, assim como, os limites e as potencialidades dessas alternativas para edifícios de escritórios da tipologia estudada localizados em São Paulo.

Além do objetivo principal apresentado acima, os seguintes objetivos específicos e complementares também estão previstos: 
- discutir o papel da energia solar e dos sistemas de condicionamento de ar em edifícios na busca de soluções para a questão energética global;

- apresentar uma revisão dos sistemas de ar condicionado solar, abordando os conceitos, os aspectos de mercado e as perspectivas de utilização desses sistemas.

- analisar o desempenho energético desses sistemas de ar condicionado solar em função do número de pavimentos do edifício, isto é, caso operassem em edifícios com a mesma tipologia e nas mesmas condições, porém que tenham um número diferente de pavimentos condicionados.

- para o sistema de ar condicionado solar térmico, desenvolver uma análise da influência da variação da tecnologia e da área de coletores solares, no desempenho energético do sistema.

A fim de atingir esses objetivos, essa pesquisa está estruturada nas seguintes etapas:

- Introdução (capítulo 1);

- Revisão bibliográfica (capítulo 2);

- Materiais e métodos (capítulo 3);

- Resultados (capítulo 4);

- Conclusões (capítulo 5);

No presente capítulo 1, o assunto da dissertação foi introduzido através da apresentação do papel energético dos sistemas de ar condicionado em edifícios de escritório, assim como da discussão da potencialidade da tecnologia solar enquanto alternativa energética renovável esses sistemas.

A revisão bibliográfica (capítulo 2) apresenta uma visão geral sobre o estadoda-arte da tecnologia de ar condicionado solar, ressaltando-se os conceitos, os tipos principais de sistemas e sua situação de mercado. 
No capítulo 3, dos materiais e métodos, serão apresentadas as premissas e ferramentas adotadas para a análise dos sistemas de ar condicionado solar a ser realizada na pesquisa.

No capítulo 4 serão apresentados e discutidos os resultados alcançados no estudo de desempenho dos sistemas de ar condicionado solar. Os resultados serão basicamente relativos ao cálculo da energia elétrica consumida pelos sistemas para cada uma das alternativas 1) e 2) apresentadas acima (e combinações entre elas). Além disso, serão obtidos resultados a partir de análises de sensibilidade do desempenho energético em função de alguns parâmetros dos sistemas tais como a tecnologia solar empregada, a área coletora e o número de pavimentos do edifício.

No capítulo de conclusões, as informações obtidas no trabalho serão apresentadas de forma resumida, de forma que se possa apresentar um conteúdo conclusivo sobre o assunto. 
"Desempenho de Sistemas de Condicionamento de Ar com Utilização de Energia Solar em Edifícios de Escritórios"

Capítullo 2

Revisão Bibliográfica 


\section{REVISÃO BIBLIOGRÁFICA}

\subsection{Sistemas de Ar Condicionado Solar: Aspectos Gerais}

Conforme foi introduzido no capítulo 1, a energia solar constitui-se em uma alternativa energética renovável interessante para sistemas de condicionamento de ar. Ao substituir uma fonte convencional por uma fonte renovável de energia, no caso, a energia solar, esses sistemas vão ao encontro das exigências sustentáveis.

Segundo Kim e Ferreira (2007, p.2), o interesse por estudar sistemas de ar condicionado solar surgiu "na década de 70 quando o mundo sofreu com a crise do petróleo" e, nas décadas seguintes, esse interesse continuou crescendo. Nessa época, foram implementados alguns projetos de desenvolvimento e demonstração, especialmente das tecnologias de refrigeração solar ${ }^{5}$, nas quais os sistemas de ar condicionado solar se baseiam (KIM; FERREIRA, 2007).

Nestas ocasiões, os sistemas de ar condicionado solar demonstraram sua viabilidade técnica e despontaram como uma alternativa tecnológica de grande potencial, seja devido à expansão do mercado de renováveis, seja devido ao crescimento no uso de sistemas de condicionamento de ar em escala global nas últimas décadas.

Essa importância crescente dada à tecnologia de ar condicionado solar, ao longo dos anos, fez com que, segundo a Agência Internacional de Energia (IEA, 2007, p.29, "Renewable for Heating and Cooling - Untapped potential") esses sistemas alcançassem atualmente "um estágio de desenvolvimento próximo de mercado".

Apesar disso, há ainda muitas barreiras à inserção de mercado dos sistemas de ar condicionado solar, tais como, os altos investimentos iniciais, a problemática da integração com os edifícios, a falta diretrizes e ferramentas de projeto e, especialmente, a falta de conhecimento da tecnologia por parte de empreendedores, profissionais e usuários (RENEWABLE ENERGY FOCUS, 2010).

\footnotetext{
${ }^{5}$ O termo refrigeração será usado algumas vezes neste trabalho. É importante ressaltar, porém, que não será objeto de estudo específico no trabalho já que o enfoque será no estudo do sistema predial como um todo integrado ao edifício.
} 
Sob o ponto de vista técnico, porém, utilizar energia solar para condicionamento de ar e refrigeração é viável e interessante de se aplicada. Nesse sentido, Kim e Ferreira (2007, p.2) afirmam que "considerando que a demanda por refrigeração cresce com a intensidade da radiação solar, a refrigeração solar pode ser considerada uma solução lógica". De fato, nos edifícios de escritórios, por exemplo, a maior demanda por ar condicionado ocorre durante as horas nas quais a radiação solar atinge os maiores valores de irradiância ${ }^{6}$. Além disso, o número de horas de utilização do sistema de ar condicionado é muito semelhante ao valor da insolação diária ${ }^{7}$.

Entretanto, embora apresente esse grande potencial, sabe-se que, com relação à tecnologia de ar condicionado solar, há ainda muito a ser explorado (RENEWABLE ENERGY FOCUS, 2010). Obviamente, nesse sentido, são determinantes a redução dos custos e o aumento do desempenho, para os quais tem papel fundamental toda a sociedade, porém, de modo especial, a comunidade científica, com suas pesquisas, e os governos, com suas políticas de incentivo.

\subsection{Descrição dos Sistemas}

Um sistema de condicionamento de ar é destinado a controlar as propriedades do ar tais como temperatura do ar, umidade relativa, velocidade e pureza (CREDER, 2004). Como foi visto, o condicionamento de ar pode ser realizado a partir do fornecimento de energia solar. De fato, conforme já foi comentado no capítulo 1, é possível transformar energia solar, tanto em energia elétrica como em calor, possibilitando que qualquer tecnologia de refrigeração seja colocada em funcionamento (PAPADOPOULOS et al., 2003).

Como foi dito, existem duas formas físicas de obter-se condicionamento de ar ou refrigeração a partir da radiação solar. Uma delas ocorre a partir da transformação da radiação solar em eletricidade e outra a partir da transformação da radiação solar em calor (HENNING, 2007).

\footnotetext{
${ }^{6}$ Intensidade instantânea de radiação solar incidente em uma superfície horizontal por metro quadrado $\left(\mathrm{W} / \mathrm{m}^{2}\right)$.

${ }^{7}$ Número de horas diárias de incidência direta de radiação solar (horas).
} 
Por um lado, os sistemas de ar condicionado solar baseados no processo elétrico, isto é, a partir da transformação da energia solar em eletricidade utilizam, a rigor, painéis fotovoltaicos como alimentação para o chiller do sistema de condicionamento de ar.

Embora os sistemas de ar condicionado solar elétricos possam abranger diversas possibilidades tecnológicas, tais como, sistemas Peltier fotovoltaicos, sistemas de resfriamento evaporativo fotovoltaico, sistemas de compressão de vapor, entre outros (PAPADOPOULOS et al., 2003) observa-se, um claro enfoque dado à utilização de sistemas de compressão de vapor. Nesse caso, a energia elétrica gerada a partir dos painéis fotovoltaicos é usada no compressor do ciclo termodinâmico do chiller. Um esquema básico é mostrado na Figura 2.1.

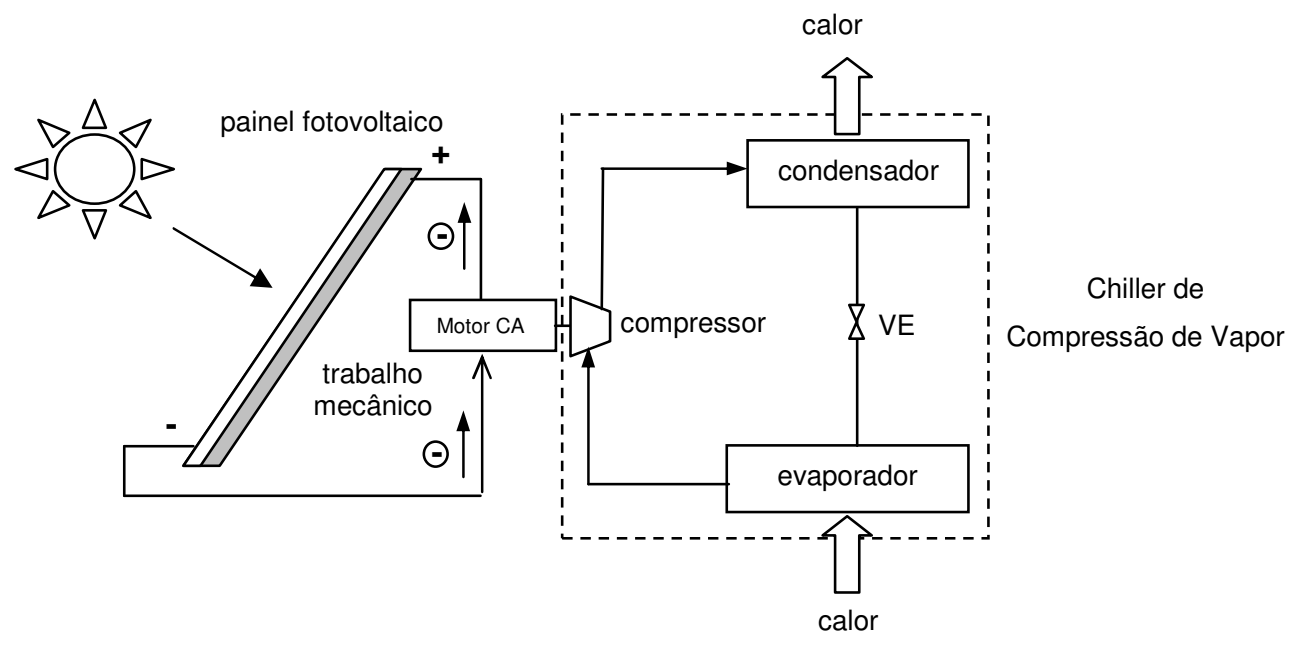

Figura 2.1 - Diagrama esquemático de um sistema de condicionamento de ar com utilização de células fotovoltaicas e chiller de compressão de vapor.

Fonte: KIM e FERREIRA (2007, p.3)

Por outro lado, os sistemas de ar condicionado solar baseados no processo térmico, ou seja, nos quais a energia solar é transformada em calor, utilizam coletores solares térmicos, a fim de alimentar o processo de condicionamento de ar. Enquanto tecnologia de ar condicionado solar, esses sistemas são mais comuns e conhecidos, apresentando, inclusive, um número significativo de instalações em funcionamento espalhadas por diversos países, conforme será apresentado no item 2.3. 
De acordo com Henning (2007), os sistemas térmicos de ar condicionado solar podem ser classificados em duas modalidades, conforme o processo térmico no qual se baseiam: sistemas termo-mecânicos ou sistemas com transformação de calor.

Os sistemas termo-mecânicos convertem o calor gerado pelos coletores solares em eletricidade, através de uma máquina térmica, para o sistema de condicionamento de ar. Em outras palavras, a radiação solar é transformada em calor e posteriormente em energia elétrica para alimentar o sistema de ar condicionado. Neste caso, portanto, associa-se uma instalação solar heliotermoelétrica com um sistema de ar condicionado convencional, climatizandose o ambiente.

As principais formas de utilização desses sistemas com processo termomecânico, de acordo com Henning (2007) são através da aplicação de ciclos de compressão de vapor de Rankine, ciclos steam jet e ciclo de Vuilleumler.

Os sistemas com transformação de calor, por sua vez, se baseiam no fornecimento de calor, ao invés de eletricidade, ao ciclo termodinâmico do chiller para se obter o efeito de condicionamento do ar. Dentro da classe dos sistemas térmicos de ar condicionado solar e em comparação com os sistemas termomecânicos, as tecnologias que utilizam transformação de calor são mais difundidas. Em resumo o funcionamento do processo de refrigeração ou condicionamento de ar ocorre como resultado do fornecimento de calor ao invés do fornecimento de eletricidade.

Esse calor possibilita que um par de substâncias presentes no ciclo (usualmente Água e Brometo de Lítio) uma vez atraídas física ou químicamente no processo - conhecido como "sorption" - se separem resultando na elevação da pressão do refrigerante (usualmente água) análogo ao efeito produzido por um compressor elétrico. Sendo assim, como foi dito, o efeito de compressão do ciclo do chiller não resulta do fornecimento de energia elétrica, mas sim do fornecimento de energia térmica.

Diversas são as classificações e nomenclaturas dadas aos sistemas de ar condicionado solar com transformação de calor (GROSSMANN; JOHANNSEN, 1981; CONSTANTINOS et al., 2007; HENNING, 2007; PAPADOPOULOS et al., 2003). Entretanto, usualmente são classificados em sistemas de ciclo fechado ou 
ciclo aberto, de acordo com a existência ou não de contato físico entre refrigerante e o ar.

Nos ciclos fechados, os fluidos refrigerantes não entram em contato direto com o meio de refrigeração, no caso, com o ar a ser condicionado, permanecendo dentro do sistema. Nos ciclos abertos, porém, isso não ocorre, já que, o condicionamento de ar é realizado por meio de mudanças nas propriedades do ar em contato com o refrigerante (GROSSMANN; JOHANNSEN, 1981).

Outra classificação comum também distingue os sistemas com transformação de calor em sistemas ciclo de absorção, adsorção ou dessecantes, acordo com o processo físico-químico que apresentam.

Nos sistemas com ciclo de absorção, de acordo com Kim e Ferreira (2007, p.6), ocorre 'um processo de 'sorption', onde um solvente líquido ou sólido absorve moléculas em seu interior e se transforma fisicamente e/ou quimicamente no processo". A Figura 2.2 mostra um esquema do ciclo de absorção:

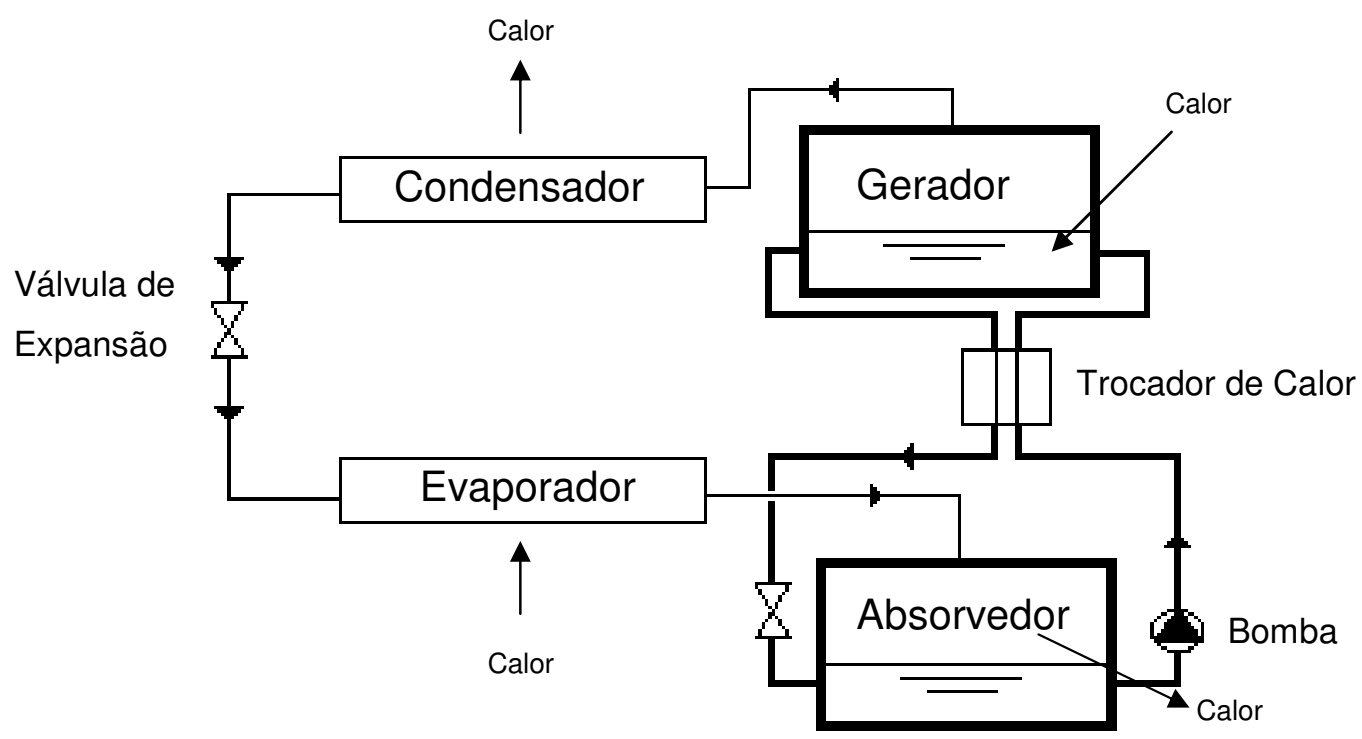

Figura 2.2 - Esquema simplificado do ciclo de absorção. Fonte: GROSSMANN e JOHANNSEN (1981, p.195, modificado)

Como se observa na Figura, o conjunto Absorvedor-Gerador substitui o compressor, do ciclo de compressão de vapor convencional. Da mesma forma, o fluido refrigerante, que seria empregado em um ciclo convencional, é substituído por um par de substâncias, um solvente e um soluto, que interagem no processo. $O$ 
solvente (usualmente Brometo de Lítio) absorve o soluto (usualmente água), chamado de refrigerante, no absorvedor. Forma-se nesse ponto a "solução forte", rica em refrigerante.

Posteriormente por meio do fornecimento de calor no gerador, o refrigerante (água) se separa o solvente na "solução forte" e se encaminha para o condensador (usualmente vapor de água) a uma pressão maior, possibilitando o prosseguimento do ciclo. A "solução fraca" após a separação do refrigerante retorna ao absorvedor para solubilizar novas quantidades de refrigerante. $O$ calor fornecido ao gerador do processo é proveniente da fonte quente que, no caso de um sistema de ar condicionado solar, corresponde aos coletores solares térmicos.

Para sistemas desse tipo, um parâmetro interessante na análise de desempenho energético é o Coeficiente de Performance (COP) ${ }^{8}$, que pode ser expresso da seguinte forma:

$$
\mathrm{COP}=\frac{Q_{E V A P}}{Q_{G E R}}
$$

Sendo:

$Q_{E V A P}$ - calor retirado do ar por meio do evaporador $(\mathrm{W})$.

$Q_{G E R}$ - calor fornecido ao gerador pelos coletores solares (W).

A grandeza $Q_{E V A P}$, em $\mathrm{W}$, representa a carga térmica retirada do ambiente condicionado. Quanto maior seu valor para $Q_{G E R}$ constante, melhor o desempenho energético do sistema, assim como, quanto menor o valor do calor fornecido pelos coletores solares para $Q_{E V A P}$ constante, melhor o desempenho energético do sistema.

Um esquema de um sistema de ar condicionado solar baseado em ciclo de absorção é mostrado na Figura 2.3. Como se pode ver na Figura, o calor que alimenta o gerador é fornecido pelos coletores solares, e a retirada de calor do ciclo, tanto no absorvedor quanto no condensador, é realizada com o auxílio da torre de resfriamento. Observa-se, também, que a água gelada (chilled water) obtida no evaporador é utilizada para o condicionamento de ar do edifício.

\footnotetext{
${ }^{8} \mathrm{O}$ mesmo conceito e expressão para o cálculo do COP é válido para os sistemas do tipo 'sorption'.
} 
Nesse ciclo, diversos pares refrigerante - absorvente podem ser utilizados (KIM; FERREIRA, 2007), porém, para as aplicações de ar condicionado, predomina, como já foi dito, o uso do par água-Brometo de Lítio, sendo a água, o refrigerante e o Brometo de Lítio, o absorvente (HENNING, 2007). Dependendo da configuração do chiller de absorção, pode-se ter mais do que um estágio de separação do refrigerante diluído no absorvente (sistemas de simples, duplo ou triplo-efeito).

\section{Torre de Resfriamento}

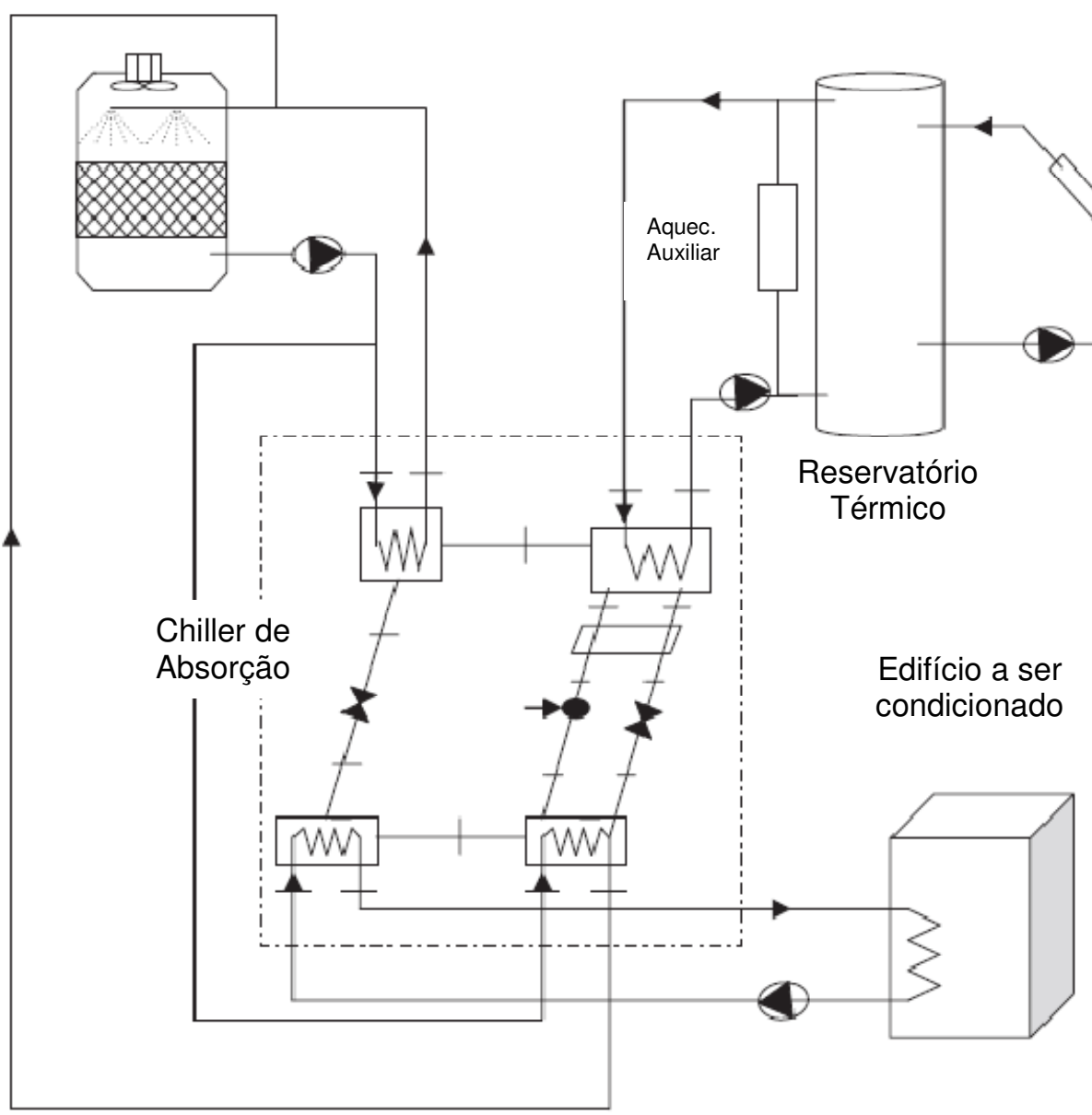

Figura 2.3 - Esquema de um sistema de condicionamento de ar com ciclo de absorção e utilização de energia solar. Fonte: BARGHOUTHI et al. (2007, p.4)

Dependendo do número de estágios existentes no ciclo, são necessárias diferentes temperatura do fluido quente vindo dos coletores, resultando em diferentes valores de COP, conforme ilustra a Tabela 2.1, extraída do trabalho de Grossmann (2001, p.58): 
Tabela 2.1 - Sistemas com absorção solar. Fonte: GROSSMANN (2001, p.58) - adaptado

\begin{tabular}{|c|c|c|c|c|c|}
\hline $\begin{array}{c}\text { Tipo de } \\
\text { Sistema }\end{array}$ & COP usual & $\begin{array}{c}\text { Temperatura } \\
\text { do fluido } \\
\text { quente }\left({ }^{\circ} \mathrm{C}\right)\end{array}$ & $\begin{array}{c}\text { Calor solar } \\
\text { requerido }(\mathrm{kW})\end{array}$ & $\begin{array}{c}\text { *ipo de } \\
\text { coletor }\end{array}$ & $\begin{array}{c}\text { Área de } \\
\text { coletor } \\
\text { requerida } \\
\left(\mathrm{m}^{2}\right)^{*}\end{array}$ \\
\hline simples-efeito & 0,7 & 85 & 1,43 & coletor plano & 7,48 \\
\hline duplo-efeito & 1,2 & 130 & 0,83 & $\begin{array}{c}\text { coletor plano } \\
\text { ou } \\
\text { CPC }\end{array}$ & 5,07 \\
\hline triplo-efeito & 1,7 & 220 & 0,59 & $\begin{array}{c}\text { tubo a vácuo } \\
\text { ou } \\
\text { concentrador }\end{array}$ & 4,49 \\
\hline
\end{tabular}

* Estimativas por kW de resfriamento do ambiente condicionado;

** Compound Parabolic collector

Ainda dentre os sistemas de ar condicionado solar térmico com transformação de calor tem-se os sistemas com ciclo de adsorção. Neste caso, a tecnologia se baseia em princípios semelhantes ao do ciclo de absorção, porém diferem principalmente quanto ao estado físico do par refrigerante - adsorvente. No caso do ciclo de adsorção, a substância que adsorve o refrigerante é solida e atrai as moléculas do refrigerante sobre a superfície por força física ou química e não muda sua forma no processo (KIM e FERREIRA, 2007).

Com relação aos pares refrigerante - adsorvente, os mais utilizados, neste caso, são zeolita-água, zeolita-refrigerantes orgânicos, gel de sílica-água e carvão ativado-metanol (RIFFEL; BELO; LEITE, 2007). Diferentemente dos sistemas por absorção, esses sistemas por adsorção evitam o uso de bomba para a solução e são relativamente mais silenciosos durante a operação, além de demandar temperaturas relativamente baixas do fluido proveniente dos coletores solares, a partir de $60^{\circ} \mathrm{C}$ (SOLAIR, "Best Practices Catalog", 2008). Entretanto, os valores de COP alcançados são mais baixos, da ordem de 0,3 a 0,7 (PAPADOPOULOS et al., 2003), em relação aos valores de COP do ciclo de absorção, que podem superar a unidade.

Comparando os valores de COP dos sistemas por absorção e adsorção, Henning (2007, p.1736) apresentou os valores de COP máximos possíveis dos ciclos, em função temperatura do fluido fornecida pelos coletores, como mostra a Figura 2.4: 


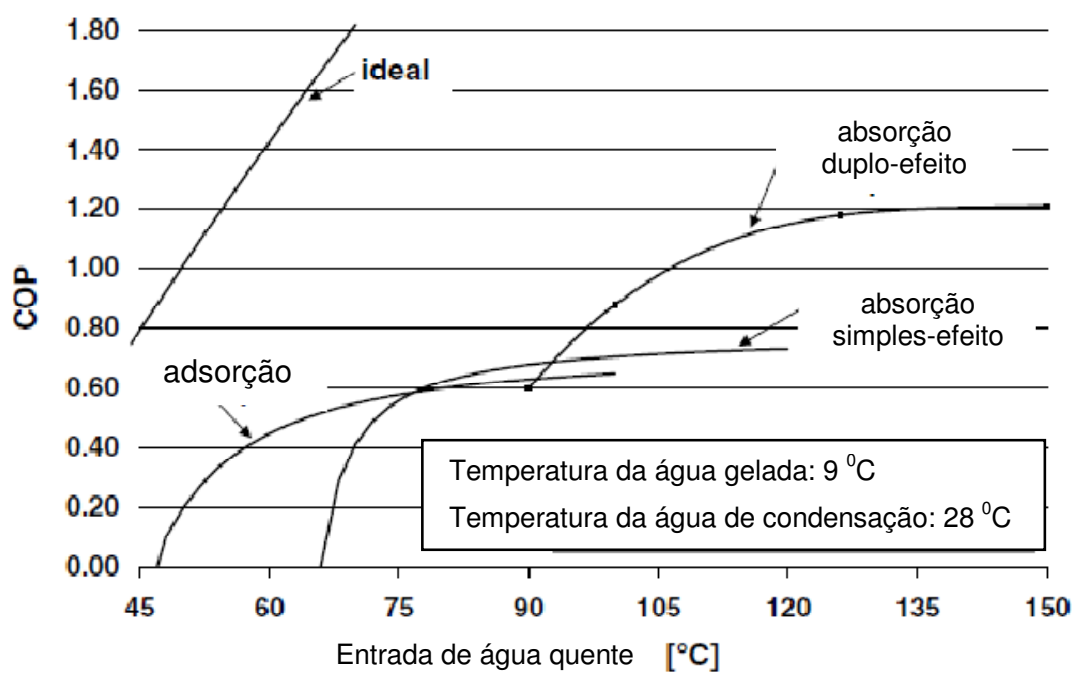

Figura 2.4 - COP ideais dos sistemas por absorção e adsorção. Fonte: HENNING (2007, p.1736)

Por fim, compondo ainda a classe de sistemas com transformação de calor, juntamente com as tecnologias por absorção e adsorção, têm-se os sistemas dessecantes. Esses sistemas funcionam também com um processo de "sorption" como os ciclos de absorção e adsorção, porém, particularmente neste caso, conforme explicam Kim e Ferreira (2007), "um solvente, isto é, um dessecante, absorve vapor do ar úmido", a fim de tratar o ar. Em geral, os sistemas dessecantes contemplam a ventilação e o controle de umidade e de temperatura do ar (KIM; FERREIRA, 2007).

Usualmente, também, esses sistemas são compostos pela combinação de um processo de resfriamento evaporativo e um processo de desumidificação, a partir de um material higroscópico, líquido ou sólido, chamado de dessecante, em geral, gel de sílica ou cloreto de lítio (HENNING, 2007). Neste caso, o calor proveniente dos coletores solares é usado para possibilitar o processo de desumidificação do fluxo de ar.

Enfim, pelo que foi apresentado até aqui no texto, pode-se dizer que os sistemas de ar condicionado solar são possíveis principalmente através de duas formas: seja a partir da geração de eletricidade por painéis fotovoltaicos ou por sistemas heliotermoelétricos, seja a partir da produção de um fluido quente por coletores solares térmicos. 
Aplicado a uma edificação, um sistema desse tipo possibilitaria a substituição, ainda que parcial, da tecnologia convencional de ar condicionado, baseada completamente em fontes convencionais de energia, resultando em uma possível contribuição aos objetivos sustentáveis delineados no início deste trabalho.

\subsection{Aspectos de Mercado}

A fim de se entender melhor a tecnologia de ar condicionado solar em estudo, não basta conhecer somente os conceitos e tipos de sistemas envolvidos, mas também é necessário se ter uma visão da inserção de mercado da tecnologia.

Como se viu no item anterior, sob o aspecto tecnológico, os sistemas de ar condicionado solar são possíveis principalmente através de duas alternativas: a conversão solar térmica e a conversão solar elétrica.

Em termos de mercado, porém, os sistemas de ar condicionado solar que utilizam conversão solar térmica para seu funcionamento são a maioria. De fato, dentre as possibilidades de sistemas existentes, sem dúvidas, para fins de condicionamento de ar, a tecnologia que está mais disseminada mundialmente é a do ar condicionado solar térmico.

Dentre os sistemas já instalados no mundo, a maioria deles adota a tecnologia solar térmica alimentando o sistema por absorção. Centenas são os projetos, a nível global, que já operam com essa tecnologia, em escalas e aplicações bastante distintas.

Entretanto, apesar da maior utilização dos sistemas solares térmicos por absorção, outras formas de fazer uso da energia solar para sistemas de ar condicionado podem se destacar em casos e aplicações específicas.

As tecnologias baseadas em conversão solar elétrica, por exemplo, seja fotovoltaica (sistemas elétricos), seja heliotermoelétrica (sistemas termo-mecânicos), mesmo pouco utilizada em termos práticos, podem apresentar-se interessantes em casos particulares. Os sistemas elétricos com painéis fotovoltaicos, por exemplo, podem tirar proveito da integração dos módulos nas fachadas dos edifícios, apresentando-se como uma alternativa interessante caso a área a ser aproveitada pelo sistema fotovoltaico seja significativa. 
De fato, a alternativa da utilização de painéis fotovoltaicos para geração de energia elétrica em edifícios leva em consideração essa interessante possibilidade de integração dos módulos ao próprio edifício, seja na cobertura como na própria fachada. Os sistemas fotovoltaicos integrados aos edifícios, de acordo com Oliver e Jackson $(2001$, p.) apud McNelis (1996) provavelmente "será a primeira forma de utilização de sistemas fotovoltaicos conectados a rede a alcançarem amplo espaço para comercialização". Essa integração fotovoltaica nos elementos construtivos dos edifícios, com certeza, pode representar um grande potencial para a alternativa fotovoltaica, que por sua vez pode ser aproveitada para o sistema de condicionamento de ar.

Da mesma forma, segundo BRAUN, P.; RÜTHER, R. (2010) "os sistemas fotovoltaicos situados estrategicamente podem contribuir para aliviar as redes elétricas urbanas, reduzindo as demandas de pico, em situações nas quais há uma adequada compatibilidade entre as cargas e a disponibilidade de radiação solar". Aproveitando-se desses fatos, portanto, a alternativa de ar condicionado solar elétrica pode ser vantajosa, valendo-se, principalmente, como foi dito, da integração dos painéis ao edifício.

Outro aspecto que pode potencializar a alternativa de ar condicionado solar elétrica corresponde, conforme comentado brevemente no capítulo 1, à expansão do mercado fotovoltaico global. Segundo Pearce (2008), "o mercado para os painéis fotovoltaicos solares continua a expandir rapidamente". A capacidade instalada de sistemas fotovoltaicos aumentou 1,46 GW em 2005, representando um crescimento anual de $34 \%$ e resultando em uma capacidade acumulada de geração elétrica de 5 GW. Conforme o volume de produção de fotovoltaicos cresce, o preço do módulo tende a reduzir-se.

Da mesma forma, o ritmo da pesquisa e desenvolvimento da tecnologia fotovoltaica indica a potencialidade dessa alternativa para o futuro. A Agência Internacional de Energia (2007), no relatório "Renewable for Heating and Cooling" ao mostrar a evolução dos investimentos em Pesquisa e Desenvolvimento com energias renováveis pelos seus países membros, deixou evidente uma parcela significativa dos investimentos em renováveis são voltados à energia solar para geração de eletricidade.

Entretanto, o grande problema, dos sistemas de ar condicionado solar elétricos segundo Kim e Ferreira (2007, p.3) corresponde aos custos ainda elevados 
dos painéis fotovoltaicos. Outra barreira a utilização de painéis fotovoltaicos como alimentação para o ar condicionado em edifícios, é também, a existência de mecanismos de incentivo aos fotovoltaicos interligados a rede elétrica (gridconnected ${ }^{9}$ ), como as políticas de "feed-in"10 na Alemanha, já que favorecem o direcionamento da energia produzida pelos painéis para a rede elétrica e não para o sistema de ar condicionado (HENNING, 2007).

Entretanto, deve-se notar que a interligação de painéis fotovoltaicos a rede elétrica não é impossibilitada no caso de se utilizar os painéis FV como alimentação para o ar condicionado, em um sistema de ar condicionado solar elétrico. A única questão é que, quando houver uma tarifa diferencial (feed-in tariff), como ocorre na Alemanha, por exemplo, será mais alimentar a rede elétrica ao invés de alimentar o sistema de ar condicionado. No Brasil, entretanto, não haveria um impedimento econômico desse tipo, pelo menos nos próximos anos.

Em resumo, pode-se dizer que mesmo com a predominância dos sistemas de ar condicionado solar térmico a nível global, os sistemas de ar condicionado solar elétrico também podem representar uma alternativa com interessante potencial de aplicação. Nesta pesquisa, como se verá mais adiante, essa alternativa resultará bastante interessante energeticamente dada à possibilidade de integração dos painéis fotovoltaicos às fachadas. Mesmo assim, é importante relembrar que os sistemas solares térmicos para ar condicionado representam ainda a solução mais utilizada para sistemas de ar condicionado solar em todo o mundo.

Também dentre os sistemas térmicos de ar condicionado solar, outras alternativas, além do sistema por absorção, mais utilizado, podem ser adotadas conforme o caso.

No geral, em se tratando de sistemas solares térmicos de ar condicionado solar, aqueles classificados como de transformação de calor (absorção, adsorção e dessecantes), de acordo com o item anterior, são os mais utilizados, especialmente, como já foi dito, os sistemas com ciclo de absorção.

\footnotetext{
9 grid-connected - designação dos sistemas fotovoltaicos interligados a rede elétrica

${ }^{10}$ feed-in tariff - forma de incentivo governamental que favorece a adoção de formas renováveis de energia através da possibilidade de venda de energia renovável para a alimentação da rede elétrica pela energia renovável gerada por preços maiores que o de mercado.
} 
Os sistemas termo-mecânicos, diferentemente, se encontram em fase inicial de desenvolvimento. De fato, quanto aos sistemas termo-mecânicos há ainda muitos problemas a serem resolvidos para que sejam alcançadas eficiências aceitáveis (PAPADOPOULOS et al., 2003). Kim e Ferreira (2007), ao compararem as diferentes técnicas de refrigeração com utilização de energia solar, concluíram que os sistemas termo-mecânicos representam uma alternativa com custo maior do que as demais tecnologias de ar condicionado solar térmicas.

Observa-se, porém, que não obstante os problemas inerentes aos sistemas termo-mecânicos, algumas tecnologias desse tipo estão ganhando cada vez mais espaço, em especial no campo da pesquisa e desenvolvimento. Um exemplo disso, são os sistemas com ciclo Steam Jet, que possuem um processo simples de construção e apresentam um grande potencial de redução de custos.

Além disso, ao utilizarem exclusivamente água como fluido refrigerante, esses sistemas constituem-se em uma alternativa interessante do ponto de vista da sustentabilidade (POLLERBERG; ALI; DOTSCH, 2009). Sendo assim, ainda com a imaturidade tecnológica dos sistemas termo-mecânicos, os sistemas térmicos de ar condicionado solar que prevalecem no mercado são aqueles que operam com transformação de calor (absorção, adsorção e dessecantes), e dentre eles, como foi dito, o sistema por absorção é o mais utilizado.

Isso pode ser observado na Figura 2.5, que ilustra a distribuição, apresentada por Núñez (2010), dos sistemas de ar condicionado solar térmicos no mundo.

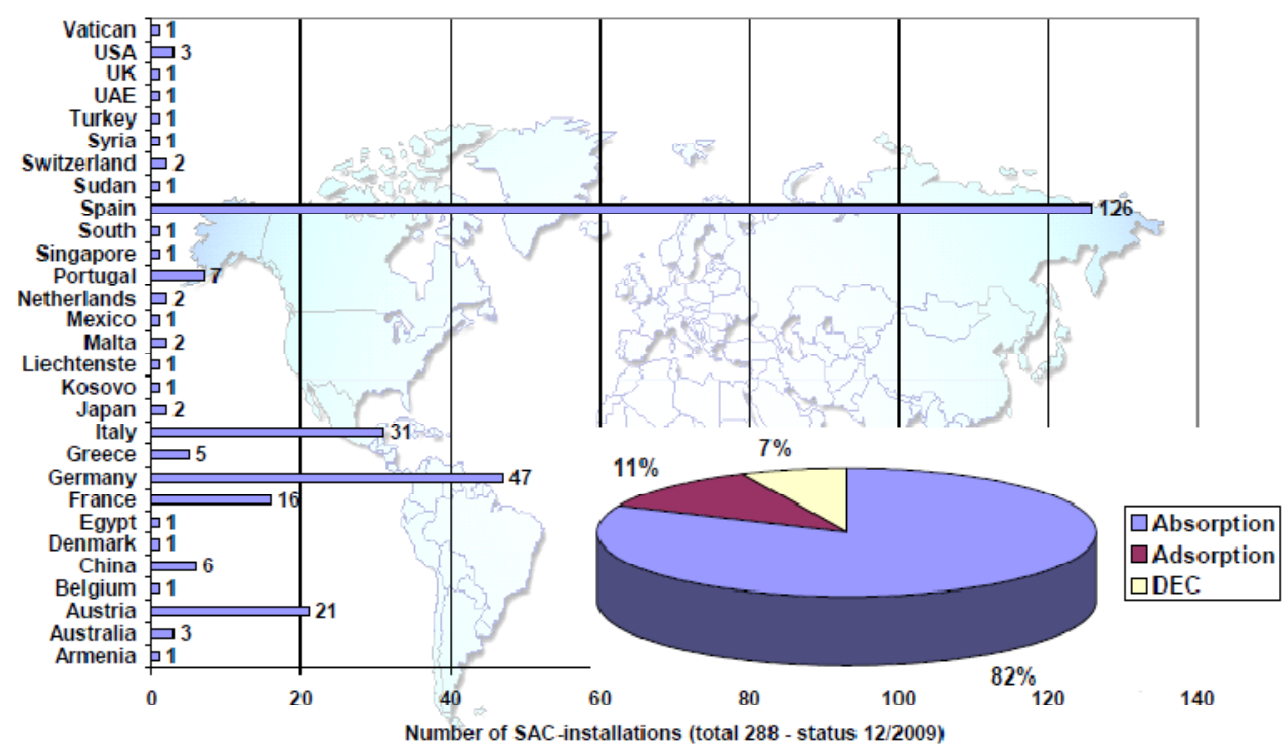

Figura 2.5 - Distribuição por países dos sistemas no mundo. Fonte: NÚÑEZ (2010) 
De fato, no total encontram-se aproximadamente duas centenas de sistemas de ar condicionado solar instalados (RENEWABLE ENERGY FOCUS, 2010), com predominância, como foi dito anteriormente, para os sistemas com ciclo de absorção.

A predominância e o potencial dos sistemas por absorção é evidente. Conforme afirmam Kim e Ferreira (2007) apud Henning (2004); Balaras et al. (2007), embora a atual tecnologia de refrigeração solar com ciclo de absorção esbarre muitas vezes na barreira dos elevados custos iniciais se comparados com os do sistema convencional de ar condicionado sem energia solar, a importância dos sistemas por absorção solar não pode ser desconsiderada. Isso se comprova pela existência de inúmeros projetos e pesquisas sobre essa tecnologia, que tem demonstrado seu grande potencial.

Da mesma forma, alguns estudos apresentam a importância dos sistemas de ar condicionado por absorção. De fato, Balghouthi et al. (2007) demonstram, por exemplo, a viabilidade do ar condicionado solar de absorção para climas mediterrâneos como o da Tunísia, e Rosiek e Batlles (2009) relatam respostas satisfatórias às cargas térmicas em um edifício com esse tipo de sistema, na Espanha. Da mesma forma, Yeung et. al. (1992) provam a viabilidade da utilização de energia solar de um sistema de condicionamento de ar por absorção instalado na Universidade de Hong Kong.

Um exemplo de sistema por absorção solar é o instalado no edifício de escritórios da Ott Ingenieure, em Langenau, na Alemanha, com capacidade nominal de $35 \mathrm{~kW}$ e $30 \mathrm{~m}^{2}$ de coletores de tubo a vácuo, produzindo água a $85^{\circ} \mathrm{C}$ para a operação do chiller (Figura 2.6). 


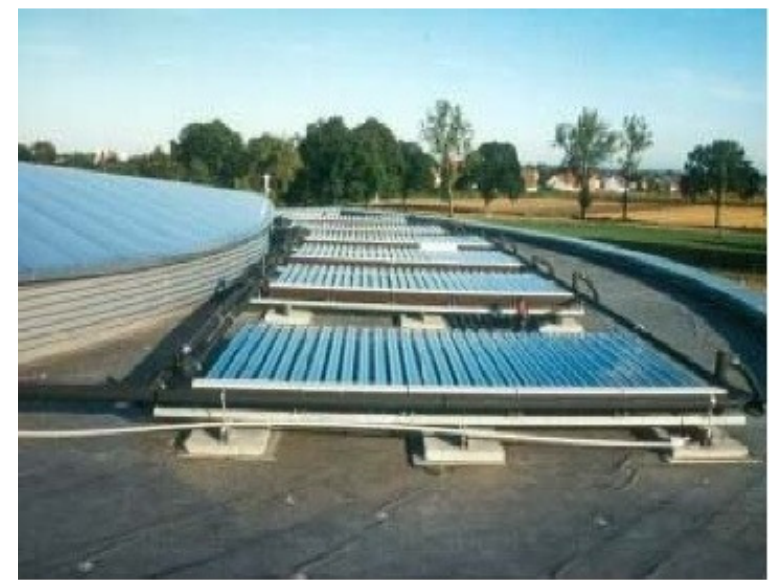

Figura 2.6 - Coletores solares do edifício da Ott Ingenieure, Langenau, Alemanha. Fonte: SOLAIR (2008, "Best Practices Catalog")

Outro sistema interessante é o instalado em um edifício de escritórios com 5 pavimentos em Saint Denis de la Réunion, da França. Neste caso, o sistema está alocado na cobertura do edifício (Figura 2.7), tem capacidade nominal de também $35 \mathrm{~kW}$ e possui $92 \mathrm{~m}^{2}$ de coletores de tubo a vácuo, que produzem água a $80^{\circ} \mathrm{C}$.

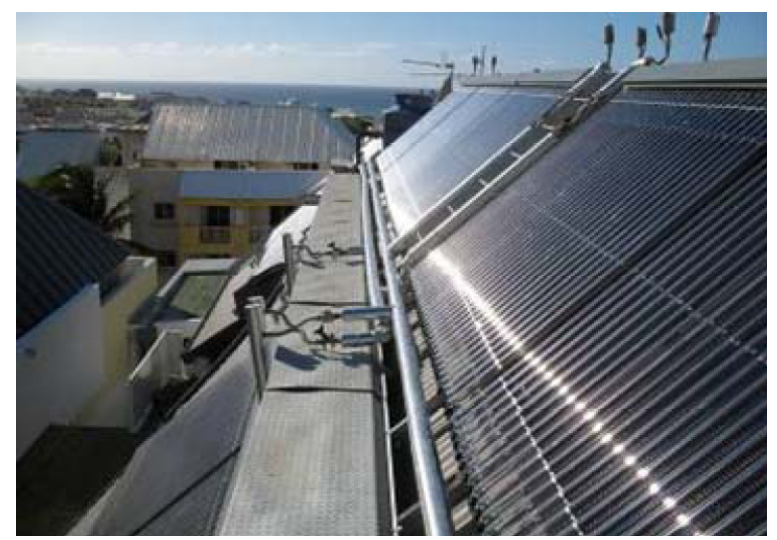

Figura 2.7 - Sistema em edifício em Saint Denis de la Réunion, França. Fonte: SOLAIR (2008, "Best Practices Catalog")

Por fim, outro sistema de condicionamento de ar por absorção, interessante de ser observado é o instalado no edifício da Escola de Engenharia de Sevilha, na Espanha. O sistema está alocado na cobertura do edifício (Figura 2.9), e opera com uma capacidade de condicionamento de ar média daria de $135 \mathrm{~kW}(77 \%$ da 
capacidade nominal). Utiliza lentes Fresnel para produção de calor que atingem eficiências de até $35 \%$.

Se por um lado, o sistemas de absorção são os mais difundidos, por outro lado, os sistemas por adsorção e os sistemas dessecantes de ar condicionado solar, apesar de serem adotados em alguns casos específicos, são bem menos disseminados que os sistemas com chiller de absorção.

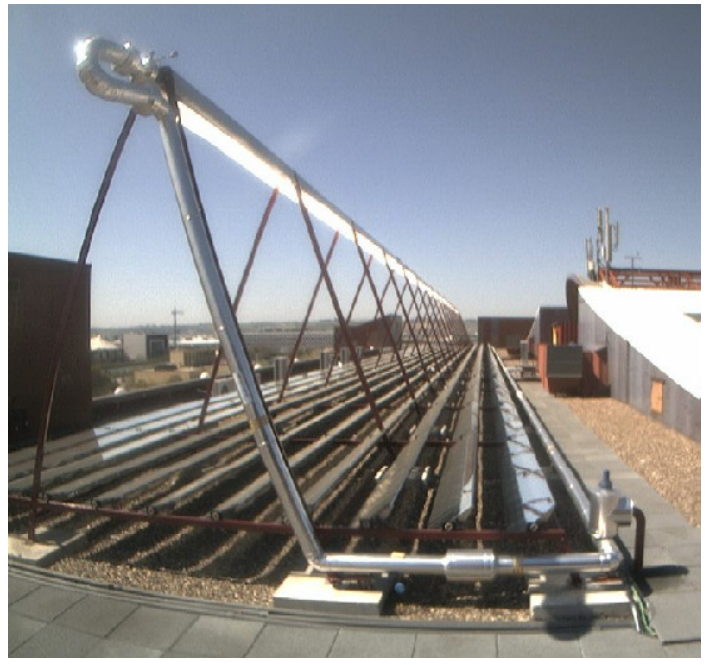

Figura 2.8 - Escola de Engenharia de Sevilha, Espanha. Fonte: BERMEJO, P.; PINO, F.J.; ROSA, F. (2010)

Nos sistemas por adsorção, por exemplo, um dos principais problemas consiste na necessidade de se ter chillers relativamente grandes. Isto pode ser afirmado pois, devido à tecnologia empregada, para que se satisfaça as mesmas cargas térmicas atendidas por chillers de absorção, são necessários equipamentos bem maiores e maios pesados. Isso faz com que os sistemas por adsorção se tornem competitivos apenas no caso da existência de grandes demandas por condicionamento de ar (KIM; FERREIRA, 2007).

Em meados de 2008, segundo o relatório "Best Practices Catalog" (2008, p.9) produzido no projeto SOLAIR ${ }^{12}$ da União Européia, existiam apenas alguns fabricantes de equipamentos por adsorção solar no Japão, China e na Alemanha.

\footnotetext{
12 Projeto financiado pela União Européia com o objetivo de promover e fortalecer o uso de sistemas de ar condicionado solar a partir de 2007.
} 
Um exemplo desse tipo de sistema com $70 \mathrm{~kW}$ de capacidade e $170 \mathrm{~m}^{2}$ de coletores de tubo a vácuo foi discutido por Henning (2007, p.1742). O chiller de adsorção que compõe esse sistema é ilustrado na Figura 2.9:

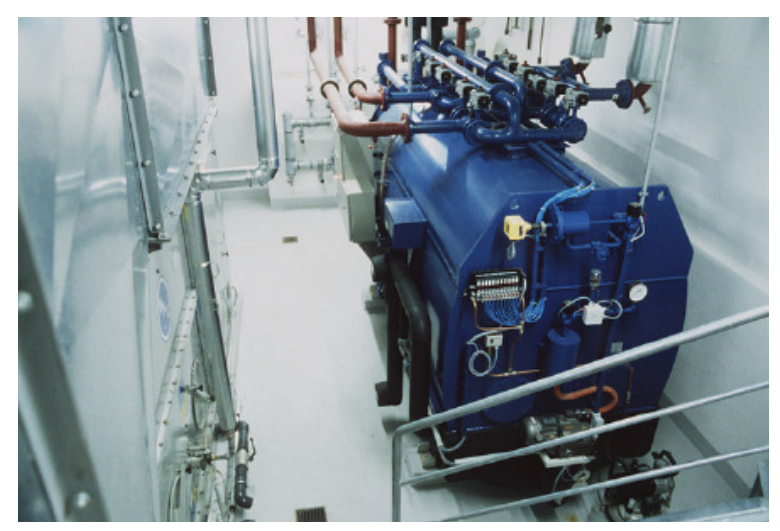

Figura 2.9 - Chiller de adsorção instalado em hospital na Alemanha.

Fonte: HENNING (2007, p.1742)

Por fim, em uma quantidade bem menor que os sistemas por absorção e por adsorção, os sistemas dessecantes são utilizados somente em casos bastante específicos. Essa tecnologia, de acordo com Kim e Ferreira (2007, p.9), "onde há uma grande demanda por ventilação e desumidificação do ar, [...] pode ser uma boa opção".

\subsection{Comentários Gerais sobre a Tecnologia}

Pelo que foi apresentado até aqui no texto, pode-se dizer que é perfeitamente possível o condicionamento de ar a partir da energia solar, seja por meio dos sistemas elétricos, trabalhando com painéis fotovoltaicos, seja por meio dos sistemas térmicos trabalhando com coletores solares.

Em resumo, observa-se a predominância de sistemas de ar condicionado solar térmicos por absorção, embora o potencial dos sistemas de ar condicionado solar elétricos com painéis fotovoltaicos não possa ser desconsiderado, principalmente quando se leva em conta a possibilidade de integração dos painéis solares à fachada. 
A Tabela 2.2, a seguir, procura resumir as tecnologias principais disponíveis para condicionamento de ar solar, assim como, apresentar comentários gerais sobre cada alternativa:

Tabela 2.2 - Comparação entre os principais sistemas de ar condicionado solar.

\begin{tabular}{|c|c|c|c|c|}
\hline \multicolumn{2}{|c|}{ Classe de Sistema } & Sistema Solar & $\begin{array}{l}\text { Tecnologia de } \\
\text { Refrigeracão }\end{array}$ & Comentários sobre a Tecnologia \\
\hline \multicolumn{2}{|c|}{ Elétrico } & fotovoltaico & $\begin{array}{l}\text { compressão de } \\
\text { vapor }\end{array}$ & $\begin{array}{c}\text { Os custos altos e baixa eficiência dos painéis } \\
\text { fotovoltaicos podem ser uma limitação, porém } \\
\text { integração dos painéis fotovoltaicos à edificação e } \\
\text { a expansão do mercado FV pode favorecer essa } \\
\text { alternativa. }\end{array}$ \\
\hline \multirow{4}{*}{ Térmico } & $\begin{array}{l}\text { termo- } \\
\text { mecânico }\end{array}$ & heliotermoelétrico & $\begin{array}{c}\text { compressão de } \\
\text { vapor }\end{array}$ & $\begin{array}{l}\text { Os custos muito altos dos sistemas solares e a } \\
\text { baixa eficiência limitam a tecnologia aos projetos } \\
\text { de desenvolvimento e demonstração. }\end{array}$ \\
\hline & \multirow{3}{*}{$\begin{array}{c}\text { transformação } \\
\text { de calor }\end{array}$} & \multirow{3}{*}{ térmico } & absorção & $\begin{array}{l}\text { Apesar dos custos ainda elevados, apresentam } \\
\text { desempenho energético e maturidade tecnológica } \\
\text { significativos, constituindo-se na tecnologia mais } \\
\text { utilizada. }\end{array}$ \\
\hline & & & adsorção & $\begin{array}{l}\text { Com altos custos e baixa eficiência e com } \\
\text { necessidade de equipamentos grandes, são } \\
\text { interessantes apenas em casos específicos. }\end{array}$ \\
\hline & & & dessecantes & $\begin{array}{l}\text { Podem ser interessantes apenas em casos } \\
\text { específicos onde há grande demanda por } \\
\text { ventilação e desumidificação do ar. }\end{array}$ \\
\hline
\end{tabular}

Resumidamente, pode-se dizer que, os sistemas de ar condicionado solar têm como limitação principal os elevados custos iniciais embora, como foi visto, sejam viáveis tecnicamente. Para um sistema desse tipo, a instalação solar (painéis fotovoltaicos ou coletores solares) correspondem à parcela principal dos custos. Isto significa que, para reduzir os custos, o objetivo deve ser gastar menos com a parte solar do sistema.

Para os sistemas elétricos, isso poderia ser alcançado com aumento da eficiência, com o aumento do COP dos chillers, ou com a redução dos custos dos painéis, possivelmente através da expansão de mercado ou de mecanismos de incentivo por parte dos governos.

Para os sistemas térmicos, a redução dos custos pode ser alcançada com o aumento do COP dos chillers, pois assim, a área de coletores necessária não seria 
tão grande e conseqüentemente os custos seriam menores. Sabe-se que coletores mais baratos, em geral, aquecem os fluidos a temperaturas menores e reduzem 0 COP do sistema (Figura 2.4). Entretanto, quando se adotam coletores mais baratos a redução dos custos do sistema é mais relevante do que o aumentos nos custos causados pela grande área coletora adotada em vista da redução do COP do sistema (KIM; FERREIRA, 2007).

Ainda com relação aos sistemas de ar condicionado solar térmico, pode-se dizer que uma a tendência para o futuro é o estudo, desenvolvimento e aprimoramento dos sistemas que trabalham a baixas temperaturas (KIM; FERREIRA, 2007). O estudo desses sistemas é ainda mais interessante se for considerado o contexto do mercado solar térmico mundial, já que os sistemas de aquecimento de água a baixas temperaturas possuem uma considerável maturidade tecnológica e de mercado a nível global.

Em resumo, por tudo que foi apresentado até aqui, pode-se dizer que quando se pensa em ar condicionado solar há duas possibilidades principais: os sistemas térmicos, que utilizam calor para o condicionamento de ar e os sistemas elétricos, que utilizam eletricidade para o condicionamento de ar. Dentre os sistemas térmicos se destaca os sistemas por absorção, devido ao seu nível de desenvolvimento tecnológico e expansão de mercado. Dentre os sistemas elétricos, o grande potencial é apresentado pelos sistemas fotovoltaicos especialmente quando se otimiza o aproveitamento solar, através, por exemplo, da integração dos painéis com o edifício.

Neste trabalho, portanto, procura-se estudar o desempenho dos sistemas de ar condicionado solar, através da análise energética dessas duas principais alternativas: a solar térmica por absorção e a solar elétrica fotovoltaica. O estudo corresponderá à simulação da aplicação desses sistemas em um edifício real existente na cidade de São Paulo.

A metodologia da análise e os seus resultados serão apresentados nos próximos capítulos. 
"Desempenho de Sistemas de Condicionamento de Ar com Utilização de Energia Solar em Edifícios de Escritórios"

Capítullo 3

Materiais e Métodos 


\section{MATERIAIS E MÉTODOS}

Pelo que foi apresentado nos capítulos 1 e 2, pode-se dizer que o objetivo principal deste trabalho corresponde ao estudo dos sistemas de condicionamento de ar com utilização de energia solar em edifícios de escritórios. Para isso, foi apresentada uma breve revisão bibliográfica sobre a tecnologia e será desenvolvida, a partir desse ponto do texto, uma análise do desempenho energético desses sistemas, através de uma simulação de caso. Essa análise do desempenho energético dos sistemas de ar condicionado solar será realizada com base no método descrito neste capítulo 3, desenvolvido especificamente para esse trabalho, como adaptação de um método já existente.

Esse método de análise de desempenho energético é composto de duas etapas. Na primeira etapa, o edifício é simulado, a fim de se obter as cargas térmicas atuantes durante sua operação. Para essa etapa será utilizado, como ferramenta, o software EnergyPlus, do Departamento de Energia dos Estados Unidos. Essa parte da análise será chamada, neste trabalho, de análise térmica do edifício.

Posteriormente, na segunda etapa da análise, os valores de carga térmica obtidos pela análise térmica do edifício, serão utilizados como dados de entrada para o cálculo do desempenho energético dos sistemas de ar condicionado solar. Isso será feito através da determinação do consumo de energia elétrica desses sistemas pela aplicação de um método de cálculo contido em um dos relatórios técnicos produzidos pelo Projeto $S O L A I R^{13}$ da União Européia e adaptado para essa pesquisa. Essa segunda parte da análise será chamada de análise energética dos sistemas de ar condicionado solar.

Sendo assim, no presente capítulo 3, dos Materiais e Métodos, passa-se a descrever a forma pela qual foram realizadas as etapas de análise térmica do edifício e de análise energética dos sistemas de ar condicionado solar, resultando no desempenho energético dos sistemas estudados.

\footnotetext{
${ }^{13}$ Projeto financiado pela União Européia com o objetivo de promover e fortalecer o uso de sistemas de ar condicionado solar, com início em janeiro de 2007 e término em dezembro de 2009.
} 
Também neste capítulo 3, são apresentadas as premissas, as ferramentas e as hipóteses adotadas para essa análise.

Antes, porém, da apresentação do método utilizado, com suas premissas e hipóteses, são definidos, com mais detalhes, o edifício e os sistemas de ar condicionado solar a serem simulados (item 3.1). Assim, passa-se finalmente a detalhar-se a metodologia para a análise térmica do edifício (item 3.2) e, por fim, a descrever-se como foi realizada a análise energética dos sistemas de ar condicionado solar, a partir dos resultados da simulação do edifício (item 3.3).

\subsection{Definição do Edifício e do Sistema de Ar Condicionado Solar em Estudo}

\subsubsection{Definição do Edifício de Escritórios}

A fim de analisar a aplicação da tecnologia de ar condicionado solar especificamente para edifícios de escritórios, foi necessária a definição de um edifício protótipo, que pudesse abrigar o sistema de ar condicionado solar a ser estudado.

Delimitando o estudo à cidade de São Paulo, procurou-se escolher, na cidade, um edifício de escritórios que representasse um caso típico de edifícios dessa tipologia, com grandes áreas internas e grandes áreas de janelas nas fachadas. Por possuir tais características e pela facilidade de acesso às informações, optou-se por adotar como edifício protótipo, um edifício de escritórios já construído, localizado na cidade de São Paulo, no bairro do Itaim Bibi.

No edifício de escritórios protótipo escolhido será simulado o funcionamento dos sistemas de ar condicionado solar em estudo. Dessa forma, os desempenhos energéticos desses sistemas de ar condicionado solar poderão ser analisados.

Algumas adaptações na planta original do edifício foram realizadas, a fim de otimizar e possibilitar a análise. Com as modificações realizadas e as hipóteses geométricas assumidas, o edifício protótipo passou a possuir as seguintes características: 


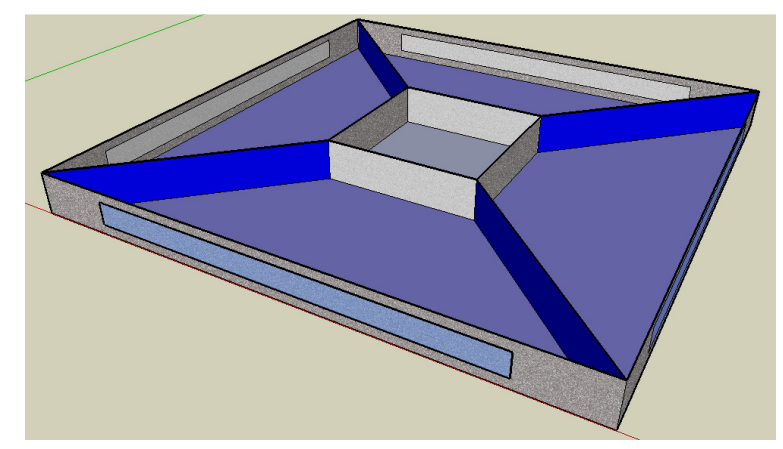

Figura 3.1 - Modelo do pavimento com suas zonas térmicas.

- 20 pavimentos (parâmetro modificado);

- Forma poligonal com quatro zonas periféricas de igual área;

- Existência de uma zona central (core);

- Core de 10x10 m localizado no centro do pavimento-tipo (parâmetro modificado);

- Pavimento Tipo de 32,91 x 32,91 m (parâmetro modificado);

- Deslocamento dos pilares das fachadas para o interior do pavimento-tipo, para não interferirem na geometria das fachadas;

- Distância da laje ao piso elevado de 20,5 cm;

- Distância do piso elevado ao forro de 2,70 m;

- Distância do forro a laje de $84,5 \mathrm{~cm}$;

- Espessura da laje de $12 \mathrm{~cm}$;

- Janelas centralizadas nas fachadas de 1,50 x 24,58 m (parâmetro modificado);

- Caixilharia fixa, sem ventilação natural, apenas trocas de ar por infiltrações;

- Paredes vedadas com alvenaria e revestidas com argamassa;

Escolhido o edifício, passou-se a definir em detalhes os sistemas de ar condicionado solar a serem analisados. 


\subsubsection{Definição dos Sistemas de Ar Condicionado Solar}

Conforme apresentado no item 1.5 do capítulo de introdução, duas são as alternativas de sistemas de ar condicionado solar a serem estudadas no trabalho. Cada uma delas terá seu funcionamento simulado no edifício de escritórios escolhido, na cidade de São Paulo, e seus desempenhos energéticos serão obtidos através do método deste capítulo.

Um dos sistemas de ar condicionado solar em estudo é o sistema térmico, com coletores solares que produzem água quente para um chiller de absorção. $\mathrm{O}$ outro sistema em estudo é o sistema elétrico, com painéis fotovoltaicos que produzem eletricidade para um chiller de compressão de vapor. O primeiro corresponde à tecnologia mais utilizada em sistemas de ar condicionado solar, como foi visto no capítulo 2. O segundo, como já apresentado, corresponde a uma alternativa de grande potencial, especialmente quando possibilita a integração de painéis fotovoltaicos às fachadas do edifício.

A metodologia para escolha das alternativas, tais como foram definidas acima, pode ser descrita pelo esquema da Figura 3.2, a seguir:

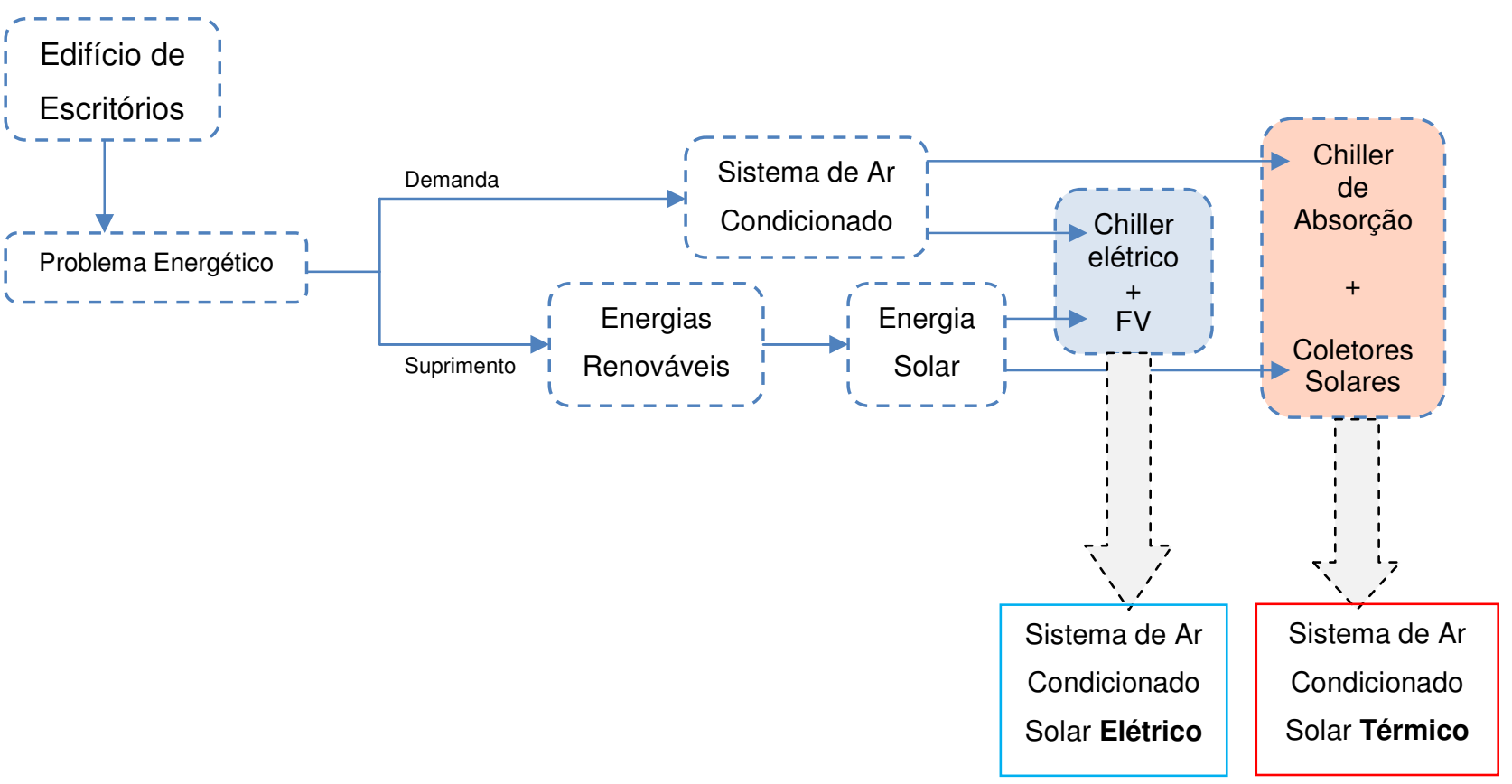

Figura 3.2 - Esquema de decisão para a escolha das duas alternativas a serem analisadas 
Devido às considerações apresentadas no capítulo de introdução, parte-se do princípio que o objetivo do empreendedor seja a implantação de um edifício de escritórios que se preocupe com a questão energética. Sendo assim, deve-se ter uma atenção especial com a demanda e o suprimento de energia do edifício, da qual, a utilização de uma fonte de energia renovável para o sistema de ar condicionado surge como uma alternativa interessante.

Pensando, então, no sistema de ar condicionado solar, particularmente, pelo que foi apresentado até esse ponto do trabalho, tem-se argumentos para afirmar que a alternativa mais provável de ser escolhida para edifícios de escritório corresponderia, a princípio, ao sistema térmico com coletores solares e ciclo de absorção.

Isso pode ser afirmado, como foi visto, pelo desenvolvimento da tecnologia de ar condicionado solar térmica, sua inserção de mercado, adequabilidade à tipologia e ao uso do edifício. De fato, essa seria, em tese, provavelmente a primeira alternativa a ser considerada na escolha por um sistema de ar condicionado solar, para o edifício em questão e para as condições específicas desse trabalho.

Tem-se, ao mesmo tempo, consciência do grande potencial e atrativo da tecnologia fotovoltaica. De fato, como foi dito, os sistemas fotovoltaicos apresentam uma visível expansão de mercado e aprimoramento tecnológico notável. Quanto se pensa em energia solar, especialmente para a tipologia e uso do edifício estudado, não é incoerente considerar a possibilidade de utilização de painéis fotovoltaicos. Isso é ainda mais verdadeiro, conforme apresentado nos capítulos anteriores, quando se considera a possibilidade integração dos painéis às fachadas de edifícios altos, tirando-se proveito da grande área disponível aos módulos.

Sendo assim, a alternativa elétrica, com chiller elétrico e painéis fotovoltaicos nas fachadas, também seria possível de ser adotada no edifício protótipo em questão, competindo, assim, em relação ao desempenho energético, com a alternativa térmica de ar condicionado solar. Dessa forma, definem-se então as duas alternativas de ar condicionado solar a serem estudadas neste trabalho: o sistema de ar condicionado térmico (absorção) alimentado por energia solar térmica e o sistema de ar condicionado elétrico (compressão de vapor) alimentado por energia solar fotovoltaica.

Antes, porém, de detalhar os sistemas a serem estudados, é importante ressaltar que, na definição do sistema térmico e do sistema elétrico de ar 
condicionado solar que serão analisados quanto ao desempenho energético, algumas premissas iniciais foram adotadas. A instalação solar para o sistema de ar condicionado solar térmico, isto é, os coletores solares térmicos, serão, por hipótese, alocados somente na cobertura do edifício e a instalação solar para o sistema de ar condicionado solar elétrico, isto é, os painéis fotovoltaicos, serão alocados somente na fachada do edifício.

Embora seja tecnicamente possível alocar coletores solares na fachada, essa possibilidade é muito mais remota do que a integração de painéis fotovoltaicos. Isso pode ser afirmado pela própria característica física, funcional e estética da tecnologia de aquecimento solar de água, sendo assim, somente o sistema fotovoltaico contará com a área de fachada para sua instalação.

Da mesma forma, seria possível instalar painéis fotovoltaicos na cobertura, porém, por hipótese, essa alternativa foi descartada, neste trabalho, a fim de possibilitar uma posterior análise complementar dos efeitos dos sistemas térmico e elétrico atuando de forma combinada.

Dito isso, passa-se a detalhar as duas alternativas de sistemas de ar condicionado solar, a térmica e a elétrica, a serem estudados neste trabalho. As Figuras 3.3 e 3.4, a seguir, mostram as concepções das alternativas estudadas.

Primeiramente, a Figura 3.3 mostra o sistema térmico de ar condicionado solar, com a instalação de coletores solares na cobertura, produzindo água quente para a alimentação do chiller de absorção. Nesta alternativa, os fan-coils do sistema de distribuição de ar, são alimentados pela água gelada produzida no chiller de absorção. Para isso, o chiller recebe o fluido quente proveniente dos coletores solares alocados na cobertura.

Quando o sistema de coletores solares não consegue suprir a demanda de calor do chiller de absorção, nos momentos em que, por exemplo, não há disponibilidade de radiação solar, é ativado um sistema de aquecimento auxiliar elétrico, para aquecer a água que se dirige ao chiller.

A Figura 3.4 mostra o sistema de ar condicionado solar elétrico, com a instalação de painéis fotovoltaicos em todas as superfícies opacas das fachadas para a alimentação do chiller de compressão de vapor. Nesta alternativa, os fan-coils do sistema de distribuição de ar são alimentados pela água gelada produzida no chiller de compressão de vapor. Para isso, o chiller recebe o eletricidade proveniente dos painéis fotovoltaicos alocados nas fachadas. 
Quando o sistema de painéis solares não consegue suprir a demanda de eletricidade do chiller de elétrico, nos momentos em que, por exemplo, não há disponibilidade de radiação solar, é utilizada a energia elétrica da rede da concessionária de energia para a alimentação do chiller.

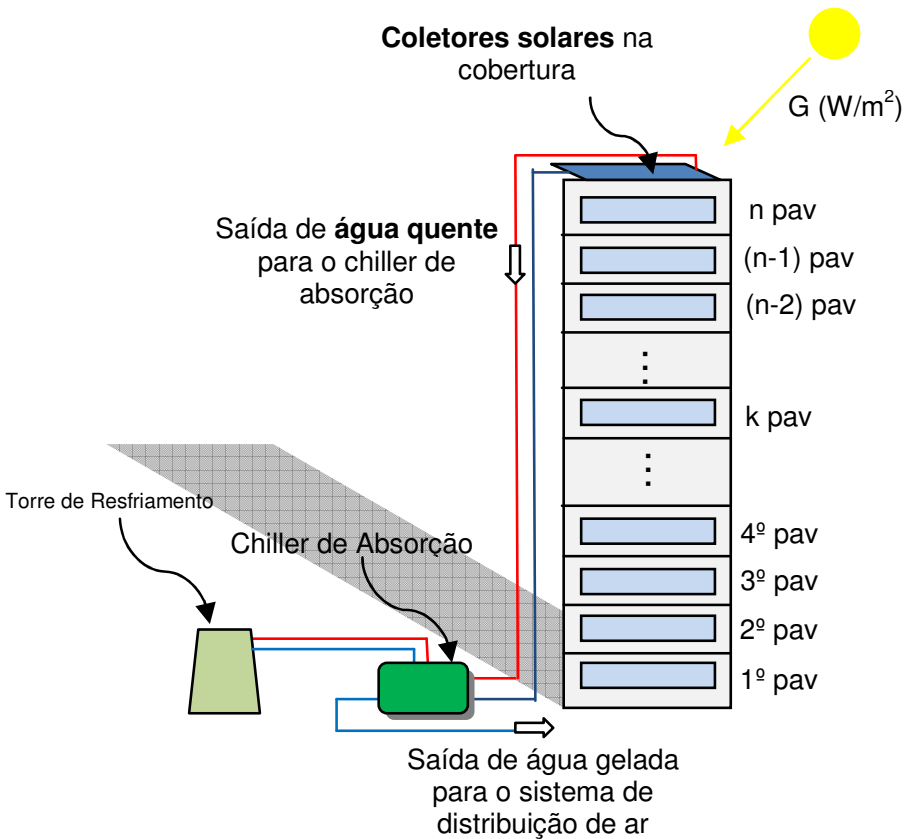

Figura 3.3 - Esquema do edifício de escritórios com o sistema de ar condicionado solar térmico.

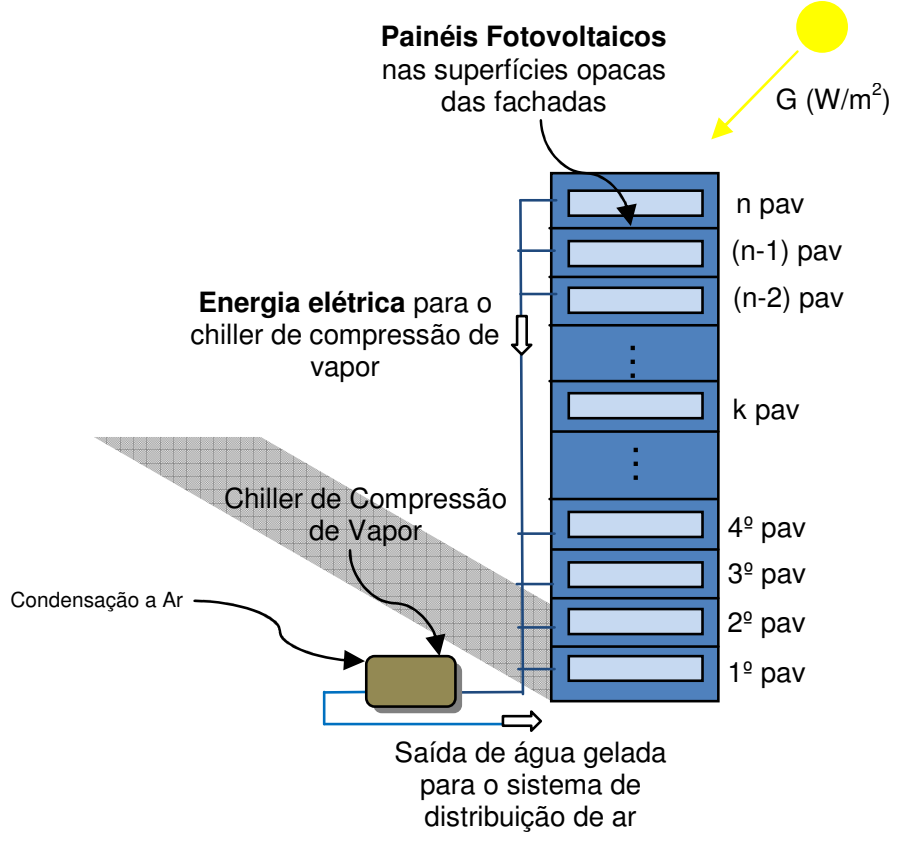

Figura 3.4 - Esquema do edifício de escritórios com o sistema de ar condicionado solar elétrico. 
As Figuras 3.5 e 3.6 detalham melhor os sistemas térmico e elétrico, respectivamente, de ar condicionado solar simulados:

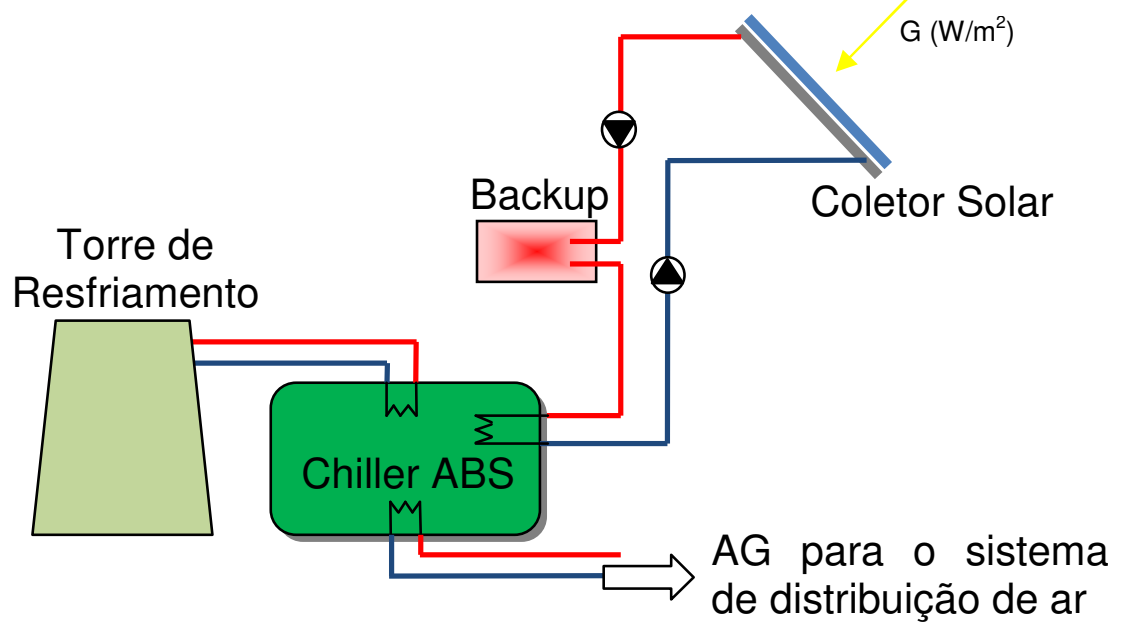

Figura 3.5 - Esquema do sistema de ar condicionado solar térmico simulado.

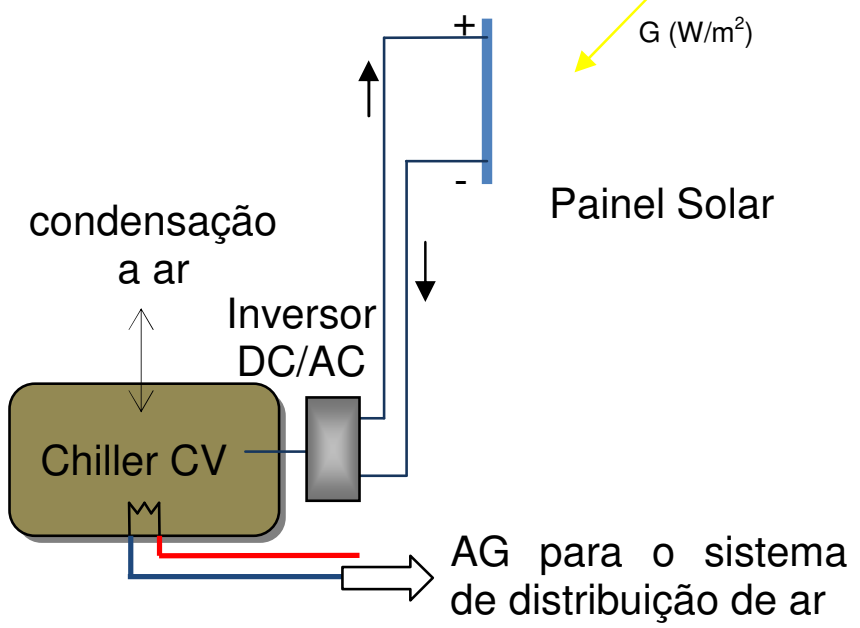

Figura 3.6 - Esquema do sistema de ar condicionado solar elétrico simulado.

Pelas Figuras 3.3 e 3.5 pode-se entender, em detalhes, o funcionamento do sistema de ar condicionado solar térmico em estudo. Os coletores solares térmicos 
na cobertura produzem água quente que é levada ao chiller de absorção solar, onde é utilizada para possibilitar a separação do par refrigerante no gerador do chiller. Com o auxilio de uma torre de resfriamento utilizada, retira-se o calor do condensador do chiller, tornando-se possível a produção de água gelada para atender os fan-coils e o sistema de distribuição de ar nos pavimentos.

As Figuras 3.4 e 3.6, por sua vez, mostram o sistema de ar condicionado solar elétrico estudado. Os painéis fotovoltaicos produzem eletricidade e são alocados nas superfícies opacas das fachadas do edifício. Isto é, a área disponível aos painéis fotovoltaicos corresponde à área total de fachada menos a área das janelas. Por hipótese, como foi dito, não foram instalados painéis fotovoltaicos na cobertura.

Quanto ao chiller de absorção do sistema térmico de ar condicionado solar, seu funcionamento (Chiller ABS da Figura 3.5) depende, portanto, do fornecimento do fluido quente proveniente dos coletores térmicos solares, na cobertura. Como foi dito, quando não há disponibilidade de radiação e há demanda por condicionamento de ar, em um dia nublado, por exemplo, o fluido que se dirige ao chiller solar é aquecido por um aquecedor auxiliar de backup (Figura 3.5).

Assim, garante-se que o funcionamento do sistema de ar condicionado solar térmico seja mantido regularmente. Devido às hipóteses do método de cálculo adotado neste trabalho, que será discutido no próximo item deste capítulo 3 , 0 aquecedor auxiliar elétrico foi considerado como sendo um aquecedor elétrico, por hipótese.

Quanto ao sistema elétrico de ar condicionado solar, a energia elétrica produzida pelos módulos é do tipo corrente contínua e é transformada em corrente alternada por inversores DC/AC em cada fachada do prédio. A energia produzida pelos painéis alimenta o chiller elétrico de compressão de vapor (Chiller CV da Figura 3.6) produzindo água gelada para atender os fan-coils e o sistema de distribuição de ar nos pavimentos.

O funcionamento do chiller elétrico de compressão de vapor depende, portanto, da eletricidade proveniente dos painéis fotovoltaicos, nas fachadas. Entretanto, nem sempre quando há demanda por condicionamento de ar, há disponibilidade de radiação solar para os painéis fotovoltaicos, e como, por hipótese, o sistema fotovoltaico adotado não possui acumulação em baterias, algum backup de energia deve ser previsto. 
Assim, quando o dia está nublado, por exemplo, e há demanda por condicionamento de ar, a eletricidade para o chiller provem da rede elétrica. Em outras palavras, o sistema fotovoltaico adotado é, por hipótese, do tipo gridconnected, no qual a rede elétrica da concessionária de energia serve na prática de backup para o sistema.

Observando-se a Figura 3.6, entretanto, pode-se perguntar porque não há torre de resfriamento no sistema de ar condicionado solar elétrico, sendo que seria usual utilizá-la. Ao contrário, adota-se para o sistema de ar condicionado solar elétrico, um sistema com condensação a ar. Isso ocorre pois, o método de cálculo da energia consumida pelos sistemas, e que será descrito ainda neste capítulo, contempla apenas a existência de condensação a água (com torre de resfriamento) para o sistema térmico de ar condicionado solar.

Além dos sistemas de ar condicionado solar térmico e elétrico apresentados até aqui, um outro sistema de ar condicionado será analisado neste trabalho. Esse sistema será do tipo convencional utilizando chiller elétrico alimentado pela rede da concessionária de energia. A fim de se ter uma referência na comparação do desempenho energético dos sistemas de ar condicionado solar térmico e elétrico definidos anteriormente, esse sistema de ar condicionado convencional também foi analisado.

O esquema do sistema de ar condicionado convencional adotado, é ilustrado pela Figura 3.7, a seguir:

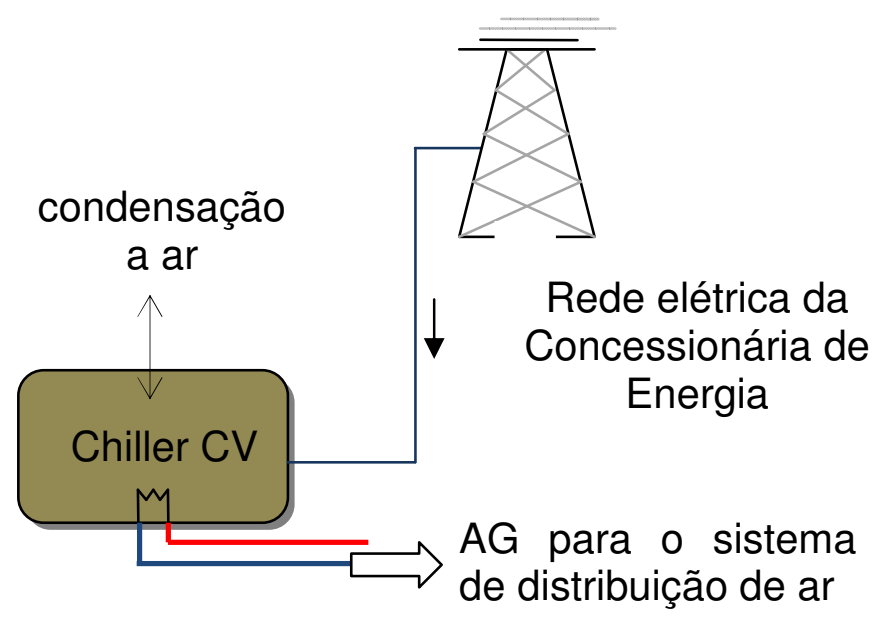

Figura 3.7 - Esquema do sistema de ar condicionado convencional simulado. 
Dessa forma, os sistemas de ar condicionado solar podem ter seu desempenho energético comparados entre si e com um sistema de ar condicionado convencional de referência, que não utiliza nenhuma tecnologia de aproveitamento solar.

Como se observa na Figura 3.7, também não há torre de resfriamento no sistema de ar condicionado convencional, pelas mesmas razões apresentadas acima para o sistema de ar condicionado solar elétrico.

Por fim, é interessante comentar que antes mesmo da análise de desempenho energético que será desenvolvida, já é possível imaginar algumas potencialidades e limitações das alternativas de ar condicionado em estudo, assumindo-se as hipóteses adotadas para esse trabalho.

A Tabela 3.1, a seguir, procura apresentar essas principais limitações e potencialidades das alternativas:

Tabela 3.1 - Vantagens e desvantagens das alternativas em estudo.

\begin{tabular}{|c|c|c|}
\hline $\begin{array}{c}\text { Alternativas / } \\
\text { Potencialidades } \\
\text { e Limitações }\end{array}$ & Térmica & Elétrica \\
\hline Potencialidade & $\begin{array}{c}\text { Baseado em chiller de } \\
\text { absorção que, a rigor, não } \\
\text { utiliza energia convencional } \\
\text { elétrica como principal fonte } \\
\text { energética para sua operação. }\end{array}$ & $\begin{array}{c}\text { Conta com a área da fachada } \\
\text { para a alocação dos painéis } \\
\text { fotovoltaicos. }\end{array}$ \\
\hline Limitação & $\begin{array}{c}\text { Conta somente com a área } \\
\text { limitada da cobertura para a } \\
\text { alocação dos coletores solares. }\end{array}$ & $\begin{array}{c}\text { Baseado em chiller de } \\
\text { compressão de vapor, que a } \\
\text { rigor, utiliza energia } \\
\text { convencional elétrica como } \\
\text { principal fonte energética para } \\
\text { sua operação. }\end{array}$ \\
\hline
\end{tabular}

As potencialidades e limitações apresentadas pelas alternativas de ar condicionado solar na Tabela 3.1, têm maior ou menor influência no desempenho energético dos sistemas de acordo com as dimensões do edifício climatizado. Para um edifício menor, por exemplo, a área disponível de fachadas será menor, prejudicando a produção fotovoltaica do sistema elétrico. 
A priori, em relação ao sistema de ar condicionado convencional, os sistemas de ar condicionado solar térmico e elétrico teriam vantagem energética de que uma parcela do suprimento de energia necessária à climatização do prédio provém da fonte renovável solar.

Se o objetivo é reduzir o consumo de energia elétrica convencional, vinda da rede da concessionária de energia, então o sistema de ar condicionado solar térmico, ao utilizar um chiller de absorção trabalhando à base de fornecimento de calor, na teoria, apresenta consumo elétrico apenas por conta do acionamento do backup de energia nos momentos de pouca radiação solar.

Diferentemente, o sistema de ar condicionado solar elétrico não utiliza um chiller de absorção e sim um chiller convencional elétrico. Entretanto, por possibilitar a integração da instalação solar fotovoltaica na fachada, valendo-se de uma grande área de capitação solar, a alternativa elétrica torna-se interessante no sentido de se reduzir a demanda por energia elétrica vinda da rede da concessionária.

A grande limitação, porém, do sistema térmico, como se verá no capítulo 4, de resultados, consiste na área relativamente pequena da cobertura para os coletores do sistema térmico já que especialmente para prédios altos, como o estudado, o fornecimento de energia solar por parte dos coletores solares pode resultar muito pequeno se comparado à grande demanda de energia para a climatização.

Entretanto, a área limitada da cobertura para os coletores solares térmicos pode se tornar compatível e suficiente caso a demanda do chiller de absorção não seja tão elevada, no caso de um edifício mais baixo, por exemplo.

Um estudo do desempenho de sistemas de ar condicionado solar, supondo a mesma tipologia do edifício escolhido, porém com menos pavimentos que o edifício original de 20 pavimentos, também será desenvolvido neste trabalho. Essa análise será chamada de análise do desempenho dos sistemas em função do número de pavimentos e será apresentada no item 4.3 do próximo capítulo.

O método e as hipóteses adotadas para este estudo serão descritas nos itens 3.2 e 3.3, a seguir, juntamente com o método e as hipóteses adotadas para a análise do edifício original de 20 pavimentos.

Os resultados finais serão apresentados no capítulo 4. 


\subsection{Análise do Desempenho Térmico do Edifício}

A fim de analisar o comportamento energético dos sistemas de ar condicionado solar, que é o foco deste trabalho, utilizou-se como base um método proposto pelo Projeto SOLAIR da União Européia, fazendo-se as devidas adaptações relacionadas ao caso dessa pesquisa. $O$ método, portanto, utilizado neste trabalho e derivado do método do SOLAIR será descrito no item 3.3, ainda neste capítulo. Com ele poderão ser calculados os consumos de energia dos sistemas de ar condicionado solar em estudo, e assim, poderão ser analisados os desempenhos energéticos dessas alternativas de ar condicionado supondo sua instalação em um edifício de escritórios na cidade de São Paulo.

Esse método, porém, a fim de calcular o consumo de energia dos sistemas exige, como dado de entrada, que sejam informadas as cargas térmicas presentes no ambiente a ser condicionado. Dessa forma, conforme foi dito anteriormente, antes da etapa de análise energética dos sistemas de ar condicionado solar (pelo método do item 3.3), foi necessária a obtenção das cargas térmicas no edifício em estudo, na etapa de análise térmica do edifício.

O método e as hipóteses adotadas nesta etapa de análise térmica serão descritos neste item 3.2.

\subsubsection{Ferramenta para Simulação do Edifício}

Para obter as cargas térmicas do edifício, foi necessário definir uma ferramenta de simulação. A ferramenta escolhida deveria, primeiramente, contemplar a possibilidade de simular edificações. Depois, deveria ser viável à pesquisa quanto ao custo, disponibilidade e complexidade. Por fim, deveria fornecer os resultados desejados, para a posterior análise dos sistemas de ar condicionado solar.

Pela facilidade de aquisição, adequabilidade à simulação térmica de edifícios, pela sua disseminação no ambiente acadêmico e empresarial e também pela 
facilidade de acesso às informações, foi escolhido o software de simulação EnergyPlus.

O software EnergyPlus é usualmente utilizado para modelar e simular fenômenos energéticos em edifícios, tais como, aquecimento, resfriamento, ventilação, além de fenômenos relacionados ao fluxo de água e desempenho energético nas edificações. Esse programa originou-se dos programas BLAST e DOE-2 do Departamento de Energia dos Estados Unidos que o precederam na simulação energética de edifícios.

O programa contempla muitas características interessantes para análise energética da edificação, tais como, possibilidade de se ter "time-steps" inferiores a uma hora, a possibilidade de consideração de sistemas com fluxo de ar atendendo diversas zonas, a análise de conforto térmico e do uso da água e ventilação natural, além de contemplar a simulação de cargas térmicas.

Uma importante característica do software EnergyPlus, é que ele adota o conceito de ser apenas o "simulator engine", isto é, permite o estabelecimento de interfaces com outros programas, a fim de se atingir a funcionalidade desejada.

Além disso, o EnergyPlus também apresenta outra característica interessante, que é o fato de que o programa simula de forma integrada as três partes principais do modelo de simulação: o sistema de aquecimento, ventilação e ar condicionado ("HVAC"), as zonas térmicas ("ZONE") do edifício e os sistemas de água ("PLANT"). Essa integração confere maior realidade aos resultados da simulação.

A simulação não integrada, isto é, que simula seqüencialmente esses três subsistemas, só seria adequada se a resposta de um sistema de condicionamento de ar dependesse somente da temperatura interna de uma zona térmica. Isso, na maioria dos casos, não corresponde à realidade, pois a resposta do sistema depende de muitas outras variáveis internas e externas ao edifício (CRAWLEY, 2007). Sendo assim, os resultados obtidos da simulação integrada do EnergyPlus são bastante confiáveis e satisfatórios.

Por fim, o software apresenta uma característica inovadora em relação aos programas anteriores, que é a modularidade. Isto significa que o programa é estruturado em módulos, ou seja, várias seções independentes entre si. Dessa forma, a fim de se alterar parte do código ou uma parte limitada do programa, não é necessário conhecer o código por inteiro, facilitando, então, tanto o acréscimo de 
recursos ao programa, quanto o estabelecimento de interfaces com outros softwares (DOE, "EnergyPlus Getting Started Manual", 2009).

Resumidamente, o EnergyPlus é o simulador que, a partir de arquivos de entrada de texto (formato ASCII) - descrevendo as condições climáticas, o edifício e os sistemas - gera arquivos de saída de texto, com os resultados de comportamento energético do edifício e do sistema. Tanto a construção de arquivos de entrada ("input files"), quanto a leitura de arquivos de saída ("output files"), podem ser auxiliadas por interfaces do usuário ("third-party user interfaces"). Na própria instalação do software, no ambiente Windows, tem-se como possibilidade a instalação de um programa de interface com o usuário, o EP-Launch, que gerencia a simulação e possibilita a escolha e a edição de arquivos de entrada e de saída.

Um dos arquivos de entrada mais importantes para a simulação é o arquivo "input data file" (IDF), que nada mais é do que um arquivo de texto, que descreve o modelo a ser simulado. O EP-Launch possibilita a edição facilitada desse arquivo IDF, através de um programa auxiliar de interface, o IDF-Editor, que pode ser aberto a partir do próprio EP-Launch. A Figura 3.8 ilustra a tela do EP-Launch com as opções de escolha e edição dos arquivos de entrada e visualização de alguns arquivos de saída.

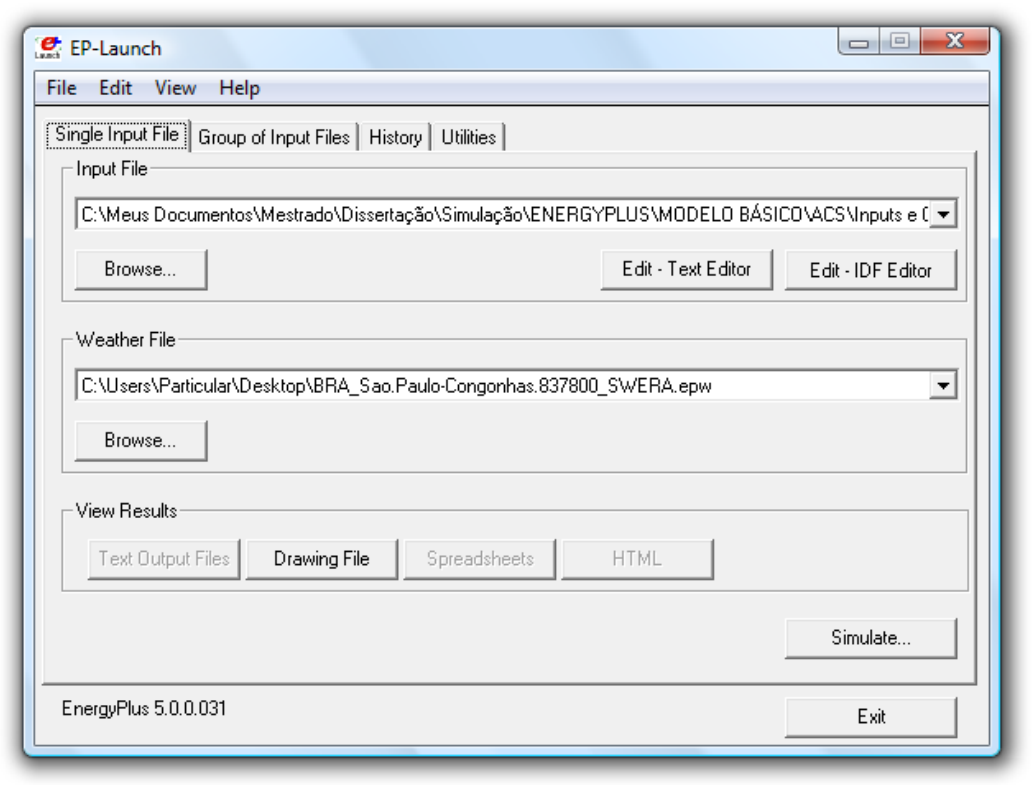

Figura 3.8 - Interface com o usuário do EP-Launch. (EnergyPlus, versão 5.0) 
No editor de arquivo IDF, o usuário informa os dados que descrevem o edifício e o sistema a ser simulado. Para isso, o IDF-Editor disponibiliza diversas classes com alguns objetos, cada um contendo, por sua vez, um conjunto de parâmetros que podem ser preenchidos com as informações alfa-numéricas que se deseja especificar. Na Figura 3.9 é mostrada a configuração do IDF-Editor podendose visualizar a classe "Location and Climate" com seu objeto "Site:Location", que é mostrado selecionado em azul e os parâmetros ("Name", "Latitude", etc) correspondentes a esse objeto.

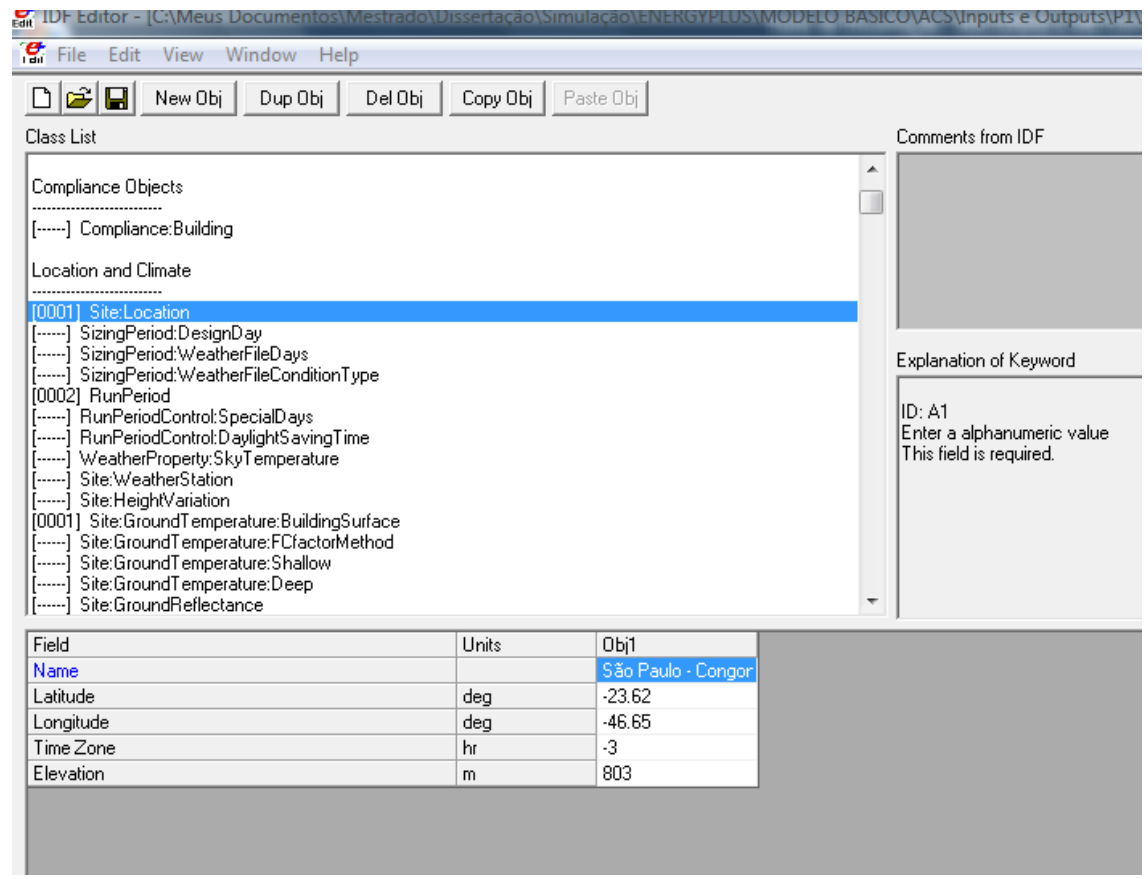

Figura 3.9 - Interface com o usuário do IDF-Editor (EnergyPlus, versão 5.0)

Construído o arquivo de entrada com a ajuda do IDF-Editor, o programa executa a simulação e são obtidos nos arquivos de saída disponibilizados com os resultados após a simulação.

Mesmo com algumas deficiências inerentes ao programa, tais como a falta de uma hierarquia de informações para a construção do modelo e a necessidade de uma nomenclatura mais clara, o EnergyPlus mostrou-se satisfatório para a análise pretendida. Sendo assim, pode-se dizer que o programa avaliou a carga térmica do edifício protótipo com razoável facilidade e obteve resultados confiáveis. Os resultados de carga térmica referentes à essa análise térmica do edifício, serão apresentados no item 4.1 do próximo capítulo. 


\subsubsection{Método para a Análise Térmica do Edifício}

Como foi dito no item anterior, o software EnergyPlus será utilizado para a análise térmica do edifício, resultando nos valores de carga térmica. Entretanto, para a simulação no EnergyPlus e a obtenção das cargas térmicas, algumas hipóteses devem ser adotadas. Essas hipóteses simplificaram e tornaram possível a análise térmica do edifício e são detalhadas a seguir, constituindo-se no método para a análise térmica do edifício e a obtenção das cargas térmicas.

\subsubsection{Modelo Geométrico do Edifício}

Dada a complexidade da obtenção do modelo completo do edifício no software EnergyPlus e a necessidade de se flexibilizar a análise, foram modelados apenas três pavimentos do edifício de escritórios. Os pavimentos modelados foram o pavimento térreo, um pavimento intermediário $\left(10^{\circ}\right)$ e o último pavimento $\left(20^{\circ}\right)$.

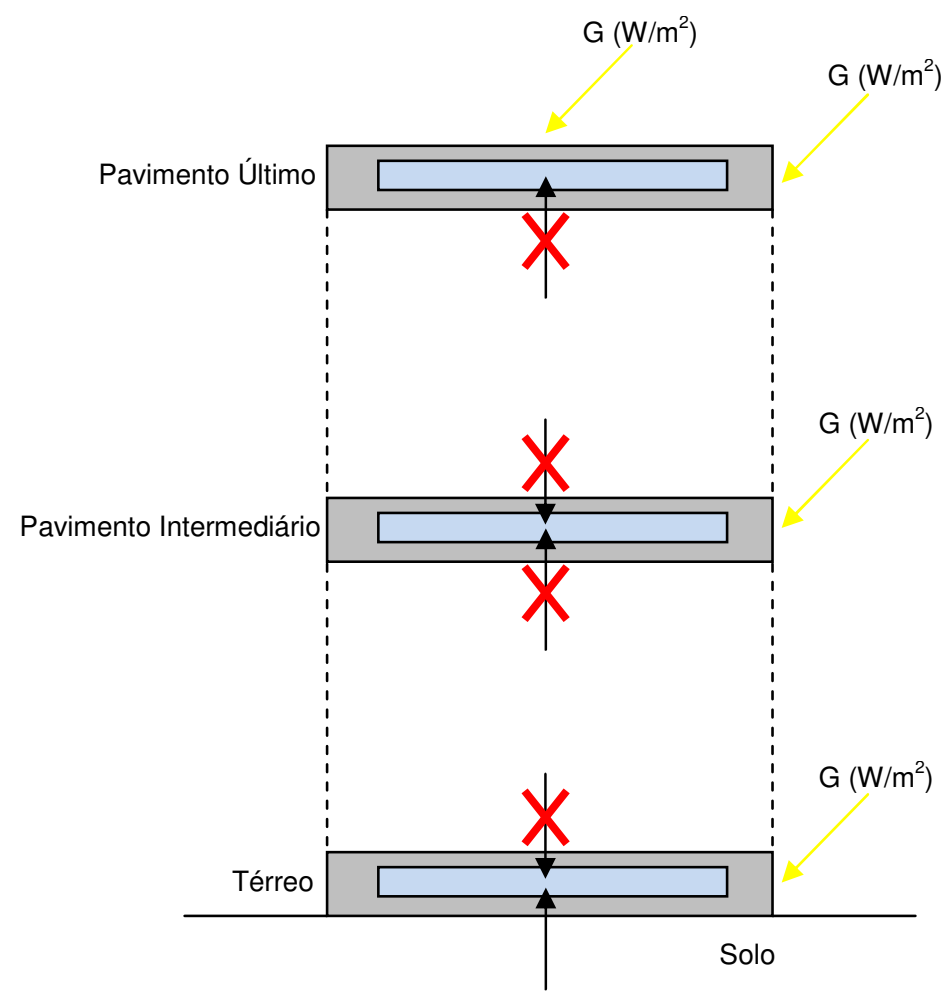

$G\left(W / m^{2}\right)$

Incidência de radiação solar

Há transferência de calor

Não há

transferência de calor

Figura 3.10 - Esquema do modelo geométrico utilizado para a simulação de carga térmica 
Como pode ser observado na Figura 3.10, para o pavimento térreo, considerou-se o contato da estrutura com o solo (coordenada $z=0,0$ ) e, portanto, permitiu-se as trocas térmicas entre o solo e a edificação. O pavimento térreo $\left(1^{\circ}\right)$ é o único pavimento que está em contato com o solo e pode admitir trocas térmicas com ele, por isso, foi considerado separadamente. Por outro lado, o último pavimento $\left(20^{\circ}\right)$ é o único que recebe a contribuição da radiação solar na laje de cobertura, por isso, também deve ser considerado de forma separada.

Já o pavimento intermediário apresenta um comportamento térmico semelhante aos demais pavimentos que possuem andares tanto acima como abaixo. Dessa forma, para efeito da simulação, a transferência de calor entre os pavimentos foi considerada nula.

A simplificação na modelagem resultou em uma redução significativa da complexidade da simulação, tornando-a mais rápida e flexível, já que a modelagem do edifício real com todos seus pavimentos poderia inviabilizar a simulação no EnergyPlus. Sendo assim, a carga térmica, em W, resultante para o edifício de 20 pavimentos para cada hora $i$ do dia $(1 \leq i \leq 24)$, foi obtido como sendo por hipótese resultado da composição dos valores de carga térmica obtidos pelo EnergyPlus para os pavimentos térreo, intermediário e último, para esta hora $i$ do dia, da seguinte forma:

$$
Q_{\text {edifício } 20, i}=\mathbf{1} \times q_{\text {térreo }, i}+\mathbf{1 8} \times q_{10^{\circ} P A V, i}+\mathbf{1} \times q_{20^{\circ} P A V, i}, \quad 1 \leq i \leq 24
$$

sendo:

$Q_{\text {edifício20,i }}$ - carga térmica calculada para o edifício real de 20 pavimentos, para a hora $i$ do dia em questão (W).

$q_{\text {térreo,i }}$ - carga térmica resultante da simulação do pavimento térreo, para a hora $i$ do dia em questão (W).

$q_{10^{\circ} P A V, i}$ - carga térmica resultante da simulação do pavimento intermediário, para a hora $i$ do dia em questão (W).

$q_{20^{\circ} P A V, i}$ - carga térmica resultante da simulação do último pavimento, para a hora $i$ do dia em questão (W). 
Conforme se observa na eq.(2), os valores de $q_{\text {térreo,i }}, q_{10^{\circ} P A V, i}$ e $q_{20^{\circ} P A V, i}$ em W, para cada hora $i$ do dia, obtidos pelo EnergyPlus para o primeiro (térreo), o décimo e o último $\left(20^{\circ}\right)$ pavimentos do edifício, respectivamente, são compostos da forma apresentada pela eq.(2) para se obter o valor total da carga térmica do prédio, para a hora $i$. Multiplicando-se por 180 valor de $q_{10^{\circ} P A V, i}$, supõe-se, por hipótese, como já foi dito, que todos os pavimentos intermediários (do $2^{\circ}$ ao $19^{\circ}$ ) tenham a mesma carga térmica.

Esse tipo de formulação apresentada pela eq.(2) também será útil na análise do desempenho energético dos sistemas em função do número de pavimentos do edifício, que será desenvolvida no item 4.2.2 do capítulo de Resultados.

Nessa análise, será estudado o efeito da adição consecutiva de pavimentos ao edifício, de forma que se observe a influência da altura do edifício na carga térmica e, posteriormente, no desempenho do sistema de ar condicionado solar.

Por isso, como foi dito, considerou-se, por hipótese, que o valor de carga térmica dos pavimentos localizados acima do térreo e abaixo do último pavimento pudessem ser aproximados ao valor obtido para o pavimento intermediário (10), já que todos possuem cargas internas semelhantes e não há transferência de calor entre pavimentos (Figura 3.10).

Sendo assim, o valor de carga térmica $Q_{k, i}$ em $\mathrm{W}$, para cada hora $i$ do dia, para um pavimento qualquer $k(2 \leq k \leq 19)$, localizado entre o térreo e o último pavimento, pode ser aproximado por:

$$
Q_{k, i} \cong q_{10^{\circ} \mathrm{PAV}, i} \quad 2 \leq k \leq 19
$$

sendo:

$Q_{k, i}$ - carga térmica do pavimento $k$ do edifício, para a hora $i$ do dia em questão (W). $q_{10^{\circ} P A V, i}$ - carga térmica resultante da simulação do pavimento intermediário, para a hora $i$ do dia em questão $(W)$. 
Além disso, para que a análise de desempenho dos sistemas de ar condicionado em função do número de andares do edifício seja realizada, devem ser calculadas as cargas térmicas para edifícios menores do que o edifício escolhido de 20 pavimentos. Em outras palavras, as cargas térmicas desses edifícios menores, com $N$ pavimentos ( $1 \leq N \leq 19$ ), também deverão ser determinadas. Por isso, para facilitar essa determinação, a formulação da eq.(4) foi adotada. Para um edifício com $N$ pavimentos $\left(1 \leq N \leq 19\right.$ ), a carga térmica $Q_{\text {edifícion, } i}$ em $\mathrm{W}$, pode ser calculada por:

$$
Q_{\text {edifícion }, i}=\mathbf{1} \times q_{\text {térreo }, i}+(\boldsymbol{N}-\mathbf{2}) \times q_{10^{\circ} \mathrm{PAV}, i}+\mathbf{1} \times q_{20^{\circ} \mathrm{PAV}, i} \quad, \quad 2 \leq N \leq 19
$$

sendo:

$Q_{\text {edifícion, } i}$ - carga térmica calculada para o edifício de $N$ pavimentos, para a hora $i$ do dia em questão $(\mathrm{W})$.

$q_{\text {térreo,i }}$ - carga térmica resultante da simulação do pavimento térreo, para a hora $i$ do dia em questão $(\mathrm{W})$.

$q_{10^{\circ} P A V, i}$ - carga térmica resultante da simulação do pavimento intermediário, para a hora $i$ do dia em questão (W).

$q_{20^{\circ} P A V, i}$ - carga térmica resultante da simulação do último pavimento, para a hora $i$ do dia em questão (W).

Para a formulação da eq.(4) acima, considerou-se, portanto, que a carga térmica atuante em um pavimento intermediário $k(2 \leq k \leq N)$, de um edifício com $N$ pavimentos, possa ser aproximada à carga calculada para $010^{\circ}$ pavimento do edifício original de 20 pavimentos, conforme a eq.(3) apresentada anteriormente.

Da mesma forma, para a formulação da eq.(4), considerou-se por hipótese, que a carga térmica $Q_{N, i}$ para a hora $i$ atuante no último pavimento ( $N$ ésimo pavimento) desse mesmo edifício com $N$ pavimentos ( $\leq N \leq 19)$, possa ser aproximada à carga calculada para $020^{\circ}$ pavimento do edifício original de 20 pavimentos, de acordo com a eq.(5), a seguir. 


$$
Q_{N, i} \cong q_{20^{\circ} P A V, i} \quad 2 \leq N \leq 19
$$

sendo:

$Q_{N, i}$ - carga térmica do pavimento $N$ do edifício de $N$ pavimentos, para a hora $i$ do dia em questão $(W)$.

$q_{\text {térreo,i }}$ - carga térmica resultante da simulação do pavimento térreo do edifício original de 20 pavimentos, para a hora $i$ do dia em questão (W).

Quando o edifício for térreo $(N=1)$, o cálculo da carga térmica será feito através de um modelo exclusivo para essa situação. Isso porque aproximar o valor da carga térmica calculada para o pavimento térreo do edifício de 20 pavimentos, $q_{\text {térreo,i }}$ ao valor da carga térmica do edifício térreo, $q_{\text {edifício1,i }}$ seria incorreto, pois quando o edifício é térreo há também a contribuição da radiação solar na laje de cobertura do térreo. Em outras palavras:

$$
Q_{\text {edifícion, } i} \neq q_{\text {térreo,i }} \quad N=1
$$

sendo:

$Q_{\text {edifícion, } i}(N=1)$ - carga térmica do edifício térreo $(N=1)$, para a hora $i$ do dia em questão (W).

$q_{\text {térreo,i }}$ - carga térmica resultante da simulação do pavimento último do edifício original de 20 pavimentos, para a hora $i$ do dia em questão (W).

Assim, o valor de $Q_{\text {edifício1,i }}$ foi obtido por um outro modelo específico construído no EnergyPlus para este caso, contemplando um modelo geométrico particular, já que, nessa situação, o pavimento único está exposto à radiação solar em sua laje de cobertura. 
Enfim, essas formulações serão de grande utilidade para a realização dos cálculos relacionados à variação do número de pavimentos do edifício. De fato, os cálculos para altura variável do edifício serão oportunos, pois permitirão uma análise comparativa interessante do desempenho dos sistemas de ar condicionado solar elétrico e térmico. De fato, conforme a altura do edifício aumenta, a área de fachada para os painéis fotovoltaicos cresce, mantendo-se, entretanto, a área de cobertura constante para os coletores solares térmicos.

Assim, embora o sistema térmico de ar condicionado solar apresente um grande potencial de economia de energia convencional elétrica e apresente, conseqüentemente, um desempenho energético interessante, conforme aumenta-se a altura do edifício, o sistema elétrico de ar condicionado solar, que utiliza painéis fotovoltaicos nas fachadas, se torna mais competitivo.

Sendo assim, um estudo desse tipo poderá informar para as condições do edifício em questão, a partir de que altura do edifício, um sistema de ar condicionado solar (térmico ou elétrico) passa a ser mais vantajoso energeticamente do que o outro. Além disso, poderá descrever o comportamento da fração solar do sistema de ar condicionado solar térmico para diferentes alturas do edifício, assim como, caracterizar a evolução do desempenho energético de um sistema de ar condicionado solar com o crescimento da altura do edifício.

Todas essas análises, porém, resultarão da determinação das cargas térmicas do edifício pelo EnergyPlus e pelas eq.(2) à eq.(6) apresentadas anteriormente e da posterior análise dos sistemas de ar condicionado pelo método que será apresentado no item 3.3, a seguir.

Ainda com relação às hipóteses para o cálculo da carga térmica, pode-se dizer que, tanto para o pavimento térreo, como para o pavimento intermediário $\left(10^{\circ}\right)$ e último pavimento $\left(20^{\circ}\right)$, o modelo geométrico adotado manteve as informações obtidas do edifício real com as adaptações apresentadas no item 3.1.1.

Em cada pavimento, há nove zonas térmicas, sendo apenas quatro delas condicionadas. A Tabela 3.2 acima ilustra as zonas modeladas e a nomenclatura adotada no modelo. 
Tabela 3.2 - Nomenclatura das zonas térmicas no modelo geométrico. Os campos em azul representam as zonas condicionadas.

\begin{tabular}{|l|l|}
\hline zonas $\quad$ pavimento $\mathrm{k}$ & \multicolumn{1}{c|}{ nomenclatura } \\
\hline Zona Sul & $\mathrm{k}-\mathrm{ZS}$ \\
\hline Zona Norte & $\mathrm{k}-\mathrm{ZN}$ \\
\hline Zona 3 & $\mathrm{k}-\mathrm{Z} 3$ \\
\hline Zona Oeste & $\mathrm{k}-\mathrm{ZO}$ \\
\hline Core & $\mathrm{k}-\mathrm{CORE}$ \\
\hline Core no Piso elevado & $\mathrm{k}-\mathrm{PE}-\mathrm{CORE}$ \\
\hline Core no Forro & $\mathrm{k}-\mathrm{FORRO}-$ CORE \\
\hline Piso Elevado & $\mathrm{k}-\mathrm{PE}-\mathrm{ZU}$ \\
\hline Forro & $\mathrm{k}-$ FORRO - ZU \\
\hline
\end{tabular}

Conforme se observa na tabela 3.2, das 9 zonas do pavimento, 2 zonas estão na altura do piso elevado (Figura 3.11), 5 zonas estão na altura dos escritórios (Figura 3.12) - sendo 4 delas condicionadas (ZN, ZS, ZL e ZO) - e 2 zonas estão na altura do forro. As figuras a seguir ilustram os modelos das zonas correspondentes ao piso elevado e a área de escritórios, para os pavimentos simulados. As zonas correspondentes ao forro são análogas ao do piso elevado, porém com altura maior.

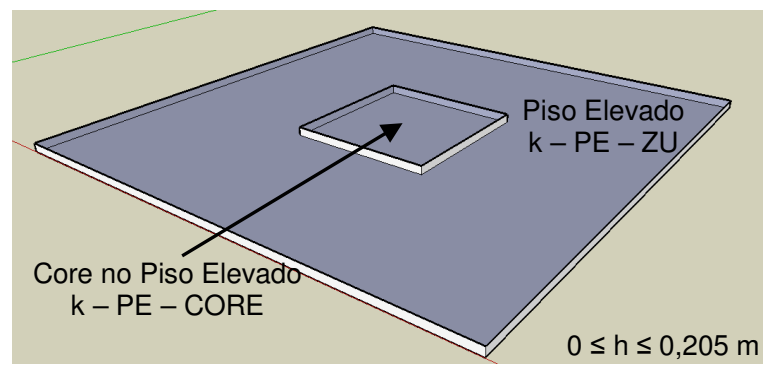

Figura 3.11 - Modelo geométrico das zonas correspondentes ao piso elevado para o piso $\mathrm{k}$.

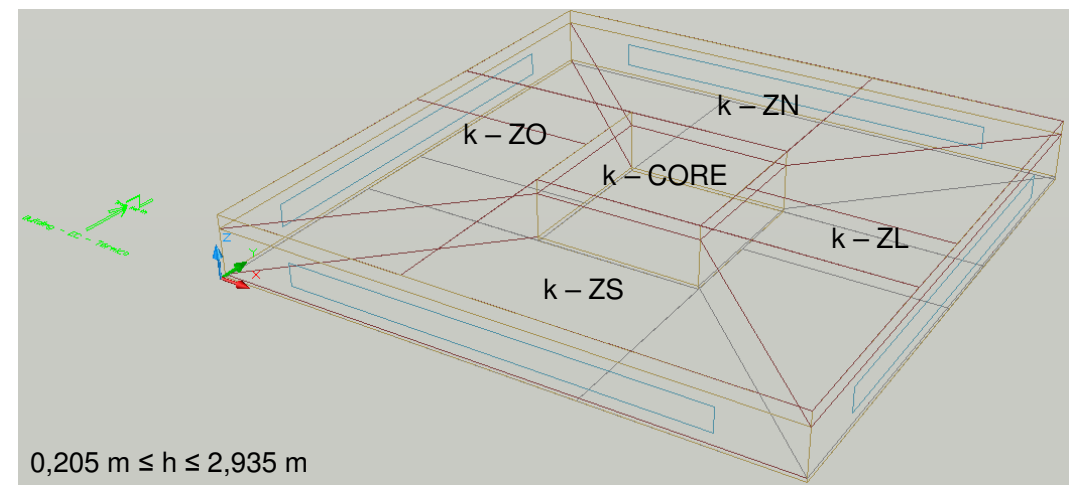

Figura 3.12 - Modelo geométrico das zonas correspondentes a área de escritórios para o piso k. 
Vale recordar, mais uma vez, que as características geométricas adotadas no modelo correspondem às características do edifício protótipo escolhido e detalhado no item 3.1.1, no início deste capítulo.

A lista dos objetos do EnergyPlus adotados para modelar as características geométricas do edifício é apresentada no Anexo 1.

\subsubsection{Modelo Construtivo do Edifício}

Para a adequada modelagem do edifício e a obtenção das cargas térmicas, foi necessário informar ao EnergyPlus as características dos elementos construtivos que compõem a edificação. Tendo-se como ponto de partida as informações obtidas sobre o edifício em estudo, adotaram-se, por hipótese, as características do modelo construtivo, de acordo com a Tabela 3.3:

Tabela 3.3 - Elementos construtivos simulados para o edifício.

\begin{tabular}{|c|c|c|}
\hline $\begin{array}{c}\text { Elemento } \\
\text { Construtivo }\end{array}$ & Material & Espessura \\
\hline Lajes & Concreto Armado & $12 \mathrm{~cm}$ \\
\hline Paredes & Alvenaria Cerâmica & $20 \mathrm{~cm}$ \\
\hline Revestimento & Argamassa & $2 \mathrm{~cm}$ \\
\hline Janelas & Vidro & $6 \mathrm{~mm}$ \\
\hline Forro & Isopor & $3 \mathrm{~cm}$ \\
\hline
\end{tabular}


As informações da Tabela 3.3 incorporam as devidas simplificações no modelo, sendo que a lista dos objetos do EnergyPlus que especificaram os elementos construtivos pode ser vista no Anexo 1.

\subsubsection{Modelo de Cargas Internas do Edifício}

Finalizando a entrada de dados do edifício no programa EnergyPlus, passouse a modelar as cargas internas. Em outras palavras, as cargas internas ao edifício representam as taxas pelas quais os elementos internos (pessoas, iluminação, computadores, infiltração de ar) contribuem para a carga térmica. O EnergyPlus exige que alguns parâmetros desse tipo sejam informados pelo usuário. No caso da presente simulação, os principais dados informados são os seguintes:

Tabela 3.4 - Dados de entrada das cargas internas para simulação no EnergyPlus.

\begin{tabular}{|c|c|}
\hline Descrição dos Parâmetros & $\begin{array}{c}\text { Dado de Entrada } \\
\text { para o EnergyPlus }\end{array}$ \\
\hline Iluminação & $12 \mathrm{~W} / \mathrm{m}^{2}$ \\
\hline Equipamento & $20 \mathrm{~W} / \mathrm{m}^{2}$ \\
\hline Pessoas & $0,1 \mathrm{pessoa} / \mathrm{m}^{2}$ \\
\hline Infiltração (não inclui renovação de ar) & $0.045 \mathrm{~m}^{3} / \mathrm{s} \mathrm{por} \mathrm{zona}$ \\
\hline
\end{tabular}

Ao se observar a Tabela 3.4, é importante lembrar que esses parâmetros correspondem à taxas de calor dissipadas pelos elementos de iluminação, equipamentos e pessoas e, portanto, representam as taxas máximas pelas quais os elementos internos à edificação contribuem para a carga térmica. Dessa forma, os valores em $\mathrm{W} / \mathrm{m}^{2}$ expressados na Tabela 3.4 correspondem às taxas de calor dissipadas e não de energia elétrica consumida, embora ambos os valores sejam numericamente muito semelhantes (ASHRAE, 2010).

Além disso, o programa EnergyPlus possibilita a definição de perfis de variação dos parâmetros ao longo do tempo (dia, mês, ano) através dos objetos do programa chamados de "schedules" que podem ser especificados no arquivo IDF de 
entrada. Esses perfis de variação foram adotados a fim de conferir maior realidade aos dados e de simular as variações de ocupação de uso de equipamentos e de iluminação, ao longo do dia. Por hipótese, adotou-se o seguinte perfil de variação diária de cargas internas:

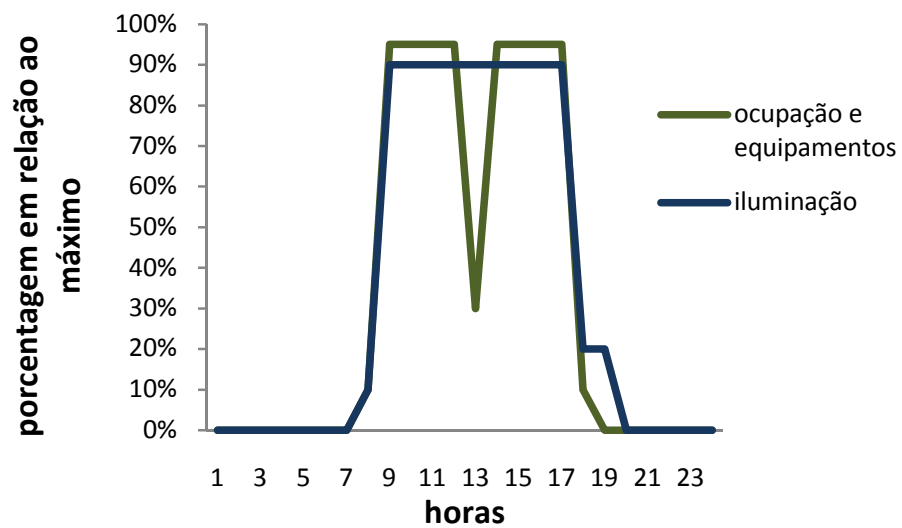

Figura 3.13 - Perfil adotado para ocupação, equipamentos e iluminação ao longo do dia.

Os perfis adotados derivam dos próprios arquivos de exemplo do programa, disponibilizados por ocasião da instalação do software, e procuram exprimir os comportamentos usuais das cargas internas dos edifícios de escritórios. Outra hipótese importante considerada na análise foi o horário de funcionamento do sistema de ar condicionado. Esse parâmetro é definido também através de um objeto de "schedule" do EnergyPlus e adotou-se, por hipótese, o horário das 9 horas da manhã às 18 horas da tarde.

Uma lista completa com os objetos do EnergyPlus adotados para a simulação pode ser encontrada no Anexo 1.

\subsubsection{Modelo Climático e Geográfico}

Para a simulação no EnergyPlus foi necessário, por fim, a definição de dados climáticos e geográficos em relação aos quais o comportamento do edifício seria analisado. 
Para isso, definiu-se as informações geográficas da simulação com os dados da Tabela 3.5, a seguir:

Tabela 3.5 - Informações geográficas utilizadas para simulação no EnergyPlus.

\begin{tabular}{|c|c|}
\hline Descrição dos Parâmetros & $\begin{array}{c}\text { Dado de Entrada para o } \\
\text { EnergyPlus }\end{array}$ \\
\hline Local & São Paulo - SP \\
\hline Característica do entorno & Cidade (urbano) \\
\hline Latitude & $-23,62^{\circ}$ \\
\hline Longitude & $-46,65^{\circ}$ \\
\hline Altitude & $803 \mathrm{~m}$ \\
\hline
\end{tabular}

Os dados climáticos para a simulação foram obtidos do banco de dados do próprio EnergyPlus, disponibilizado no web site do Departamento de Energia dos Estados Unidos (DOE), em extensão ".epw". No caso específico deste trabalho, utilizaram-se os dados do arquivo BRA_Sao.Paulo-Congonhas_SWERA.epw, chamado de "Weather File" referente à cidade de São Paulo. $O$ arquivo contém informações climáticas da localidade em questão ao longo de todo o ano.

Para efeito dessa pesquisa, o desempenho dos sistemas de ar condicionado solar foram estudados para dois dias do ano: o dia 21 de junho a fim de contemplar uma situação de inverno, e o dia 21 de dezembro, a fim de contemplar uma situação de verão.

Isso foi feito utilizando-se 0 arquivo climático anual e especificando dois períodos de simulação, contendo os dias simulados através do objeto "RunPeriod" do EnergyPlus, conforme a Figura 3.14, a seguir: 


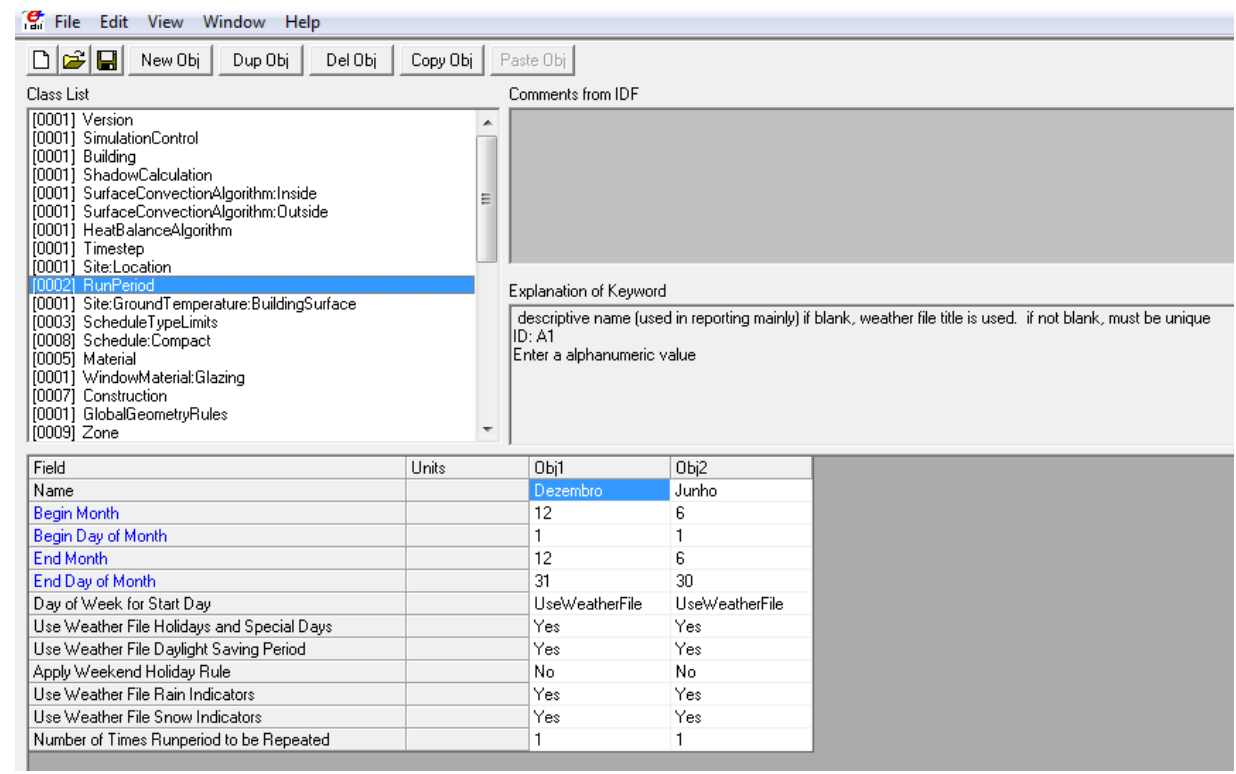

Figura 3.14 - Interface do usuário do EnergyPlus mostrando a escolha do período de simulação, no qual será utilizado o dia 21 de junho e o dia 21 de dezembro.

Dessa forma, as condições climáticas contidas no "Weather File" foram utilizadas na simulação dos dias 21 de junho e 21 de dezembro, expressando as condições da cidade de São Paulo, nestes dias do ano.

\subsection{Análise Energética dos Sistemas de Ar Condicionado Solar}

Até aqui, foi apresentado o método pelo qual as cargas térmicas do edifício foram calculadas. Esse processo consistiu, a partir de algumas hipóteses, na modelagem do edifício pelo software EnergyPlus e no cálculo da carga térmica para cada hora do dia 21 de junho e do dia 21 de dezembro, por meio das equações apresentadas. Esses valores de carga térmica, que representam a demanda por condicionamento de ar do edifício, devem, a princípio, ser atendidos pelos sistemas de ar condicionado solar em estudo.

Até esse ponto, porém, os sistemas de condicionamento de ar não foram ainda considerados, pois apenas a carga térmica do edifício foi obtida, representando a energia térmica que deve ser retirada do edifício, por esses 
sistemas de ar condicionado, a fim de que se mantenha nas condições de conforto térmico.

Para considerar, portanto, o funcionamento desses sistemas de ar condicionado solar, um método de análise energética dos sistemas de ar condicionado solar foi adotado. Esse método é derivado de uma formulação presente na literatura (Guidelines SOLAIR, 2008) e será descrito a seguir.

\subsubsection{Método de Análise Energética dos Sistemas de Ar Condicionado Solar}

\subsubsection{Método de Cálculo do Consumo de Energia Primária Proposto pelo Projeto} "SOLAIR" da União Européia

No período de janeiro de 2007 a dezembro de 2009, a Comissão Européia órgão executivo da União Européia - através do Programa "Intelligent Energy Europe", com parcerias de institutos de pesquisas, empresas de consultoria, indústrias, instituições públicas e privadas, lançou o Projeto SOLAIR (Solar Air Conditioning for Europe).

Esse projeto teve como objetivo promover o fortalecer a utilização de sistemas de ar condicionado solar através da implementação de sistemas, da difusão do conhecimento sobre a tecnologia, da criação de ferramentas e instrumentos para a expansão de mercado, do estabelecimento de metas de crescimento e da disseminação da tecnologia a nível nacional e internacional.

Dentre as documentações produzidas pelo projeto SOLAIR, é possível obter um documento intitulado "Guidelines" com as principais diretrizes de análise e projeto desses sistemas. Nesse documento é apresentado um método de análise do desempenho energético de sistemas de ar condicionado solar, baseado no cálculo do Consumo de Energia Primária.

O consumo de energia primária de um sistema corresponde ao consumo de energia na fonte primária original, isto é, antes das transformações que levaram ao uso final do recurso energético. 
O Método apresentado pelo SOLAIR calcula o consumo de energia primária $\left(E_{0} \text {, em } \mathrm{kWh}\right)^{14}$, por um determinado período de tempo ${ }^{15}$, para dois tipos de sistemas de ar condicionado (sistemas a) e b) abaixo):

a) Sistema de ar condicionado solar térmico, conforme apresentado no item 3.1.2 (Figuras 3.3 e 3.5 );

b) Sistema de ar condicionado convencional elétrico, conforme apresentado no item 3.1.2 (Figura 3.7);

Para o sistema (a), solar térmico, esse cálculo é feito, para o período estudado, a partir dos valores de energia térmica retirada do edifício $\left(Q_{c o l d}\right.$, em $\mathrm{kWh}$ ), a partir da fração solar do sistema ( $s$ ), do coeficiente de performance do chiller solar $\left(\mathrm{COP}_{S}\right)$ e de parâmetros de eficiência do sistema $\left(\eta_{1}, \eta_{2}, \eta_{3}, f_{1}, f_{2}, f_{3}\right)$ relacionados, por sua vez, à demanda de energia dos subsistemas presentes na instalação.

Assim, o cálculo do consumo de energia primária de um sistema de ar condicionado solar térmico $\left(E_{0, \text { térmico }}\right)$, de acordo com o método apresentado no documento "Guidelines" do projeto SOLAIR, pode ser resumido pela eq.(7) e eq.(8), a seguir:

$$
\begin{aligned}
& E_{0, \text { térmico }}=\frac{Q_{\text {cold }}}{\operatorname{COP}_{S}} \times K \\
& K=\frac{(1-s)}{\eta_{1} \times \eta_{2}}+\frac{s \times f_{1}}{\eta_{3}}+\frac{C O P_{S} \times f_{2}}{\eta_{3}}+\frac{f_{3} \times\left(\operatorname{COP}_{S}+1\right)}{\eta_{3}}
\end{aligned}
$$

\footnotetext{
${ }^{14}$ No documento "Guidelines" do Projeto SOLAIR, o consumo de energia primária é representado por $P E_{C}$ em kWh, porém nesse trabalho será representado por $E_{0}$.

${ }^{15}$ O termo "consumo de energia primária" utilizado no texto, foi traduzido para este trabalho do termo em inglês "primary energy demand", em kWh, presente no documento do Projeto SOLAIR. Na realidade, a formulação apresentado pelo SOLAIR calcula o consumo de energia durante um intervalo de tempo, em kWh, chamado de $P E_{C}$, supondo uma demanda constante de condicionamento de ar nesse período.
} 
sendo:

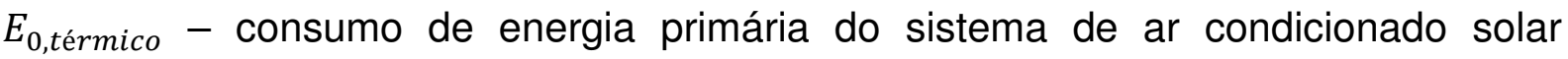
térmico, no período estudado (kWh).

$\mathrm{COP}_{S}$ - Coeficiente de Performance do chiller solar de absorção (adm.).

$Q_{\text {cold }}$ - energia térmica retirada do edifício pelo sistema de condicionamento de ar, no período estudado (kWh).

$s$ - fração solar do sistema (\%).

$\eta_{1}$ - eficiência do aquecedor auxiliar (\%).

$\eta_{2}$ - eficiência energética primária do combustível fóssil utilizado no aquecedor auxiliar (\%).

$\eta_{3}$ - eficiência energética primária da eletricidade da rede (\%).

$f_{1}$ - demanda específica de eletricidade da instalação solar (razão entre o consumo de energia elétrica da instalação solar e a energia térmica produzida pelos coletores) (\%).

$f_{2}$ - demanda específica de eletricidade do chiller solar (razão entre o consumo de energia elétrica do chiller solar e a energia térmica retirada do edifício pelo chiller solar) (\%).

$f_{3}$ - demanda específica de eletricidade do chiller solar (razão entre o consumo de energia elétrica do sistema de rejeição de calor, isto é, das torres de resfriamento, e a energia térmica retirada) (\%).

Para o sistema (b), convencional elétrico, esse cálculo é feito, para o período estudado, a partir dos valores de energia térmica retirada do edifício $\left(Q_{c o l d}\right.$, em kWh), a partir do coeficiente de performance do chiller convencional de compressão de vapor $\left(C O P_{C V}\right)$ e do parâmetro de eficiência do sistema $\left(\eta_{3}\right)$ relacionado à alimentação de energia pela rede elétrica.

Assim, o cálculo do consumo de energia primária de um sistema de ar condicionado convencional $\left(E_{0, c o n v}\right)$, de acordo com o método apresentado no documento "Guidelines" do projeto SOLAIR, pode ser resumido pela eq.(9) e eq.(10), a seguir: 


$$
\begin{aligned}
& E_{0, \text { conv }}=\frac{Q_{\text {cold }}}{\operatorname{COP}_{C V}} \times K \\
& K=\frac{1}{\eta_{3}}
\end{aligned}
$$

sendo:

$E_{0, \text { térmico }}$ - consumo de energia primária do sistema de ar condicionado convencional, no período estudado (kWh).

$C O P_{C V}$ - Coeficiente de Performance do chiller elétrico de compressão de vapor (adm.).

$Q_{\text {cold }}$ - energia térmica retirada do edifício pelo sistema de condicionamento de ar, no período estudado (kWh).

$\eta_{3}$ - eficiência energética primária da eletricidade da rede (\%).

Assim, através da eq.(7) e eq.(8), pode-se calcular o consumo de energia primária do sistema de ar condicionado solar térmico $\left(E_{0, t e ́ r m i c o}\right)$, conforme definido no item 3.1.2, e por meio da eq. (9) e eq.(10), pode-se calcular o consumo de energia primária do sistema de ar condicionado convencional, conforme definido também no item 3.1.2. Esse é o método de análise de desempenho energético dos sistemas de ar condicionado solar apresentado pelo projeto SOLAIR.

\subsubsection{Comentários sobre o Método Proposto pelo Projeto "SOLAIR"}

Com relação ao método de análise energética dos sistemas de ar condicionado solar, proposto pelo Projeto $S O L A I R$, dois comentários importantes devem ser feitos: 
(1) O cálculo proposto pelo método determina os valores de consumo de energia primária do sistema de ar condicionado e não de consumo de energia do sistema de ar condicionado no próprio edifício, no local de uso.

(2) O método não contempla a análise energética do sistema de ar condicionado solar elétrico, que como foi apresentado anteriormente, é objeto de estudo desta pesquisa.

Com relação ao comentário (1), pode-se dizer que, no contexto desta pesquisa, que estuda a aplicação desses sistemas especificamente no caso da cidade de São Paulo, localizada no Brasil, obter uma avaliação do consumo de energia primária não apresenta um significado tão importante quanto na Europa.

Em outras palavras, o estudo da energia primária, que, de forma geral, avalia o consumo energético das reservas de combustível fóssil, faz mais sentido em um país com uma matriz energética majoritariamente baseada em combustíveis fosséis. Além disso, o detalhamento de energia primária não é o foco do presente trabalho.

No Brasil, de fato, de acordo com a Resenha Energética Nacional de 2010, do Ministério de Minas e Energia, 47,2\% da matriz energética nacional, no ano de 2009, era composta de renováveis e $52,8 \%$ de não renováveis (MME, 2010). Isso faz com que a análise de energia primária não convenha para o Brasil.

Entretanto, a atenção dada ao problema energético, ao papel dos sistemas de condicionamento de ar e ao papel da energia solar como fonte de energia, apresentadas no capítulo 1 , continuam válidas para a realidade nacional, já que a redução do consumo (e da demanda) de energia dos sistemas de ar condicionado e sua eficiência energética permanecem, também no caso do Brasil, sendo objetivos de sustentabilidade para os edifícios de escritórios.

No que diz respeito ao comentário (2) acima, deduz-se da mesma forma, que - método SOLAIR, da forma como é apresentado, também não atende completamente a proposta da pesquisa, que pretende analisar não somente a alternativa de ar condicionado solar térmica, mas também a alternativa de ar condicionado solar elétrica.

De fato, o método apresentado no documento "Guidelines" do Projeto SOLAIR contempla somente a análise do sistema de ar condicionado solar térmico, 
pelas eq.(7) e eq.(8), e de um sistema de ar condicionado convencional elétrico, pelas eq.(9) e eq.(10).

Em resumo, considerando-se os comentários acima, propõem-se, a partir desse ponto do texto, algumas alterações e adaptações no método do SOLAIR, a fim de que as limitações apresentadas pelos comentários (1) e (2) não prejudiquem os objetivos dessa pesquisa.

\subsubsection{Adaptação no Método Proposto pelo Projeto "SOLAIR"}

Como explicado no item anterior, passa-se, neste item, a adaptar o método proposto no Projeto SOLAIR para o caso dessa pesquisa. Em primeiro lugar, devese procurar obter não o consumo de energia primária do sistema de ar condicionado (na fonte), mas o consumo de energia do sistema no local de sua operação, isto é, no próprio edifício.

Substituindo $K$ da eq.(8) na eq.(9), e desenvolvendo-se a equação resultante obtém-se que:

$$
\begin{aligned}
& E_{0, \text { térmico }}=\frac{Q_{\text {cold }}}{C O P_{S}} \times\left\{\frac{(1-s)}{\eta_{1} \times \eta_{2}}+\frac{s \times f_{1}}{\eta_{3}}+\frac{C O P_{S} \times f_{2}}{\eta_{3}}+\frac{f_{3} \times\left(C O P_{S}+1\right)}{\eta_{3}}\right\} \\
& E_{0, \text { térmico }}=\underbrace{\left[\frac{Q_{\text {cold }}}{\operatorname{COP}} \times \frac{(1-s)}{\eta_{1} \times \eta_{2}}\right]}_{A}+\underbrace{\left[\frac{Q_{\text {cold }}}{C O P_{S}} \times \frac{s \times f_{1}}{\eta_{3}}\right]}_{B}+\underbrace{\left[\frac{Q_{\text {cold }}}{C O P_{S}} \times \frac{C O P_{S} \times f_{2}}{\eta_{3}}\right]}_{C}+\underbrace{\left[\frac{Q_{\text {cold }}}{C O P_{S}} \times \frac{f_{3} \times\left(C O P_{S}+1\right)}{\eta_{3}}\right]}_{D}
\end{aligned}
$$

Chamando cada termo da eq.(12) de A, B, C e D, tem-se que:

$$
A=\left[\frac{Q_{\text {cold }}}{\operatorname{COP}_{S}} \times \frac{(1-s)}{\eta_{1} \times \eta_{2}}\right]
$$




$$
\begin{aligned}
& B=\left[\frac{Q_{\text {cold }}}{\operatorname{COP} S} \times \frac{s \times f_{1}}{\eta_{3}}\right] \\
& C=\left[\frac{Q_{\text {cold }}}{\operatorname{COP} S} \times \frac{\operatorname{COP}_{S} \times f_{2}}{\eta_{3}}\right] \\
& D=\left[\frac{Q_{\text {cold }}}{\operatorname{COP}_{S}} \times \frac{f_{3} \times\left(\mathrm{COP}_{S}+1\right)}{\eta_{3}}\right]
\end{aligned}
$$

Supõe-se, por hipótese, que no período considerado para o cálculo de $E_{0, \text { térmico }}$, o valor de $C_{S O P}$ e de $s$ se mantenham constantes. Assim, a energia térmica $Q_{a u x}$, em kWh, que é fornecida à água de alimentação do chiller solar, por parte do aquecedor auxiliar operando a base de combustível fóssil, no período estudado, pode ser escrita como:

$$
Q_{\text {aux }}=\frac{Q_{\text {cold }}}{\operatorname{COP}_{S}} \times(1-s)
$$

sendo:

$Q_{a u x}$ - energia térmica fornecida à água pelo aquecedor auxiliar, no período estudado (kWh).

$\mathrm{COP}_{S}$ - Coeficiente de Performance do chiller solar de absorção (adm.).

$Q_{\text {cold }}$ - energia térmica retirada do edifício pelo sistema de condicionamento de ar, no período estudado (kWh).

$s$ - fração solar do sistema no período considerado (\%).

Se o valor de $Q_{a u x}$ representa a energia térmica que é transferida para a água pelo aquecedor auxiliar, sendo $\eta_{1}$ a eficiência do aquecedor auxiliar, o valor da energia térmica total consumida pelo aquecedor auxiliar $\left(E_{T, a u x}\right.$, em $\left.\mathrm{kWh}\right)$ pode ser representada pela eq.(18), a seguir: 


$$
E_{T, a u x}=\frac{Q_{a u x}}{\eta_{1}}
$$

sendo:

$E_{T, \text { aux }}$ - energia térmica total consumida pelo aquecedor auxiliar (operando com combustível fóssil) (kWh).

$Q_{a u x}$ - energia térmica fornecida à água pelo aquecedor auxiliar, no período estudado (kWh).

$\eta_{1}$ - eficiência do aquecedor auxiliar (\%), isto é, razão entre a energia térmica que efetivamente é transmitida à água e a energia térmica consumida do combustível fóssil.

Substituindo-se a eq.(18) na eq.(17) e a eq.(17) na eq.(13), obtém-se uma nova expressão para o termo $A$ :

$$
A=\frac{E_{T, a u x}}{\eta_{2}}
$$

sendo:

$E_{T, \text { aux }}$ - energia térmica total consumida pelo aquecedor auxiliar (operando com combustível fóssil) (kWh).

$\eta_{2}$ - eficiência energética primária do combustível fóssil utilizado no aquecedor auxiliar (\%), representando a razão entre a energia térmica total consumida pelo combustível e a energia primária consumida correspondente a essa utilização do combustível fóssil.

Assim, o consumo de energia térmica, em kWh, do aquecedor auxiliar do sistema de ar condicionado solar térmico no local de uso $\left(E_{T, a u x}\right)$, dividido pela eficiência de conversão da energia primária em combustível para o aquecedor $\left(\eta_{2}\right)$, que é menor que 1, resulta em um consumo de energia primária devido ao aquecedor auxiliar $\left(E_{0_{T, a u x}}\right)$ numericamente maior do que o consumo devido ao aquecedor auxiliar levando-se em conta apenas o uso final $\left(E_{T, \text { aux }}\right)$. 
De fato, o fator $\eta_{2}$ leva em conta as perdas de energia em todo o processo de transmissão e transformação desde a fonte energética primária até seu uso final. Por isso, tem-se $\eta_{2}<1$ e conseqüentemente:

$$
E_{0_{T, a u x}}>E_{T, a u x}
$$

sendo:

$E_{0_{T, a u x}}$ - energia primária consumida pelo aquecedor auxiliar (operando com combustível fóssil) (kWh).

$E_{T, \text { aux }}$ - energia térmica total consumida pelo aquecedor auxiliar (operando com combustível fóssil) (kWh).

Analogamente ao termo $A$, os termos $B, C$ e $D$ da eq.(12) também podem ser desenvolvidos de forma que resultem nas expressões das eq.(21) à eq.(23):

$$
\begin{aligned}
& B=\frac{E_{E, \text { instalação solar }}}{\eta_{3}}=E_{0_{E, \text { instalação solar }}} \\
& C=\frac{E_{E, \text { chiller solar }}}{\eta_{3}}=E_{0_{E, \text { chiller solar }}} \\
& D=\frac{E_{E, \text { torre de resf }}}{\eta_{3}}=E_{0_{E, \text { torre de resf }}}
\end{aligned}
$$

sendo:

$E_{E, \text { instalação solar }}$ - energia elétrica consumida pela instalação dos coletores solares, no período estudado (kWh).

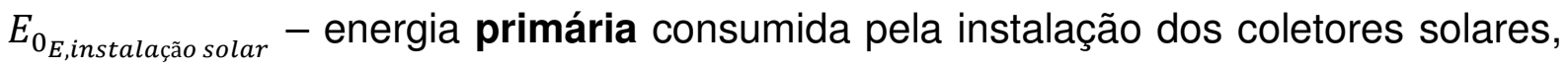
no período estudado (kWh). 
$E_{E, \text { chiller solar }}$ - energia elétrica consumida pelo chiller solar, no período estudado (kWh).

$E_{0_{E, \text { chiller solar }}}$ - energia primária consumida pelo chiller solar, no período estudado (kWh).

$E_{E, \text { torre de resf }}$ - energia elétrica consumida pela torre de resfriamento, no período estudado (kWh).

$E_{0_{E, \text { torre deresf }}}$ - energia primária consumida pela torre de resfriamento, no período estudado (kWh).

$\eta_{3}$ - eficiência energética primária da eletricidade da rede (\%), $\eta_{3}<1$.

Dessa forma, os consumos de energia térmica, em kWh, dos subsistemas do ar condicionado solar térmico (instalação solar, chiller solar e torre de resfriamento) no local de uso ( $\left.E_{E, \text { instalação solar, }} E_{E \text {,chiller solar, }} E_{E, \text { torre de resf }}\right)$, divididos pela eficiência de conversão da energia primária da eletricidade da rede $\left(\eta_{3}\right)$, que é menor que 1, resulta em um consumo de energia primária devido aos subsistemas

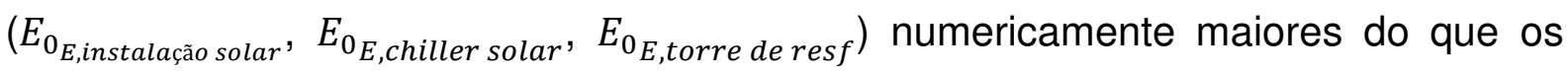
consumos devidos aos subsistemas levando-se em conta apenas o uso final.

Com as expressões das eq.(19), eq.(21), eq.(22) e eq.(23), pode-se reescrever a eq.(12) do consumo de energia primária do sistema de ar condicionado solar térmico ( $\left.E_{0, \text { térmico }}\right)$, da seguinte forma:

$$
E_{0, \text { térmico }}=A+B+C+D=\frac{E_{T, \text { aux }}}{\eta_{2}}+\frac{E_{E, \text { instalação solar }}}{\eta_{3}}+\frac{E_{E, \text { chiller solar }}}{\eta_{3}}+\frac{E_{E, \text { torre de resf }}}{\eta_{3}}
$$

A fim de obter-se somente o consumo final de energia do sistema no local de uso, já que, conforme discutido no item anterior, a obtenção do consumo de energia primária não é o foco desta pesquisa, basta deixar de dividir os membros da eq.(24) pelas eficiências de conversão da energia primária $\eta_{2}$ e $\eta_{3}$. 
Assim, ao invés de se obter o consumo de energia primária do sistema $\left(E_{0, t e ́ r m i c o}\right)$, obter-se-ia o consumo de energia do sistema de ar condicionado solar no local de uso. Entretanto, não é possível retirar-se os coeficientes $\eta_{2}$ e $\eta_{3}$ pois, se for feito, o resultado não teria significado físico, já que, estar-se-ia somando energia

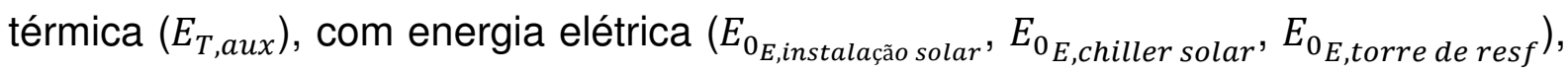
o que não é admissível.

Portanto, mais uma modificação no método SOLAIR foi introduzida a fim de possibilitar a análise. Considerou-se, por hipótese, que o aquecedor auxiliar do sistema de ar condicionado solar térmico em análise é um aquecedor elétrico, diferentemente do aquecedor baseado em combustível fóssil do método europeu.

Com isso, o termo $A$ da eq.(24) deve levar em conta o consumo elétrico do aquecedor auxiliar. Para isso, deve-se tomar a eficiência do aquecedor elétrico $\eta_{e}$ utilizado, que nessa pesquisa, foi considerado por hipótese, baseado nos valores usuais de mercado, como sendo de $80 \%$.

Escrevendo a definição dessa eficiência $\eta_{e}$, tem-se:

$$
\eta_{e}=\frac{Q_{a u x}}{E_{E, \text { aux }}}
$$

sendo:

$E_{E, \text { aux }}$ - energia elétrica total consumida pelo aquecedor auxiliar (operando com eletricidade) (kWh).

$Q_{a u x}$ - energia térmica fornecida à água pelo aquecedor auxiliar, no período estudado (kWh).

$\eta_{e}$ - eficiência do aquecedor elétrico (\%).

Substituindo o valor de $Q_{a u x}$ da eq.(18) na eq.(25) e isolando o valor de $E_{E, a u x}$ obtém-se:

$$
E_{E, a u x}=E_{T, a u x} \times\left\{\frac{\eta_{1}}{\eta_{e}}\right\}
$$


sendo:

$E_{E, \text { aux }}$ - energia elétrica total consumida pelo aquecedor auxiliar (operando com eletricidade) (kWh).

$E_{T, a u x}$ - energia térmica total consumida pelo aquecedor auxiliar (operando com combustível fóssil) (kWh).

$\eta_{e}$ - eficiência do aquecedor auxiliar elétrico (\%).

$\eta_{1}$ - eficiência do aquecedor auxiliar (\%).

Substituindo o valor de $E_{T, a u x}$ da eq.(17) e eq.(18) na eq.(26) obtém-se:

$$
E_{E, \text { aux }}=\frac{Q_{\text {cold }}}{\operatorname{COPS}_{S}} \times(1-s) \times\left(\frac{1}{\eta_{e}}\right)
$$

Reescrevendo-se, portanto, a eq.(24), agora com a consideração do aquecedor elétrico, torna-se possível a retirada os coeficientes $\eta_{2}$ e $\eta_{3}$ e soma das parcelas, obtendo o consumo de energia elétrica do sistema de ar condicionado solar térmico $\left(E_{\text {térmico }}\right.$ ), no local do uso final, em $\mathrm{kWh}$, para o período considerado, conforme a eq.(28):

$$
E_{\text {térmico }}=E_{E, \text { aux }}+E_{E \text {,instalação solar }}+E_{E, \text { chiller solar }}+E_{E, \text { torre de resf }}
$$

E, por fim, colocando a eq.(24) escrita com os parâmetros do sistema obtémse:

$$
\begin{aligned}
& E_{\text {térmico }}=\frac{Q_{\text {cold }}}{\operatorname{COP}_{S}} \times K \\
& K=\left[(1-s) \times\left(\frac{\mathbf{1}}{\eta_{e}}\right)\right]+\left[s \times f_{1}\right]+\left[\operatorname{COP}_{S} \times f_{2}\right]+\left[f_{3} \times\left(\operatorname{COP}_{S}+1\right)\right]
\end{aligned}
$$


sendo:

$E_{\text {térmico }}$ - consumo de energia elétrica do sistema de ar condicionado solar térmico, no local de uso final, no período estudado (kWh).

$\mathrm{COP}_{S}$ - Coeficiente de Performance do chiller solar de absorção (adm.).

$Q_{\text {cold }}$ - energia térmica retirada do edifício pelo sistema de condicionamento de ar, no período estudado (kWh).

$s$ - fração solar do sistema (\%).

$\eta_{e}$ - eficiência do aquecedor auxiliar elétrico (\%).

$f_{1}$ - demanda específica de eletricidade da instalação solar (razão entre o consumo de energia elétrica da instalação solar e a energia térmica produzida pelos coletores) $(\%)$.

$f_{2}$ - demanda específica de eletricidade do chiller solar (razão entre o consumo de energia elétrica do chiller solar e a energia térmica retirada do edifício pelo chiller solar) (\%).

$f_{3}$ - demanda específica de eletricidade do chiller solar (razão entre o consumo de energia elétrica do sistema de rejeição de calor, isto é, das torres de resfriamento, e a energia térmica retirada) (\%).

Enfim, com a eq.(29) e eq.(30), ao invés da eq.(7) e eq.(8), elimina-se, no cálculo do desempenho energético do sistema de ar condicionado solar térmico, o problema de se considerar energia primária, que não possui sentido prático no contexto dessa pesquisa.

Para o sistema de ar condicionado convencional, definido pela Figura 3.7, a não consideração da energia primária pode ser efetuada, da mesma forma, com a desconsideração do fator $\eta_{3}$ da eq.(10). Assim, com a eq.(31) e eq.(32) a seguir, ao invés da eq.(9) e eq.(10), elimina-se o problema de se considerar energia primária, também no cálculo do desempenho energético do sistema de ar condicionado convencional.

$$
\begin{aligned}
& E_{\text {conv }}=\frac{Q_{\text {cold }}}{\operatorname{COP}_{C V}} \times K \\
& K=1
\end{aligned}
$$


sendo:

$E_{c o n v}$ - consumo de energia do sistema de ar condicionado convencional, no local de uso final, no período estudado (kWh).

$C O P_{C V}$ - Coeficiente de Performance do chiller elétrico de compressão de vapor (adm.).

$Q_{\text {cold }}$ - energia térmica retirada do edifício pelo sistema de condicionamento de ar, no período estudado (kWh).

Com as adaptações feitas até aqui, pode-se considerar que a limitação apresentada ao comentário (1) do item 3.3.1.2, anterior, de calcular-se energia primária, foi resolvida.

Entretanto, deve-se fazer ainda mais uma adaptação ao método SOLAIR de modo que leve em conta o comentário (2) do item anterior e considere também o sistema elétrico de ar condicionado solar. Para isso, de acordo com as concepções dos sistemas apresentados no início desse capítulo, basta subtrair da energia consumida pelo chiller elétrico do sistema de ar condicionado convencional, a energia fotovoltaica produzida no mesmo período, de acordo com a eq.(33), a seguir:

$$
E_{\text {elétrico }}=\frac{Q_{\text {cold }}}{\operatorname{COP}_{C V}}-P_{f v}
$$

sendo:

$E_{\text {elétrico }}$ - consumo de energia do sistema de ar condicionado solar elétrico, no local de uso final, no período estudado (kWh).

$\mathrm{COP}_{C V}$ - Coeficiente de Performance do chiller elétrico de compressão de vapor (adm.).

$Q_{\text {cold }}$ - energia térmica retirada do edifício pelo sistema de condicionamento de ar, no período estudado (kWh).

$P_{f v}$ - produção de energia fotovoltaica pelos painéis nas fachadas, no período estudado (kWh). 
Assim, com o método adaptado apresentado neste item, será possível analisar o consumo de energia dos sistemas de ar condicionado térmico, elétrico e convencional em estudo, de forma que seja possível estudar seus desempenhos energéticos.

3.3.2 Determinação dos Parâmetros a serem utilizados no Método de Análise Energética dos Sistemas de Ar Condicionado Solar

Para a aplicação do método adaptado do Projeto SOLAIR, apresentado no item anterior, os parâmetros envolvidos na análise devem ser determinados. Esse item 3.3.2, mostra como serão determinados os parâmetros envolvidos no cálculo do consumo de energia dos sistemas de ar condicionado, pelas equações apresentadas anteriormente.

Como foi dito até aqui, os valores de consumo de energia elétrica, seja do sistema de ar condicionado solar térmico $\left(E_{\text {térmico }}\right)$, seja do sistema de ar condicionado solar elétrico ( $\left.E_{\text {elétrico}}\right)$, seja do sistema de ar condicionado convencional $\left(E_{\text {conv }}\right)$ correspondem a um valor em $\mathrm{kWh}$, referente a um determinado período de tempo $\Delta \mathrm{T}$. Nesse período, de acordo com as eq.(29), eq.(31) e eq.(33), o ar condicionado retira do ambiente a energia térmica expressa por $Q_{\text {cold }}$ em $\mathrm{kWh}$.

Pelo método proposto, durante o período $\Delta \mathrm{T}$ considerado para o cálculo dos consumos de energia elétrica dos sistemas, os parâmetros não poderão variar, já que deverão ter um valor fixo para ser utilizado nas eq.(29), eq.(31) e eq.(33). Os valores dos parâmetros $Q_{\text {cold }}$ e $P_{f v}$ das eq.(29), eq.(31) e eq.(33) que expressam energia durante o período de tempo $\Delta \mathrm{T}$, dependem da duração do período.

Já os parâmetros que possuem valores instantâneos $\left(C O P_{S}\right.$, $\left.\operatorname{COP}_{C V}, f_{1}, f_{2}, f_{3}, \eta_{e}, s\right)$ serão considerados, por hipótese, constantes no decorrer do período de tempo $\Delta \mathrm{T}$ utilizado para o cálculo de $E_{\text {térmico }}, E_{\text {elétrico }}$ e de $E_{c o n v}$.

Por hipótese, foi definido que, para o cálculo desse trabalho, o período para cada determinação do consumo elétrico (no qual os parâmetros instantâneos serão considerados constantes) será de uma hora $(\Delta T=1 \mathrm{~h})$. Assim, para o dia 21 de junho, 
haverão 24 determinações do consumo de energia dos sistemas de ar condicionado, assim como para o dia 21 de dezembro, uma para cada hora do dia.

Cada hora $i$ do dia 21 de junho e do dia 21 de dezembro terá um valor calculado de $E_{\text {térmico }}, E_{\text {elétrico }}$ e de $E_{\text {conv }}$ sendo chamados de $E_{\text {térmico }, i}, E_{\text {elétrico }, i}$ e de $E_{c o n v, i}$. Para cada uma dessas horas, como foi dito, os valores dos parâmetros instantâneos serão considerados constantes $\left(C O P_{S}, C O P_{C V}, f_{1}, f_{2}, f_{3}, \eta_{e}, s\right)$.

Por hipótese, adota-se também, que desses parâmetros instantâneos somente o valor da fração solar $s$ poderá variar de hora para hora do dia. Os demais parâmetros $\left(C O P_{S}, C O P_{C V}, f_{1}, f_{2}, f_{3}, \eta_{e}\right)$, portanto, permanecerão constantes não somente ao longo de cada hora, mas também de todo o dia e terão seus valores arbitrados para o estudo (Tabelas 3.5, 3.6 e 3.6, do próximo item), baseados em referências da literatura ou de mercado.

Sendo, portanto, essas grandezas arbitradas, por hipótese, os únicos parâmetros que restam para serem determinados são os valores de $Q_{c o l d}, P_{f v}$ e de $s$, já que o método proposto pelo SOLAIR não especifica sua determinação. Sendo assim, seu cálculo será detalhado a seguir.

A energia retirada das zonas do edifício pelo sistema de ar condicionado $Q_{\text {cold }}$, em kWh, depende dos valores de carga térmica instantânea $Q(t)$ atuantes na edificação, no período $\Delta \mathrm{T}$. Como foi dito acima, o período $\Delta \mathrm{T}$ considerado para cada cálculo de $Q_{\text {cold }}$ é de 1 hora.

Pela simulação realizada no EnergyPLus, os valores obtidos de carga térmica, são valores médios de cada hora do dia, definidos e calculados, para o edifício de $N$ pavimentos ( $Q_{\text {edifícion, } i}$ ) pela eq.(4), apresentada neste capítulo.

Assim, para a determinação de $Q_{\text {cold }}$ para cada hora $i$ do dia, basta multiplicar o valor encontrado de $Q_{\text {edifícioN,i }}$ da carga térmica na hora $i$ obtido pela eq.(4), por 1 hora (Figura 3.15). 


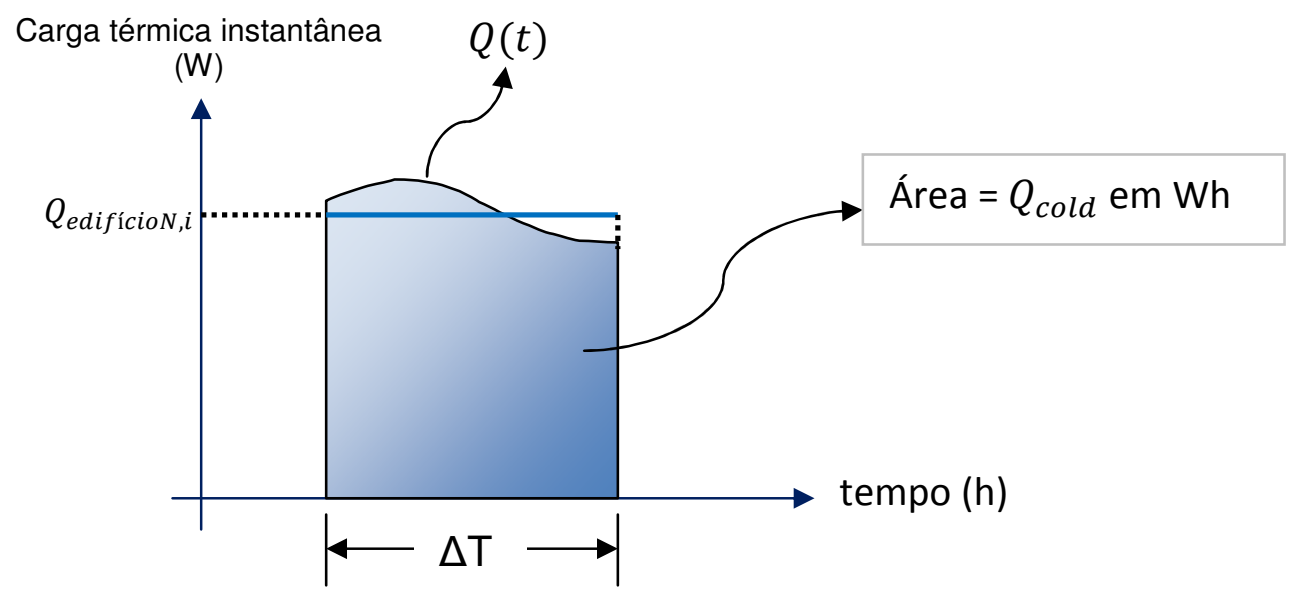

Figura 3.15 - Representação gráfica do comportamento da função carga térmica $Q(t)$ ao longo do tempo.

Portanto, para o edifício de $N$ pavimentos, pode-se determinar o valor de $Q_{\text {cold }}$ em Wh, para cada hora $i$ do dia estudado, multiplicando-se o valor da carga térmica $Q_{\text {edifícion,i }}$ em W, obtido na eq.(4), a partir dos resultados da simulação no EnergyPlus do pavimento térreo $q_{\text {térreo,i }}$, para o pavimento intermediário $q_{10^{\circ} P A V, i}$ e para $\circ$ último pavimento $q_{20^{\circ} P A V, i}$ por 1 hora. Portanto,

$$
Q_{\text {cold }}=\frac{Q_{\text {edifícioN }, i \times 1 h}}{1000}
$$

sendo:

$Q_{\text {cold }}$ - energia térmica retirada do edifício de $N$ pavimentos $(1 \leq N \leq 20)$ pelo sistema de ar condicionado, na hora $i$ do dia considerado $(\mathrm{kWh})$.

$Q_{\text {edifícion, } i}$ - carga térmica horária atuante no edifício de $N$ pavimentos na hora $i$, calculada pela eq.(5), a partir dos valores de carga térmica obtidos na simulação do EnergyPLus (W)

Determinado o valor de $Q_{\text {cold }}$, em $\mathrm{kWh}$, para cada hora $i$ do dia, resta a determinação de $P_{f v}$ e de $s$. $O$ valor de $P_{f v}$ pode ser obtido do próprio EnergyPlus 
para cada hora $i$ do dia, simulando-se os painéis FV nas superfícies opacas das fachadas, com os parâmetros que serão apresentados no próximo item.

A fração solar $(s)$ do sistema pode ser obtida teoricamente da expressão do coeficiente de performance do chiller solar. De fato, pode-se definir a fração solar média na hora $i$ do dia estudado, como sendo a parcela de toda a energia térmica que alimenta o chiller solar, que provem dos coletores solares, nesta hora. Se, por exemplo, a fração solar é $50 \%$, a instalação solar é responsável por metade da energia que alimenta o chiller, sendo a outra metade suprida pelo aquecedor auxiliar.

Em outras palavras, a fração solar $s$ na hora $i$ do dia, corresponde à razão entre a energia térmica que aquece a água que alimenta o chiller proveniente dos coletores solares $\left(Q_{\text {solar }, i}\right)$ nesta hora $i$ e a energia térmica total que alimenta o chiller $\operatorname{solar}\left(Q_{\text {solar }, i}+Q_{\text {aux }, i}\right)$ :

$$
s=\frac{Q_{\text {solar }, i}}{Q_{\text {solar }, i}+Q_{\text {aux }, i}}
$$

sendo:

$Q_{\text {solar }, i}$ - energia térmica fornecida ao chiller solar proveniente dos coletores térmicos na hora $i(\mathrm{kWh})$.

$Q_{a u x, i}$ - energia térmica fornecida ao chiller solar proveniente do aquecedor auxiliar na hora $i(\mathrm{kWh})$.

$\mathrm{Na}$ eq.(35), colocando-se a energia térmica vinda do aquecedor auxiliar elétrico $\left(Q_{a u x, i}\right)$ em função da fração solar, tem-se:

$$
\begin{aligned}
& s \times Q_{\text {solar }, i}+s \times Q_{\text {aux }, i}=Q_{\text {solar }, i} \\
& Q_{\text {aux }, i}=\frac{Q_{\text {solar }, i} \times(1-s)}{s}
\end{aligned}
$$


Pela definição de coeficiente de performance (COP), tem-se, para o chiller solar:

$$
\operatorname{COP}_{S}=\frac{Q_{\text {cold }}}{Q_{\text {solar }, i}+Q_{\text {aux }, i}}
$$

Substituindo-se $Q_{a u x, i}$ da eq.(37) na eq.(38), e substituindo-se o valor de $Q_{c o l d}$ da eq.(34) na eq.(38), obtém-se:

$$
\operatorname{COP}_{S}=\frac{Q_{\text {Edificion }, i}}{Q_{\text {solar }, i}+\frac{Q_{\text {solar }, \times(1-s)}}{s}}=\frac{s \times Q_{\text {Edificion }, i}}{Q_{\text {solar }, i}} \rightarrow s=\frac{\operatorname{COP}_{S} \times Q_{\text {solar }, i}}{Q_{\text {Edifícion, } i}}
$$

Como a energia térmica proveniente dos coletores $\left(Q_{\text {solar }, i}\right)$ em $\mathrm{kWh}$, pode ser representada pelo produto da eficiência dos coletores $\left(\eta_{\text {SOLAR }}\right)$, da irradiância solar $\left(G_{S O L A R}\right)$ em $\mathrm{W} / \mathrm{m}^{2}$ e da área coletora $\left(A_{S O L A R}\right)$ em $\mathrm{m}^{2}$, chega-se a expressão final para a fração solar, expressa pela eq.(40), a seguir:

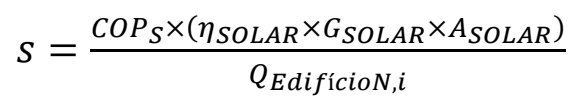

Supondo a eficiência dos coletores $\left(\eta_{\text {SOLAR }}\right)$ e a área dos coletores $\left(A_{\text {SOLAR }}\right)$ constantes, por hipótese, durante o dia, para o sistema de ar condicionado solar térmico, os únicos parâmetros variáveis ao longo do dia seriam a carga térmica do edifício $\left(Q_{E \text { difícion, } i}\right)$ determinada pela eq.(4), para cada hora $i$ e a irradiância solar $\left(G_{S O L A R}\right)$ incidente sobre os coletores, determinada pelo EnergyPlus para cada hora $i$ e a produção FV $P_{f v}$ para cada hora $i$ do dia, que será determinada pelo EnergyPlus.

Em síntese, toda a formulação apresentada até aqui, será utilizada para o cálculo do consumo de energia elétrica dos sistemas de ar condicionado em estudo, para os dias 21 de junho e 21 de dezembro, e esses valores de consumo de energia representarão o desempenho energético dos sistemas nesses dias. 


\subsection{Considerações Finais sobre o Método de Pesquisa}

\subsubsection{Síntese do Método de Pesquisa}

O método descrito anteriormente, para ser utilizado na análise do desempenho energético dos sistemas de ar condicionado solar desse trabalho, será neste item, apresentado de forma resumida e algumas considerações finais sobre $o$ método serão traçadas.

Primeiramente, de acordo com o que foi apresentado, o método propõe que o desempenho energético dos sistemas de ar condicionado solar será avaliado pelo cálculo do consumo de energia elétrica desses sistemas. Esse cálculo será realizado de acordo com o método adaptado da formulação proposta pelo documento "Guidelines" do projeto SOLAIR (2007 - 2009) da União Européia.

No método original são obtidos os consumos de energia primária dos sistemas de ar condicionado solar. Com a adaptação do método para a realidade do Brasil (item 3.3.1.3), possibilitando o cálculo apenas do consumo de energia final dos sistemas, ao invés de energia primária, adotou-se, por hipótese, que o aquecimento auxiliar para o sistema de ar condicionado solar térmico seria do tipo elétrico.

Esse aquecimento auxiliar era originalmente a gás, no método SOLAIR, o que corresponde à situação mais usual. Com as adaptações, a alimentação do aquecedor auxiliar precisou ser elétrica, o que não corresponde à situação mais comum de ser utilizada na prática. Mesmo assim, o backup elétrico foi considerado a fim de possibilitar o cálculo da energia consumida $E_{t}$ pela eq.(30). Sem a consideração do aquecimento auxiliar elétrico, representado pelo coeficiente $\left(1 / \eta_{e}\right)$, o primeiro termo da eq.(30) não resultaria em energia elétrica, e sim, em energia térmica, e não poderia ser somado aos demais termos da eq. (30) que correspondem a consumos de energia elétrica.

Outra forma de se projetar o aquecimento auxiliar no sistema de ar condicionado solar térmico seria através da utilização de um chiller convencional de 
compressão de vapor em paralelo com o chiller de absorção solar. Certamente essa alternativa de ar condicionado solar térmica teria um desempenho energético melhor que a estudada neste trabalho, que, por sua vez, considera aquecimento auxiliar elétrico da água para o chiller solar. Mesmo assim, a alternativa de sistema de aquecimento auxiliar elétrico foi mantida para que se pudesse avaliar de forma mais simplificada os sistemas em estudo e possibilitar também uma análise independente da utilização do chiller de compressão de vapor e do chiller de absorção solar.

Outro comentário que se deve fazer com relação ao método proposto, é que, por hipótese, não foi considerada a influência tanto dos coletores solares térmicos, quanto dos painéis fotovoltaicos, na carga térmica do edifício. Sabe-se que, na realidade, o aquecimento desses sistemas de captação solar provoca uma alteração da carga térmica do edifício. Por razões de simplificação da análise, essa influência não foi considerada no presente trabalho, supondo-se a carga térmica independente da presença dos sistemas de aproveitamento solar.

Para cada um dos dias estudados (21 de junho e 21 de dezembro) e para cada sistema de ar condicionado em análise, o valor do consumo de energia elétrica ( $E_{i}$, em $\mathrm{kWh}$ ), a cada hora do dia, quando somado ao longo do dia, resultará no consumo de energia do sistema naquele dia ( $E$, em $\mathrm{kWh})$. Esse consumo, por hipótese, representará o desempenho energético do sistema de ar condicionado em estudo. Um sistema com maior valor de consumo de energia elétrica será considerado de pior desempenho energético do que um sistema com menor consumo elétrico. Isso será considerado como hipótese da análise.

A Figura 3.16, a seguir, resume o método a ser utilizado para a análise de desempenho dos sistemas de ar condicionado solar.

Neste trabalho, também, como foi dito, será possível desenvolver uma análise do desempenho dos sistemas de ar condicionado solar em função do número de pavimentos do edifício. É por isso que o cálculo da carga térmica e do consumo de energia elétrica é feita para o edifício com $N$ pavimentos $(1 \leq N \leq 20)$, a fim de possibilitar esse tipo de estudo. Por fim, ainda será possível um estudo complementar da influência no desempenho energético do sistema de ar condicionado solar térmico, da tecnologia e da área de coletores solares utilizada. Para concluir esse capítulo apresenta-se, no item seguinte 3.4.2, um resumo das principais hipóteses adotadas no trabalho. 
ETAPA 1: Análise Térmica do;Edifício (item 3.2)

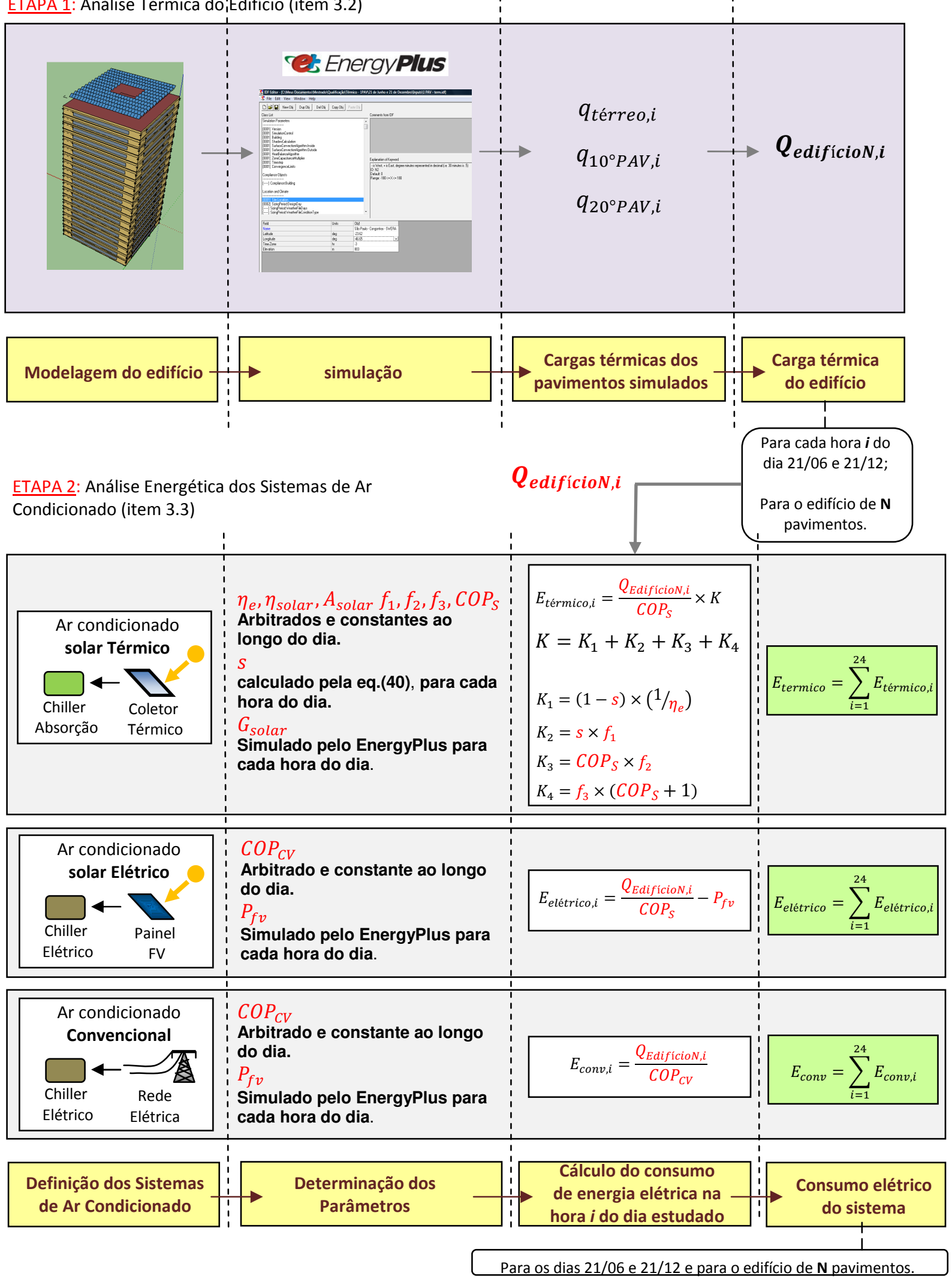

Figura 3.16 - Resumo do Método utilizado na pesquisa. 
3.4.2 Resumo das Premissas e Hipóteses adotadas na Pesquisa

As principais premissas e hipóteses adotadas na pesquisa são as seguintes:

\subsubsection{Edifício de Escritório}

\section{- Tipologia}

Foi adotado o edifício especificado no item 3.1, com as adaptações apresentadas neste capítulo. $O$ edifício tem 20 pavimentos e uma área em planta de $1000 \mathrm{~m}^{2}$ por pavimento. O edifício possui forma quadrangular e janelas de vidro em cada fachada. Além disso, utiliza forro e piso elevado em cada pavimento.

\section{- Elementos Construtivos}

O edifício analisado é construído em concreto armado e revestido em argamassa. As características dos elementos construtivos são apresentadas em detalhes na Tabela 3.3.

\section{- Cargas Internas}

As cargas internas são consideradas, por hipótese, na Tabela 3.4, e correspondem as cargas iluminação, equipamentos e ocupação. A infiltração de ar foi considerada com uma taxa de $0,045 \mathrm{~m}^{3} / \mathrm{s}$ para cada zona térmica do edifício e a ventilação foi considerada respeitando-se os padrões mínimos de renovação de ar da ANVISA de $27 \mathrm{~m}^{3} / \mathrm{s}$.pessoa (ANVISA, 2009).

As variações horárias das cargas térmicas são apresentadas na Figura 3.13. 
- Operação do Sistema de Climatização

A operação dos sistemas de ar condicionado foi adotada, por hipótese, como sendo das 9 horas às 18 horas.

\section{- Obtenção da Carga Térmica}

A obtenção das cargas térmicas ocorreu pelo método da analise térmica do edifício, apresentado no item 3.2. A Ferramenta utilizada para essa obtenção foi o software EnergyPlus do Departamento de Energia dos Estados Unidos, com o qual foram simulados três pavimentos distintos: o pavimento térreo, o pavimento intermediário $\left(10^{\circ}\right)$ e o último pavimento $\left(20^{\circ}\right)$. Esses resultados foram compostos através das equações apresentadas no item 3.2, resultando na carga térmica total do edifício.

\subsubsection{Dados Geográficos e Climáticos}

- Localização

O estudo se refere à um edifício de escritórios localizado na cidade de São Paulo-SP, no Brasil.

\section{- Características Climáticas}

As características climáticas adotadas para a análise corresponderam às características apresentadas no arquivo climático referente à cidade de São Paulo, obtidas do banco de dados do EnergyPlus, por meio do arquivo climático anual "BRA_Sao.Paulo-Congonhas_SWERA.epw". 


\section{- Período da Análise}

Para a análise do desempenho energético dos sistemas de ar condicionado foram estudados dois dias do ano: um deles referente a uma situação de inverno (21 de junho) e outro referente a uma situação de verão (21 de dezembro).

\section{- Determinação da Radiação da Solar}

Os níveis de radiação solar incidentes $G_{\text {solar }}$ sobre o edifício e sobre os sistemas de aproveitamento solar, sejam eles térmicos ou fotovoltaicos, foram calculados pelo EnergyPlus, para cada hora dos dias estudados.

\subsubsection{Sistema de Ar Condicionado Solar Térmico}

\section{- Concepção}

A concepção do sistema de ar condicionado solar térmico é definido pelas Figuras 3.3 e 3.5. Esse sistema associa coletores solares térmicos que produzem água quente para o chiller solar de absorção. O backup de energia térmica é realizado pelo aquecedor auxiliar elétrico. O sistema possui também torre de resfriamento para a água de condensação.

\section{- Sistema de Aproveitamento Solar Térmico}

O sistema de aproveitamento solar térmico (instalação solar) é constituído basicamente de coletores solares e reservatório térmico. Os coletores, por hipótese, são coletores planos (FPC) orientados ao Norte, com uma inclinação de $23^{\circ}$, alocados na cobertura do edifício. A área da instalação solar é de $950 \mathrm{~m}^{2}$ em planta, isto é, $95 \%$ da área de cobertura do prédio. Foi adotado, também, um espaçamento entre as fileiras de coletores. Com essas considerações, a somatória das áreas das 
superfícies dos módulos resultou em $77 \%$ da área em planta ocupada pela instalação solar.

Os coletores planos têm eficiência de $50 \%$ e produzem água a uma temperatura de até $90^{\circ} \mathrm{C}$, alimentando um chiller de simples-efeito.

No final do trabalho, para a análise da influência da tecnologia e da área de coletores no desempenho do sistema, foram adotados, como será explicado no capítulo seguinte, coletores de tubo à vácuo (ETC), ao invés de coletores planos. Para eles supôs-se a eficiência de $50 \%$ e a produção de vapor de água a $150^{\circ} \mathrm{C}$, possibilitando a utilização de um chiller de duplo-efeito.

Os valores dos parâmetros utilizados na pesquisa e relacionados ao sistema de aproveitamento solar foram os seguintes:

Tabela 3.6 - Parâmetros da instalação solar.

\begin{tabular}{|c|c|c|c|}
\hline Parâmetros & Nomenclatura & Valor & Obtenção \\
\hline$\eta_{\text {solar }}$ & $\begin{array}{c}\text { Eficiência dos coletores solares (FPC e } \\
\text { ETC) }\end{array}$ & $50 \%$ & $\begin{array}{c}\text { Valor arbitrado com base em } \\
\text { KIM; FERREIRA, 2007 }\end{array}$ \\
\hline$A_{\text {solar }}$ & Área em planta da instalação solar $\left(\mathrm{m}^{2}\right)$ & $950 \mathrm{~m}^{2}$ & $\begin{array}{c}\text { Valor arbitrado de acordo com } \\
\text { a geometria do edifício }\end{array}$ \\
\hline$f_{1}$ & $\begin{array}{c}\text { Razão entre o consumo de energia } \\
\text { elétrica da instalação solar e a energia } \\
\text { térmica produzida pelos coletores (adm.) }\end{array}$ & $\begin{array}{c}0,02 \\
\text { Fração solar do sistema (adm.) }\end{array}$ & $\begin{array}{c}\text { Valor arbitrado com base em } \\
\text { GUIDELINES SOLAIR, 2007 }\end{array}$ \\
\hline \multirow{2}{*}{$\begin{array}{c}\text { Obtido pela dedução teórica apresentada } \\
\text { anteriormente: }\end{array}$} \\
\end{tabular}

\section{- Aquecimento Auxiliar}

O sistema de aquecimento auxiliar foi adotado, por hipótese, como sendo um sistema de aquecimento elétrico. A eficiência de conversão da energia elétrica para energia térmica do fluido aquecido é de $80 \%$.

O valor do parâmetro utilizado na pesquisa e relacionado ao sistema de aquecimento auxiliar foi o seguinte: 
Tabela 3.7 - Parâmetro do sistema de aquecimento auxiliar elétrico.

\begin{tabular}{|c|c|c|c|}
\hline Parâmetros & Nomenclatura & Valor & Obtenção \\
\hline$\eta_{e}$ & Eficiência do aquecedor auxiliar elétrico & $80 \%$ & $\begin{array}{c}\text { Adotado por hipótese com } \\
\text { base nos valores de mercado }\end{array}$ \\
\hline
\end{tabular}

\section{- Chiller Solar}

O chiller solar adotado, por hipótese, correspondeu a um chiller de absorção de simples-efeito, no caso dos coletores FPC. No caso dos coletores ETC, o chiller adotado correspondeu a um chiller de absorção de duplo-efeito.

Os valores dos parâmetros utilizados na pesquisa e relacionados ao chiller solar foram os seguintes:

Tabela 3.8 - Parâmetros do chiller solar de absorção.

\begin{tabular}{|c|c|c|c|}
\hline Parâmetros & Nomenclatura & Valor & Obtenção \\
\hline COP $_{S}$ & $\begin{array}{c}\text { Coeficiente de Performance do chiller de } \\
\text { absorção solar (adm.) }\end{array}$ & $\begin{array}{c}0,7 \text { (simples efeito) } \\
1,2 \text { (duplo efeito) }\end{array}$ & $\begin{array}{c}\text { Valor arbitrado com base em } \\
\text { KIM; FERREIRA, 2007 }\end{array}$ \\
\hline$f_{2}$ & $\begin{array}{c}\text { Razão entre o consumo de energia } \\
\text { elétrica do chiller solar e a energia } \\
\text { térmica retirada do edifício pelo chiller } \\
\text { (adm.) }\end{array}$ & 0,01 & $\begin{array}{c}\text { Valor arbitrado com base em } \\
\text { KIM; FERREIRA, 2007 }\end{array}$ \\
\hline
\end{tabular}

- Sistema de Rejeição de Calor

O sistema de rejeição de calor adotado para o ar condicionado solar térmico foi o sistema de condensação à água, com torre de resfriamento. $O$ valor do parâmetro utilizado na pesquisa e relacionado ao sistema de rejeição de calor foi o seguinte:

Tabela 3.9 - Parâmetros do sistema de rejeição de calor do ar condicionado solar térmico.

\begin{tabular}{|c|c|c|c|}
\hline Parâmetros & Nomenclatura & Valor & Obtenção \\
\hline$f_{3}$ & $\begin{array}{c}\text { Razão entre o consumo de energia } \\
\text { elétrica do sistema de rejeição de calor } \\
\text { (torres de resfriamento) e a energia } \\
\text { térmica retirada (adm.) }\end{array}$ & 0,03 & $\begin{array}{c}\text { Valor arbitrado com base em } \\
\text { GUIDELINES SOLAIR, 2007 }\end{array}$ \\
\hline
\end{tabular}


3.4.2.4 Sistema de Ar Condicionado Solar Elétrico

\section{- Concepção}

A concepção do sistema de ar condicionado solar elétrico é definida pelas Figuras 3.4 e 3.6. Esse sistema associa painéis fotovoltaicos que produzem eletricidade com o chiller de compressão de vapor. O backup de energia elétrica é realizado pela rede elétrica da concessionária.

\section{- Sistema de Rejeição de Calor}

O sistema de rejeição de calor adotado para o ar condicionado solar elétrico foi o sistema de condensação a ar, sem torre de resfriamento, conforme as justificativas apresentadas anteriormente.

\section{- Sistema de Aproveitamento Solar Fotovoltaico}

O sistema de aproveitamento solar fotovoltaico (instalação solar) é constituído basicamente de painéis FV e inversores. Os painéis, por hipótese, são de Silício Amorfo (a-Si) alocados nas superfícies opacas das fachadas e os inversores são utilizados um para cada circuito, sendo que cada circuito corresponde à uma única e exclusiva fachada do edifício.

A eficiência adotada para os painéis foi de 10\% (a-Si) e a eficiência dos inversores foi adotada como sendo de $85 \%$. Além disso, foi considerado na simulação, o sombreamento de $50 \%$ da fachada térrea do edifício.

Essas informações alimentaram a simulação no EnergyPLus resultando na avaliação da produção de energia do sistema fotovoltaico para cada hora do dia.

\section{- Chiller de Compressão de Vapor}

O chiller adotado, por hipótese, correspondeu a um chiller de compressão de vapor. O valor do parâmetro utilizado na pesquisa e relacionado ao chiller elétrico foi o seguinte: 
Tabela 3.10 - Parâmetros do chiller do ar condicionado solar elétrico.

\begin{tabular}{|c|c|c|c|}
\hline Parâmetros & Nomenclatura & Valor & Obtenção \\
\hline COP $C V$ & $\begin{array}{c}\text { Coeficiente de Performance do chiller de } \\
\text { compressão de vapor (adm.) }\end{array}$ & 3,0 & $\begin{array}{c}\text { Valor arbitrado com base nos } \\
\text { valores de mercado. }\end{array}$ \\
\hline
\end{tabular}

\subsubsection{Sistema de Ar Condicionado Convencional}

\section{- Concepção}

A concepção do sistema de ar condicionado convencional é definida pela Figura 3.7. Esse sistema utiliza simplesmente um chiller de compressão de vapor alimentado pela rede elétrica da concessionária.

\section{- Sistema de Rejeição de Calor}

O sistema de rejeição de calor adotado para o ar condicionado convencional foi o sistema de condensação a ar, sem torre de resfriamento, conforme as justificativas apresentadas anteriormente.

\section{- Chiller de Compressão de Vapor}

O chiller adotado, por hipótese, correspondeu a um chiller de compressão de vapor. O valor do parâmetro utilizado na pesquisa e relacionado ao chiller elétrico foi o seguinte:

Tabela 3.11 - Parâmetros do chiller do ar condicionado convencional.

\begin{tabular}{|c|c|c|c|}
\hline Parâmetros & Nomenclatura & Valor & Obtenção \\
\hline$C O P_{C V}$ & $\begin{array}{c}\text { Coeficiente de Performance do chiller de } \\
\text { compressão de vapor (adm.) }\end{array}$ & 3,0 & $\begin{array}{c}\text { Valor arbitrado com base nos } \\
\text { valores de mercado. }\end{array}$ \\
\hline
\end{tabular}

Com essas hipóteses e com a formulação desenvolvida, foi possível obter os resultados que serão apresentados a partir do próximo capítulo. 
"Desempenho de Sistemas de Condicionamento de Ar com Utilização de Energia Solar em Edifícios de Escritórios"

Capítulo 4

Resultados 


\section{RESULTADOS}

No capítulo 1 introduziu-se o trabalho de pesquisa e no capítulo 2 apresentouse a revisão bibliográfica sobre 0 assunto. No capítulo 3 , dissertou-se sobre 0 método de pesquisa a ser adotado no trabalho. A aplicação desse método aos sistemas de condicionamento de ar em estudo resultou na obtenção dos parâmetros de desempenho energético desses sistemas. Esses resultados são apresentados no presente capítulo 4.

Pela metodologia de pesquisa, pode-se dizer que a análise de desempenho energético proposta neste trabalho, compõe-se, basicamente, de duas etapas: a primeira consiste no cálculo das cargas térmicas do edifício e a segunda consiste na obtenção, a partir dessas cargas térmicas, do consumo de energia elétrica convencional ${ }^{16}$ por parte dos sistemas de ar condicionado solar em estudo.

Os valores de consumo de energia elétrica, por hipótese, representarão o desempenho energético dos sistemas de condicionamento de ar, de forma que o sistema com menor consumo de energia será classificado como um sistema de melhor desempenho energético.

A primeira etapa da análise de desempenho energético dos sistemas de ar condicionado solar, isto é, a obtenção dos valores de carga térmica através do software EnergyPlus conforme a metodologia apresentada no capítulo 3, foi chamada de "Análise Térmica do Edifício". Esses resultados serão apresentados no item 4.1 a seguir, para o edifício protótipo estudado, nas condições estabelecidas neste trabalho.

A segunda etapa da análise de desempenho energético dos sistemas de ar condicionado solar, isto é, a obtenção dos valores de consumo de energia elétrica dos sistemas a partir dos resultados de carga térmica como dados de entrada para método proposto no capítulo 3, foi chamada de "Análise Energética dos Sistemas de

\footnotetext{
${ }^{16}$ Conforme apresentado no capítulo 3, o método proposto neste trabalho para a obtenção do desempenho energético dos sistemas de ar condicionado solar, calcula o consumo de energia elétrica do sistema, proveniente da rede elétrica da concessionária de energia. No texto, essa energia será chamada de convencional e, a não ser que se especifique explicitamente, a energia elétrica em questão será sempre a convencional, isto é, da rede elétrica da concessionária.
} 
Ar Condicionado Solar". Esses resultados serão apresentados no item 4.2 a seguir, para os sistemas de ar condicionado estudados, nas condições estabelecidas neste trabalho.

\subsection{Análise Térmica do Edifício}

A etapa de análise térmica obteve as cargas térmicas no edifício, para cada hora dos dias 21 de Junho e 21 de Dezembro. O gráfico da Figura 4.1 mostra os valores das cargas térmicas obtidas, em MWth, para cada hora de operação do edifício, para os dias 21 de dezembro e 21 de Junho:

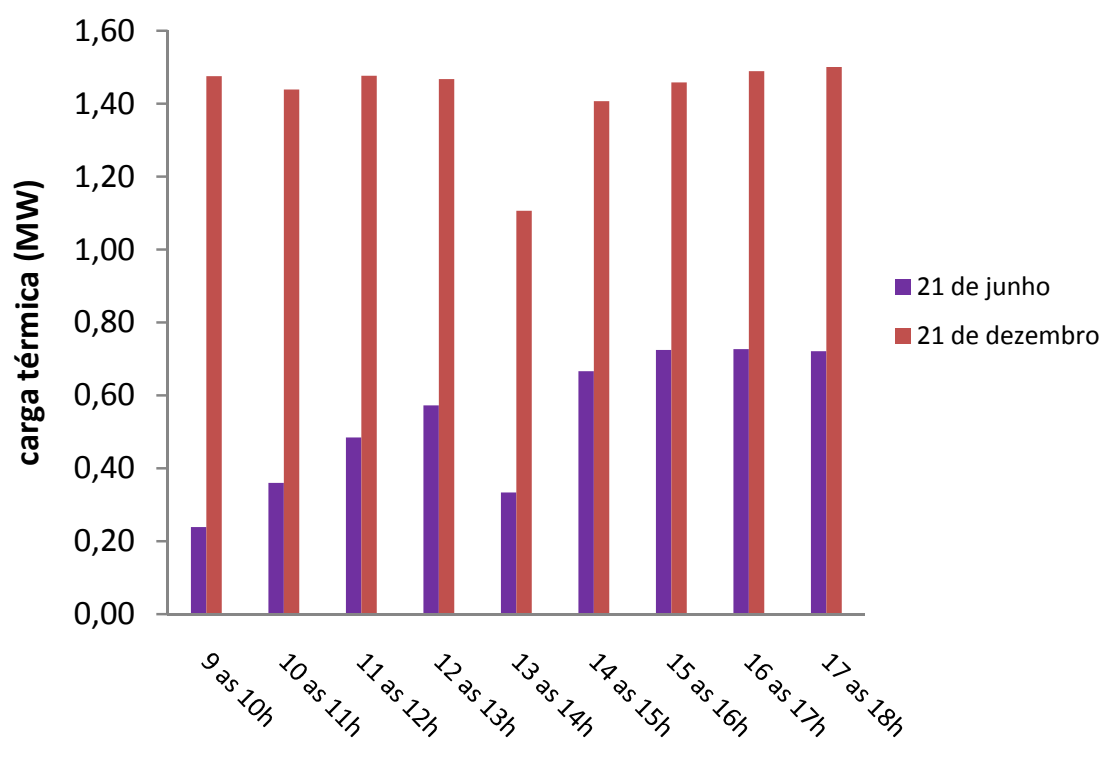

Figura 4.1 - Carga térmica horária do edifício simulado.

Conforme se observa pela Figura 4.1 , as cargas térmicas presentes no edifício no dia 21 de dezembro são significativamente superiores as cargas térmicas para o dia 21 de junho.

A carga térmica na hora de pico do dia 21 de dezembro atingiu o valor de 1,50 $\mathrm{MW}$, enquanto que a carga térmica na hora de pico do dia 21 de junho chegou a $0,73 \mathrm{MW}$. Em outras palavras, o pico de carga térmica obtido no dia de verão resultou em mais que o dobro (1,50 MW contra $0,73 \mathrm{MW})$ do pico de carga térmica 
no dia de inverno, mostrando a importante influência da época do ano no comportamento térmico do edifício.

Da mesma forma, o mínimo valor horário da carga térmica do dia 21 de Dezembro, 1,11 MW é bem maior que o mínimo valor horário da carga térmica do dia 21 de Junho, que é de 0,24 MW (Figura 4.2). É interessante notar, também, que a elevação da carga térmica é tão significativa no verão que o mínimo da carga térmica no dia de verão $(1,11 \mathrm{MW})$ ainda é maior que o máximo da carga térmica no dia de inverno $(0,73 \mathrm{MW})$.

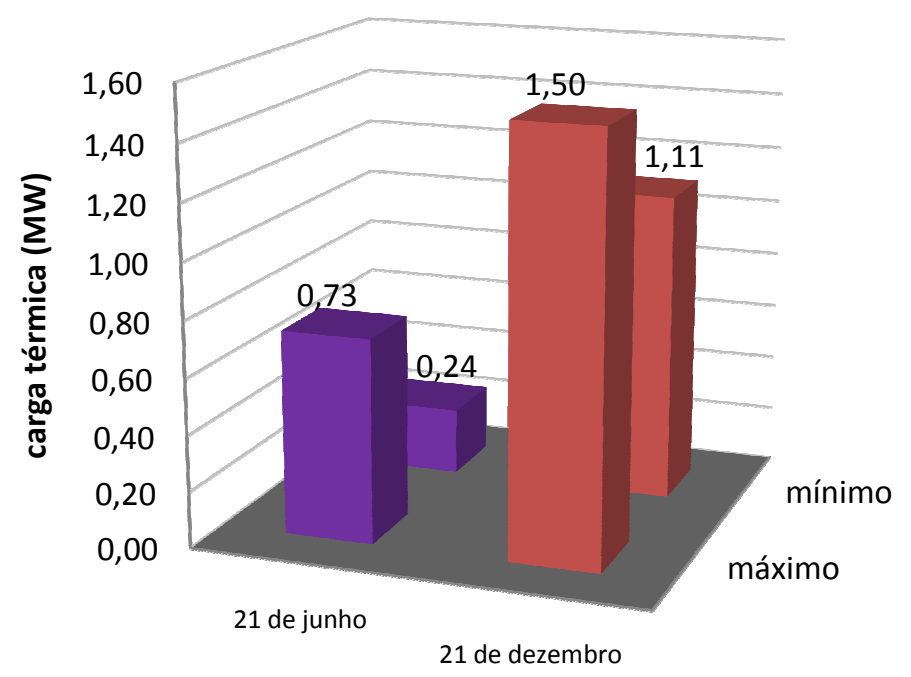

Figura 4.2 - valores máximos e mínimos de carga térmica para os dias 21/06 e 21/12.

De forma geral, observando os resultados da simulação térmica, constata-se, primeiramente, que a época do ano tem uma significativa influência no comportamento térmico do edifício, já que a carga térmica para o dia de verão resultou em todas as horas do dia, maior que a carga térmica para o dia de inverno.

Além disso, observa-se nos resultados, uma significativa diminuição da carga térmica no período das 12 horas às 13 horas. Isso é devido à redução do uso de computadores e à redução do número de pessoas no escritório por ocasião do almoço, previstos na modelagem da ocupação do edifício no arquivo de entrada do EnergyPlus, de acordo com o que foi apresentado no item 3.2.2.3.

É interessante observar, também, que para o dia de verão, não ocorre o crescimento da carga térmica ao longo do dia da forma como ocorre no dia de 
inverno. Isso se explica, pois, nas condições de verão, a temperatura ambiente já é elevada ainda antes de se iniciar o período de funcionamento do ar condicionado, que opera das 9 horas às 18 horas, fazendo com que nas primeiras e últimas horas de operação, as cargas térmicas sejam relativamente altas (Figura 4.1).

Por fim, constatou-se que os valores de carga térmica se mostraram razoavelmente reduzidos se comparados com a referência de $20 \mathrm{~m}^{2} / \mathrm{TR}$ algumas vezes utilizada para estimativa da carga térmica de escritórios na cidade de São Paulo. De fato, para o edifício de 20 pavimentos se obteve os seguintes valores de área para cada TR de carga térmica no edifício, em $\mathrm{m}^{2} / \mathrm{TR}$ :

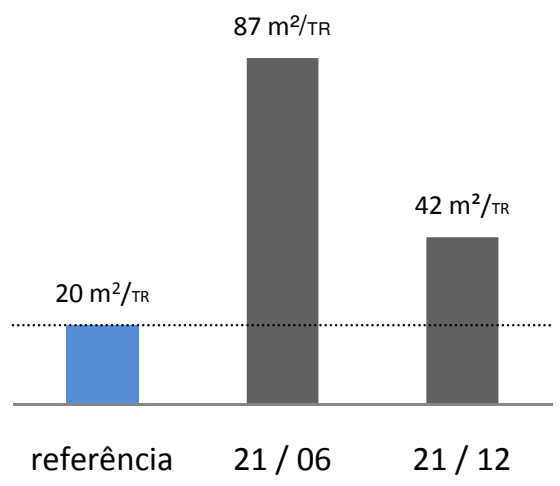

Figura 4.3 - Área de escritório por TR de carga térmica, no dia 21/06 e no dia 21/12, comparadas com o valor de referência de $20 \mathrm{~m}^{2} / T R$.

Pela Figura acima, se observa que o valor de $20 \mathrm{~m}^{2} / \mathrm{TR}$ corresponde a um valor reduzido em relação à realidade. Além disso, a geometria do edifício caracterizada por uma grande área central em planta, sem a influência direta da radiação solar pelas janelas, propiciou que as cargas térmicas não fossem muito elevadas, como aquelas representadas pelo parâmetro de $20 \mathrm{~m}^{2} / \mathrm{TR}$.

No capítulo 3, apresentou-se a proposta de avaliar a influência do número de pavimentos do edifício no desempenho do sistema de ar condicionado solar, já que o desempenho dos sistemas podem ser melhor ou pior se o edifício for mais alto ou mais baixo.

Para avaliar, porém, o desempenho energético dos sistemas de ar condicionado instalados em edifícios com um número diferente de pavimentos em relação ao edifício protótipo de 20 andares, conforme discutido no item 3.2.2.1, foi 
necessário obter os valores de carga térmica presentes nestes casos, isto é, nos edifícios mais baixos que o original de 20 pavimentos.

Assim, além da carga térmica para o edifício de 20 pavimentos, apresentada pela Figura 4.1, obteve-se também no EnergyPlus, os resultados de carga térmica para edifícios da mesma tipologia do estudado, porém com $n$ pavimentos ( $1 \leq n<$ $20)$, isto é, para um edifício com mesma tipologia, porém térreo $(n=1)$, para um edifício com mesma tipologia, porém com 2 pavimentos $(n=2)$, para um edifício com a mesma tipologia, porém com 3 pavimentos $(n=3)$, assim consecutivamente, até 19 pavimentos $(n=19)$.

Os resultados de carga térmica para o edifício térreo $(n=1)$ serão utilizados para o cálculo do consumo de energia elétrica do sistema de ar condicionado solar supostamente instalado em um edifício térreo, de acordo com o método do capítulo 3. Da mesma forma, os resultados de carga térmica para o edifício de $n$ pavimentos $(1 \leq n<20)$ serão utilizados para o cálculo do consumo de energia elétrica do sistema de ar condicionado solar supostamente instalado em um edifício de $n$ pavimentos $(1 \leq n<20)$, de acordo com o método do capítulo 3 .

A Figura 4.3 mostra os picos horários de carga térmica para os dias 21 de dezembro e 21 de junho em função do número de pavimentos $n$ do edifício estudado.

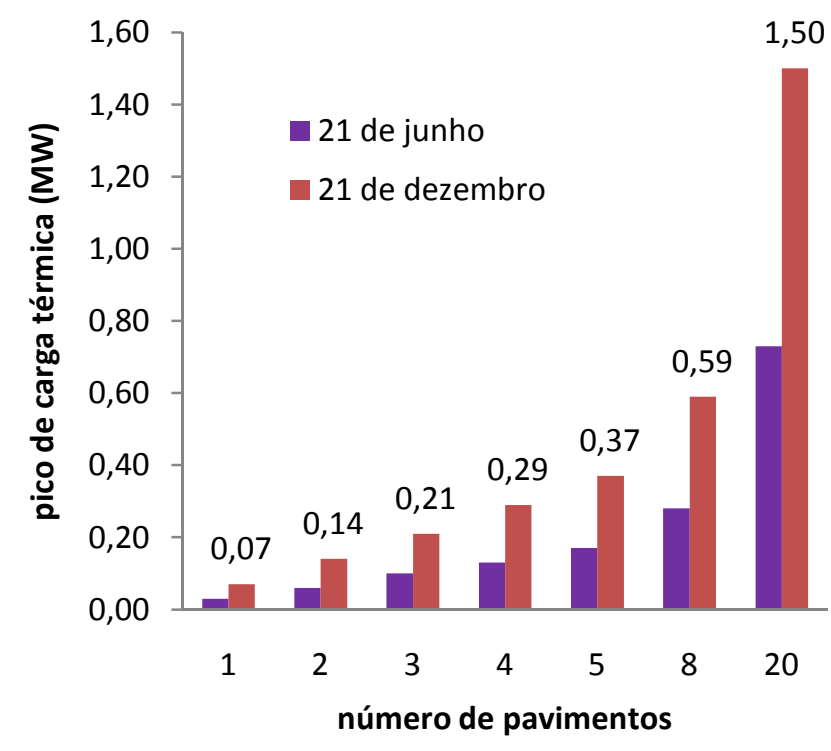

Figura 4.4 - Carga térmica diária em função do número de pavimentos do edifício. 


\subsection{Análise Energética dos Sistemas de Ar Condicionado Solar}

Depois de realizada a primeira etapa correspondente à análise térmica do edifício, obtendo-se as cargas térmicas atuantes no prédio, nos dias 21 de junho e 21 de dezembro, passou-se ao desenvolvimento da segunda etapa do estudo do desempenho energético dos sistemas de condicionamento solar, isto é, da etapa de análise energética dos sistemas. Os resultados desta etapa serão apresentados a seguir neste item 4.2 .

Essa etapa consistiu, como já foi dito, na determinação, a partir dos valores de carga térmica obtidos na análise térmica do edifício (item 4.1), dos consumos de energia elétrica por parte dos sistemas de ar condicionado solar. Essa análise foi desenvolvida de acordo com o método e as hipóteses definidas no item 3.3 do capítulo anterior.

\subsubsection{Consumo de Energia dos Sistemas de Ar Condicionado Solar}

Os sistemas de ar condicionado estudados, de acordo com o que foi definido no capítulo de Materiais e Métodos, são os seguintes:

(1) Sistema de Ar Condicionado Convencional: sistema com chiller elétrico de compressão de vapor alimentado por eletricidade proveniente da rede da concessionária de energia. Os detalhes da concepção e os parâmetros do sistema podem ser vistos no capítulo 3;

(2) Sistema de Ar Condicionado Solar Térmico: sistema com chiller de absorção alimentado pelo fluido quente proveniente de coletores solares térmicos alocados na cobertura do edifício. O back-up de energia térmica é provido por um aquecedor auxiliar elétrico. Os detalhes da concepção e os parâmetros do sistema podem ser vistos no capítulo 3; 
(3) Sistema de Ar Condicionado Solar Elétrico: sistema com chiller elétrico de compressão de vapor alimentado pela eletricidade proveniente dos painéis fotovoltaicos alocados nas superfícies opacas das fachadas do edifício. $O$ back-up de energia elétrica é provido pela rede da concessionária de energia. Os detalhes da concepção e os parâmetros do sistema podem ser vistos no capítulo 3;

Esses sistemas, simulados no edifício de 20 pavimentos estudado, de acordo com o método e as hipóteses propostas, resultaram nos seguintes consumos de energia elétrica em cada um dos dias estudados, 21 de junho e 21 de dezembro:

\begin{tabular}{|c|c|c|}
\hline sistema de ar condicionado & $\begin{array}{c}\text { Consumo de Energia, em } \\
\text { MWh, no dia 21 de Junho. }\end{array}$ & $\begin{array}{c}\text { Consumo de Energia, em } \\
\text { MWh, no dia 21 de Junho. }\end{array}$ \\
\hline Convencional & $\mathbf{1 , 6 1}$ & $\mathbf{4 , 2 7}$ \\
\hline Solar Térmico & 7,04 & 21,50 \\
\hline Solar Elétrico & 0,47 & 3,08 \\
\hline
\end{tabular}

Tabela 4.1 - Consumo de energia elétrica, em $\mathrm{MWh} / \mathrm{dia}$, dos sistemas de ar condicionado convencional $\left(E_{\text {conv }}\right)$, de ar condicionado solar térmico $\left(E_{\text {térmico }}\right)$ e de ar condicionado solar elétrico $\left(E_{\text {eletrico }}\right)$, nos dias 21/06 e 21/12, para o edifício de 20 pavimentos em estudo.

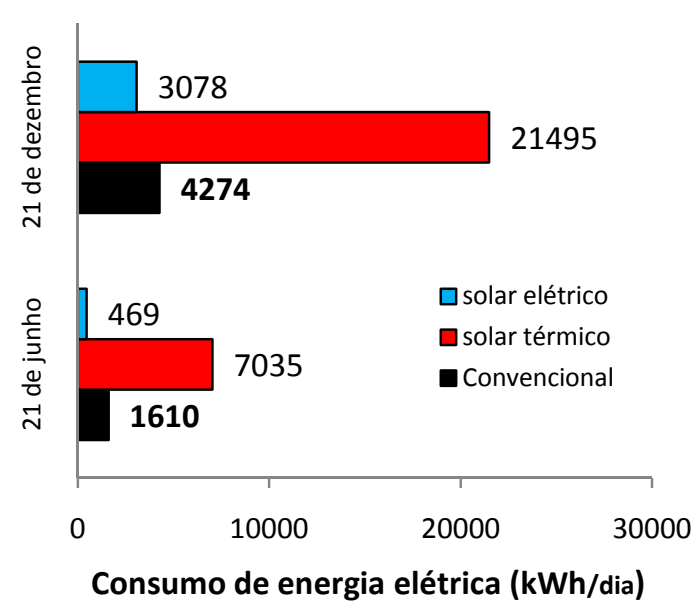

Figura 4.4 - Consumo de energia elétrica, em MWh/dia, dos sistemas de ar condicionado estudados, nos dias 21/06 e 21/12, para o edifício de 20 pavimentos. 
Conforme se observa na Tabela e na Figura anteriores, a simulação do edifício de escritórios de 20 pavimentos, modelado de acordo com as hipóteses apresentadas neste trabalho, provido de um sistema de ar condicionado solar térmico, de acordo com as definições e hipóteses adotadas, resultou no consumo de 7,04 MWh de energia elétrica por parte do ar condicionado, no dia 21 de junho, e no consumo de 21,50 MWh de energia elétrica pelo ar condicionado, no dia 21 de dezembro.

A simulação do edifício provido de um sistema de ar condicionado solar elétrico, de acordo com as definições e hipóteses adotadas, resultou no consumo de 0,47 MWh de energia elétrica por parte do ar condicionado, no dia 21 de junho, e no consumo de 3,08 MWh de energia elétrica pelo ar condicionado, no dia 21 de dezembro.

Por fim, a simulação do edifício provido de um sistema de ar condicionado convencional, de acordo com as definições e hipóteses adotadas, resultou no consumo de 1,61 MWh de energia elétrica por parte do ar condicionado, no dia 21 de junho, e no consumo de 4,27 MWh de energia elétrica pelo ar condicionado, no dia 21 de dezembro.

A partir desses resultados, nas condições e hipóteses dessa pesquisa, constata-se que a aplicação de sistemas de condicionamento de ar com utilização de energia solar em edifícios de escritórios da tipologia estudada, somente seria vantajosa energeticamente - em relação à aplicação de um sistema convencional de condicionamento de ar - se for adotado o sistema elétrico de ar condicionado solar.

De fato, o sistema elétrico de ar condicionado solar, com chiller de compressão de vapor alimentado por painéis fotovoltaicos, no dia 21 de junho, consumiu $28 \%$ do valor da energia elétrica consumida pelo sistema de ar condicionado convencional e, no dia 21 de dezembro, o sistema de ar condicionado solar elétrico consumiu $71 \%$ do valor da energia elétrica consumida pelo sistema convencional. Em outras palavras, utilizar o sistema elétrico de ar condicionado solar resultou em uma economia de energia elétrica de 1,14 MWh, apenas no dia 21 de junho, e em uma economia de 1,20 MWh de energia elétrica, apenas no dia 21 de dezembro.

A utilização do sistema térmico de ar condicionado solar, com chiller de absorção alimentado por coletores solares, resultou, ao contrário, em prejuízo de energia elétrica se comparado com o sistema de ar condicionado convencional. De 
fato, o sistema de ar condicionado solar térmico, no dia 21 de junho, consumiu $437 \%$ do valor da energia elétrica consumida pelo sistema convencional e, no dia 21 de dezembro, consumiu $503 \%$ do valor da energia elétrica consumida pelo sistema convencional.

No dia 21 de junho, o valor da energia elétrica consumido a mais pelo sistema de ar condicionado solar térmico foi quase 3,5 vezes maior $(337 \%$ a mais de consumo de energia) do que o consumo do ar condicionado convencional. Isso representou um consumo de 5,43 MWh de energia elétrica a mais do que se fosse utilizado o sistema convencional.

No dia 21 de dezembro, o valor da energia elétrica consumido a mais pelo sistema de ar condicionado solar térmico foi 4 vezes maior $(403 \%$ a mais de consumo de energia) do que o consumo do ar condicionado convencional. Isso representou um consumo de 17,22 MWh de energia elétrica a mais que o sistema convencional.

Em resumo, com relação ao consumo de energia elétrica, o sistema solar elétrico apresentou melhor resultado. O sistema convencional, por sua vez, consumiu mais energia que o solar elétrico (1,20 MWh e 1,14 MWh a mais, nos dias 21 de junho e 21 de dezembro, respectivamente). Porém, o sistema solar térmico consumiu mais energia ainda do que o sistema convencional (17,22 MWh e 5,43 MWh a mais, nos dias 21 de junho e 21 de dezembro, respectivamente). A Figura 4.5 ilustra esses valores:

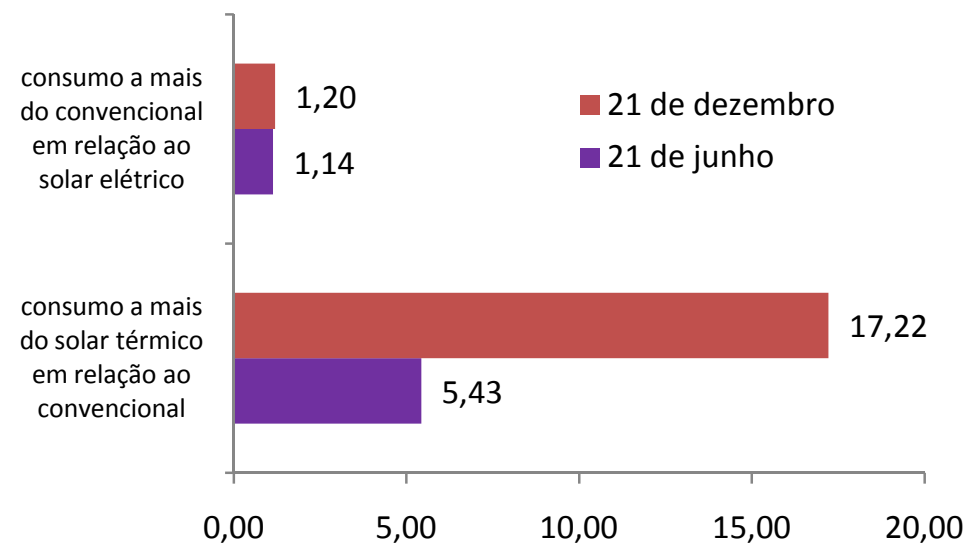

Figura 4.5 - Consumo de energia adicional, em MWh/dia, do sistema convencional em relação ao solar elétrico e do sistema solar térmico em relação ao convencional, nos dias 21/06 e 21/12. 
Neste ponto, pelo que foi apresentado até aqui nos resultados, é razoável questionar-se quanto às razões do desempenho energético do sistema de ar condicionado solar térmico ter resultado tão reduzido. De fato, para o edifício estudado, a aplicação de um sistema de condicionamento de ar térmico, mesmo utilizando energia renovável, resultou em um consumo de energia convencional muito maior do que um sistema usual de ar condicionado.

Em primeiro lugar, deve-se observar que o edifício estudado corresponde a um edifício de grande porte, com uma elevada área construída, e assim, a demanda para condicionamento de ar é razoavelmente grande. Como a área destinada aos coletores solares é limitada a cobertura do edifício ${ }^{17}$, o suprimento de energia solar também é limitado.

Em outras palavras, como por hipótese deste trabalho, a instalação solar de coletores planos foi restrita a área de cobertura, ocorreu uma limitação para a produção de calor por parte do sistema de aquecimento solar. Assim, na maioria das horas do dia, seja no dia 21 de junho, seja no dia 21 de dezembro, a quantidade de calor produzida pela instalação solar não foi suficiente para alimentar de forma autônoma o chiller de absorção adotado.

Dessa forma, para a operação normal do chiller de absorção foi necessário o acionamento freqüente do aquecedor auxiliar elétrico. Trabalhando com o auxílio do back-up de energia, o chiller de absorção é muito ineficiente energeticamente, pois seus valores de COP são baixos (ver capítulo 2), resultando em um elevado consumo de energia elétrica por parte do sistema.

A Figura 4.6, mostra exatamente isso, ao ilustrar os valores resultantes de fração solar horária obtidos na operação do sistema de ar condicionado solar térmico:

\footnotetext{
${ }^{17}$ A área em planta da cobertura, destinada à instalação solar e utilizada para a simulação, correspondeu a 95\% da área total de cobertura. Foi utilizado, também, o fator de minoração apresentado na Tabela 3.8, para levar em conta o estabelecimento de espaçamentos entre os módulos, que resulta na redução da área de superfície coletora em relação a área em planta da instalação. Todas essas considerações, já foram apresentadas nas hipóteses do método no capítulo 3.
} 


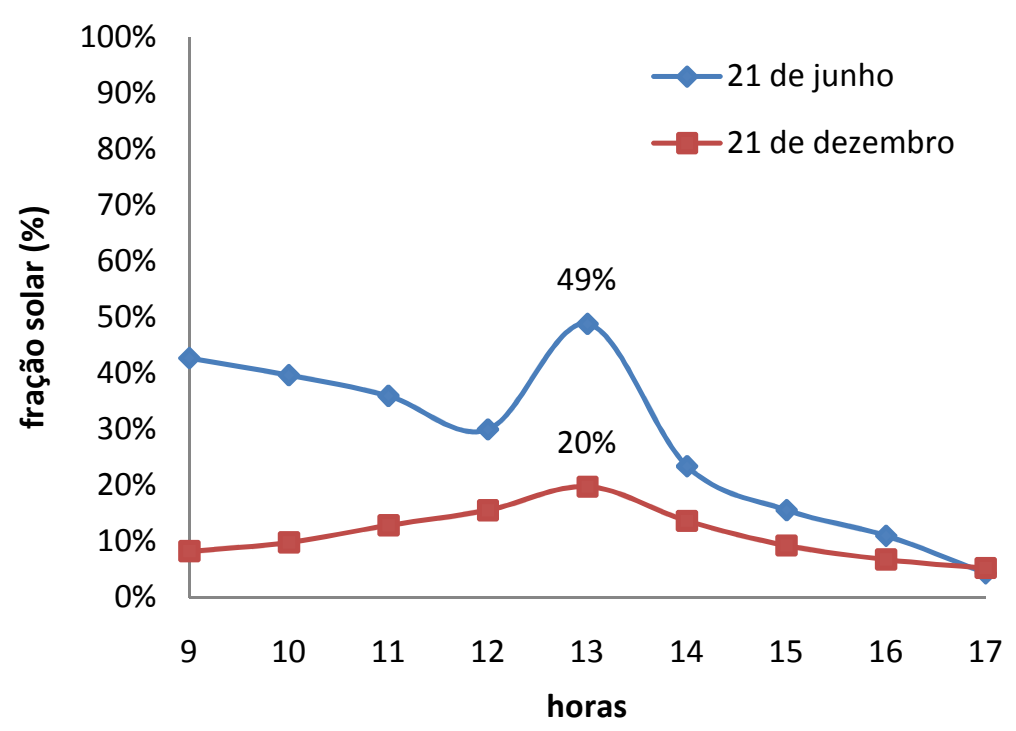

Figura 4.6 - Frações solares para o ar condicionado solar térmico para inverno e verão.

A Figura 4.6, portanto, mostra as frações solares obtidas na simulação do dia 21 de junho e 21 de dezembro, na operação do sistema de ar condicionado solar térmico. Esses valores representam o quanto da energia térmica demandada pelo chiller de absorção é satisfeita em cada hora pelo suprimento de energia renovável. Em outras palavras, observando a Figura, pode-se dizer que em nenhum instante dos dias 21 de junho e dezembro, o suprimento de energia proveniente dos coletores solares foi superior a $50 \%$ da demanda de energia térmica do chiller.

Como se observa na Figura acima, a fração solar máxima, isto é, a fração máxima da demanda do chiller satisfeita pelo fornecimento de energia solar, ocorreu para o dia de Junho e de Dezembro no período das 13 horas às 14 horas e correspondeu, respectivamente a $49 \%$ e a $20 \%$. Estes valores são bastante baixos e refletem no desempenho energético reduzido do sistema de ar condicionado solar, como se observou no valor elevado de consumo de energia do sistema solar térmico, apresentado pela Figura 4.4. De fato, se a fração solar é baixa, o consumo elétrico do aquecedor auxiliar é alto, elevando o consumo do sistema.

Por esses motivos, portanto, o desempenho energético do sistema de ar condicionado solar térmico é bastante insatisfatório. Por outro lado, o desempenho energético do sistema de ar condicionado solar elétrico é interessante, já que esse sistema corresponde basicamente, como foi definido no capítulo 3 , ao sistema convencional de ar condicionado, alimentado com a energia proveniente dos painéis 
fotovoltaicos. Para um prédio razoavelmente alto como o estudado com elevada área de fachadas, a produção de energia é significativa, resultando um ganho de energia em relação ao sistema convencional. Isso já não ocorre no sistema solar térmico de ar condicionado que, além de, por hipótese deste trabalho, não possuir o apoio do sistema fotovoltaico, ainda apresenta o elevado consumo do back-up de energia, conforme discutido acima.

Além da questão do desempenho reduzido do sistema solar térmico, outro ponto que merece uma consideração especial, a partir dos resultados, é a variação sazonal dos resultados, isto é, a influência da época do ano.

Ao utilizar para a simulação, os arquivos climáticos disponibilizados pelo EnergyPlus, conforme descrito no capítulo 3 , e considerando nas simulações os dias 21 de Junho e 21 de Dezembro, que diferem significativamente quanto as condições climáticas, o consumo de energia dos sistemas resultou significativamente diverso de acordo com a época do ano.

Isso se observa na Figura 4.4, na qual, fica claro que o consumo de energia de cada sistema de ar condicionado é menor no inverno do que no verão.

Por um lado, para o sistema convencional, não alimentado por energia solar, isso pode ser considerado razoável, já que no verão, presume-se a existência de uma carga térmica maior, resultando em um consumo maior de energia pelo ar condicionado.

Por outro lado, os sistemas de condicionamento solar de ar envolvem sistemas de aproveitamento de energia solar. Dessa forma, ao mesmo tempo que a carga térmica no edifício aumenta no período de verão, também aumenta a oferta de energia solar para os sistemas de aproveitamento solar, restando saber que efeito é mais significativo na operação do sistema.

Pela análise desenvolvida e pelos resultados obtidos, observou-se que ainda que o suprimento de energia solar seja maior no verão do que no inverno (com picos de irradiância solar de $891 \mathrm{~W} / \mathrm{m}^{2}$ no verão e $680 \mathrm{~W} / \mathrm{m}^{2}$ no inverno, no plano dos coletores térmicos, por exemplo), como mostra a Figura 4.7, esse aumento de disponibilidade de energia solar não compensa o aumento da carga térmica do edifício. 


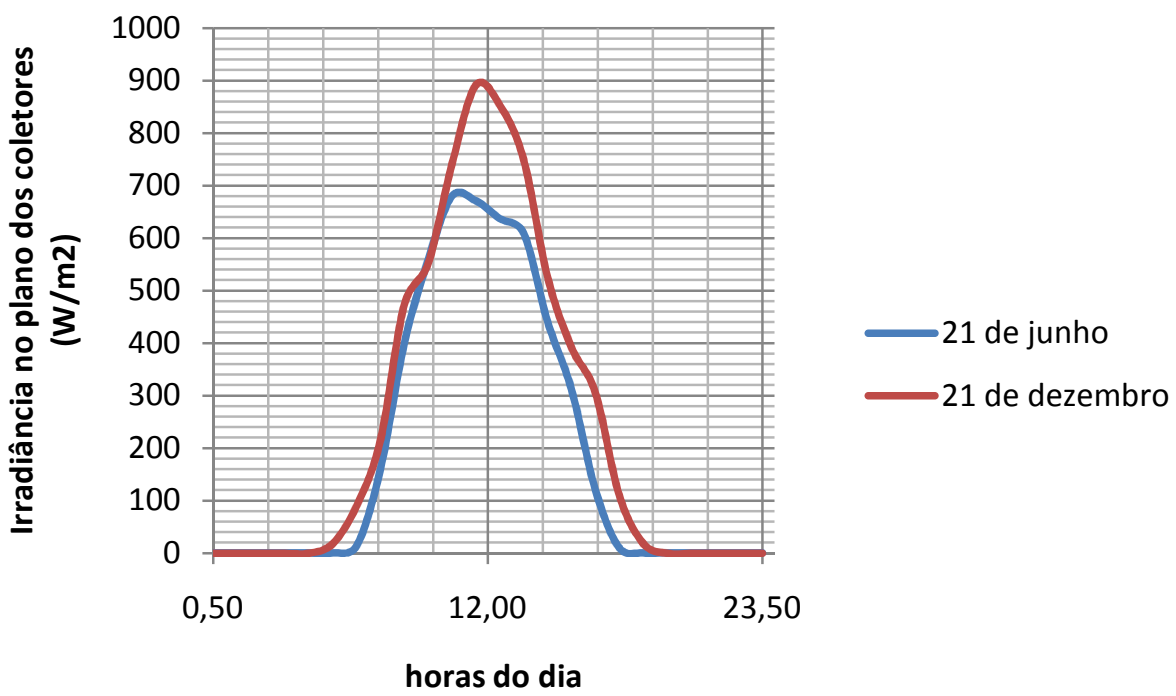

Figura 4.7 - Irradiância solar simulada no plano dos coletores inclinados a 23ํㅜ e orientados ao norte.

Em resumo, como se observa na Figura 4.5, os sistemas de ar condicionado solar simulados apresentaram desempenho energético melhor no inverno do que no verão, mesmo com o maior suprimento de energia solar no verão.

Para o sistema de ar condicionado solar térmico, essa melhora do desempenho energético no inverno pode ser constatada, observando-se os valores da variável $K$ definido pelo método do capítulo anterior pela eq. (7). $O$ valor de $K$ representa o fator, para cada hora do dia, (menor que 1, igual a 1 ou maior que 1) multiplicativo da demanda de energia térmica do chiller solar daquela hora (em $\mathrm{kWh}$ térmicos) para se obter o consumo de energia elétrica, em kWh elétricos, daquela hora, por parte do do sistema de ar condicionado solar térmico.

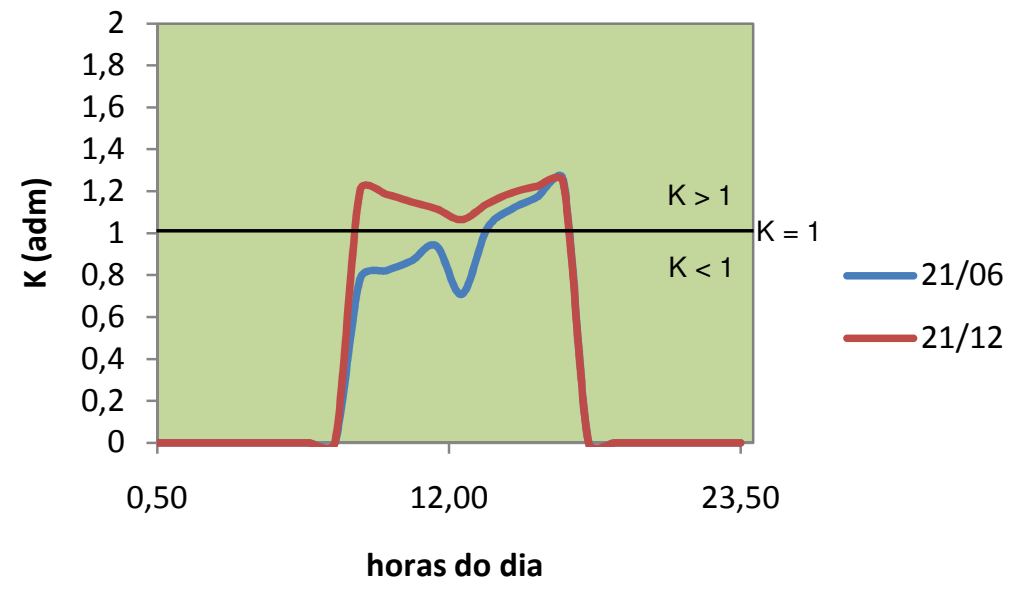

Figura 4.8 - Valores de $K$ para o sistema de ar condicionado solar térmico. 
Os valores de $K$ para as horas do dia 21 de junho e 21 de dezembro, são apresentados na Figura 4.8, a seguir, que mostra que, para todas as horas do dia, os valores de $K$ para o dia de verão são superiores aos valores de $K$ para o dia de inverno.

Até aqui, os consumos de energia elétrica apresentados representam valores diários, para um dia de inverno e um dia de verão. Porém, é interessante também analisar o consumo de energia dos sistemas de ar condicionado solar ao longo das horas dos dias 21 de junho e 21 de dezembro estudados.

A Figura 4.9 e 4.10 mostram os valores de consumo de energia elétrica dos sistemas solar térmico e solar elétrico de ar condicionado, ao longo das horas do dias 21 de junho e 21 de dezembro, respectivamente. Vale lembrar que, por hipótese, no capítulo 3 , considerou-se o funcionamento do ar condicionado das 9 horas da manhã às 18 horas da tarde. Nas Figuras a seguir, o valor numérico da hora indicado em cada intervalo no eixo das ordenadas representa o horário final do período correspondente.

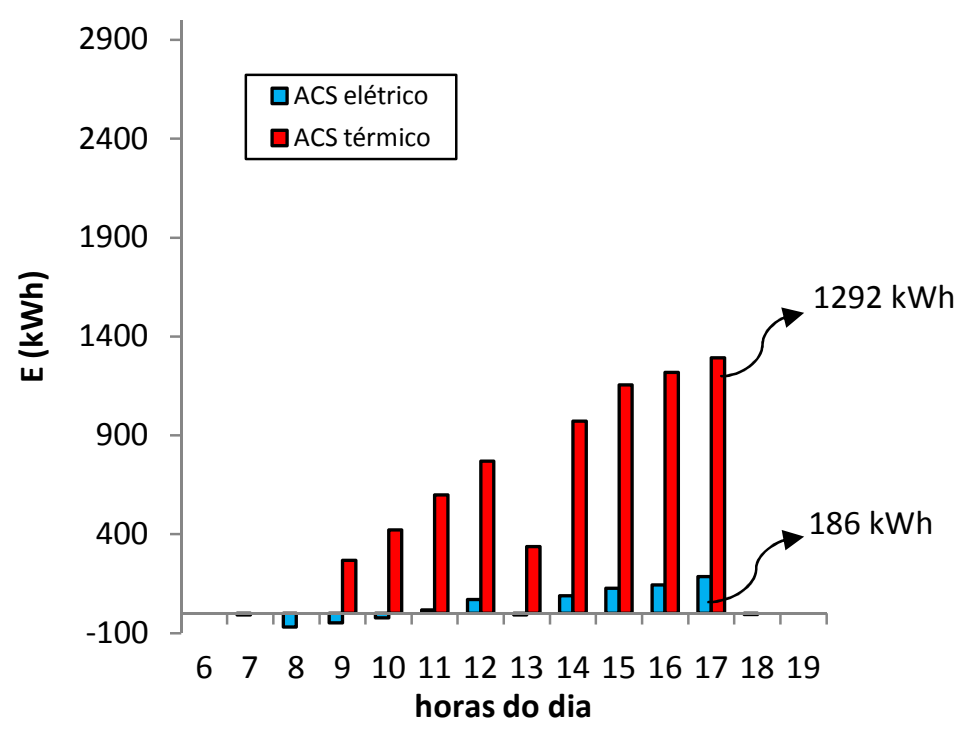

Figura 4.9 - Consumo de energia dos sistemas de ar condicionado solar ao longo do dias 21/06. 


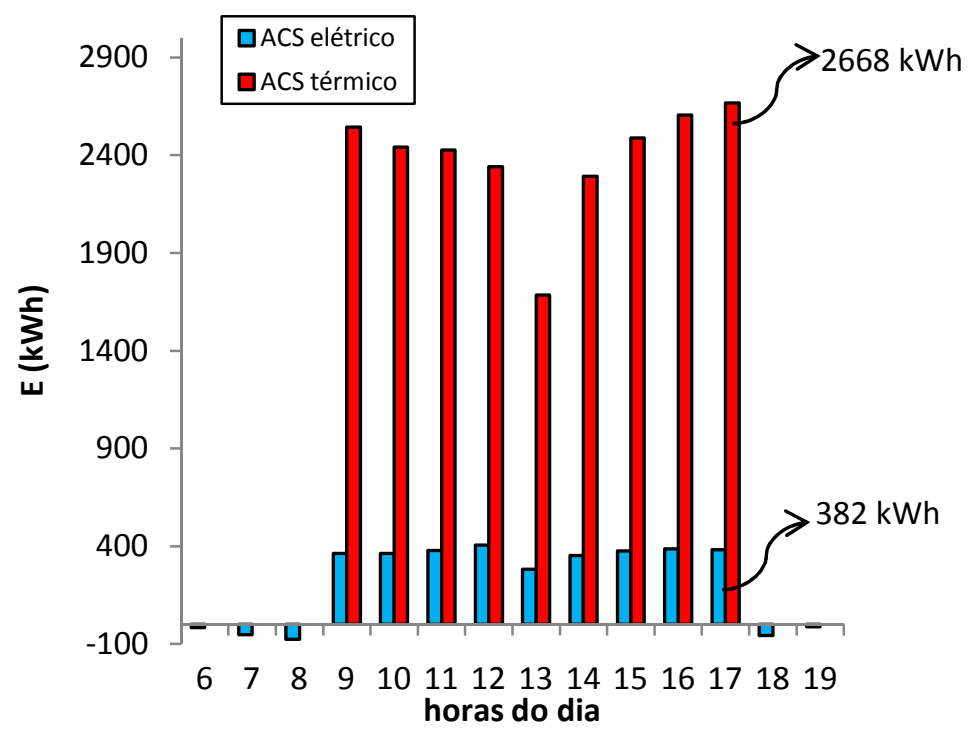

Figura 4.10 - Consumo de energia dos sistemas de ar condicionado solar ao longo do dias 21/12.

Comparando-se os gráficos das Figura 4.9 e 4.10 acima, com o gráfico da Figura 4.1, observa-se uma considerável semelhança dos valores de carga térmica (Figura 4.1), com o consumo de energia elétrica ao longo do dia (Figura 4.9 e Figura 4.10). Isso evidencia o fato de que o comportamento energético do sistema de ar condicionado solar está atrelado fortemente ao comportamento térmico do edifício.

Essa constatação, aparentemente óbvia, deve ser levada em consideração na adoção desses sistemas de ar condicionado solar, já que uma redução na carga térmica, tanto por meios passivos como ativos, resulta certamente em uma melhora do desempenho energético dos sistemas de ar condicionado.

Nas Figuras 4.9 e 4.10, também, como se era de esperar, observam-se consumos de energia maiores no dia de verão do que no dia de inverno. Os valores máximos horários de consumo de energia elétrica, para o dia de inverno e de verão, respectivamente, foram $1292 \mathrm{kWh}$ e $2668 \mathrm{kWh}$ para o sistema de ar condicionado solar térmico, assim como, $186 \mathrm{kWh}$ e $382 \mathrm{kWh}$ para o sistema de ar condicionado solar elétrico. A soma dos consumos horários resulta nos valores de consumo de energia apresentados na Figura 4.4 e na Tabela 4.1, no início deste capítulo.

É interessante observar, também, que para o sistema de ar condicionado solar elétrico, conforme definido neste trabalho, em algumas horas do dia, a produção de energia solar fotovoltaica supera o consumo do ar condicionado, havendo um saldo positivo de energia que pode ser aproveitado pelo próprio edifício. 
Esse fato é representado pelas colunas de valor negativo, nas primeiras e últimas horas do dia, apresentados pelas Figuras 4.9 e 4.10.

De fato, o sistema fotovoltaico foi responsável pela produção de uma quantidade considerável de energia elétrica para o sistema de ar condicionado solar elétrico. Essa energia foi significativa para o desempenho energético do sistema.

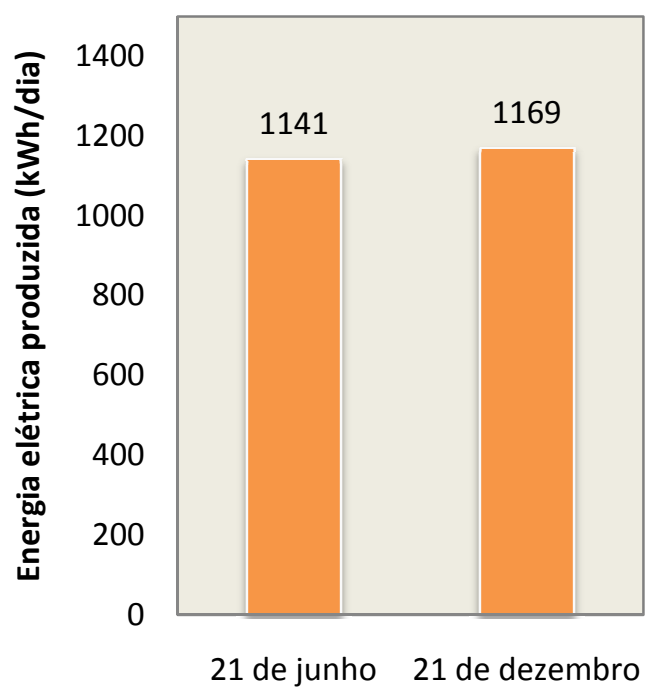

Figura 4.11 - Produção de energia fotovoltaica em kWh/dia nos dias 21/06 e 21/12.

A Figura 4.11, acima, mostra a energia fotovoltaica produzida, já em corrente alternada, nos dias 21 de junho e 21 de dezembro.

Ainda para se ter uma idéia da ordem de grandeza dos resultados de desempenho energético dos sistemas, uma análise interessante pode ser desenvolvida calculando-se, para cada um dos sistemas de ar condicionado solar, para o dia de inverno e verão, o valor da área de escritório condicionada para cada kWh de energia elétrica convencional (da rede) fornecida ao sistema, na hora de pico da carga térmica.

Isto é, pode-se determinar quantos metros quadrados de área do escritório podem ser condicionados, na hora de pico do ar condicionado, para cada kWh consumido de energia elétrica convencional. Os resultados são mostrados na Figura 4.12: 


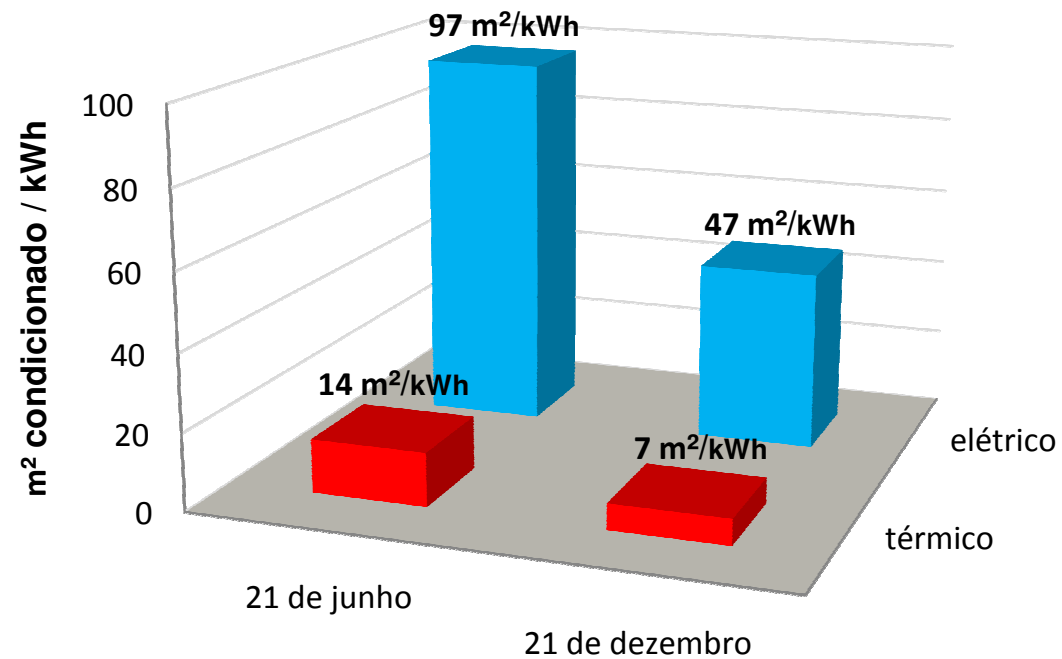

Figura 4.12 - Área de escritórios condicionada, na hora de pico, para cada kWh de energia convencional consumida.

Pela figura 4.12, se observa claramente que a área de escritórios condicionada durante a hora de pico do ar condicionado para cada $\mathrm{kWh}$ de energia elétrica convencional consumida da rede é bem menor para o sistema solar térmico do que para o sistema solar elétrico. Isso tem relação, como já foi apresentado, com desempenho energético melhor do ar condicionado solar elétrico em comparação com o desempenho do ar condicionado solar térmico. Também se observa, em ambos os sistemas, a melhora do desempenho energético dos sistemas no inverno, em relação ao verão, conforme já explicado neste capítulo.

Para concluir a análise energética dos sistemas de ar condicionado solar aplicados ao edifício original de 20 pavimentos, escolhido na cidade de São Paulo, algumas considerações sobre o desempenho energético do sistema de ar condicionado solar térmico devem ser mencionadas.

Primeiramente, é interessante estudar o funcionamento do sistema de aquecimento auxiliar, que, como já foi visto, exerce grande influência no reduzido desempenho energético do ar condicionado solar térmico. 

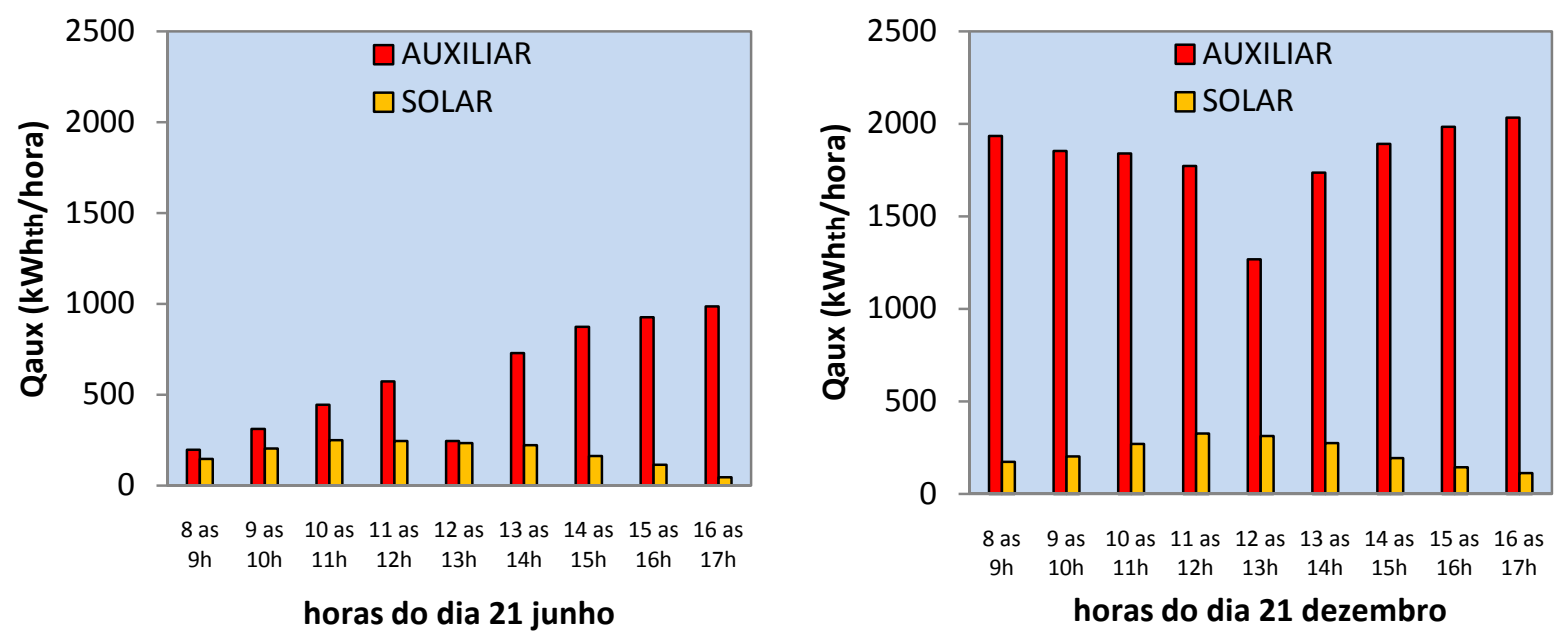

Figura 4.13 - Energia térmica fornecida à água, em KWh, pelo aquecimento auxiliar (AUXILIAR) e pelo sistema de aquecimento solar (SOLAR) ao longo dos dias 21 de junho e 21 de dezembro.

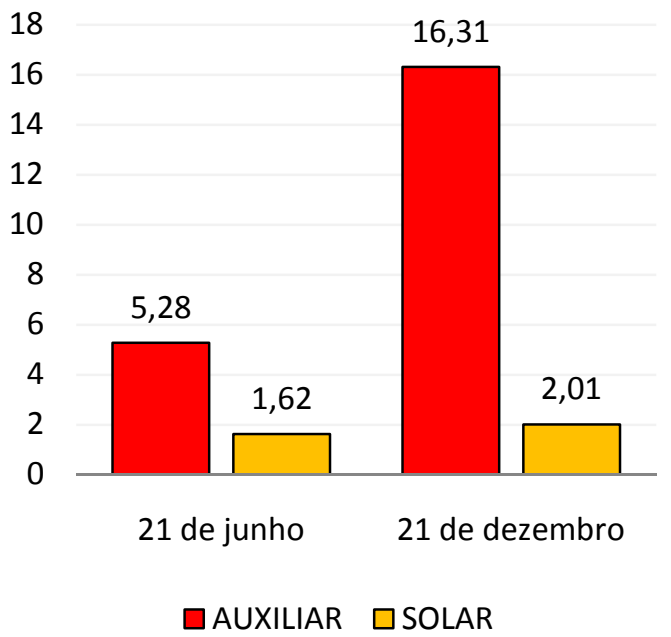

Figura 4.14 - Energia térmica fornecida à água, em MWh, pelo aquecimento auxiliar (AUXILIAR) e pelo sistema de aquecimento solar (SOLAR) total dos dias 21 de junho e 21 de dezembro.

Na simulação, avaliou-se, hora a hora de operação, a quantidade de energia térmica em $\mathrm{KWh} /$ dia, que o sistema de aquecimento auxiliar fornece à água que se dirige ao chiller solar de absorção, assim como, a quantidade de energia térmica fornecida pelos coletores solares à água. As Figura 4.13 e a Figura 4.14 mostram os resultados. De fato, como já foi dito, o consumo de energia do sistema auxiliar é muito significativo no caso estudado.

Outro resultado que mostra a elevada participação do consumo do aquecedor auxiliar do sistema de ar condicionado solar térmico é o calculo da energia elétrica consumida por cada um dos subsistemas que compõem o sistema de ar 
condicionado solar térmico, isto é, o aquecedor auxiliar, o chiller de absorção, a instalação solar e o sistema de rejeição de calor com a torre de resfriamento. Os resultados dessa análise são apresentados na Figura 4.15, a seguir:
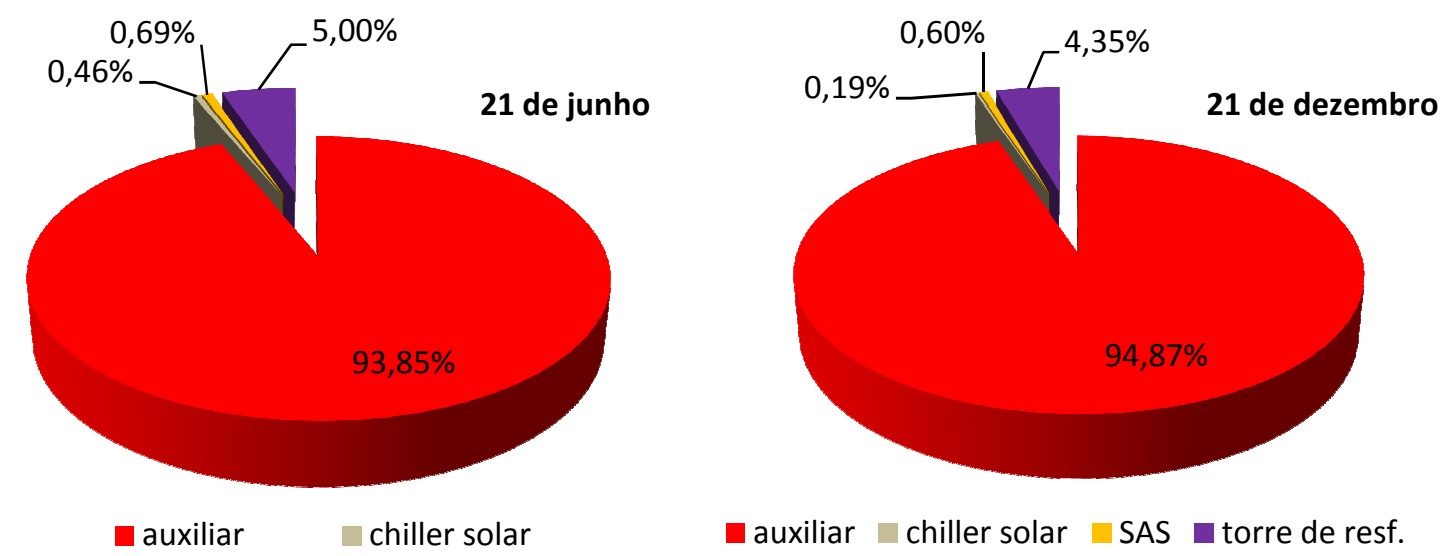

Figura 4.15 - Distribuição da energia elétrica consumida pelos subsistemas (auxiliar: aquecedor auxiliar; chiller solar: chiller de absorção solar; SAS: sistema de aquecimento solar; torre de resf:: sistema de rejeição de calor) do sistema de ar condicionado solar térmico nos dias 21 de junho e 21 de dezembro.

Pela Figura 4.15, pode-se ver o papel predominante do aquecimento auxiliar no consumo de energia do sistema de ar condicionado solar térmico.

Em resumo, para o edifício estudado, a adoção do sistema de condicionamento de ar com utilização de energia solar é interessante energeticamente somente no caso do sistema solar elétrico. No caso da adoção do sistema solar térmico de condicionamento de ar, o desempenho energético é muito reduzido.

Como foi visto, a grande limitação do sistema térmico de condicionamento de ar é o elevado consumo do back-up de energia, devido à necessidade de se atender uma grande demanda de condicionamento de ar (20 pavimentos com $1000 \mathrm{~m}^{2}$ de área cada um), porém com uma área limitada de coletores solares ( $95 \%$ da área de cobertura de $1000 \mathrm{~m}^{2}$ ).

Sendo assim, se o sistema for instalado em um edifício com um número menor de pavimentos é razoável pensar que seu desempenho energético do sistema seria melhor. De fato, como foi discutido ainda neste capítulo, a redução da carga térmica reduz o consumo de energia do sistema de ar condicionado. Dessa 
forma, se para um edifício de 20 pavimentos o sistema de ar condicionado solar térmico não é interessante energeticamente, pode ser que seja para um edifício mais baixo.

Em síntese, enquanto que, por um lado, a aplicação do sistema de ar condicionado solar elétrico é sempre interessante energeticamente em relação à aplicação do sistema convencional, independentemente do número de pavimentos do edifício ${ }^{18}$, por outro lado, a aplicação do sistema térmico de ar condicionado solar pode ser interessante energeticamente somente para edifícios mais baixos que um determinado número de pavimentos.

Por esse motivo, como já foi comentado tanto no capítulo 3 como no início deste capítulo, será desenvolvida uma análise do desempenho desses sistemas em função do número de pavimentos do edifício. Esse assunto será tratado no item 4.2.2 a seguir.

\footnotetext{
${ }^{18}$ Neste caso, a aplicação do sistema de condicionamento de ar solar elétrico é sempre interessante energeticamente em relação ao sistema convencional pois com a área de fachada, para qualquer altura de edifício será sempre maior que zero, haverá sempre produção de energia fotovoltaica e conseqüentemente o consumo de energia elétrica do sistema solar elétrico de ar condicionado será menor que o consumo do sistema convencional de ar condicionado.
} 
4.2.2 Desempenho dos Sistemas em Função do Número de Pavimentos

Como foi dito, a diminuição do número de pavimentos do edifício reduz o consumo de energia do ar condicionado solar, pois a área a ser condicionada diminui. Assim, neste item, desenvolve-se uma análise do comportamento dos sistemas em função do número de pavimentos do edifício no qual estão instalados.

Nesta análise foram estudados, além dos três sistemas de condicionamento de ar já abordados, isto é, do sistema convencional, do sistema solar térmico de ar condicionado e do sistema solar elétrico de ar condicionado, uma quarta alternativa de sistema, definida abaixo:

(4) Sistema de Ar Condicionado Solar Térmico com apoio fotovoltaico: sistema idêntico ao sistema de ar condicionado solar térmico definido no capítulo 3 (com coletores térmicos e chiller de absorção), porém, incluindo os painéis fotovoltaicos nas fachadas - tais quais foram utilizados no sistema elétrico de ar condicionado solar - como suporte para o consumo de energia do aquecedor auxiliar ${ }^{19}$;

Na Figura 4.16 a seguir, são apresentados os resultados da análise do desempenho energético do sistema de ar condicionado convencional ("ACS conv"), do sistema de ar condicionado solar elétrico ("ACS elétrico"), do sistema de ar condicionado solar térmico ("ACS térmico") e do sistema de ar condicionado solar térmico com apoio fotovoltaico ("ACS térm+fv"), definido acima, em função do número de pavimentos do edifício, para os dias 21 de junho e 21 de dezembro.

\footnotetext{
${ }^{19}$ Pensou-se em analisar, também, esse sistema de ar condicionado solar, a fim de potencializar a utilização dos sistemas de aproveitamento solar fotovoltaico e térmico. De fato, no ar condicionado solar térmico, definido no capítulo 3 , os coletores solares estão somente alocados na cobertura e no ar condicionado solar elétrico, definido no capítulo 3 , os painéis fotovoltaicos estão somente alocados nas fachadas. É razoável se pensar, então, na possibilidade de se unir as duas concepções, utilizando coletores térmicos na cobertura, ao mesmo tempo que, painéis fotovoltaicos nas fachadas, resultando no sistema de ar condicionado solar térmico com apoio fotovoltaico.
} 
É importante lembrar também que, para a simulação e a análise deste item 4.2.2, os sistemas estudados e a tipologia do edifício conservaram-se as mesmas das definidas no capítulo 3 , assim como as hipóteses e parâmetros adotados. 0 único parâmetro que se alterou, em relação à análise desenvolvida no item 4.2.1 anterior, foi o número de pavimentos do edifício, que deixou de ser constante e igual a 20.

Além disso, foi incluída na análise uma quarta alternativa de sistema de ar condicionado, o sistema de ar condicionado térmico com apoio fotovoltaico, definido acima, de forma que o sistema térmico de ar condicionado solar pudesse ser aprimorado com o apoio de painéis fotovoltaicos, auxiliando no consumo elétrico do aquecedor auxiliar. Neste caso, a alimentação elétrica do aquecedor auxiliar não é feita somente pela energia da rede, mas é apoiada pela produção de energia fotovoltaica que auxilia no suprimento de energia para o aquecedor.

Também na concepção do sistema de ar condicionado solar térmico com apoio fotovoltaico, todas as hipóteses e parâmetros já adotados para o edifício, para o sistema de condicionamento de ar e para os sistemas de aproveitamento solar, definidos no capítulo 3 , foram mantidos.
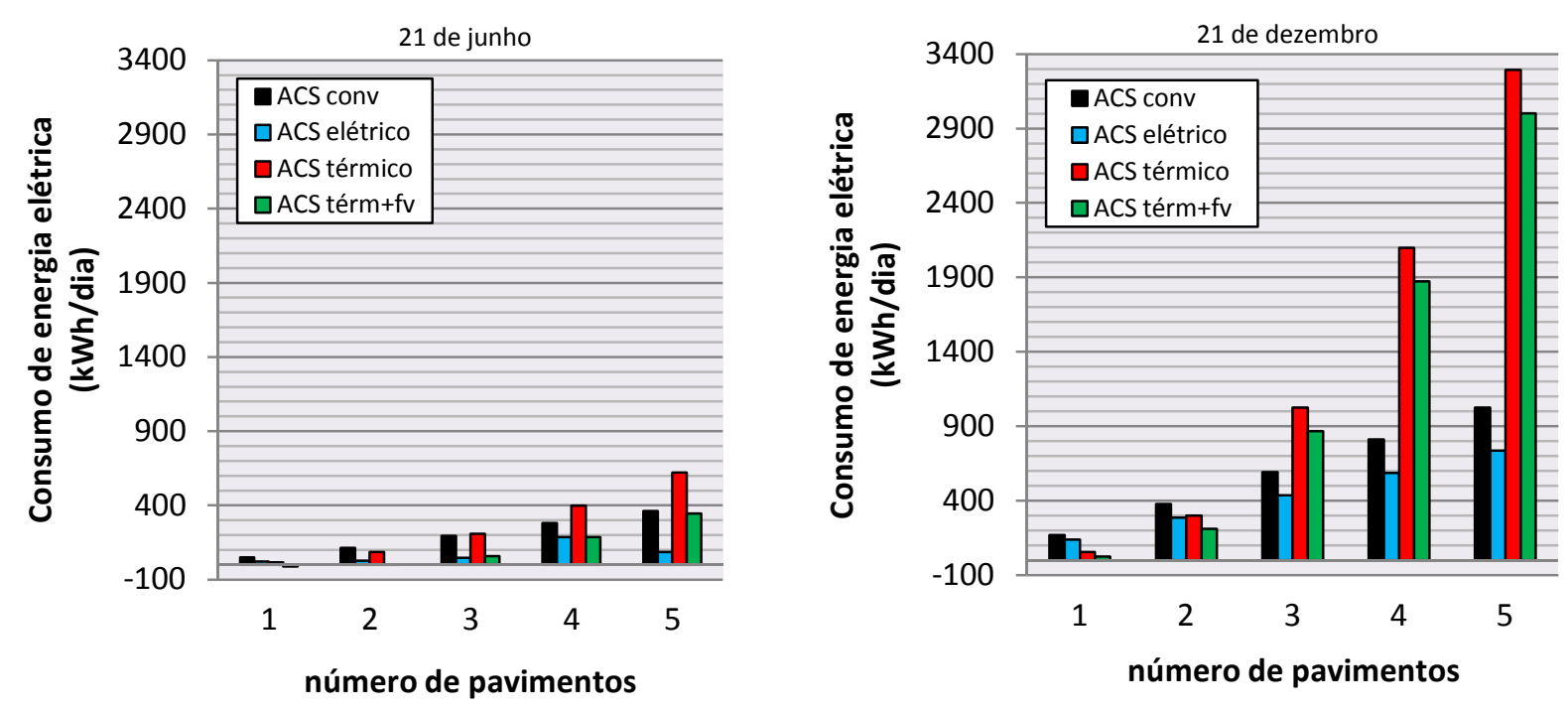

Figura 4.16 - Consumo de energia elétrica dos sistemas de ar condicionado estudados em função do número de pavimentos para os dias 21/06 e 21/12. 
Pela Figura 4.16, se observa, primeiramente que, assim como ocorreu no caso do edifício de 20 pavimentos, o consumo energético dos sistemas de ar condicionado, neste caso aplicados à edifícios mais baixos $(1,2,3,4$ ou 5 pavimentos), é ainda superior no dia de verão (21 de dezembro) do que no dia de inverno (21 de junho).

Depois, se observa na Figura 4.16, conforme esperado, que os resultados de consumo de energia elétrica dos sistemas de ar condicionado solar, para edifícios com poucos pavimentos, são menores em relação ao consumo obtido no caso do edifício original de 20 pavimentos.

Enquanto que o consumo de energia do sistema de ar condicionado solar térmico, por exemplo, para o edifício de 20 pavimentos, apresentado no item 4.2.1 anterior, foi de 7,04 MWh e de 21,50 MWh, nos dias 21 de junho e 21 de dezembro, respectivamente, o consumo de energia desse sistema para o edifício com 5 pavimentos foi de 0,62 MWh e de 3,29 MWh, nos dias 21 de junho e 21 de dezembro respectivamente.

Da mesma forma, enquanto que o consumo de energia do sistema de ar condicionado solar elétrico, para o edifício de 20 pavimentos, apresentado no item 4.2.1 anterior, foi de 0,47 MWh e de 3,08 MWh, nos dias 21 de junho e 21 de dezembro, respectivamente, o consumo de energia desse sistema para o edifício com 5 pavimentos foi de 0,09 MWh e de 0,74 MWh, nos dias 21 de junho e 21 de dezembro respectivamente.

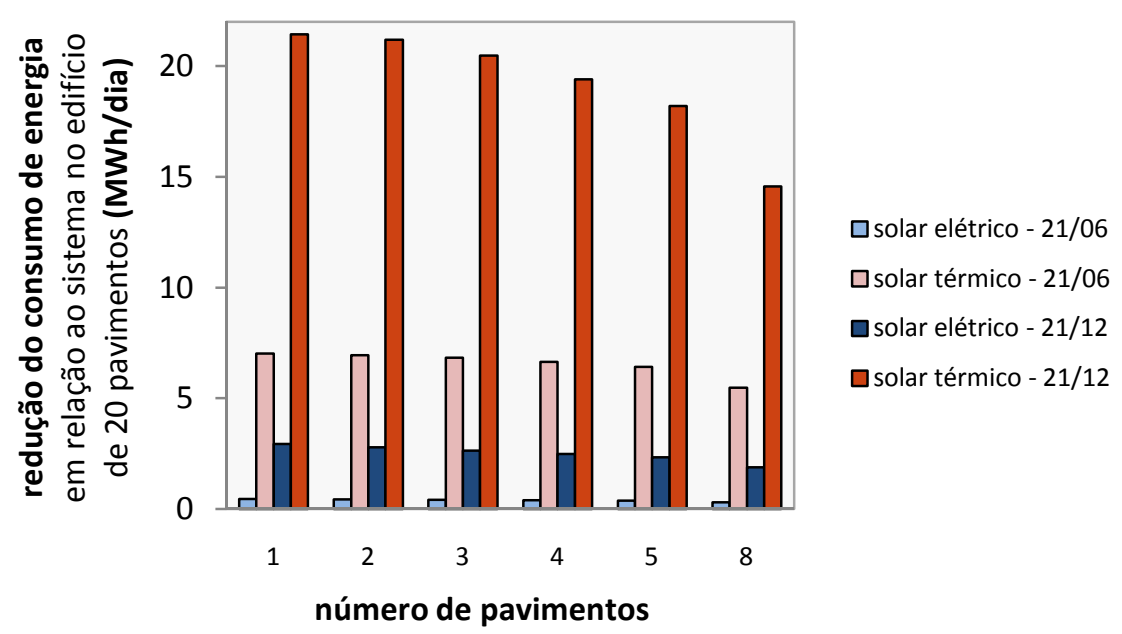

Figura 4.17 - Redução do consumo de energia elétrica dos sistemas de ar condicionado por ocasião da alteração do número de pavimentos do edifício de 20 para 1, 2, 3, 4, 5 e 8. 
A Figura 4.17, mostra essa redução do consumo de energia resultante da modificação do edifício de 20 pavimentos para um número menor de pavimentos. No caso da Figura 4.17, mostra-se os valores de redução do consumo elétrico do sistema de ar condicionado solar térmico e do sistema de ar condicionado solar elétrico, se ao invés de serem aplicados ao edifício de 20 pavimentos, forem aplicados a edifícios idênticos com 1, 2, 3, 4, 5 e 8 pavimentos.

Como foi visto no item 4.2.1 anterior, o sistema térmico de ar condicionado solar, para o edifício de 20 pavimentos, apresenta um desempenho energético muito ruim, se comparado com o desempenho energético do sistema de ar condicionado convencional e do sistema de ar condicionado solar elétrico. Essa situação, entretanto, não ocorre no caso de edifícios baixos, nos quais o desempenho do sistema térmico de ar condicionado solar chega a ser melhor do que os outros.

Isso pode ser visualizado pela Figura 4.18 , na qual são representados os consumos de energia elétrica dos sistemas de ar condicionado solar elétrico e solar térmico, para as situações do edifício com 1 pavimento (térreo apenas), 2 pavimentos e 3 pavimentos.
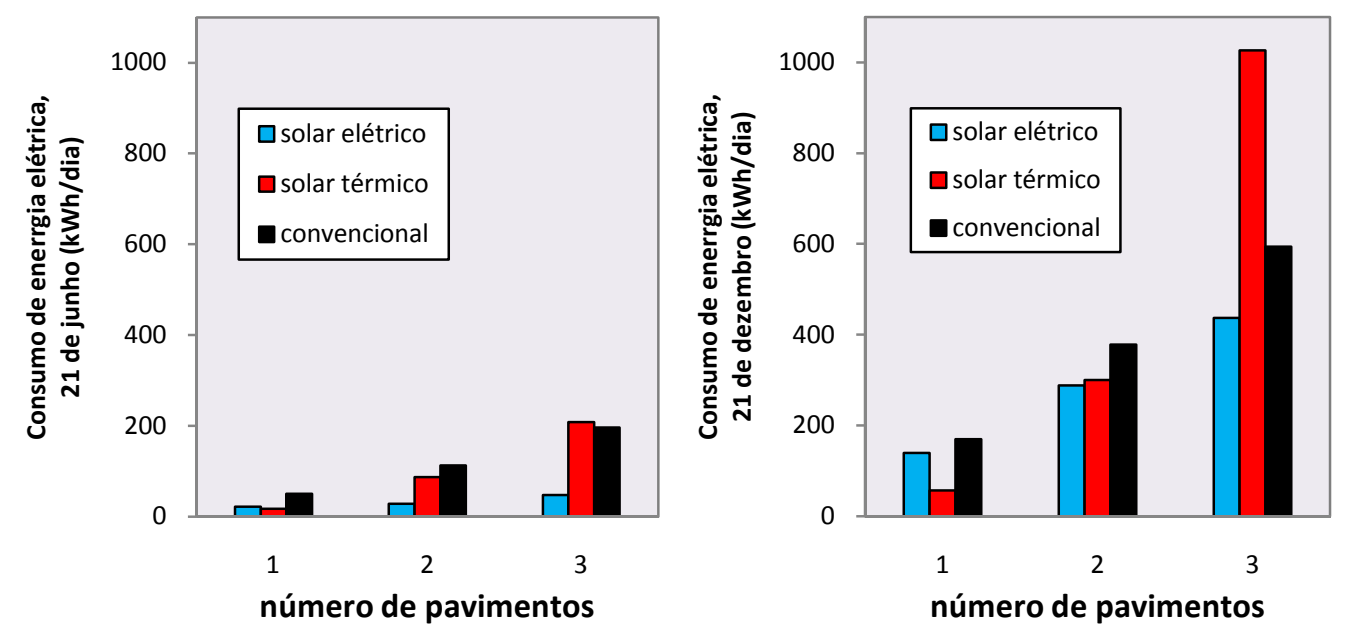

Figura 4.18 - Consumos de energia dos sistemas de ar condicionado solar elétrico e térmico para os dias 21/06 e 21/12, aplicados ao edifício de 1, 2 e 3 pavimentos.

De fato, da análise do desempenho energético do ar condicionado em função do número de pavimentos do edifício (Figura 4.18) constatou-se que, por exemplo, quanto o número de pavimentos é 1 (edifício térreo), o desempenho energético do 
sistema térmico de ar condicionado solar (coluna vermelha) chega a ser melhor do que o desempenho dos sistemas de ar condicionado solar elétrico (coluna azul) do que do ar condicionado convencional (coluna preta). Isso ocorre tanto no dia 21 de junho como no dia 21 de dezembro.

De forma semelhante, constatou-se que quanto o número de pavimentos é 2 (edifício com o pavimento térreo e mais um andar), o desempenho energético do sistema térmico de ar condicionado solar (coluna vermelha) já não é melhor do que o desempenho do sistema de ar condicionado solar elétrico (coluna azul). Porém é ainda melhor do que o desempenho do ar condicionado convencional (coluna preta). Isso ocorre tanto no dia 21 de junho como no dia 21 de dezembro.

O que ocorre é que, para o sistema de ar condicionado convencional, a diminuição do número de pavimentos causa uma diminuição gradual no consumo de energia elétrica. Da mesma forma, para o sistema de ar condicionado solar elétrico, a diminuição do número de pavimentos também resultou na diminuição do consumo de energia elétrica do sistema. Além disso, devido à produção de energia fotovoltaica nas fachadas, esse consumo manteve-se menor que o do sistema convencional.

Para o sistema de ar condicionado solar térmico, porém, o consumo de energia reduziu-se significativamente com a redução do número de pavimentos. $\mathrm{Na}$ realidade, a instalação solar térmica alocada na cobertura, no caso do edifício mais baixo, passou a conseguir suprir satisfatoriamente as necessidades energéticas do chiller de absorção. Assim, a área limitada na cobertura passou a ser suficiente para conseguir suprir a demanda do chiller solar, sem tanta necessidade de utilização do aquecimento auxiliar, aumentando assim a fração solar e reduzindo o consumo.

Em outras palavras, quanto menor é o edifício, menor é a necessidade de se utilizar o back-up de energia convencional e melhor é o desempenho do sistema térmico. $O$ interessante, porém, é que esse consumo do sistema solar térmico de ar condicionado, não somente se reduz com a diminuição do número de pavimentos, mas também se reduz em proporções cada vez maiores.

Definindo a redução porcentual no consumo de energia elétrica do sistema de ar condicionado solar térmico ( $\alpha_{\text {térmico,N }}$, em \%), causado pela redução do número de pavimentos do edifício de $(N+1)$ pavimentos para $N$ pavimentos, conforme a eq.(40), a seguir, tem-se que $\alpha_{E, N}$ cresce em função da redução do número de pavimentos (variável $M$ ), conforme a Figura 4.19. 


$$
\alpha_{E, N}=\frac{E_{t e ́ r m i c o, N+1}-E_{\text {térmico,N }}}{E_{\text {térmico, } N+1}}
$$

sendo:

$\alpha_{E, N}$ - redução porcentual no consumo de energia elétrica diário do sistema de ar condicionado solar térmico, causado pela redução do número de pavimentos do edifício de $(N+1)$ pavimentos para $N$ pavimentos $(\%)$.

$E_{\text {térmico,N+1 }}$ - consumo diário de energia elétrica do sistema de ar condicionado solar térmico, aplicado ao edifício de $N+1$ pavimentos ( $\mathrm{kWh} / \mathrm{dia})$.

$E_{\text {térmico,N }}$ - consumo diário de energia elétrica do sistema de ar condicionado solar térmico, aplicado ao edifício de $N$ pavimentos (kWh/dia).

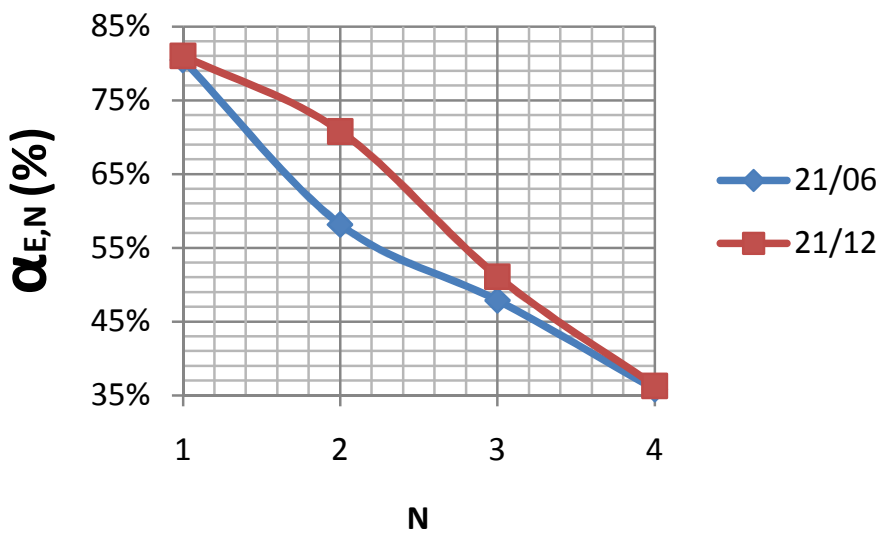

Figura 4.19 - redução porcentual no consumo de energia elétrica do sistema de ar condicionado solar térmico, causado pela redução do número de pavimentos do edifício de $(N+1)$ pavimentos para $n$ pavimentos (em \%), em função do número $N$ de pavimentos.

De fato, se a fração solar do sistema térmico se mantivesse constante com a diminuição da altura do prédio, o valor de $\alpha_{C E, n}$ seria constante em função de $n$, pois o ar condicionado economizaria um valor sempre igual de energia para seu funcionamento, a cada pavimento suprimido do edifício. Como a fração solar, ao invés de permanecer constante, aumenta com a diminuição do número de 
pavimentos, então o consumo de energia elétrica do sistema reduz cada vez mais com a diminuição altura do edifício $\left(\alpha_{E, N}\right)$ crescente em função da redução de $\left.n\right)$.

Por fim, para ilustrar melhor essa influência da altura do edifício no desempenho do sistema, é interessante observar a Figura 4.20 e a Figura 4.21, que mostram, para o dia de inverno e de verão, respectivamente, as proporções entre os consumos de energia dos três sistemas de ar condicionado solar estudados (elétrico, térmico e térmico com apoio fotovoltaico) em relação ao consumo de energia do sistema convencional.

Essa proporção foi calculada, para os três sistemas de ar condicionado solar estudados (elétrico, térmico e térmico com apoio fotovoltaico) pelos fatores $i_{\text {elétrico,N }}$, $i_{\text {térmico,N }}$ e $i_{\text {térm } f f v, N}$ conforme as eq. (41), eq.(42) e eq.(43), respectivamente. A proporção entre o consumo de energia elétrica do sistema de ar condicionado solar elétrico e o consumo de energia elétrica do sistema de ar condicionado convencional $\left(i_{\text {elétrico,N }}\right)$, para o edifício com $N$ pavimentos, é calculada pela eq.(41):

$$
i_{\text {elétrico, } N}=\frac{E_{\text {elétrico }}(\mathrm{kWh} / \text { dia })}{E_{\text {conv }}(\mathrm{kWh} / \mathrm{dia})} \times 100
$$

sendo:

$i_{\text {elétrico,N }}$ - proporção entre o consumo de energia elétrica do sistema de ar condicionado solar elétrico e o consumo de energia elétrica do sistema de ar condicionado convencional, para o edifício com $N$ pavimentos (\%).

$E_{\text {elétrico }}$ - consumo diário de energia elétrica do sistema de ar condicionado solar elétrico, para o edifício com $N$ pavimentos ( $\mathrm{kWh} / \mathrm{dia}$ ).

$E_{c o n v}$ - consumo diário de energia elétrica do sistema de ar condicionado convencional, para o edifício com $n$ pavimentos ( $\mathrm{kWh} / \mathrm{dia})$.

A proporção entre o consumo de energia elétrica do sistema de ar condicionado solar térmico e o consumo de energia elétrica do sistema de ar condicionado convencional ( $i_{\text {térmico,N }}$ ), para o edifício com $N$ pavimentos, é calculada pela eq.(42): 


$$
i_{\text {térmico,N }}=\frac{E_{\text {térmico }}(\mathrm{kWh} / \mathrm{dia})}{E_{\text {conv }}\left({ }^{\mathrm{kWh} / \mathrm{dia}}\right)} \times 100
$$

sendo:

$i_{\text {térmico,N }}$ - proporção entre o consumo de energia elétrica do sistema de ar condicionado solar térmico e o consumo de energia elétrica do sistema de ar condicionado convencional, para o edifício com $N$ pavimentos (\%).

$E_{\text {térmico,N }}$ - consumo diário de energia elétrica do sistema de ar condicionado solar térmico, para o edifício com $N$ pavimentos (kWh/dia).

$E_{\text {conv }, N}$ - consumo diário de energia elétrica do sistema de ar condicionado convencional, para o edifício com $N$ pavimentos (kWh/dia).

A proporção entre o consumo de energia elétrica do sistema de ar condicionado solar térmico com apoio fotovoltaico e o consumo de energia elétrica do sistema de ar condicionado convencional $\left(i_{\text {térm }+f v, N}\right)$, para o edifício com $N$ pavimentos, é calculada pela eq.(43):

$$
i_{\text {térmi }+f v, N}=\frac{E_{\text {térm }+f v}(k W h / d i a)}{E_{c o n v}(k W h / d i a)} \times 100
$$

sendo:

$i_{\text {térm }+f v, N}$ - proporção entre o consumo de energia elétrica do sistema de ar condicionado solar térmico com apoio fotovoltaico e o consumo de energia elétrica do sistema de ar condicionado convencional, para o edifício com $N$ pavimentos (\%). $E_{\text {térm }+f v, N}$ - consumo diário de energia elétrica do sistema de ar condicionado solar térmico com apoio fotovoltaico, para o edifício com $N$ pavimentos (kWh/dia). $E_{c o n v, N}$ - consumo diário de energia elétrica do sistema de ar condicionado convencional, para o edifício com $N$ pavimentos ( $\mathrm{kWh} / \mathrm{dia})$.

As Figuras 4.20 e 4.21, que mostram os valores de $i$ em função do número $N$ de pavimentos do edifício são apresentadas abaixo: 


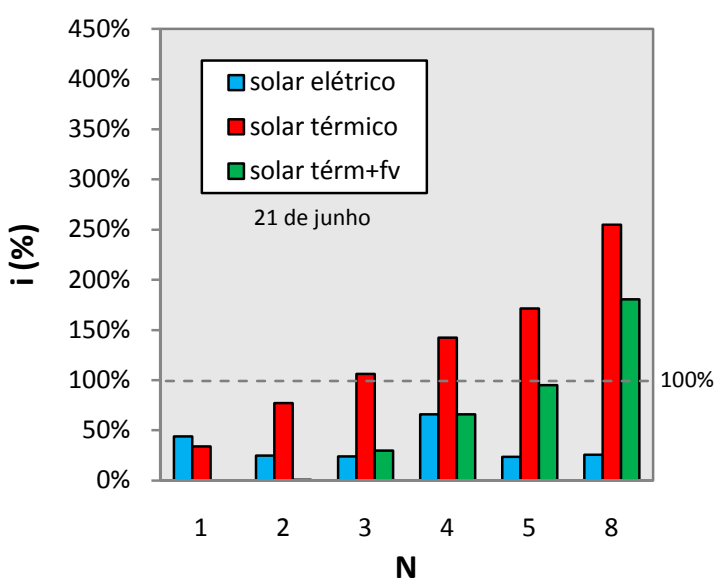

Figura 4.20 - Proporções entre os consumos de energia dos sistemas de ar condicionado solar e o do sistema de ar condicionado convencional para o dia 21 de junho, em função do número de pavimentos do edifício.

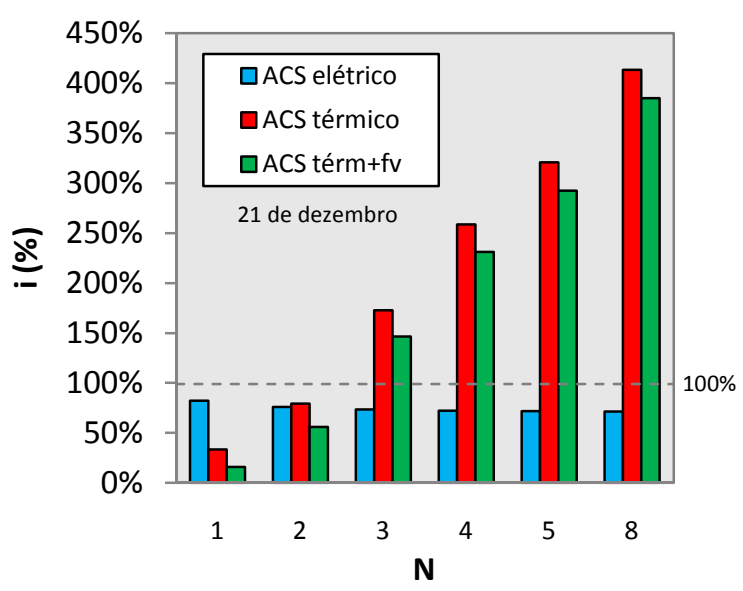

Figura 4.21 - Proporções entre os consumos de energia dos sistemas de ar condicionado solar e o do sistema de ar condicionado convencional para o dia 21 de dezembro, em função do número de pavimentos do edifício.

As Figuras 4.20 e 4.21, são interessantes de serem observadas, pois, além de facilitar a comparação do consumo energético entre as alternativas de ar condicionado, pode-se, com o auxílio da linha tracejada correspondente a $i=100 \%$, comparar facilmente o desempenho energético dos sistemas de ar condicionado solar em relação ao sistema convencional de ar condicionado.

De fato, nos casos em que $i<100 \%$, o sistema de ar condicionado em questão é mais vantajoso energeticamente do que o sistema convencional. Por outro lado, nos casos em que $i>100 \%$, o sistema de ar condicionado em questão é menos vantajoso energeticamente do que o sistema convencional. 
De acordo com as Figuras anteriores, observa-se, primeiramente, que o sistema de ar condicionado solar elétrico consome menos energia elétrica que o convencional, em todos os casos. De fato, o consumo de energia do sistema elétrico de ar condicionado solar, nas Figuras 4.20 e 4.21, está sempre abaixo da linha tracejada, isto é, $E_{\text {elétrico }}<E_{\text {conv }}$ em todos os casos.

De fato, quanto maior o número de pavimentos do edifício, maior é a produção de energia fotovoltaica (Figura 4.22), pois maior é a área de fachadas disponível. Assim, como foi dito, para qualquer altura de edifício o sistema de ar condicionado solar elétrico levará vantagem energética em relação ao sistema convencional de ar condicionado.
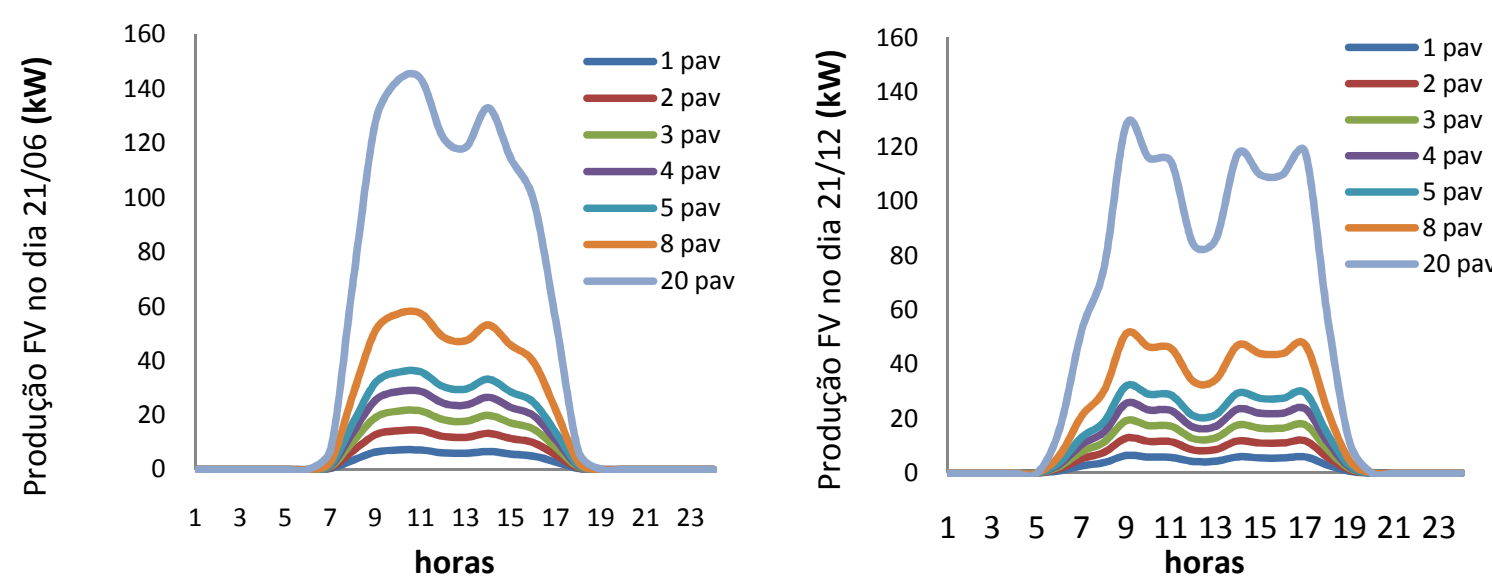

Figura 4.22 - Produção de energia elétrica pelo sistema fotovoltaico alocado nas fachadas do edifício, nos dias 21 de junho e 21 de dezembro.

Observa-se, porém, que o sistema de ar condicionado solar térmico (Figuras 4.20 e 4.21), apresenta consumos de energia abaixo do sistema convencional, isto é, abaixo da linha tracejada, apenas para edifícios com 1 ou 2 pavimentos, tanto no dia 21 de junho como no dia 21 de dezembro.

Quanto ao sistema de ar condicionado solar térmico com apoio fotovoltaico, por sua vez, se obtém desempenhos energéticos superiores ao sistema convencional para alturas maiores de edifício. Para o dia 21 de junho, por exemplo, como mostra a Figura 4.20 , em um prédio de 5 pavimentos, o desempenho energético do sistema térmico com apoio fotovoltaico é ainda superior do que o desempenho energético do sistema convencional de ar condicionado. 
Em resumo, pelo que foi apresentado até aqui, pode-se concluir que sistemas de ar condicionado solar térmicos são vantajosos energeticamente somente em aplicações em edifícios baixos, com pouca demanda de ar condicionado. Para edifícios mais altos são mais vantajosos energeticamente os sistemas de ar condicionado solar elétricos.

Uma forma interessante de se verificar esse fato é através do cálculo da economia de energia elétrica do sistema de ar condicionado solar para o edifício com $N$ pavimentos $\left(\Delta E_{N}\right)$, definida como a diferença entre o consumo de energia elétrica do sistema convencional e o consumo de energia elétrica do sistema de ar condicionado solar, para um edifício com $N$ pavimentos, conforme as eq.(44) e eq.(45) (GUIDELINES, SOLAIR, 2008):

$$
\begin{aligned}
& \Delta E_{N, \text { térmico }}=E_{N, \text { conv }}-E_{N, \text { térmico }} \\
& \Delta E_{N, \text { elétrico }}=E_{N, \text { conv }}-E_{N, \text { elétrico }}
\end{aligned}
$$

Assim, pode-se avaliar quando um sistema de ar condicionado solar passa a ser mais vantajoso energeticamente que o sistema convencional, bastando determinar, para isso, o número de pavimentos para o qual $\Delta E_{\text {conv }}=0$.

Da mesma forma, determinando-se o número de pavimentos para o qual

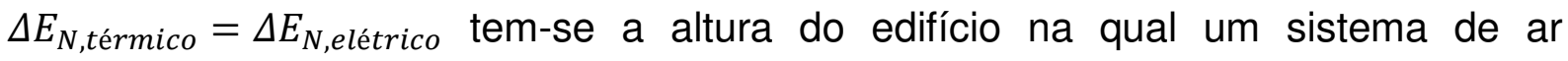
condicionado solar passa a ser mais vantajoso energeticamente do que o outro. 


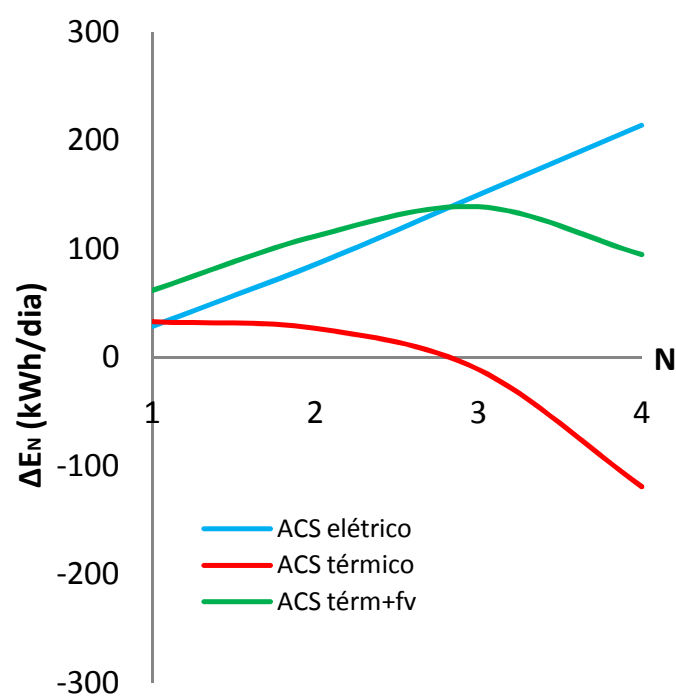

Figura 4.23 - Economia de energia elétrica dos sistemas de ar condicionado solar para o mesmo edifício em função do número de pavimentos para o dia 21 de Junho.

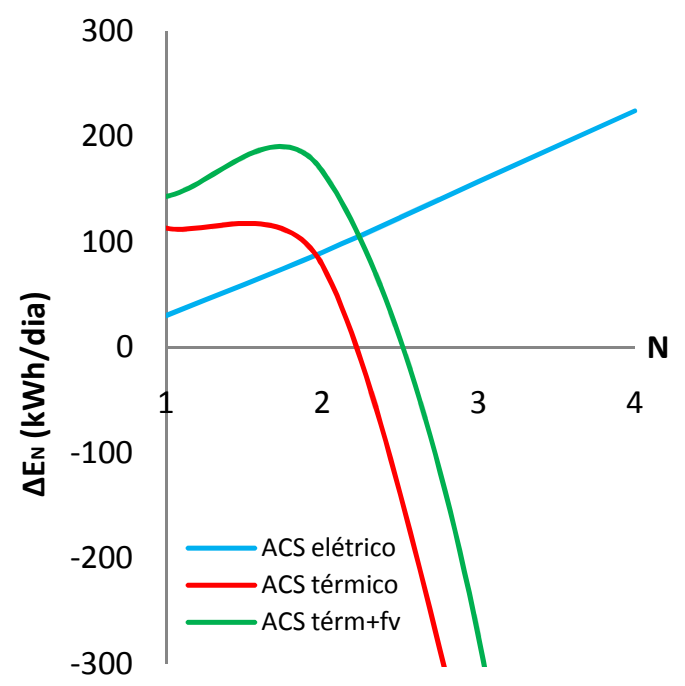

Figura 4.24 - Economia de energia elétrica dos sistemas de ar condicionado solar para o mesmo edifício em função do número de pavimentos para o dia 21 de Dezembro.

Simulando, então, os valores de economia de energia elétrica $\left(\Delta E_{N}\right)$ em função do número de pavimentos $N$, obteve-se, para os dias de inverno e verão, os gráficos das Figuras 4.23 e 4.24, respectivamente.

A primeira constatação que se faz, a partir das Figuras acima, é que, no dia de verão, as economias de energia são maiores do que no dia de inverno, ao utilizar-se um sistema de ar condicionado solar em detrimento de um sistema de ar 
condicionado convencional. De fato, os valores de $\Delta E_{N}$ dos três sistemas de ar condicionado solar estudados (linhas verde, vermelha e azul) são maiores para para poucos pavimentos para o dia 21 de dezembro, em relação ao dia 21 de junho. Isso não significa, porém, que o consumo de energia dos sistemas no dia de verão seja menor que no dia de inverno, como já foi apresentado neste capítulo.

Em compensação, quando $\Delta E_{N}<0$, então, o consumo de energia do sistema de ar condicionado solar é maior do que o consumo do sistema convencional. Para o dia 21 de dezembro, quanto maior é o prédio em questão, mais rápido aumenta a desvantagem energética do ar condicionado solar em relação ao sistema convencional. Já para o dia 21 de junho, o aumento de $N$ não causa apresenta um impacto muito grande na queda do desempenho do ar condicionado solar.

Pelas Figuras, se observa que até a altura do prédio (correspondente ao

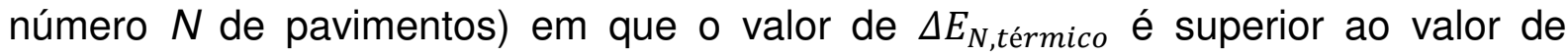
$\Delta E_{N, \text { elétrico, }}$ O sistema térmico com coletores solares tem melhor desempenho energético do que o sistema elétrico com painéis fotovoltaicos. A partir da altura em que os valores de $\Delta E_{N}$ se igualam, o segundo sistema passa a ser mais vantajoso energeticamente do que o primeiro.

Sendo assim, dos gráficos das Figuras 4.23 e 4.24 foi possível encontrar as equações para representar $\Delta E_{N}=f(N)$, sendo $N$ o número de pavimentos do edifício:

$$
\begin{gathered}
\Delta E_{n, \text { térmico }}=f_{\text {t,inverno }}(N)=-6,3 N^{3}+22 N^{2}-27,7 N+45 \\
\Delta E_{N, \text { térm } f \text { fv }}=f_{t+f v, \text { inverno }}(N)=-23,5 N^{2}+130,1 N-47 \\
\Delta E_{\text {conv,elétrico }}=f_{\text {, inverno }}(N)=1,8 N^{3}+53,2 N^{2}-26,3 N
\end{gathered}
$$

para 21 de junho e,

$$
\begin{gathered}
\Delta E_{N, \text { térmico }}=f_{t, \text { verão }}(N)=59 N^{3}-591,5 N^{2}+1326,5 N-681 \\
\Delta E_{N, \text { térm }+f v}=f_{t+f v, \text { verão }}(N)=-17,3 N^{3}-129 N^{2}+532,3 N-243 \\
\Delta E_{\text {conv,elétrico }}=f_{e, v e r a ̃ o}(N)=1,75 N^{3}+56,2 N^{2}-28,5 N
\end{gathered}
$$

para 21 de dezembro. 
Fazendo $f_{t, \text { inverno }}=0$ na eq.(46), obtém-se o número de pavimentos a partir do qual o sistema de ar condicionado solar térmico passa a ter desempenho energético pior do que o sistema convencional, no dia 21 de junho. Da mesma forma, fazendo $f_{t, v e r a ̃ o}=0$ na eq.(49), obtém-se o número de pavimentos a partir do qual o sistema de ar condicionado solar térmico passa a ter desempenho energético pior do que o sistema convencional no dia 21 de dezembro.

De forma semelhante, igualando-se $f_{t+f v \text {,inverno }}=0$ e $f_{t+f v, v e r a ̃ o}=0$ nas eq.(47) e eq.(48), obtém-se o número de pavimentos $n$ máximo para o qual o sistema de ar condicionado solar térmico com apoio fotovoltaico tem desempenho melhor que o sistema convencional.

Os resultados dessa análise são mostrados na Figura 4.25, a seguir: mais vantajoso que o sistema convencional

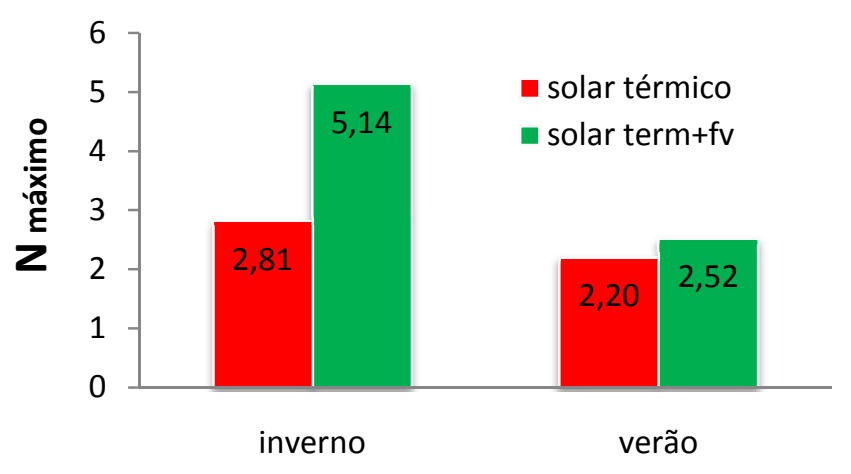

Figura 4.25 - valor máximo de $\boldsymbol{N}$ para que o desempenho energético do sistema térmico e do sistema térmico com apoio fotovoltaico seja melhor do que o do sistema convencional.

Conforme se pode observar na Figura, se comparado ao sistema convencional, o sistema térmico de ar condicionado solar, passa a ser desvantajoso energeticamente com 3 ou mais pavimentos na situação de inverno (número de pavimentos máximo igual a 2,81), e também com 3 ou mais pavimentos na situação de verão (número de pavimentos máximo igual a 2,20). Pode-se dizer que, no dia 21 de junho e 21 de dezembro, devido ao maior consumo do ar condicionado, em particular do aquecimento auxiliar, um edifício com 3 pavimentos já apresentaria um consumo de back-up bastante significativo ao ponto de tornar a alternativa térmica desvantajosa. 
Analogamente, se comparado ao sistema convencional, o sistema térmico com apoio fotovoltaico, passa a ser desvantajoso com 6 ou mais pavimentos na situação de inverno (número de pavimentos máximo igual a 5,14), e com 3 ou mais pavimentos na situação de verão (número de pavimentos máximo igual a 2,52).

Adotando-se o sistema térmico de ar condicionado solar ou sistema térmico com apoio fotovoltaico, para que se tenha economia de energia elétrica por parte do sistema de ar condicionado, na situação de inverno e de verão, em relação ao sistema convencional, deve-se ter um edifício com menos de 3 pavimentos.

Se o objetivo, porém, é que haja economia de energia somente na situação de inverno, o edifício da mesma forma terá que ter menos de 3 pavimentos, se for adotado o sistema térmico de ar condicionado solar. Por outro lado, se for adotado o sistema térmico com apoio fotovoltaico, o edifício pode ter até 5 pavimentos.

Igualando-se os valores das funções $f_{t}$ e $f_{e}$, que representam a economia de energia do sistema térmico de ar condicionado solar e do sistema elétrico de ar condicionado solar, respectivamente, pode-se determinar o valor de $N$ para o qual um sistema passa a ser mais vantajoso energeticamente do que o outro.

Desenvolvendo-se essa análise, obtém-se os resultados apresentados na Figura 4.26, a seguir, que representa o número de pavimentos máximo que o edifício pode ter, no dia 21 de junho e no dia 21 de dezembro, a fim de que o sistema térmico de ar condicionado solar tenha um desempenho energético melhor que o do sistema elétrico de ar condicionado solar.

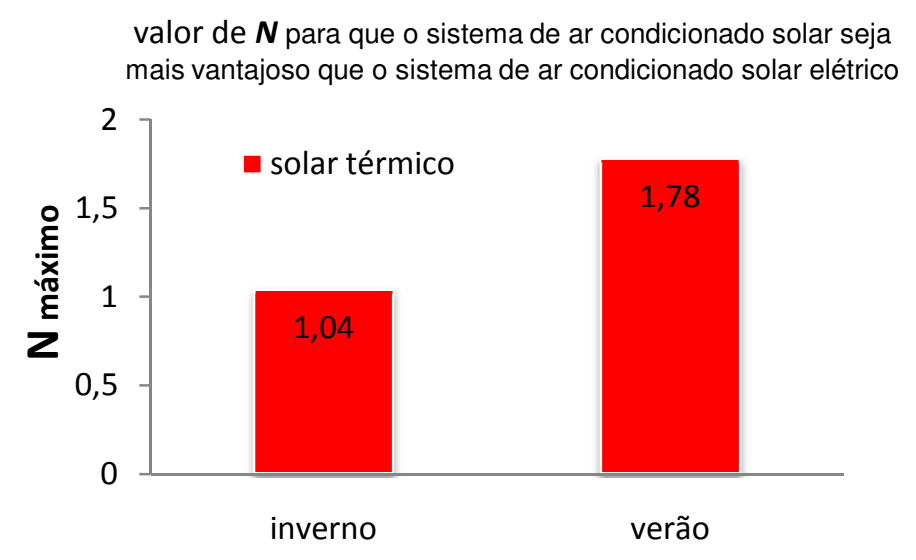

Figura 4.26 - valor máximo de $\boldsymbol{N}$ para que o desempenho energético do sistema térmico e do sistema térmico com apoio fotovoltaico seja melhor do que o do sistema elétrico. 
Com os resultados anteriores, pode-se dizer que, o sistema térmico de ar condicionado solar, somente é mais vantajoso energeticamente que o sistema elétrico de ar condicionado solar somente no caso do edifício térreo $(N=1)$.

Neste ponto, cabe fazer outro comentário relativo aos gráficos de $\Delta E_{N}$ (Figura 4.22 e 4.23). Para o sistema de ar condicionado térmico com apoio fotovoltaico, embora o valor de $\Delta E_{N}$ decresça com o aumento do número de pavimentos $N$, o máximo de $\Delta E_{N}$ não foi obtido para $N=1$, mas para um edifício mais alto que o térreo.

Por exemplo, no dia 21 de dezembro (Figura 4.24), a utilização do sistema térmico com apoio fotovoltaico, no edifício térreo, economizaria $143 \mathrm{kWh}$ em relação ao sistema convencional, enquanto que esse sistema de ar condicionado solar, no edifício com 2 pavimentos economizaria $167 \mathrm{kWh}$.

Esses valores não significam, porém, que o sistema no edifício com 2 pavimentos tenha um consumo energético menor que o sistema no edifício térreo, apenas expressa que, o valor absoluto da economia de energia, em $\mathrm{kWh}$, se comparado com o sistema convencional é maior no edifício de 2 pavimentos do que no edifício térreo. De fato, o valor de consumo de energia elétrica do sistema $E_{N}$ sempre cresce com o número de pavimentos, como se observa pela Figura 4.18.

O que ocorre é apenas que com o acréscimo de 1 pavimento no edifício, o aumento no valor absoluto do consumo de energia do sistema convencional é maior do que o aumento no valor absoluto do consumo de energia do sistema de ar condicionado solar térmico com apoio fotovoltaico.

Um outro aspecto que precisa ser comentado é que, no caso dos sistemas térmicos de ar condicionado solar, o grande ganho que se teve com a redução da altura do edifício consistiu na elevação da fração solar de operação do sistema ao longo dos dias estudados. Isso pode ser observado na Figura 4.27, a seguir, que mostra a evolução do valor da fração solar $s$ obtida na operação do sistema de ar condicionado solar térmico em função do número de pavimentos do edifício: 


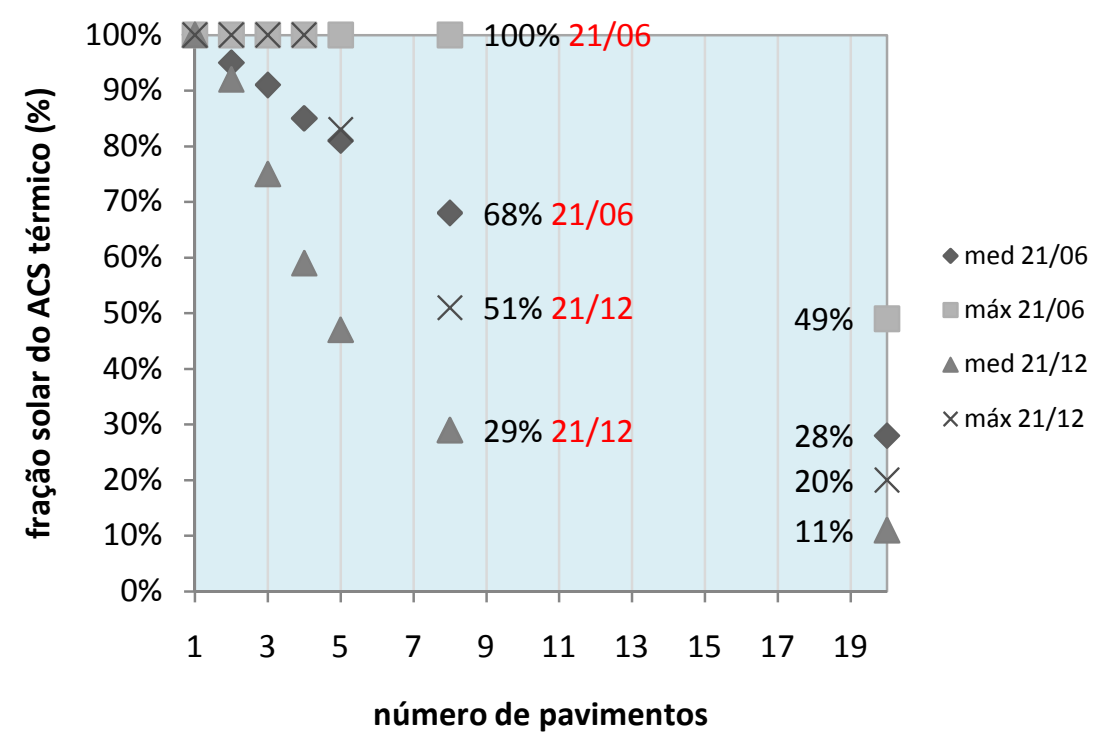

Figura 4.27 - Comportamento dos valores de fração solar diária (média e máxima) em função do número de pavimentos para o sistema de ar condicionado solar térmico e para os dias 21/06 e 21/12.

De fato, como se observa na Figura, a fração solar, obtida na operação de um sistema aplicado ao edifício mais baixo, foi maior. Isso ocorreu para os valores tanto de máxima diária como para os valores de média diária, mostrados no gráfico.

Seguindo o mesmo raciocínio, nas Figuras 4.28 e 4.29 se observa a fração não-solar obtida na operação do sistema térmico de ar condicionado solar e a energia térmica fornecida à água pelo aquecimento auxiliar, respectivamente, em função do número de pavimentos do edifício. Elas evidenciam o fato já constatado anteriormente de que o desempenho energético do sistema decresce com a altura do edifício:

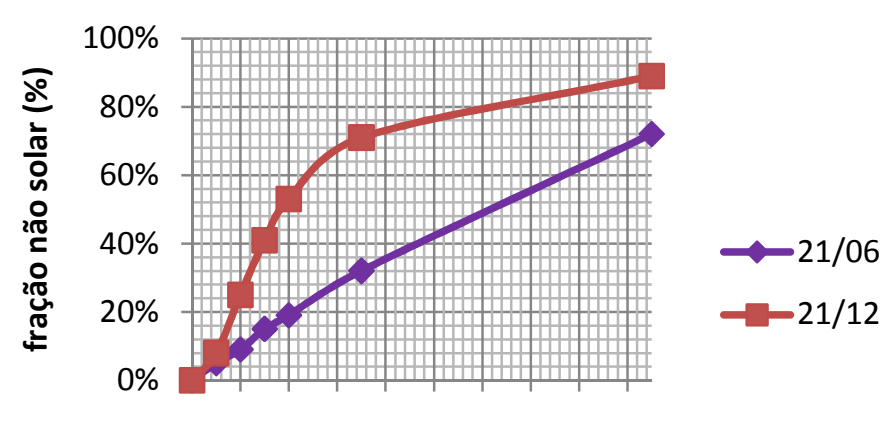

$\begin{array}{llllllllll}1 & 3 & 5 & 7 & 9 & 11 & 13 & 15 & 17 & 19\end{array}$

$\mathbf{N}$

Figura 4.28 - Comportamento dos valores de fração não solar diária média em função do número de pavimentos para o sistema de ar condicionado solar térmico e para os dias 21/06 e 21/12. 


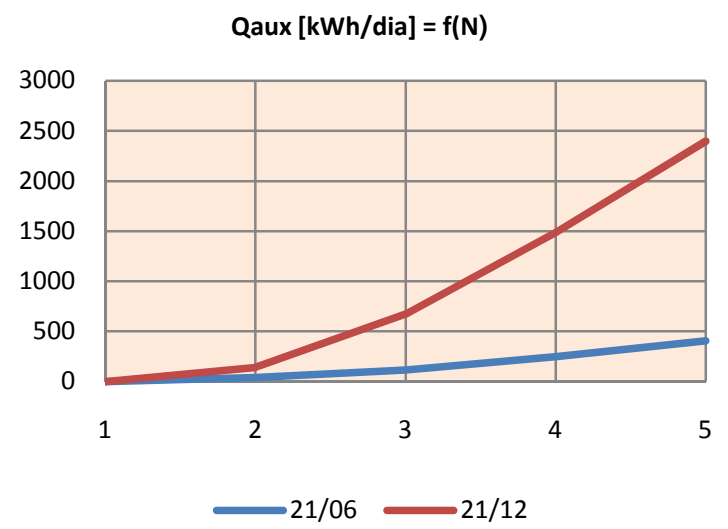

Figura 4.29 - Energia térmica fornecida à água pelo aquecedor auxiliar em função do número de pavimentos para o sistema de ar condicionado solar térmico e para os dias 21/06 e 21/12.

Por fim, para concluir esse item 4.2.2, é interessante apresentar, paralelamente ao que foi discutido anteriormente, as parcelas de contribuição dos subsistemas do ar condicionado solar térmico, no consumo de energia total dessa tecnologia. Esses resultados já foram apresentados no item 4.2.1 para o edifício de 20 pavimentos. Agora, porém, pretende-se discutir os resultados em função do número de pavimentos de edifício, a fim de que se analise a contribuição no consumo energético de cada subsistema do ar condicionado solar térmico, também no caso de edifícios mais baixos.

As parcelas de contribuição dos subsistemas do ar condicionado térmico, para edifícios com 1 a 4 pavimentos, são mostradas nas Figuras 4.30 e 4.31, a seguir:

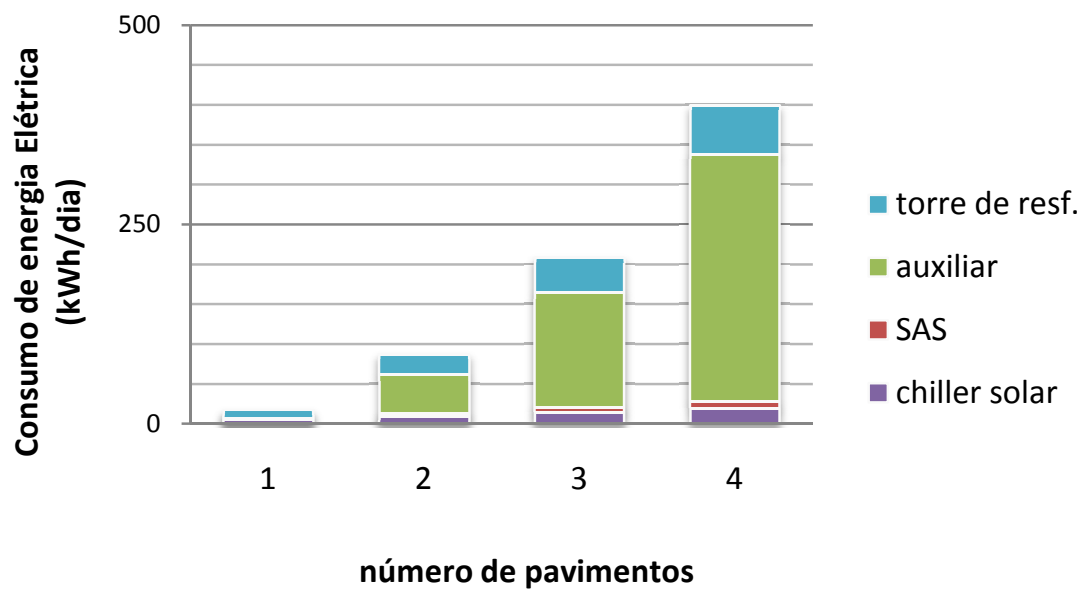

Figura 4.30 - Consumos de energia dos subsistemas do ar condicionado solar térmico (21/06) 


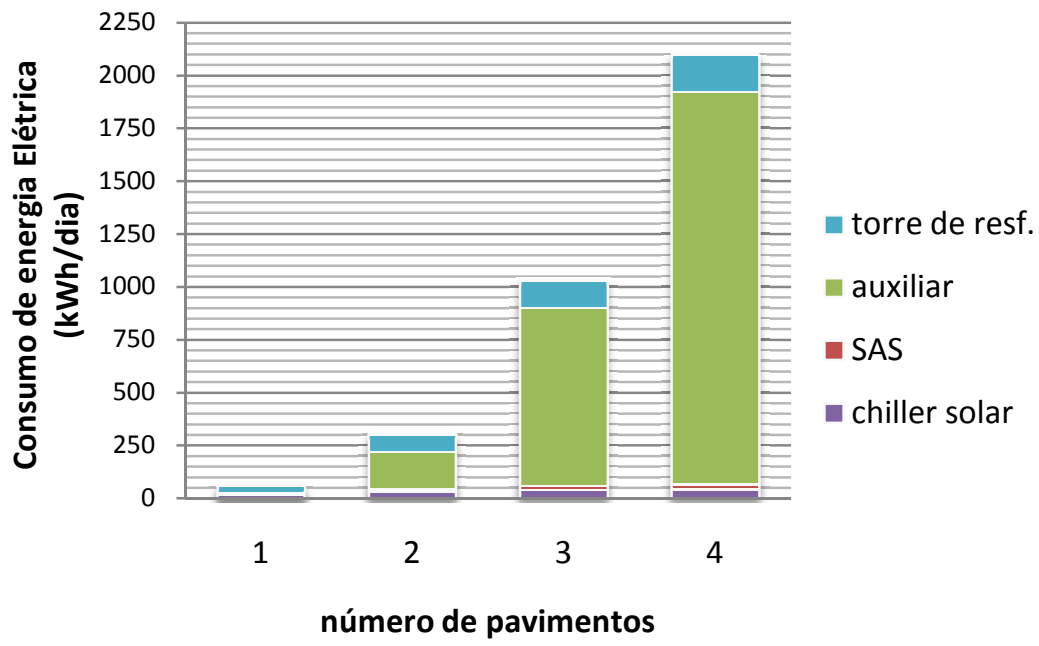

Figura 4.31 - Consumos de energia dos subsistemas do ar condicionado solar térmico (21/12)

Esses consumos de energia representam uma participação ainda predominante, porém menor, do aquecimento auxiliar no consumo total de energia do ar condicionado, em relação ao que se observou para o edifício de 20 pavimentos. Para se ter uma idéia desse menor impacto do aquecimento auxiliar no consumo do sistema, basta comparar os gráficos da Figura 4.15 com os gráficos da Figura 4.32, a seguir, que mostra os resultados para o edifício de 2 pavimentos:

21 de junho

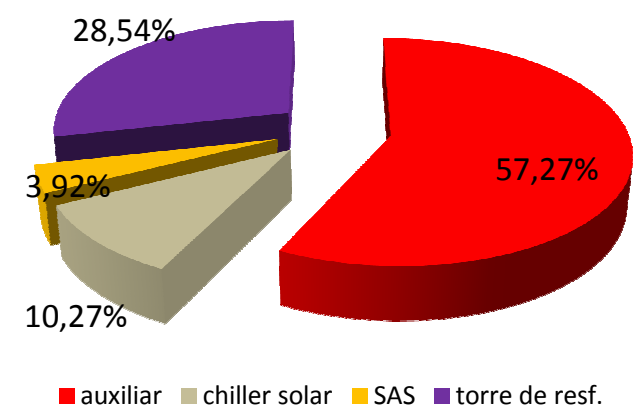

21 de dezembro

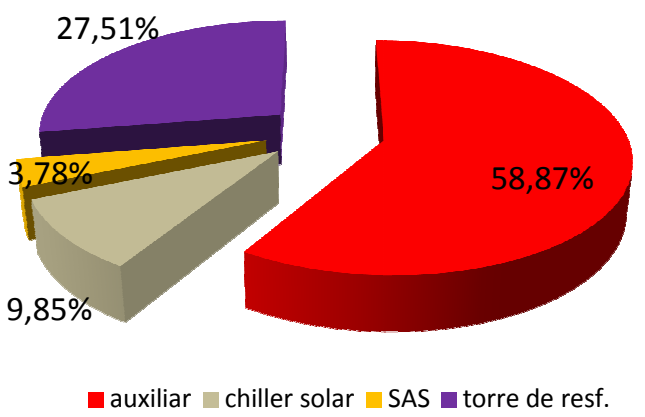

Figura 4.32 - Distribuição da energia elétrica consumida pelos subsistemas (auxiliar: aquecedor auxiliar; chiller solar: chiller de absorção solar; SAS: sistema de aquecimento solar; torre de resf:: sistema de rejeição de calor) do sistema de ar condicionado solar térmico nos dias 21 de junho e 21 de dezembro, para o edifício com 2 pavimentos. 
4.2.3 Desempenho do Sistema Térmico em Função da Área e do Tipo de Coletores

Pelo que se observou nos resultados até aqui apresentados, o desempenho energético do sistema térmico de ar condicionado solar, isto é, aquele que utiliza coletores solares térmicos e chiller de absorção, não foi satisfatoriamente elevado. Esse fato é mais evidente, como foi visto, para edifícios altos, devido à área limitada de coletores solares na cobertura, que não supre adequadamente a demanda do chiller solar e resulta em um grande consumo de energia por parte de aquecimento auxiliar.

De acordo com o que foi apresentado na revisão bibliográfica do capítulo 2, a tecnologia de ar condicionado solar admite que o chiller solar de absorção trabalhe a diferentes temperaturas do fluido quente utilizado no gerador, dependendo do tipo de coletor solar aplicado ao sistema.

Se a tecnologia de aquecimento solar permitir uma elevação significativa da temperatura do fluido de trabalho (neste caso, da água), é possível fazer uso de chillers solares de absorção mais eficientes (com COP mais elevados), conforme apresentado no capítulo 2, na Figura 2.4.

Até aqui, a simulação foi desenvolvida supondo-se, para o sistema térmico, a utilização dos usuais coletores planos ${ }^{19}$ que trabalham a temperaturas menores do que $100^{\circ} \mathrm{C}$. No Brasil e em outros países, essa tecnologia predomina no mercado. Entretanto, existem outras possibilidades tecnológicas para o sistema de aquecimento solar de água.

Uma tecnologia bastante interessante é a dos coletores de tubo a vácuo ${ }^{20}$, que conforme apresentado no capítulo de revisão bibliográfica, mesmo com custos iniciais maiores, apresenta algumas características interessantes de serem aproveitadas. Como foi dito, os coletores de tubo a vácuo, possibilitam a elevação da temperatura do fluido à valores muito mais elevados, superando os $100^{\circ} \mathrm{C}$.

\footnotetext{
${ }^{19}$ Conforme apresentado no capítulo 2, a tecnologia de aquecimento solar com coletores planos é a mais difundida no mundo atualmente. Neste trabalho a sigla FPC será utilizada para designar essa tecnologia, da expressão em inglês "Flat Plate Collectors".

${ }^{20}$ Neste trabalho a sigla ETC será utilizada para designar a tecnologia de aquecimento solar com coletores de tubo a vácuo, da expressão em inglês "Evacuated Tube Collectors".
} 
A questão que se coloca é se a adoção de coletores de tubo a vácuo, capazes de aquecer a água a temperaturas elevadas, possibilitando a utilização de chillers solares mais eficientes, resultaria em um impacto significativo no desempenho energético do sistema de ar condicionado térmico. Em outras palavras, ao invés de se utilizar os coletores planos até aqui estudados, propõe-se utilizar os coletores de tubo a vácuo e se analisar a influência dessa mudança no consumo de energia do sistema de ar condicionado solar térmico.

Portanto, a fim de analisar essa situação, utilizou-se o mesmo edifício escolhido, com as mesmas hipóteses apresentadas no capítulo 3, e o mesmo sistema de ar condicionado solar térmico definido no capítulo 3, incluindo, porém, as devidas modificações relacionadas ao uso dos coletores de tubo a vácuo (ETC), ao invés dos coletores planos (FPC).

Os parâmetros e hipóteses adotados por ocasião da consideração dos coletores de tubo a vácuo estão igualmente apresentados no capítulo 3 (Tabela 3.5) na qual assume-se, para os coletores de tubo a vácuo, uma eficiência de $50 \%$ e o aquecimento do fluido quente a $150^{\circ} \mathrm{C}$ para alimentar um chiller solar com COP de 1,2, de acordo com os valores sugeridos pela bibliografia (KIM; FERREIRA, 2007).

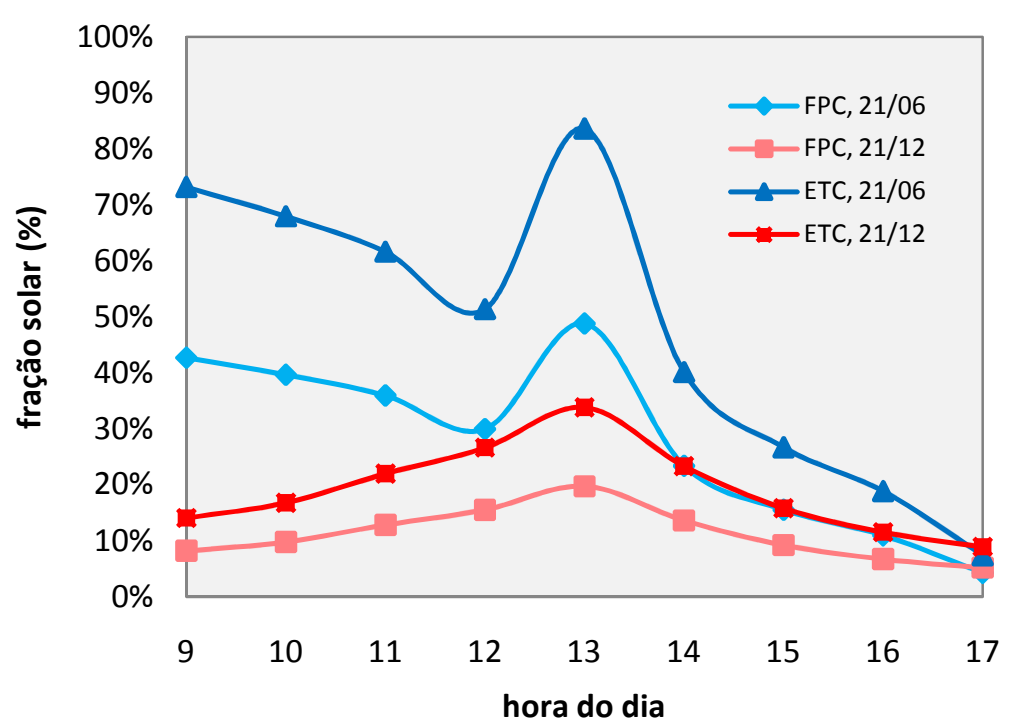

Figura 4.33 - Frações solares obtidas na operação do sistema de ar condicionado solar térmico nos dias 21/06 e 21/12, para a adoção de coletores FPC ou coletores ETC, e para o edifício de 20 pavimentos. 
A Figura 4.33 mostra os resultados das frações solares horárias obtidas com a operação do sistema de ar condicionado solar térmico, com as duas alternativas de coletores solares (FPC ou ETC).

Pelo que se observa na Figura, as frações solares se elevaram com a utilização da tecnologia de coletores tubo a vácuo, tanto no dia de inverno (linhas azuis) como no dia de verão (linha vermelha), refletindo a melhora no desempenho energético do sistema de ar condicionado solar térmico.

Esse fato pode ser observado facilmente nas Figuras de 4.34 à 4.37, nas quais se mostra as frações solares médias diárias obtidas no sistema de ar condicionado solar térmico, para as situações de inverno ou verão, ETC ou FPC, e 20 pavimentos ou 4 pavimentos.

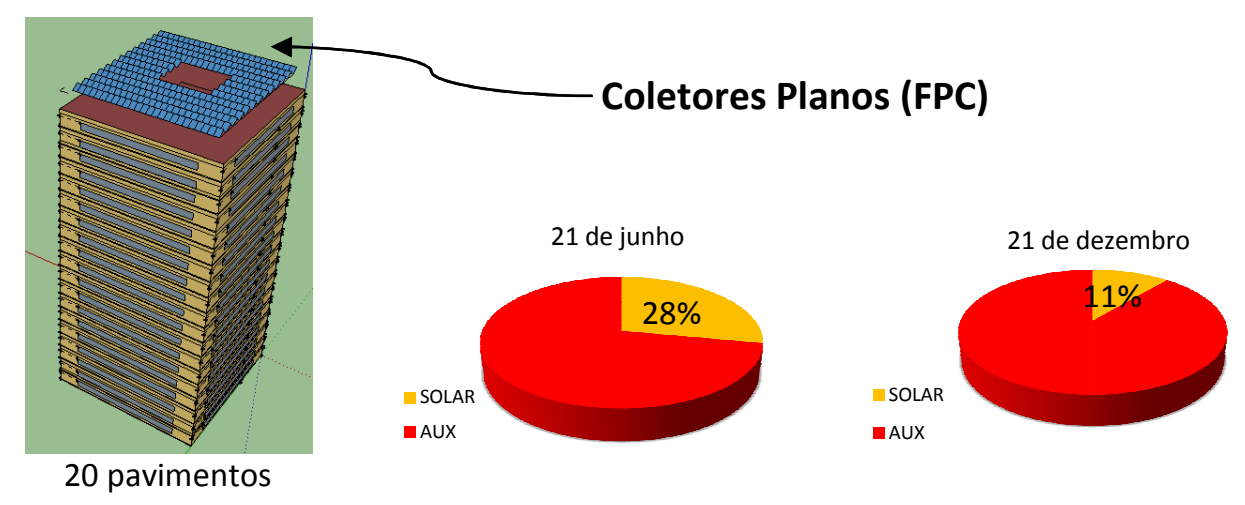

Figura 4.34 - Frações solares médias diárias obtidas na operação do sistema de ar condicionado solar térmico, com coletores planos (FPC), no dia 21/06 e no dia 21/12, para o edifício de 20 pavimentos.

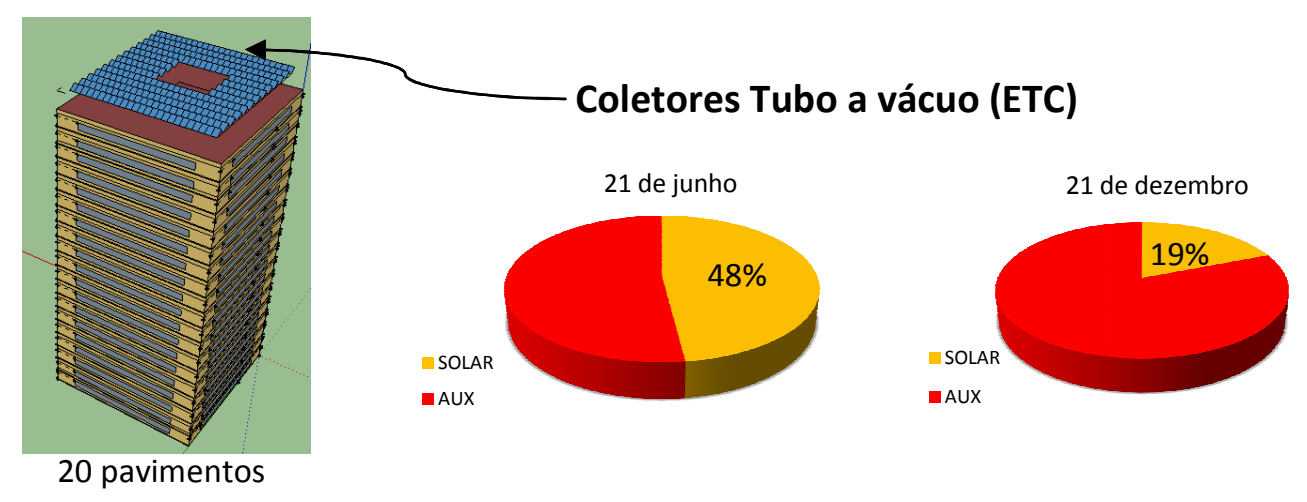

Figura 4.35 - Frações solares médias diárias obtidas na operação do sistema de ar condicionado solar térmico, com coletores de tubo à vácuo (ETC), no dia 21/06 e no dia 21/12, para o edifício de 2pavimentos. 


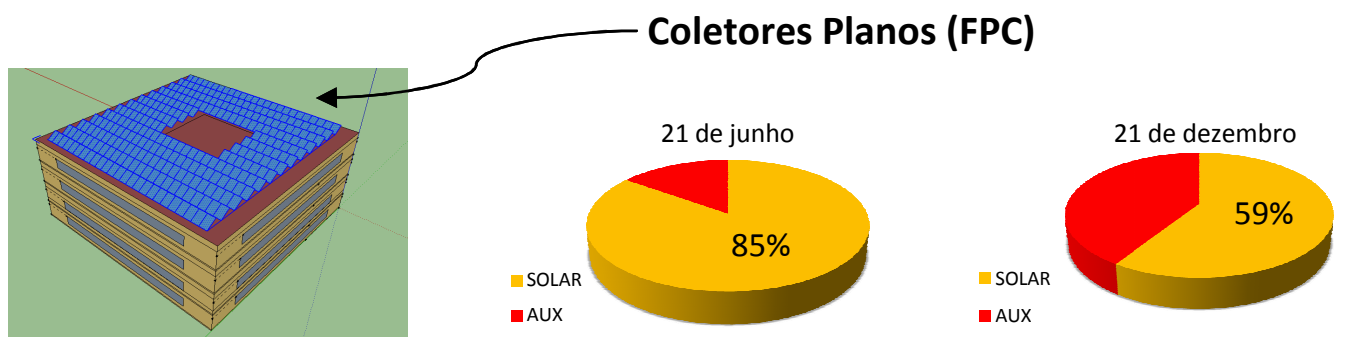

Figura 4.36 - Frações solares médias diárias obtidas na operação do sistema de ar condicionado solar térmico, com coletores planos (FPC), no dia 21/06 e no dia 21/12, para o edifício de 4 pavimentos.

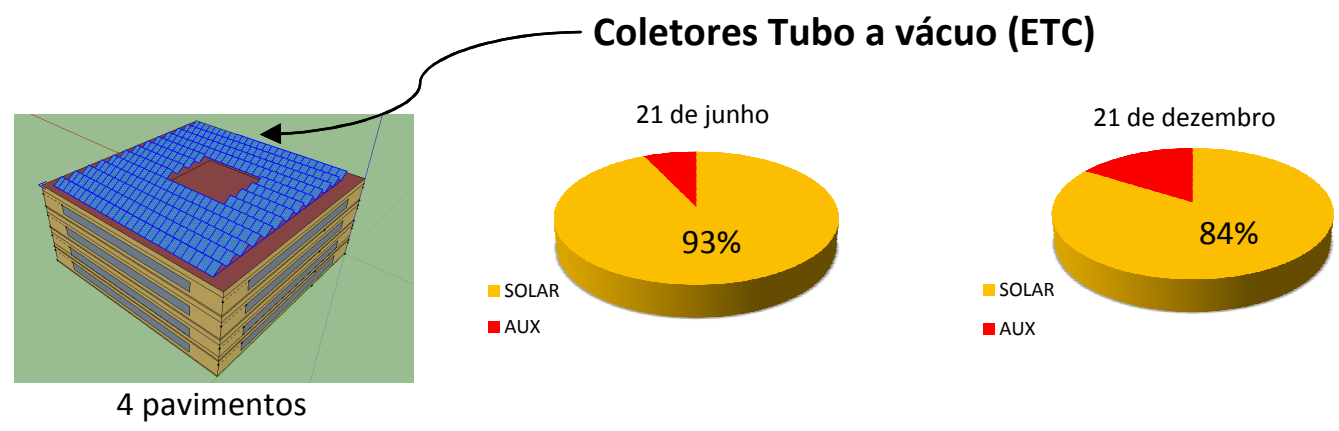

Figura 4.37 - Frações solares médias diárias obtidas na operação do sistema de ar condicionado solar térmico, com coletores de tubo à vácuo (ETC), no dia 21/06 e no dia 21/12, para o edifício de 4 pavimentos.

De fato, pelo que se observa nas Figuras, realmente a adoção de coletores de tubo à vácuo aprimorou o desempenho energético do sistema de ar condicionado solar térmico. Em outras palavras, constatou-se que a tecnologia de coletores solares utilizada apresenta importante influência no desempenho energético do sistema de ar condicionado solar térmico.

Com as hipóteses adotadas no trabalho, para o edifício de 20 pavimentos, a fração solar média do sistema aumentou de $28 \%$ para $48 \%$, no dia de inverno, e de $11 \%$ para $19 \%$, no dia de verão, com a adoção de coletores de tubo a vácuo (ETC), que trabalham a altas temperaturas, ao invés de coletores planos (FPC), que trabalham a baixas temperaturas.

Para o mesmo edifício com 4 pavimentos apenas, por exemplo, a fração solar média, no dia 21 de dezembro, subiu de $59 \%$ para $84 \%$ e, no dia 21 de junho, subiu de $85 \%$ para $93 \%$ devido à alteração dos coletores de FPC para ETC. 
Com relação à comparação dos consumos de energia elétrica do sistema de ar condicionado solar térmico com as duas alternativas de coletores (FPC ou ETC), é interessante analisar as Figuras de 4.38 à 4.41. Elas mostram o fator $i$ definido no item anterior pelas eq. (40), eq.(41) e eq.(42) e ajudam a visualizar o ganho que se obteve em termos da redução do consumo de energia, por conta da adoção de coletores ETC ao invés de coletores FPC, para o prédio de 20 pavimentos (Figuras 4.38 e 4.39) e para o prédio térreo (Figuras 4.40 e 4.41 ).

i (\%), 21 de Junho, 20 pavimentos

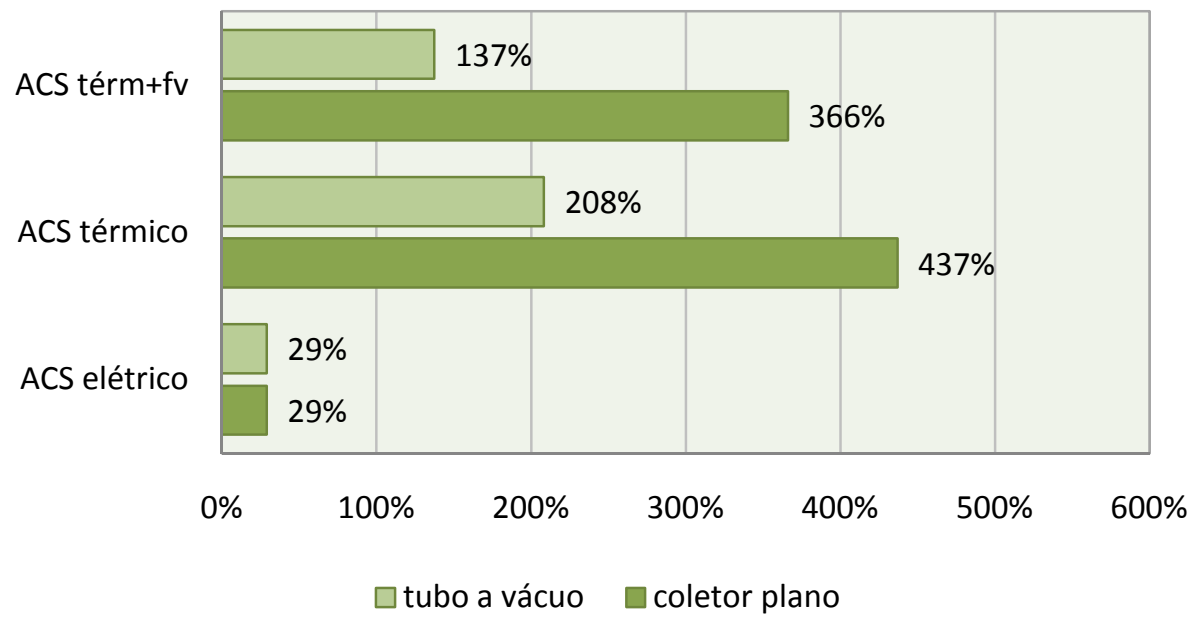

Figura 4.38 - Fator $i(\mathrm{em} \%)$ para os sistemas de ar condicionado solar, no dia 21/06, para o edifício de 20 pavimentos.

i (\%), 21 de dezembro, 20 pavimentos

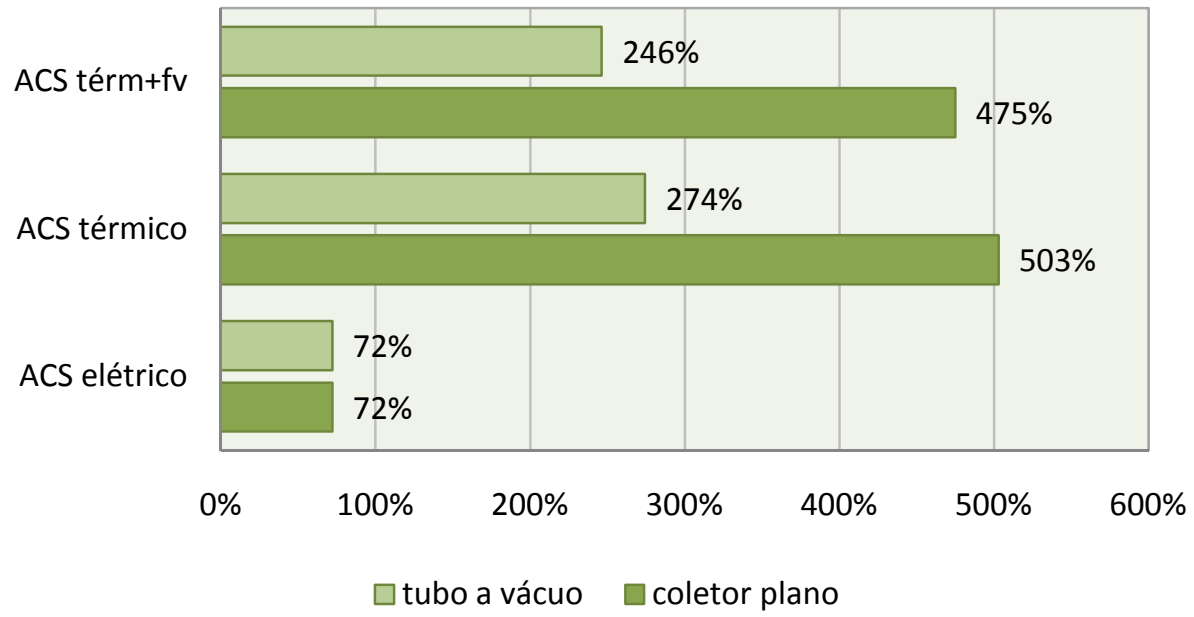

Figura 4.39 - Fator $i$ (em \%) para os sistemas de ar condicionado solar, no dia 21/12, para o edifício de 20 pavimentos. 
Como se observa nas Figuras 4.38 e 4.39 acima, o fator $i$, quando se trata do edifício de 20 pavimentos, é menor que $100 \%$, somente no caso do sistema de ar condicionado solar elétrico. De fato, como foi discutido neste capítulo, o sistema térmico de ar condicionado solar, com ou sem o apoio fotovoltaico, possui um desempenho energético muito ruim, devido principalmente ao elevado consumo do aquecimento auxiliar.

Assim, os valores de $i$ resultaram bastante elevados para esses sistemas, quando aplicados ao edifício de 20 pavimentos. Para o sistema térmico de ar condicionado solar, por exemplo, o valor de $i$, resultou em 437\% para o dia 21 de junho e em 503\% para o dia 21 de dezembro. Ou seja, para o dia 21 de junho, a razão entre o consumo de energia do sistema de ar condicionado solar térmico e o consumo do sistema de ar condicionado convencional foi de $437 \%$, e para o dia 21 de dezembro foi de $503 \%$.

Isso significa que, no dia de verão, por exemplo, o sistema térmico consumiu cerca de 4 vezes mais energia elétrica ( $i$ 500\%) que o sistema convencional de ar condicionado. O sistema de ar condicionado solar térmico com apoio fotovoltaico, como já foi discutido anteriormente, consumiu menos energia que o sistema sem apoio fotovoltaico. Entretanto, o consumo de energia elétrica desse sistema também foi elevado, tornando a alternativa também desfavorável energeticamente.

É interessante notar, porém, como está sendo discutido neste item 4.2.3, que a aplicação de coletores de tubo a vácuo, resultou na redução significativa do fator $i$, e em outras palavras, do consumo de energia dos sistemas térmicos de ar condicionado solar. De fato, para o sistema térmico de ar condicionado solar, por exemplo, a proporção $i$ reduziu-se de $437 \%$ para $208 \%$, no dia 21 de junho, e de $503 \%$ para $274 \%$, no dia 21 de dezembro, por ocasião da mudança dos coletores solares de FPC para ETC.

Isso significa que para o edifício de 20 pavimentos estudado, no dia 21 de dezembro, o sistema térmico de ar condicionado solar, que consumia aproximadamente 4 vezes mais energia elétrica que o sistema convencional, quando utilizava coletores FPC, agora, com coletores ETC, consome pouco mais de 1,7 vezes mais energia que o convencional. Assim, novamente se observa o ganho energético que se tem com o aprimoramento da tecnologia de aquecimento de água. 
Os resultados para o edifício térreo são mostrados nas Figuras 4.40 e 4.41, a seguir. Como já foi discutido neste capítulo 5, a simulação para edifícios mais baixos, tais como o edifício térreo, conduzem a resultados mais favoráveis energeticamente para os sistemas de ar condicionado solar térmico. De fato, como se observa nas Figuras abaixo, todos os sistemas de ar condicionado solar estudados são vantajosos energeticamente em relação ao sistema convencional de ar condicionado, para o edifício térreo $(i<100 \%)$.

No dia 21 de junho (Figura 4.40), inclusive, o sistema de ar condicionado solar térmico com apoio fotovoltaico, não consome nenhuma energia, já que a quantidade de energia fotovoltaica produzida é suficiente para suprir as necessidades do sistema. Isso torna o sistema de ar condicionado nessas condições, um sistema net zero energy.

i (\%), 21 de Junho, edifício térreo

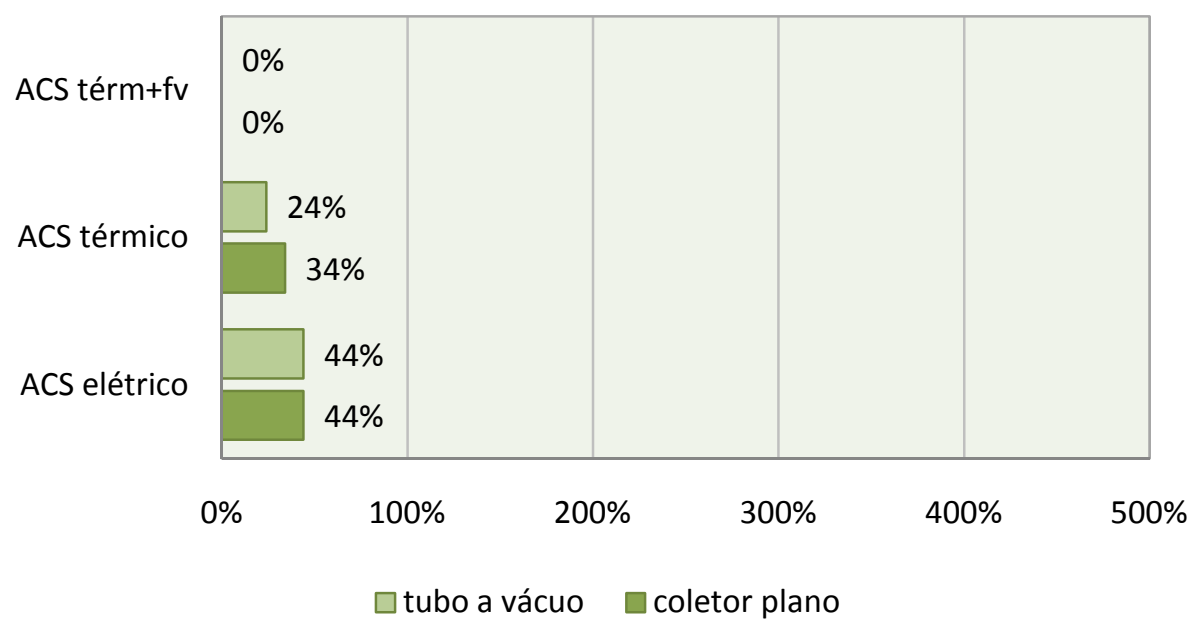

Figura 4.40 - Fator $i$ (em \%) para os sistemas de ar condicionado solar, no dia 21/06, para o edifício térreo.

Como se observa pela Figura 4.41, para o dia de verão e para o edifício térreo, por exemplo, o sistema de ar condicionado solar térmico, que economizava $66 \%$ da energia consumida pelo sistema convencional de ar condicionado $(i=34 \%)$ com a utilização de coletores solares FPC, quando passou a utilizar coletores ETC economizou $75 \%$ da energia do sistema convencional $(i=25 \%)$. 
i (\%), 21 de Dezembro, edifício térreo

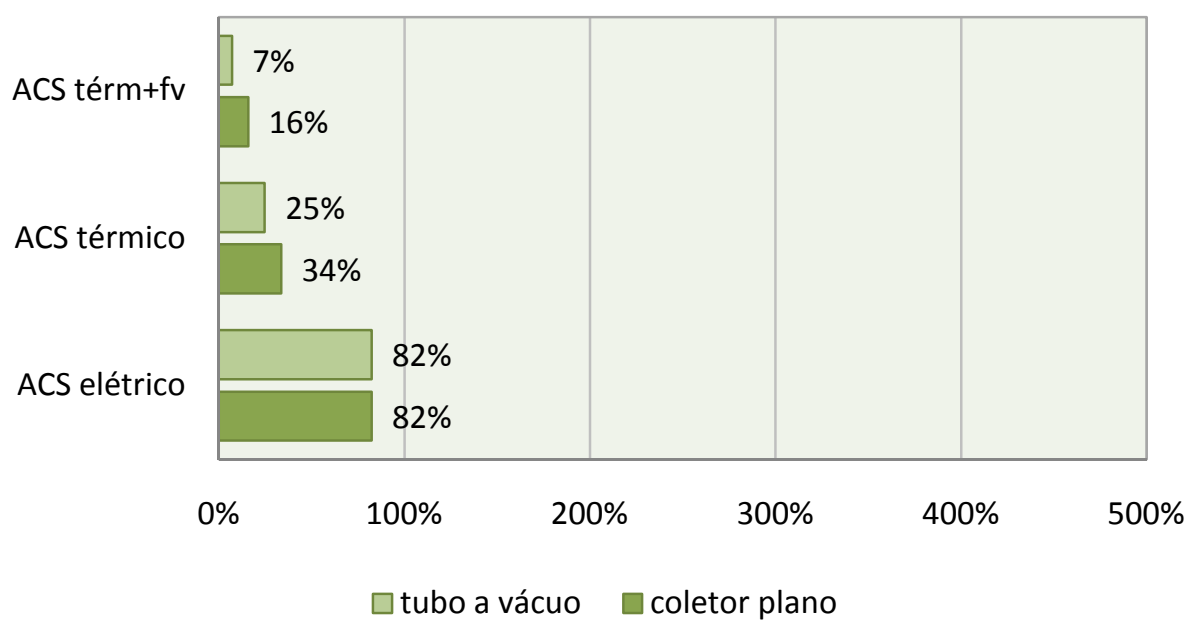

Figura 4.41 - Fator $i$ (em \%) para os sistemas de ar condicionado solar, no dia 21/12, para o edifício térreo.

Da mesma forma, para o dia de verão e para o edifício térreo (Figura 4.41), por exemplo, o sistema de ar condicionado solar térmico com apoio fotovoltaico, que economizava $84 \%$ da energia consumida pelo sistema convencional de ar condicionado $(i=16 \%$ ) com a utilização de coletores solares FPC, quando passou a utilizar coletores ETC economizou 93\% da energia do sistema convencional $(i=7 \%)$.

Esses resultados apontam uma influência significativa do tipo de coletor utilizado no desempenho do sistema. Teoricamente, esse fato pode ser explicado pois o COP do chiller de absorção cresce com o aumento da temperatura da fonte quente.

O cuidado que se deve ter é que os coletores solares, como já foi comentado no capítulo 2, correspondem a maior parcela do custo do sistema. Sendo assim, não se deve comparar os sistemas somente através de seu desempenho energético, mas deve-se levar em conta, também, uma análise econômica. De fato, com a adoção de coletores de tubo a vácuo, mais caros, deve-se considerar o aumento dos custos iniciais, para se comprovar a viabilidade da alternativa.

Outro aspecto interessante de ser notado nas Figuras acima é que o fator $i$ mostrado nos gráficos, praticamente não se alterou, no caso do sistema de ar condicionado solar térmico, do dia 21 de junho para o dia 21 de dezembro. Isso ocorreu, nas condições do edifício térreo, pois esse sistema, seja com coletores FPC 
seja com coletores ETC, trabalha com folga, isto é, produz mais energia térmica do que necessita para a operação.

Assim, o consumo de energia elétrica se resume aos outros subsistemas do ar condicionado, tais como, torres de resfriamento, bombas e equipamentos do sistema solar de aquecimento de água e chiller de absorção. Dessa forma, a proporção i para o dia de inverno e o dia de verão praticamente não se altera.

Outro ponto que deve se lembrado ainda, com relação às Figuras 4.40 e 4.41, é que, conforme se observa nos gráficos, a mudança de coletores planos para tubo à vácuo não alterou o consumo de energia do sistema de ar condicionado solar elétrico. Isso é óbvio, pois o sistema elétrico não utiliza coletores solares térmicos.

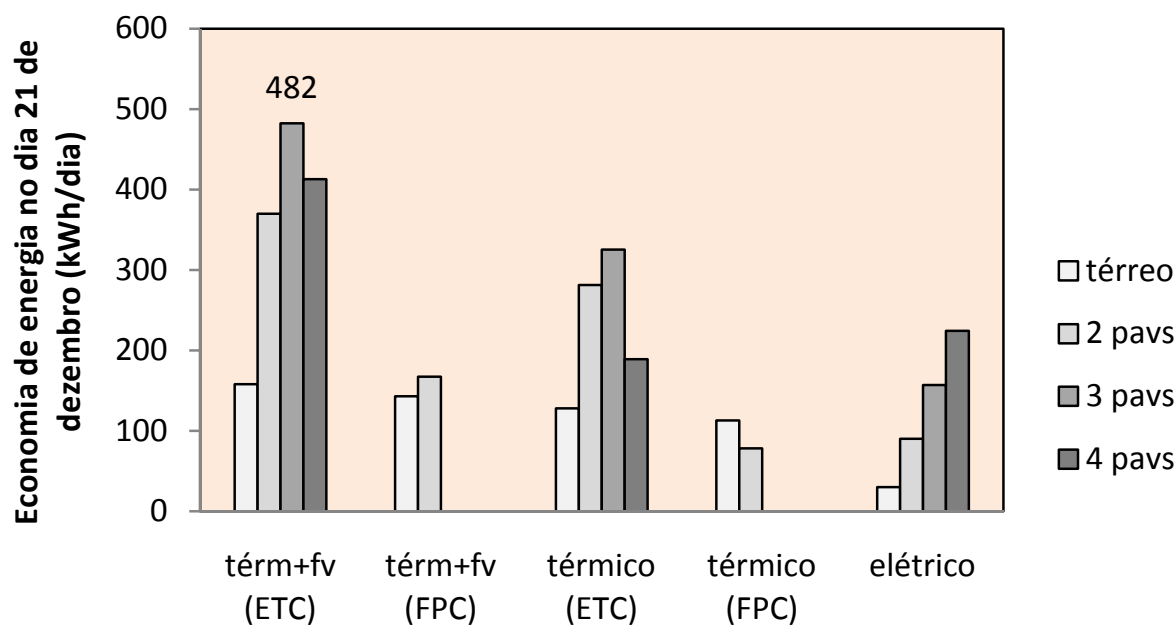

sistema de ar condicionado solar

Figura 4.42 - Economia de energia elétrica, em KWh/dia, dos sistemas de ar condicionado solar estudados: térmico com apoio fotovoltaico e coletores ETC, "térm+fv (ETC)", térmico e coletores ETC, "térmico (ETC)", térmico com apoio fotovoltaico e coletores FPC, "térm+fv (FPC)", térmico e coletores FPC, "térmico (FPC)" e elétrico, para os edifícios de 1 a 4 pavimentos, no dia 21 de dezembro.

Conforme se observa na Figura 4.42, a configuração mais otimizada para 0 sistema dentre os tipos de ar condicionado estudados, isto é, o sistema de ar condicionado solar térmico com apoio fotovoltaico e operando com coletores de tubo a vácuo, para o prédio térreo, chega a economizar, no dia de verão, quase 500 kWh de energia elétrica. Isso ocorre para o prédio de 3 andares. 
Por fim, vale destacar que, assim como o tipo de coletor, outro parâmetro que interfere no desempenho do sistema térmico de ar condicionado solar é a área coletora. Como foi apresentado no item 4.2.1, o cálculo que se desenvolveu até aqui se refere a área em planta de $950 \mathrm{~m}^{2}$ para a instalação solar, representando $95 \%$ da área disponível na cobertura. Sabe-se, porém, que muitas vezes não é possível contar com uma parte significativa da cobertura do edifício devido a outros usos, tais como, manutenção, caixas d'água, telecomunicações, estruturas do edifício, entre outros.

Sendo assim, a questão que se coloca é saber de que forma a área de coletores solares interfere no desempenho energético do sistema. Em outras palavras, propõe-se estudar qual o impacto da redução da área coletora no consumo de energia do sistema de ar condicionado solar térmico.

As Figuras 4.43 e 4.44, a seguir, mostram os valores de consumo de energia elétrica do sistema de ar condicionado solar térmico para três valores diferentes de áreas destinadas aos coletores planos $\left(500 \mathrm{~m}^{2}\right.$ ou $50 \%$ da cobertura, $700 \mathrm{~m}^{2}$ ou $70 \%$ da cobertura, e a área já simulada de $950 \mathrm{~m}^{2}$ ou $95 \%$ da cobertura), para o edifício de 1 e 2 pavimentos, e os coletores FPC ou ETC:

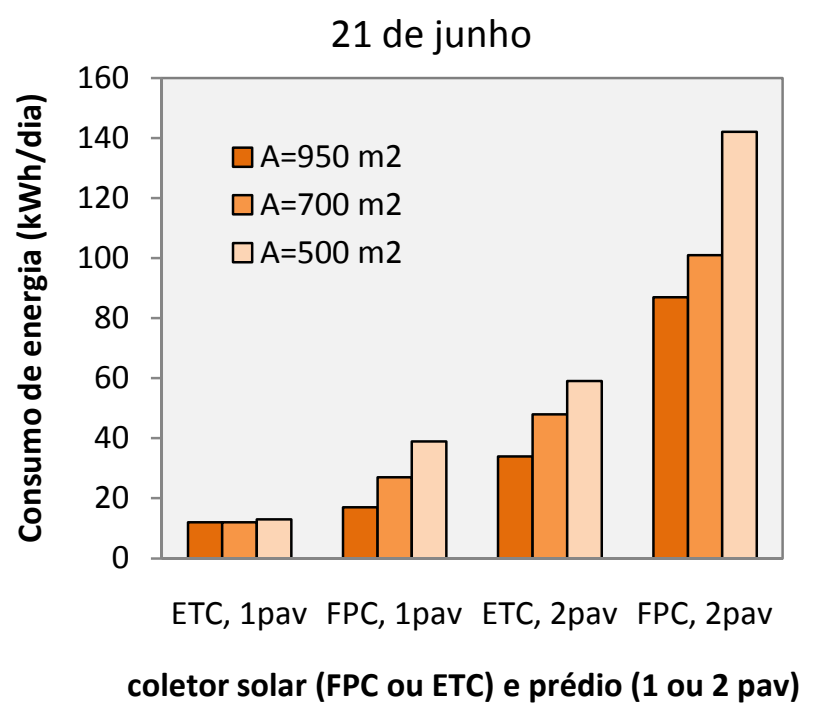

Figura 4.43 - Consumo de energia elétrica, em KWh/dia, do sistema de ar condicionado solar térmico, para o dia 21 de junho, e para o edifício de 1 ou 2 pavimentos, e os coletores FPC ou ETC. 


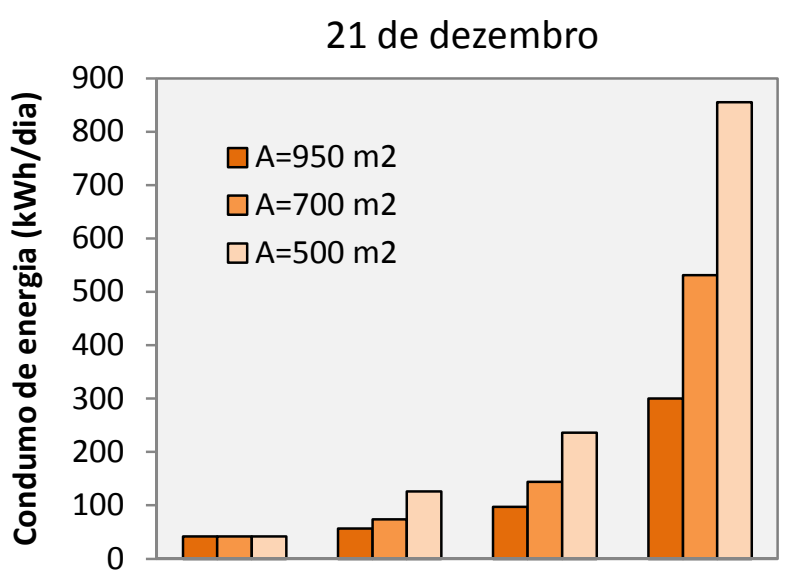

ETC, 1pav FPC, 1pav ETC, 2pav FPC, 2pav

coletor solar (FPC ou ETC) e prédio (1 ou 2 pav)

Figura 4.44 - Consumo de energia elétrica, em KWh/dia, do sistema de ar condicionado solar térmico, para o dia 21 de dezembro, e para o edifício de 1 ou 2 pavimentos, e os coletores FPC ou ETC.

Das Figuras anteriores, uma constatação interessante pode ser feita. $O$ fato de se alterar a tecnologia de coletores solares (de FPC para ETC) aliado ao aumento da área de coletores de $500 \mathrm{~m}^{2}$ para $950 \mathrm{~m}^{2}$, faz com que o sistema de ar condicionado solar térmico no edifício de 2 pavimentos, consuma menos energia do que esse sistema no edifício térreo.

Conforme se observa nas Figuras anteriores, o consumo de energia do sistema térmico de ar condicionado solar cresce com a diminuição da área destinada aos coletores solares. Para o edifício mais baixo (térreo) e com a tecnologia mais eficiente de coletores solares (ETC), esse crescimento do consumo é pequeno, ou quase inexistente (Figura 4.43 e 4.44), já que, como foi dito anteriormente, o sistema operou com folga e frações solares iguais ou próximas de $100 \%$.

Entretanto, para o edifício de 2 pavimentos e coletores FPC, por exemplo, o aumento do consumo por conta da redução da área coletora foi bastante significativo. Neste caso, para o dia 21 de dezembro, o consumo de energia elétrica do sistema passou de $300 \mathrm{kWh}$ para $855 \mathrm{kWh}$, quase triplicando no mesmo período.

Tomando-se, por exemplo, o edifício de 4 pavimentos, pode-se observar o decréscimo da fração solar média diária, conforme se reduz a área destinada aos coletores solares. As Figuras de 4.45 à 4.47 ilustram esse fato: 


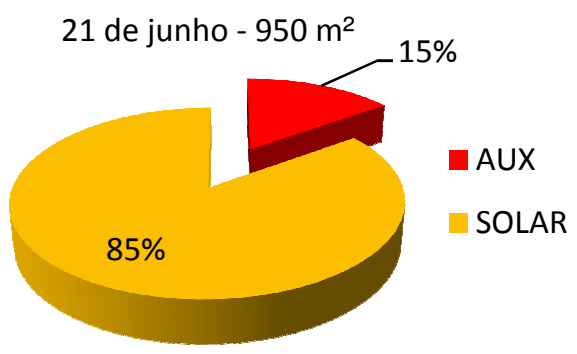

21 de dezembro - $950 \mathrm{~m}^{2}$

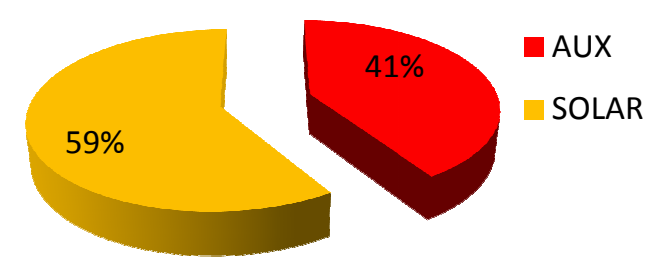

Figura

4.45 - Frações solares diárias médias do sistema de ar condicionado solar térmico para 95\% da cobertura com coletores solares, para o edifício simulado com 4 pavimentos e para 21/06 e 21/12.

21 de junho - $700 \mathrm{~m}^{2}$

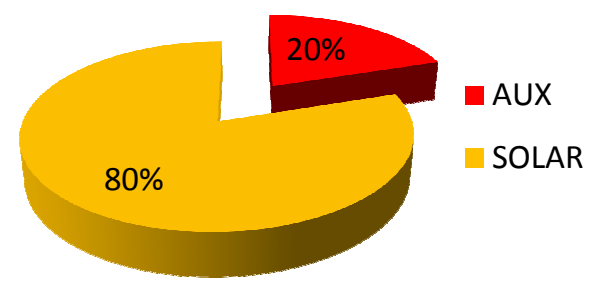

21 de dezembro - $700 \mathrm{~m}^{2}$

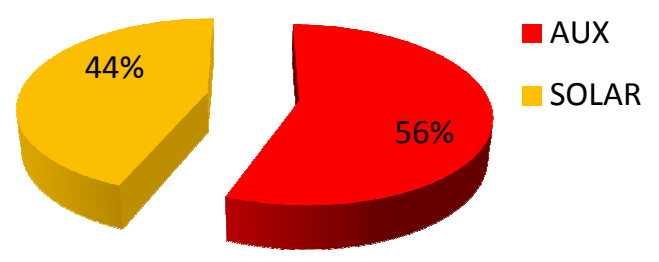

4.46 - Frações solares diárias médias do sistema de ar condicionado solar térmico para $70 \%$ da cobertura com coletores solares, para o edifício simulado com 4 pavimentos e para 21/06 e 21/12.

21 de junho $-500 \mathrm{~m}^{2}$

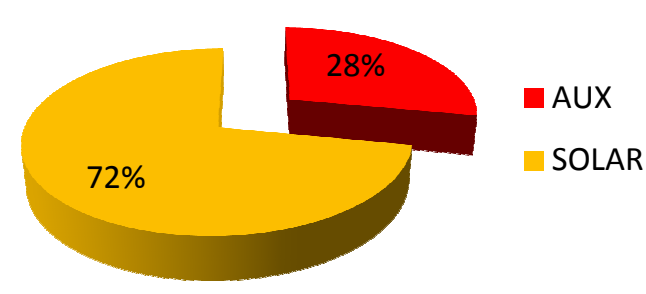

21 de dezembro - $500 \mathrm{~m}^{2}$

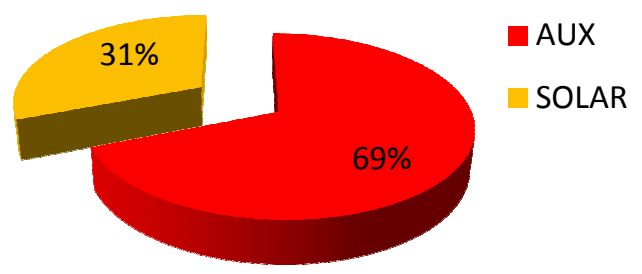

4.47 - Frações solares diárias médias do sistema de ar condicionado solar térmico para $50 \%$ da cobertura com coletores solares, para o edifício simulado com 4 pavimentos e para 21/06 e 21/12.

Assim, pode-se dizer, que a área de cobertura ocupada por coletores solares tem significativa influência no desempenho do sistema. De fato, como se observa nas Figuras acima, para as mesmas condições de funcionamento, a fração solar média do sistema pode cair de $85 \%$ para $72 \%$, no dia de inverno, e de $59 \%$ para 
$31 \%$, no dia de verão, se ao invés de se utilizar $95 \%$ da cobertura para a instalação solar, for utilizada metade da área de cobertura.

Esse fato ressalta a importância de se maximizar, em projetos desse tipo, a área da cobertura destinada aos coletores solares, já na fase de projeto, procurando-se alocar somente outros usos indispensáveis na cobertura. 
"Desempenho de Sistemas de Condicionamento de Ar com Utilização de Energia Solar em Edifícios de Escritórios"

Capítullo 5

Conclusões 


\section{CONCLUSÕES}

Ao final da pesquisa, tendo-se desenvolvido o assunto dos sistemas de ar condicionado solar em edifícios de escritórios e de posse dos resultados apresentados, procura-se, neste capítulo 5 , desenvolver uma conclusão para o trabalho.

Antes de tudo, como primeiro ponto a ser concluído deste trabalho, ressaltase a necessidade de se atuar frente ao problema energético global. Providências de caráter sustentável devem ser tomadas, em particular, na construção civil para que se evitem, nos próximos anos, conseqüências sociais, econômicas e ambientais do uso não-sustentável dos recursos energéticos.

Conclui-se, também, que, neste contexto, deve-se ter especial atenção com os sistemas de condicionamento de ar dos edifícios de escritórios. De fato, o papel desses sistemas na questão energética global é significativo. Assim, com relação aos sistemas de condicionamento de ar, conclui-se que é essencial considerar-se a utilização de energias renováveis, em especial da energia solar, que apresenta grande potencial para o futuro.

Sabendo-se da compatibilidade entre carga térmica do edifício e radiação solar, do avanço de mercado da tecnologia solar e das possibilidades técnicas de utilização dessa fonte para condicionamento de ar, pode-se dizer que a tecnologia de ar condicionado solar é uma solução bastante interessante de ser considerada, em especial em países com razoáveis níveis de radiação solar, tais como o Brasil.

Conclui-se que para a tipologia de edifício de escritórios estudada - com 20 pavimentos e com uma área em planta de aproximadamente $1000 \mathrm{~m}^{2}$ - e para as hipóteses adotadas na pesquisa, a utilização de um sistema de ar condicionado solar elétrico, conforme definido neste trabalho, é a solução mais vantajosa energeticamente se comparada com o sistema de ar condicionado convencional (com chiller de compressão de vapor) e se comparada, também, com o sistema de ar condicionado solar térmico, conforme definido neste trabalho.

Para o edifício estudado, o sistema de ar condicionado solar elétrico, economizou $\mathbf{2 8 \%}$ da energia elétrica que consumiria um sistema convencional de ar condicionado, no dia 21 de dezembro. Isso significou uma economia de $1169 \mathrm{kWh}$ 
neste dia, o que equivale a uma economia de $\mathbf{R} \mathbf{3} 38,48$ apenas no dia 21 de dezembro, considerando-se a tarifa média de 289,55 $\mathrm{R} \$ / \mathrm{MWh}$ de energia elétrica da ANEEL para o setor comercial e de serviços, de agosto de 2010. Da mesma forma, para o edifício estudado, o sistema de ar condicionado solar elétrico, economizou $71 \%$ da energia elétrica que consumiria o sistema convencional de ar condicionado solar, no dia 21 de junho. Isso significou uma economia de $1141 \mathrm{kWh}$ neste dia, e uma economia de $\mathbf{R} \mathbf{\$} \mathbf{3 3 0 , 3 8}$ apenas no dia 21 de junho.

Dessa forma, conclui-se que o desempenho energético de sistemas de ar condicionado solar elétrico, conforme definido neste trabalho e com as premissas e hipóteses adotadas, é bastante satisfatório. Assim, esse sistema, sob o ponto de vista energético, é interessante de ser aplicado.

Por outro lado, observou-se que o sistema térmico de ar condicionado solar mostra um desempenho energético bastante ruim nas condições estudadas, isto é, de um edifício de escritórios de 20 pavimentos e $1000 \mathrm{~m}^{2}$ de área cada, com cargas térmicas relativamente elevadas e com a área de coletores solares limitada somente à cobertura do edifício.

De fato, constatou-se que um sistema de ar condicionado solar térmico, nas condições estudadas, consome cerca de 4 vezes mais energia elétrica do que um sistema convencional de ar condicionado em um dia de verão (21 de dezembro) e pouco mais de 3 vezes mais energia elétrica do que um sistema convencional em um dia de inverno (21 de junho).

Pelo que foi analisado, conclui-se que o sistema de ar condicionado solar térmico seria interessante, sob o aspecto do consumo de energia, somente quando a carga térmica do edifício for relativamente pequena. Em outras palavras, concluise que o sistema de ar condicionado solar térmico é uma solução interessante de se adotada, em edifícios baixos, com poucos pavimentos.

De fato, em prédios altos, a área de cobertura destinada ao sistema de aquecimento solar de água que alimenta o chiller solar, no sistema de ar condicionado solar térmico, é relativamente pequena para a grande demanda de condicionamento de ar. Assim, a instalação solar não consegue suprir todo o calor necessário para a operação do chiller solar, apresentando frações solares reduzidas e da ordem de $\mathbf{5 0} \%$, no pico, no dia de verão e de $\mathbf{2 0} \%$, no pico, no dia de inverno. Assim, torna-se necessária a utilização excessiva do sistema de aquecimento auxiliar elétrico gerando um consumo de energia elevado para o sistema. 
Com efeito, para o edifício estudado, o consumo do aquecedor auxiliar representa mais de $\mathbf{9 0 \%}$ da energia elétrica consumida por todo o sistema de ar condicionado solar térmico, seja no dia de inverno como no dia de verão. Em termos numéricos, a energia térmica fornecida à água que alimenta o chiller solar de absorção, por parte do aquecedor elétrico correspondeu a 16,31 $\mathbf{M} \mathbf{W h}_{\text {th }}$, no dia de verão, e a 5,28 $\mathbf{M W h}$ th, no dia de inverno, enquanto que, a contribuição da energia solar para o aquecimento da água foi de apenas 2,01 $\mathbf{M W h}_{\mathrm{th}}$, no dia de verão, e de 1,62 MWhth, no dia de inverno.

Em prédios mais baixos, porém, a área de coletores já consegue produzir uma fração solar mais significativa de forma que o consumo de energia elétrica do aquecedor auxiliar não seja tão elevado e o desempenho energético do sistema de ar condicionado solar térmico seja satisfatório.

De fato, se o sistema de ar condicionado solar térmico fosse utilizado em um edifício com a mesma tipologia do estudado, porém térreo, esse sistema seria a solução mais vantajosa energeticamente se comparada com o sistema de ar condicionado convencional (com chiller de compressão de vapor) e também se comparada com o sistema de ar condicionado solar elétrico, conforme definido neste trabalho.

Para o edifício térreo o sistema de ar condicionado solar térmico economizou aproximadamente $2 / 3$ da energia elétrica que consumiria o sistema convencional de ar condicionado solar tanto no dia 21 de dezembro como no dia 21 de junho.

Neste sentido, dado o impacto significativo das dimensões do edifício no consumo de energia do sistema, conclui-se que é imperativo, para o bom desempenho do sistema de ar condicionado solar térmico, que o prédio tenha poucos pavimentos.

Assim, pelo que foi analisado, para que o sistema de ar condicionado térmico seja mais vantajoso energeticamente do que o sistema de ar condicionado convencional, o edifício deve ter no máximo 2 pavimentos (térreo e mais um pavimento). Se esse sistema de ar condicionado térmico for aprimorado com o apoio de painéis fotovoltaicos (sistema de ar condicionado térmico com apoio fotovoltaico), o edifício deverá ter ainda 2 pavimentos a fim de possuir desempenho melhor tanto no dia de inverno como no dia de verão, porém poderá ter até 5 pavimentos se o 
objetivo for possuir melhor desempenho energético do que o convencional, apenas no dia de inverno.

Entretanto, para que o sistema térmico de ar condicionado solar (com apoio fotovoltaico ou não) seja mais vantajoso energeticamente do que o sistema de ar condicionado solar elétrico, o edifício deve ter no máximo 1 pavimento (edifício térreo).

Para a viabilidade energética da aplicação do ar condicionado solar térmico em edifícios mais altos, conclui-se que medidas adicionais devem ser tomadas tais como, a redução da carga térmica do edifício (através de meios passivos de arquitetura, por exemplo), o aprimoramento do sistema de aquecimento auxiliar, seja através do aumento de eficiência do back-up de energia, seja através da otimização do sistema de acumulação térmica ou o aumento da produção de energia solar (através da ampliação da área coletora ou da eficiência dos coletores). Com essas considerações o sistema pode possivelmente se tornar viável energeticamente.

Deve-se lembrar, porém, que nessa análise desenvolvida não se considerou os aspectos econômicos envolvidos no projeto, instalação e manutenção do sistema de ar condicionado solar. Sabe-se, entretanto, que esses aspectos podem ser condicionantes para a escolha do sistema, não obstante o desempenho energético das alternativas.

Por fim, observou-se também o significativo papel do comportamento da carga térmica no desempenho dos sistemas de ar condicionado solar. De fato, a própria melhora do desempenho dos sistemas no inverno, deveu-se ao fato de que neste período, a carga térmica se reduziu. Conclui-se, como já foi dito, que o bom desempenho do sistema de ar condicionado solar deve ser acompanhado pela aplicação de técnicas passivas, tais como, o controle de iluminação, a ventilação natural, entre outras, de forma que a carga térmica seja reduzida.

Em outras palavras, pode-se dizer que a tecnologia de ar condicionado solar, a princípio para o caso e condições estudadas, não se resolve apenas tecnologicamente. Para apresentar bom desempenho, sua aplicação deve ser acompanhada por medidas passivas de climatização no edifício e por um projeto e operação, do edifício e do sistema, que favoreça a eficiência energética.

Observa-se também a significativa sensibilidade do desempenho energético desses sistemas de ar condicionado solar à época do ano. Em todos os casos 
observa-se que o desempenho dos sistemas é melhor no inverno do que no verão, na cidade de São Paulo. Isso ocorre não obstante a elevação dos níveis de radiação solar no período de verão. Em outras palavras, conclui-se que, nos dias de verão, a elevação da carga térmica do edifício exerce mais influência no desempenho dos sistemas do que a elevação da disponibilidade de radiação solar.

De fato, embora o nível máximo de irradiância solar durante o dia, aumente de $680 \mathrm{~W} / \mathrm{m}^{2}$, no dia 21 de junho, para $891 \mathrm{~W} / \mathrm{m}^{2}$, no dia 21 de dezembro, o consumo de energia do sistema de ar condicionado solar térmico na hora pico do dia 21 de dezembro, é pouco mais de 2 vezes o consumo de energia do sistema de ar condicionado solar térmico, na hora pico do dia 21 de junho. Da mesma forma, embora o nível de irradiância solar tenha aumentado do dia de inverno para o dia de verão, o consumo de energia do sistema de ar condicionado solar elétrico na hora pico do dia 21 de dezembro, é também pouco mais de 2 vezes o consumo de energia do sistema de ar condicionado solar elétrico, na hora pico do dia 21 de junho.

Além disso, dos resultados obtidos, conclui-se que para os sistemas de ar condicionado solar térmico, em particular, o tipo de tecnologia de aquecimento solar de água e a maximização da área coletora são parâmetros que exercem uma influência significativa no desempenho energético dos sistemas e que devem ser considerados com atenção na escolha da solução a ser adotada.

Pelo que foi analisado, adotar coletores de tubo à vácuo (ETC) em detrimento de coletores solares planos (FPC), para a instalação solar, é interessante para o desempenho energético do sistema de ar condicionado solar térmico. Entretanto, mesmo com a adoção de coletores ETC, o sistema de ar condicionado solar térmico, para o edifício de 20 pavimentos estudado, ainda não apresentou vantagem energética em relação ao sistema de convencional.

Com efeito, embora a fração solar média da operação do sistema tenha se elevado de $28 \%$ para $48 \%$, no dia de inverno, e de $11 \%$ para $19 \%$, no dia de verão, com a adoção de coletores ETC, a participação do aquecimento auxiliar no consumo de energia do sistema foi ainda significativa. Assim, o ar condicionado térmico, aprimorado com coletores ETC, embora consuma $52 \%$ a menos energia do que quando utilizava coletores FPC, no dia de inverno, e $45 \%$ a menos energia, no dia de verão, ainda consome 1,1 vezes mais energia elétrica do que o sistema convencional, no dia de inverno, e 1,7 vezes mais, no dia de verão. 
Entretanto, se esse sistema de ar condicionado solar térmico com coletores ETC for aplicado à edifícios mais baixos, conforme discutido anteriormente, o desempenho energético do sistema resulta bastante satisfatório. De fato, para o edifício térreo, o sistema de ar condicionado solar térmico com coletores ETC, economizou pouco mais de $3 / \mathbf{4}$ da energia elétrica que consumiria o sistema convencional de ar condicionado solar, tanto no dia 21 de dezembro como no dia 21 de junho. Essa economia, como foi apresentado ainda nesse capítulo, com a utilização dos coletores planos (FPC) era de aproximadamente $2 / 3$ da energia consumida pelo sistema convencional de ar condicionado.

Com a adoção da tecnologia de coletores solares de tubo à vácuo (ETC) no edifício térreo, foi possível, ainda, a obtenção da condição, para o dia 21 de junho, de net zero energy por parte do sistema de ar condicionado solar térmico com apoio fotovoltaico. Isto é, o sistema de ar condicionado solar térmico com apoio fotovoltaico instalado no edifício térreo, produziu, no dia de inverno (21 de junho), mais energia elétrica do que consumiu.

Por fim, com relação ainda aos sistemas de ar condicionado solar térmico, conclui-se que a área destinada à instalação solar é determinante no desempenho energético do sistema. Para as mesmas condições de funcionamento e para o edifício de 4 pavimentos, por exemplo, a fração solar média do sistema se reduz de $85 \%$ para $\mathbf{7 2} \%$, no dia de inverno, e de $59 \%$ para $31 \%$, no dia de verão, se ao invés de se utilizar $95 \%$ da cobertura para a instalação solar, for utilizada metade da área de cobertura.

Disso conclui-se que é importante maximizar, em projetos de sistemas de ar condicionado solar térmicos, a área destinada aos coletores solares, desde a fase de projeto desses sistemas. Quando a área utilizada é a de cobertura, deve procurar-se restringir apenas outros usos indispensáveis à cobertura, além dos coletores solares.

Por fim, conclui-se que a tecnologia de ar condicionado solar, embora interessante, deve ser ainda aprimorada a fim de que possa representar uma solução atrativa para edifícios de escritório, em especial, para que se atinja o estagio de mercado, principalmente, no que diz respeito ao desempenho de instalações de grande porte e ao custo inicial dos sistemas. 
O sistema de ar condicionado solar térmico, utilizando chiller solar de absorção e coletores solares térmicos, apesar de mais conhecido e mais utilizado, nem sempre pode ser viável energeticamente. Sua utilização deve ser restrita aos edifícios relativamente baixos, com pouca carga térmica, a fim de atingir economias de energia satisfatórias em relação a um sistema convencional de ar condicionado.

Já o sistema de ar condicionado solar elétrico pode ser uma alternativa interessante quando se dispõe de possibilidades para otimizar a área fotovoltaica, através da integração dos módulos aos elementos construtivos do edifício, tal como ocorre pela integração dos painéis em edifícios altos.

Obviamente uma atenção especial deve ser dada aos elevados custos dos sistemas que, embora não sendo o escopo deste trabalho, devem ser considerados em uma análise da viabilidade dessa tecnologia em edifícios de escritórios. Entretanto, a economia de energia pode ser vista como um aspecto positivo na redução do custo de operação desses sistemas de ar condicionado.

Muito ainda deve ser avançado a fim de que, no Brasil, essas alternativas atinjam o estágio de mercado. Entretanto, desde já, os sistemas de ar condicionado solar devem ser considerados com atenção, aproveitando-se de características favoráveis do projeto em questão e da razoável disponibilidade de radiação solar do Brasil. 
"Desempenho de Sistemas de Condicionamento de Ar com utilização de Energia Solar em Edifícios de Escritórios"

Referências
Bibliográficas 


\section{REFERÊNCIAS BIBLIOGRÁFICAS}

AFONSO, C.F.A. Recent advances in building air conditioning systems. Applied Thermal Engineering 26, 2006, p 1961-1971.

BALARAS, C.A.; GROSSMAN, G.; HENNING, H.M.; FERREIRA, C.A.I.; PODESSER, E.; WANG, L.; WIENKEN, E. Solar air conditioning in Europe - an overview. Renewable and Sustainable Energy Reviews 11, 2007, p 299-314.

BALGHOUTHI, M; CHAHBANI, M.H.; GUIZANI, A. Feasibility of solar absorption air conditioning in Tunisia. Building and Environment.

BRASIL. Agência Nacional de Vigilância Sanitária - ANVISA. Resolução o 9 de 16 de janeiro de 2003. Padrões Referenciais de Qualidade do Ar Interior em Ambientes Climatizados Artificialmente de Uso Público e Coletivo. Disponível em: http://e-legis.anvisa.gov.br/leisref/public/showAct.php. Acesso em 20 fev. 2009.

BRAUN, P.; RÜTHER, R. The role of grid-connected, building-integrated photovoltaic generation in commercial building energy and power loads in a warm and sunny climate. Energy Conversion and Management 51, 2010, p.24572466.

CELIK, A.N.; MUNEER T.; CLARKE P. A review of installed solar photovoltaic and thermal capacities in relation to solar potential for EU-15. Renewable Energy 34, 2009, p 849-856.

CENTRO DE PESQUISA DE ENERGIA ELÉTRICA (CEPEL). Informe PRODEEM. Energia para comunidades isoladas, 1996.

CEPEL; CRESESB. Manual de Engenharia para Sistemas Fotovoltaicos. Grupo de Trabalho de Energia Solar (GTES). 2ª edição. Rio de Janeiro. Agosto, 2004. 
CIDADES SOLARES. Mercado da energia solar. Apresentação do curso de "Projetista Solar", 2009.

COLLE, S.; PAPST, A.L.; GHISI, E.; COLLE, F.; DE ABREU, S.L.; GOULART, S.; BORGES, T. Eficiência energética e uso racional de energia na edificação. Material didático do curso "Eficiência Energética e uso Racional de Energia na Edificação". LABSOLAR, UFSC, Florianópolis, 2005.

CRAWLEY, D. Apresentações do curso de "Energy Plus" ministrado na Escola Politécnica da USP, 2007.

CREDER, H. Instalações de Ar Condicionado. LTC, 6ª edição, 2004.

DEPARTAMENTO DE ENERGIA DOS ESTADOS UNIDOS. Getting Started Manual. Documento de apoio sobre o Software "Energy Plus", 2009

DEPARTAMENTO DE ENERGIA DOS ESTADOS UNIDOS. Input-Output Reference. 2094p. Manual do Software "Energy Plus", 2009

DEPARTAMENTO DE ENERGIA DOS ESTADOS UNIDOS. Site do software "Energy Plus". <http://apps1.eere.energy.gov/buildings/energyplus/

DHERE, N.G. et al. History of solar Energy Research in Brazil. Solar World Congress, 2005, Proceedings of the ISES 2005 Solar World Congress.

DUFFIE, J.A.; BECKMAN, W.A. Solar engineering of thermal processes. John Wiley \& Sons, Inc, Hoboken, New Jersey. 3ํe edição, 2006.

PV TECHNOLOGY PLATFORM. A Strategic Research Agenda for Photovoltaic Solar Energy Technology. Comunidade Européia, 2007

EPIA. European Photovoltaic Industry Association. Solar Generation V. 2008 
ESTIF. European Solar Thermal Industry Federation. Solar Thermal Action Plan for Europe. Janeiro de 2007

FRAIDENRAICH, N. Tecnologia Solar no Brasil - próximos 20 anos. Evento "Sustentabilidade na Geração e Uso da Energia no Brasil: os próximos 20 anos, 2002, trabalho do evento, UNICAMP.

GROSSMAN, G. Solar-powered systems for cooling, dehumidification and airconditioning. Solar Energy, v.72, ํํ.1, 2002, p 53-62.

GROSSMAN, G.; JOHANNSEN A. Solar cooling and air conditioning. Progress in Energy and Combustion Science 7, 1981, p.185-228.

HAGEMANN I.B. Examples of Successful Architectural Integration of PV: Germany. Progress in Photovoltaics: Research and Applications 12, 2004, p 461470.

HENNING, H.M. Solar assisted air conditioning of buildings - an overview. Applied Thermal Engineering 27, 2007, p.1734-1749.

INTERNATIONAL ENERGY AGENCY (IEA). Renewables for Heating and cooling - untapped potential. Report. Disponível em <http://www.iea.org $>$

IPCC. Intergovernmental Panel on Climate Change. Working group II report Impacts, Adaptation and Vulnerability. Technical Summary. Disponível em: $<\underline{\text { http://www.ipcc.ch }>\text {. }}$

IPCC. Intergovernmental Panel on Climate Change. Working group III report Mitigation of Climate Change. Summary for Policymakers. Disponível em: $<$ http://www.ipcc.ch>.

IPCC. Intergovernmental Panel on Climate Change. Working group III report Mitigation of Climate Change. Technical Summary. Disponível em: $<$ http://www.ipcc.ch $>$. 
KALOGIROU, S.A. Solar thermal collectors and applications. Progress in Energy and Combustion Science 30, 2004, p.231-295.

KIM, D.S.; FERREIRA, C.A.I. Solar refrigeration options - a state-of-the-art review. Review. International Journal of Refrigeration 30, 2007, p.1-13.

LOMBARD, L.P.; ORTIZ, J.; POUT, C. A review on buildings energy consumption information. Energy and Buildings 40, 2008, p.394-398.

MARTINS, F.R. et al. Solar energy scenarios in Brazil, Part One: Resource assessment. Energy Policy 36, 2008, p.2843-2854.

NÚÑEZ, T. Technologies, potential and examples. Fraunhofer Institute for Solar Energy Systems ISE (Alemanha). Apresentação nas seções plenárias do III Congresso Brasileiro de Energia Solar. Belém - Brasil, setembro de 2010.

OLIVER, M.; JACKSON, T. Energy and economic evaluation of buildingintegrated photovoltaics. Energy 26, 2001, p.431-439.

PABLO, B.; PINO, F.J.; FELIPE, R. Solar absorption cooling plant in Seville. Solar Energy 84, 2010, p.1503-1512.

PAPADOPOULOS, A.M.; OXIZIDIS, S.; KYRIAKIS, N. Perspectives of solar cooling in view of the developments in the air-conditioning sector. Renewable and Sustainable Energy Reviews 7, 2003, p.419-438.

PEARCE, J.M. Industrial symbiosis of very large-scale photovoltaic manufacturing. Technical Note. Renewable Energy 33, 2008, p.1101-1108.

PÉREZ-LOMBARD, L.; ORTIZ, J.; POUT, C. A review on buildings energy consumption information. Energy and Buildings 40, 2008, p.394-398. 
POLLERBERG, C.; ALI, A.H.H.; DÖTSCH, C. Solar driven steam jet ejector chiller. Applied Thermal Engeneering 29, 2009, p.1245-1252.

REVISTA SOLBRASIL. A Lei Solar de São Paulo. Fevereiro de 2008, p.24-29.

RENEWABLE ENERGY FOCUS. Heating and cooling Europe with solar. Março/Abril de 2010, p.56-61.

RIFFEL, D.B.; BELO, F.A.; LEITE, A.P.F. Ar condicionado solar por adsorção: fundamentos e estado da arte. I Congresso Brasileiro de Energia Solar, 2007, Fortaleza.

ROSIEK, S.; BATLLES, F.J. Integration of the solar thermal energy in the construction: Analysis of the solar-assisted air-conditioning system installed in the CIESOL building. Renewable Energy 34, 2009, p.1423-1431.

SOLAIR. Solar Air Conditioning for Europe. Best Practices Catalog. 2008

SOLAIR. Solar Air Conditioning for Europe. Guidelines: requirements on the design and configuration of small and medium sized solar air-conditioning applications. Abril, 2009.

STRONG, S.J.; SCHELLER, W. The solar electric house - energy for environmentally responsive, energy-independent home. Still River, Mass.: Sustainability Press, c1993.

BESSA, V.M.T. Contribuição à metodologia de avaliação das emissões de dioxido de carbono no ciclo de vida das fachadas de edifícios de escritórios. 2010. 260p. Tese (Doutorado) - Escola Politécnica da Universidade de São Paulo, São Paulo, 2010.

TIBA, C. et al. Solar energy resource assessment - Brazil. Renewable Energy 27, 2002, p.383-400. 
YEUNG, M.R et al. Performance of a solar-powered air conditioning system in Hong Kong. Solar Energy 48, 1992, p.309-319.

ZILLES, R. Energia Solar Fotovoltaica. Seminário Internacional de Fontes Alternativas de Energia e Eficiência Energética. Palestra. Junho de 2002. IEE-USPSP.

ZILLES, R. Sistemas fotovoltaicos para geração de eletricidade: introdução, componentes dos sistemas e dimensionamento. Material da disciplina "Energia Solar: Conversão Térmica e Fotovoltaica" do Instituto de Energia e Elétrotécnica (IEE-USP). Apresentação em ppt., 2007. 
"Desempenho de Sistemas de Condicionado de Ar com Utilização de Energia Solar em Edifícios de Escritórios"

Anexos 


\section{ANEXO 1}

\section{Exemplo das Planilhas utilizadas para o cálculo do consumo de energia elétrica dos sistemas de ar condicionado}

a. Planilha de cálculo do consumo de energia do sistema de ar condicionado convencional (edifício original de 20 pavimentos), para os dias 21 de junho e 21 de dezembro:

\begin{tabular}{|c|c|c|c|c|c|}
\hline \multicolumn{6}{|c|}{ Ar Condicionado Convencional ( 21 de junho) } \\
\hline \multirow{2}{*}{ horas } & \multicolumn{3}{|c|}{ Carga Térmica simulada (W) } & \multirow{2}{*}{$\begin{array}{l}\text { Qedifício20,i } \\
\text { (Wh) }\end{array}$} & \multirow{2}{*}{ Econv,i (kWh) } \\
\hline & qtérro,i & $\mathrm{q} 10^{\circ} \mathrm{PAV}, \mathrm{i}$ & q20으, $\mathrm{i}$ & & \\
\hline 9 & 4455 & 12864 & 3557 & 239556 & 80 \\
\hline 10 & 9568 & 19046 & 8077 & 360473 & 120 \\
\hline 11 & 15720 & 25244 & 14495 & 484608 & 162 \\
\hline 12 & 20374 & 29617 & 19484 & 572970 & 191 \\
\hline 13 & 8466 & 17639 & 8175 & 334151 & 111 \\
\hline 14 & 25883 & 34136 & 25856 & 666186 & 222 \\
\hline 15 & 28693 & 37049 & 29225 & 724795 & 242 \\
\hline 16 & 28894 & 37144 & 30071 & 727554 & 243 \\
\hline 17 & 28412 & 36777 & 30456 & 720859 & 240 \\
\hline & & & & & 1610 \\
\hline
\end{tabular}

\begin{tabular}{|c|c|c|c|c|c|}
\hline \multicolumn{6}{|c|}{ Ar Condicionado Convencional ( 21 de dezembro) } \\
\hline \multirow{2}{*}{ horas } & \multicolumn{3}{|c|}{ Carga Térmica simulada (W) } & \multirow{2}{*}{$\begin{array}{l}\text { Qedifício20,i } \\
\text { (Wh) }\end{array}$} & \multirow{2}{*}{ Econv, $i(k W h)$} \\
\hline & qtérro,i & $\mathrm{q} 10^{\circ} \mathrm{PAV}, \mathrm{i}$ & q20요 PAV,i & & \\
\hline 9 & 44828 & 75129 & 78353 & 1475511 & 492 \\
\hline 10 & 47330 & 73111 & 75339 & 1438673 & 480 \\
\hline 11 & 51094 & 74912 & 77275 & 1476778 & 492 \\
\hline 12 & 52134 & 74363 & 77213 & 1467873 & 489 \\
\hline 13 & 35299 & 56200 & 59508 & 1106407 & 369 \\
\hline 14 & 51131 & 71141 & 75655 & 1407322 & 469 \\
\hline 15 & 53828 & 73659 & 78968 & 1458660 & 486 \\
\hline 16 & 55847 & 75127 & 81032 & 1489170 & 496 \\
\hline 17 & 56761 & 75695 & 81974 & 1501245 & 500 \\
\hline & & & & & 4274 \\
\hline
\end{tabular}

Tabela A1 - Cálculo do consumo de energia do ar condicionado convencional. 
b. Planilha de cálculo do consumo de energia do sistema de ar condicionado solar elétrico (edifício original de 20 pavimentos), para os dias 21 de junho e 21 de dezembro:

\begin{tabular}{|c|c|c|c|c|c|c|}
\hline \multicolumn{7}{|c|}{ Ar Condicionado Solar Elétrico ( 21 de junho) } \\
\hline \multirow{2}{*}{ horas } & \multicolumn{3}{|c|}{ Carga Térmica simulada (W) } & \multirow{2}{*}{$\begin{array}{l}\text { Qedifício20,i } \\
\text { (Wh) }\end{array}$} & \multirow{2}{*}{$\begin{array}{l}P_{f v} \\
(k W h)\end{array}$} & \multirow{2}{*}{ Eelétrico,i (kWh) } \\
\hline & qtérro,i & q10PAV,i & $\mathrm{q} 20^{\circ} \mathrm{PAV}, \mathrm{i}$ & & & \\
\hline 6 & 0 & 0 & 0 & 0 & 0 & 0 \\
\hline 7 & 0 & 0 & 0 & 0 & 8 & -8 \\
\hline 8 & 0 & 0 & 0 & 0 & 70 & -70 \\
\hline 9 & 4455 & 12864 & 3557 & 239556 & 128 & -49 \\
\hline 10 & 9568 & 19046 & 8077 & 360473 & 143 & -23 \\
\hline 11 & 15720 & 25244 & 14495 & 484608 & 144 & 18 \\
\hline 12 & 20374 & 29617 & 19484 & 572970 & 122 & 69 \\
\hline 13 & 8466 & 17639 & 8175 & 334151 & 119 & -7 \\
\hline 14 & 25883 & 34136 & 25856 & 666186 & 133 & 89 \\
\hline 15 & 28693 & 37049 & 29225 & 724795 & 114 & 127 \\
\hline 16 & 28894 & 37144 & 30071 & 727554 & 99 & 143 \\
\hline 17 & 28412 & 36777 & 30456 & 720859 & 54 & 186 \\
\hline 18 & 0 & 0 & 0 & 0 & 7 & -7 \\
\hline 19 & 0 & 0 & 0 & 0 & 0 & 0 \\
\hline & & & & & & 468 \\
\hline
\end{tabular}

\begin{tabular}{|c|c|c|c|c|c|c|}
\hline \multicolumn{7}{|c|}{ Ar Condicionado Solar Elétrico (21 de dezembro) } \\
\hline \multirow{2}{*}{ horas } & \multicolumn{3}{|c|}{ Carga Térmica simulada (W) } & \multirow{2}{*}{$\begin{array}{l}\text { Qedifício20,i } \\
\text { (Wh) }\end{array}$} & \multirow{2}{*}{$\begin{array}{c}P_{f v} \\
(k W h)\end{array}$} & \multirow{2}{*}{ Eelétrico,i (kWh) } \\
\hline & qtérro,i & $\mathrm{q} 10^{\circ} \mathrm{PAV}, \mathrm{i}$ & $\mathrm{q} 20^{\circ} \mathrm{PAV}, \mathrm{i}$ & & & \\
\hline 6 & 0 & 0 & 0 & 0 & 16 & -16 \\
\hline 7 & 0 & 0 & 0 & 0 & 52 & -52 \\
\hline 8 & 0 & 0 & 0 & 0 & 76 & -76 \\
\hline 9 & 44828 & 75129 & 78353 & 1475511 & 128 & 364 \\
\hline 10 & 47330 & 73111 & 75339 & 1438673 & 116 & 364 \\
\hline 11 & 51094 & 74912 & 77275 & 1476778 & 114 & 378 \\
\hline 12 & 52134 & 74363 & 77213 & 1467873 & 84 & 405 \\
\hline 13 & 35299 & 56200 & 59508 & 1106407 & 86 & 283 \\
\hline 14 & 51131 & 71141 & 75655 & 1407322 & 118 & 352 \\
\hline 15 & 53828 & 73659 & 78968 & 1458660 & 110 & 377 \\
\hline 16 & 55847 & 75127 & 81032 & 1489170 & 110 & 387 \\
\hline 17 & 56761 & 75695 & 81974 & 1501245 & 118 & 382 \\
\hline 18 & 0 & 0 & 0 & 0 & 58 & -58 \\
\hline 19 & 0 & 0 & 0 & 0 & 11 & -11 \\
\hline & & & & & & 3078 \\
\hline
\end{tabular}

Tabela A2 - Cálculo do consumo de energia do ar condicionado solar elétrico. 
c. Planilha de cálculo do consumo de energia do sistema de ar condicionado solar térmico (edifício original de 20 pavimentos), para o dia 21 de junho:

\begin{tabular}{|c|c|c|c|c|c|c|c|c|c|}
\hline \multicolumn{10}{|c|}{ Ar Condicionado Solar Térmico (21 de junho) } \\
\hline \multirow{2}{*}{ horas } & \multicolumn{3}{|c|}{ Carga Térmica simulada (W) } & \multirow{2}{*}{$\begin{array}{l}\text { Qedifício20,i } \\
\text { (Wh) }\end{array}$} & \multirow{2}{*}{$\mathrm{G}(\mathrm{W} / \mathrm{m} 2)$} & \multirow{2}{*}{$\mathrm{s}$} & \multirow{2}{*}{ K } & \multirow{2}{*}{ Qaux,i (kWht) } & \multirow{2}{*}{ Etérmico,i (kWh) } \\
\hline & qtérro,i & $\mathrm{q} 10^{\circ} \mathrm{PAV}, \mathrm{i}$ & q20PAV,i & & & & & & \\
\hline 6 & 0 & 0 & 0 & 0 & 0 & - & - & - & - \\
\hline 7 & 0 & 0 & 0 & 0 & 13 & - & - & - & - \\
\hline 8 & 0 & 0 & 0 & 0 & 159 & - & - & - & - \\
\hline 9 & 4455 & 12864 & 3557 & 239556 & 399 & 0.427 & 0.783 & 196.1 & 268 \\
\hline 10 & 9568 & 19046 & 8077 & 360473 & 558 & 0.396 & 0.820 & 310.8 & 422 \\
\hline 11 & 15720 & 25244 & 14495 & 484608 & 680 & 0.359 & 0.866 & 443.4 & 599 \\
\hline 12 & 20374 & 29617 & 19484 & 572970 & 671 & 0.300 & 0.939 & 573.2 & 769 \\
\hline 13 & 8466 & 17639 & 8175 & 334151 & 637 & 0.488 & 0.708 & 244.4 & 338 \\
\hline 14 & 25883 & 34136 & 25856 & 666186 & 609 & 0.234 & 1.020 & 729.0 & 971 \\
\hline 15 & 28693 & 37049 & 29225 & 724795 & 441 & 0.156 & 1.116 & 874.2 & 1156 \\
\hline 16 & 28894 & 37144 & 30071 & 727554 & 312 & 0.110 & 1.173 & 925.1 & 1219 \\
\hline 17 & 28412 & 36777 & 30456 & 720859 & 121 & 0.043 & 1.255 & 985.5 & 1292 \\
\hline 18 & 0 & 0 & 0 & 0 & 10 & - & - & - & - \\
\hline 19 & 0 & 0 & 0 & 0 & 0 & - & - & - & - \\
\hline & & & & & & & & & 7035 \\
\hline
\end{tabular}

Tabela A3 - Cálculo do consumo de energia do ar condicionado solar térmico (21 de junho). 
d. Planilha de cálculo do consumo de energia do sistema de ar condicionado solar térmico (edifício original de 20 pavimentos), para o dia 21 de dezembro:

\begin{tabular}{|c|c|c|c|c|c|c|c|c|c|}
\hline \multicolumn{10}{|c|}{ Ar Condicionado Solar Térmico (21 de dezembro) } \\
\hline \multirow{2}{*}{ horas } & \multicolumn{3}{|c|}{ Carga Térmica simulada (W) } & \multirow{2}{*}{$\begin{array}{l}\text { Qedifício20,i } \\
\text { (Wh) }\end{array}$} & \multirow{2}{*}{$\mathrm{G}(\mathrm{W} / \mathrm{m} 2)$} & \multirow{2}{*}{ s } & \multirow{2}{*}{ K } & \multirow{2}{*}{ Qaux,i (kWht) } & \multirow{2}{*}{ Etérmico,i (kWh) } \\
\hline & qtérro,i & $\mathrm{q} 10^{\circ} \mathrm{PAV}, \mathrm{i}$ & $\mathrm{q} 20^{\circ} \mathrm{PAV}, \mathrm{i}$ & & & & & & \\
\hline 6 & 0 & 0 & 0 & 0 & 18 & - & - & - & - \\
\hline 7 & 0 & 0 & 0 & 0 & 90 & - & - & - & - \\
\hline 8 & 0 & 0 & 0 & 0 & 215 & - & - & - & - \\
\hline 9 & 44828 & 75129 & 78353 & 1475511 & 473 & 0.082 & 1.207 & 1934.7 & 2544 \\
\hline 10 & 47330 & 73111 & 75339 & 1438673 & 551 & 0.098 & 1.187 & 1853.6 & 2440 \\
\hline 11 & 51094 & 74912 & 77275 & 1476778 & 741 & 0.128 & 1.150 & 1838.7 & 2426 \\
\hline 12 & 52134 & 74363 & 77213 & 1467873 & 891 & 0.155 & 1.117 & 1771.0 & 2342 \\
\hline 13 & 35299 & 56200 & 59508 & 1106407 & 853 & 0.197 & 1.065 & 1268.6 & 1684 \\
\hline 14 & 51131 & 71141 & 75655 & 1407322 & 749 & 0.136 & 1.140 & 1736.5 & 2293 \\
\hline 15 & 53828 & 73659 & 78968 & 1458660 & 526 & 0.092 & 1.194 & 1891.2 & 2489 \\
\hline 16 & 55847 & 75127 & 81032 & 1489170 & 392 & 0.067 & 1.225 & 1984.0 & 2606 \\
\hline 17 & 56761 & 75695 & 81974 & 1501245 & 306 & 0.052 & 1.244 & 2032.8 & 2668 \\
\hline 18 & 0 & 0 & 0 & 0 & 111 & - & - & - & - \\
\hline 19 & 0 & 0 & 0 & 0 & 19 & - & - & - & - \\
\hline
\end{tabular}

Tabela A4 - Cálculo do consumo de energia do ar condicionado solar térmico (21 de dezembro). 


\section{ANEXO 2}

\section{Classes de objetos utilizados na simulação da carga térmica do edifício no software EnergyPlus ${ }^{\circledR}$}

a. Simulação da Carga Térmica $\left(q_{\text {térreo,i } i}, q_{10^{\circ} P A V}\right.$ e $\left.q_{20^{\circ} P A V}\right)$ :

Building,

BuildingSurface:Detailed,

Construction,

ElectricEquipment,

FenestrationSurface:Detailed,

GlobalGeometryRules,

HeatBalanceAlgorithm,

Lights,

Material,

Output:Constructions,

Output:Surfaces:Drawing,

Output:Surfaces:List,Details;
Output:Table:SummaryReports,

Output:Variable,

Output:VariableDictionary,

OutputControl:Table:Style,

People,

RunPeriod,

Schedule:Compact,

ScheduleTypeLimits,

Shading:Building:Detailed,

ShadowCalculation,

SimulationControl,

Site:GroundTemperature:BuildingSurface,

\author{
Site:Location, \\ SurfaceConvectionAlgorithm:Inside, \\ SurfaceConvectionAlgorithm:Outside, \\ ThermostatSetpoint:SingleCooling, \\ Timestep, \\ WindowMaterial:Glazing, \\ Zonelnfiltration:DesignFlowRate, \\ Zone, \\ ZoneControl:Thermostat, \\ ZoneHVAC:EquipmentConnections, \\ ZoneHVAC:EquipmentList, \\ ZoneHVAC:IdealLoadsAirSystem,
}

b. Simulação da produção de energia fotovoltaica $\left(P_{f v}\right)$ e da radiação solar no plano dos coletores térmicos $(G)$ :

Generator:Photovoltaic,

PhotovoltaicPerformance:Simple,
ElectricLoadCenter:Generators,

ElectricLoadCenter:Inverter:Simple,
ElectricLoadCenter:Distribution,

Output:Variable,Plano $1 \mathrm{~m}^{2}$ - 23 graus,Surface Ext Solar Incident,Hourly; 